Florida International University FIU Digital Commons

\title{
A Study on Uncertain Dynamic Disaster Management Tasks, Knowledge Sharing, and Task Performance
}

Jose Rocha

Florida International University, JG.RochaMier@Fiu.Edu

DOI: $10.25148 /$ etd.FI1 1081002

Follow this and additional works at: https://digitalcommons.fiu.edu/etd

\section{Recommended Citation}

Rocha, Jose, "A Study on Uncertain Dynamic Disaster Management Tasks, Knowledge Sharing, and Task Performance" (2011). FIU Electronic Theses and Dissertations. 468.

https://digitalcommons.fiu.edu/etd/468 


\title{
FLORIDA INTERNATIONAL UNIVERSITY \\ Miami, Florida
}

\section{A STUDY ON \\ UNCERTAIN DYNAMIC DISASTER MANAGEMENT TASKS, KNOWLEDGE SHARING, AND TASK PERFORMANCE}

\author{
A dissertation submitted in partial fulfillment of the \\ requirements for the degree of \\ DOCTOR OF PHILOSOPHY \\ in \\ BUSINESS ADMINISTRATION
}

by

Jose Rocha

2011 
To: Dean Joyce Elam

College of Business Administration

This dissertation, written by Jose Rocha, and entitled A Study on Uncertain Dynamic Disaster Management Tasks, Knowledge Sharing, and Task Performance, having been approved in respect to style and intellectual content, is referred to you for judgment.

We have read this dissertation and recommend that it be approved.

Weidong Xia

Mary Ann Von Glinow

Steve Zanakis

Irma Becerra-Fernandez, Major Professor

Date of Defense: April 29, 2011

The dissertation of Jose Rocha is approved.

\begin{tabular}{r} 
Dean Joyce Elam \\
College of Business Administration \\
\hline Interim Dean Kevin O'Shea \\
University Graduate School
\end{tabular}

Florida International University, 2011 
(C) Copyright 2011 by Jose Rocha

All rights reserved. 


\section{DEDICATION}

I dedicate this dissertation to my mother María Susana Mier Vela and my father

Jose Rocha Pedraza for their endless support, spiritual guidance, and inspiration in my life. 


\section{ACKNOWLEDGMENTS}

I would like to thank my major professor: Dr. Irma Becerra-Fernandez for her guidance throughout this entire research process. Her advice and encouragement were instrumental in the completion of this dissertation thesis, and she has truly made this a valuable long life learning experience. I would like to thank also Dr. Weidong Xia for guiding me through the complex world of empirical research and mediating, moderating, and interaction effects, and for giving generously of his time and encouragement through all the stages of this dissertation. His timely and constant feedback provided me with a solid research grounds to complete this dissertation work: Xiexie. I would like also to thank Dr. Mary Ann Von Glinow for her constant support and guidance, especially during my two year independent study under her supervision that gave the initial theoretical and research methods grounds for this dissertation thesis. Further, I would like to thank Dr. Steve Zanakis for his expert advice and feedback in data analysis which allowed me to produce a better data analysis work for this research, and therefore a better quality of dissertation thesis. Last but not least, I would like to thank my Ph.D. classmates: Arvind Gudi and Gladys Simpson for always being there for me and their words of encouragement and support. 
Also, I would like to acknowledge the financial support for part of this study provided through the following grants, scholarships, and fellowships

- Florida International University, Dissertation Year Fellowship 2008-2009

- Florida International University Doctoral Evidence Acquisition Fellowship $2009-2010$

- Florida International University, College of Business Administration Graduate Assistantship 2005-2008

Similarly, I would like to acknowledge this Ph.D. Dissertation to the memory of Frank J. Reddish who was the Miami-Dade Office of Emergency Management Coordinator during the time this research was conducted and who selflessly educated and mentored our research team. I would like also to acknowledge the support of Robert Palestrant, Division Chief, Miami Dade Fire Rescue, Curtis Sommerhoff, Director of Miami-Dade Department of Emergency Management, David Perez, Office ofEmergency Management Government Affairs Coordinator, Soheila Ajabshir, GIS Manager / Senior Systems Analyst, Troy Johnson, Emergency Management Coordinator, Raymond Misomali, Emergency Management Coordinator, and Craig Hall Emergency Management Coordinator, and all the personnel at Miami-Dade Office of Emergency Management and Emergency Operations Center which was the main site for the data acquisition process of this research work.

Also, I would like to specially thank Ing. Juan Manuel Durán, Dr. Héctor Escamilla, Ing. Alejandro Cristerna, Don Guillermo Brun Ramos, Dr. Jose Llerenas, Ing. Fidel Aguilar Trillo, and the Barrera family. You all made a big impact in my professional life at the Tec de Monterrey. 
Finally, this work would not have been possible without the love and support of my sisters and brothers: Susy, Lety, Cristy, Enrique, and Fer; as well as my brothers in law: Ricardo Alvarez, Alberto García, and the late Albert Nieto, and my "family" and friends in South Florida:

- Miguel Angel Molina

- Charly Mendez

- Juan Meza

- Diego Rincón

- Carolina Forero

- Enrique Castillo

- Salvador Bautista

- Gustavo Fernández- Ana Gaby

Tirado

- Claudia Villarreal-Miguel Carrillo, y Sebastian

- Campbell Berkeley

- Mari Carmen and Eliza Suárez

- Mercedes Vigón

- Rocio Magaña y Paco

- Ricardo and Marina González

- Marta M. Gómez Llorente

- Frida Dangond
- Luis Fernando Salazar

- Fabian Figueroa

- Carlos Saitcevsky

- Paty Leyva - Carlos Parra

- Javier and Karin Arrangoiz

- Claudia Reithauser

- Violeta Gómez

- More Aguilera

- Amy Shaheen

- Paty and Oscar Valencia

- Aida Barragán

- Karla Coronado and Enrique

Alemán

- Leonel Azuela

- Miguel Rey

- Gabriel Abaroa

- Daniel Loria

- Rocio Pellerano 
- Dr. Amada Vargas

- Ana Lagos

- Elyse Sitomer

- Danielle Maham

- Luis Casas

- $\quad$ Bill and Tere Kraus

- Frank Carrillo

- Sandra Ramos

- Luisa Alonso and Fernando

- Ma. Elena Saiz
- Mary Pat Berger

- Fritz Hentschel

- Patrice McDaniel

- Luis Mario León

- Bob Allen

- Umberto Bonavita

- Gil Acevedo

- Tanya Denis-Irias

- Elba Hentschel 


\section{ABSTRACT OF THE DISSERTATION \\ A STUDY ON UNCERTAIN DYNAMIC DISASTER MANAGEMENT TASKS, KNOWLEDGE SHARING,}

AND TASK PERFORMANCE

by

Jose Rocha

Florida International University, 2011

Miami, Florida

\section{Professor Irma Becerra-Fernandez, Major Professor}

Each disaster presents itself with a unique set of characteristics that are hard to determine a priori. Thus disaster management tasks are inherently uncertain, requiring knowledge sharing and quick decision making that involves coordination across different levels and collaborators. While there has been an increasing interest among both researchers and practitioners in utilizing knowledge management to improve disaster management, little research has been reported about how to assess the dynamic nature of disaster management tasks, and what kinds of knowledge sharing are appropriate for different dimensions of task uncertainty characteristics.

Using combinations of qualitative and quantitative methods, this research study developed the dimensions and their corresponding measures of the uncertain dynamic characteristics of disaster management tasks and tested the relationships between the various dimensions of uncertain dynamic disaster management tasks and task performance through the moderating and mediating effects of knowledge sharing. 
Furthermore, this research work conceptualized and assessed task uncertainty along three dimensions: novelty, unanalyzability, and significance; knowledge sharing along two dimensions: knowledge sharing purposes and knowledge sharing mechanisms; and task performance along two dimensions: task effectiveness and task efficiency. Analysis results of survey data collected from Miami-Dade County emergency managers suggested that knowledge sharing purposes and knowledge sharing mechanisms moderate and mediate uncertain dynamic disaster management task and task performance. Implications for research and practice as well directions for future research are discussed. 


\section{TABLE OF CONTENTS}

CHAPTER

PAGE

1. Introduction

1.1 Research background

1.2 Problem statement and research objectives

1.3 Research site

1.4 Research outline

1.5 Research scope and limitations

$\begin{array}{ll}2 . & \text { Literature review } \\ 2.18\end{array}$

$\begin{array}{lll}2.1 & \text { Disaster management } & 18\end{array}$

$\begin{array}{lll}2.1 .1 & \text { Critical issues in disaster management } & 20\end{array}$

2.1.2 Open problems in disaster management 23

$\begin{array}{ll}2.2 & \text { Uncertainty of disaster management tasks } \\ 2.3 & 25\end{array}$

\begin{tabular}{ll}
2.3 & Knowledge management (KM) \\
\hline
\end{tabular}

$\begin{array}{lll}2.3 .1 & \text { Knowledge creation theory } & 61\end{array}$

2.3.2 Knowledge-based theory of the firm 62

2.3.3 Social capital theory stepping-stone for knowledge 63 management and knowledge sharing

2.4 The EOC as knowledge-based organization 69

$\begin{array}{ll}2.5 & \text { Knowledge sharing } \\ 2.6 & 72\end{array}$

$\begin{array}{ll}2.6 & \text { Why share knowledge? }\end{array}$

$\begin{array}{lll}2.7 & \text { Knowledge-sharing mechanisms and purposes } & 79\end{array}$

$\begin{array}{ll}\text { 2.7.1 Knowledge-sharing mechanisms } & 80\end{array}$

$\begin{array}{lll}\text { 2.7.2 Knowledge-sharing purposes } & 83\end{array}$

3. Research model and hypotheses 94

$\begin{array}{ll}3.1 & \text { Research model } \\ 3.2 & 94\end{array}$

$\begin{array}{ll}3.2 & \text { Research questions } \\ 3.3 & 95\end{array}$

$\begin{array}{lll}3.3 & \text { Research hypotheses } & 97\end{array}$

3.3.1 Research hypotheses for direct effects 98

$\begin{array}{ll}\text { 3.3.2 Research hypotheses for moderating effects } & 117\end{array}$

3.3.3 Research hypotheses for mediating effects 133

3.3.4 Research hypotheses for knowledge sharing moderating-mediating 138 interaction effects between uncertain dynamic disaster management tasks and task performance

3.3.4.1 Research hypotheses for moderating-interaction effects 138

$\begin{array}{ll}\text { 3.3.4.2 Research hypotheses for mediating effects } & 149\end{array}$ 
4. Research design and methodology 154

4.1 Research design and methodology 154

4.2 Data collection instrument design, measurement items generation, 155 and sorting procedure

4.2.1 Survey questionnaire design 155

4.2.2 Generation and refinement of measurement items 161

$\begin{array}{lll}4.2 .3 & \text { Sorting procedure } & 164\end{array}$

5. Data analysis and results 176

$\begin{array}{lll}5.1 & \text { Survey data collection } & 176\end{array}$

$\begin{array}{lll}5.2 & \text { Pre-analysis and data screening } & 178\end{array}$

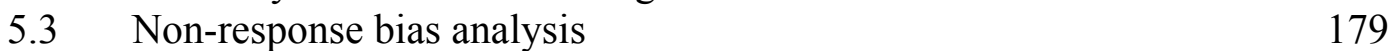

$\begin{array}{ll}5.4 & 182\end{array}$

$\begin{array}{ll}5.5 & 185\end{array}$

$\begin{array}{lll}\text { 5.5.1 Task novelty } & 188\end{array}$

$\begin{array}{lll}\text { 5.5.2 Task unanalyzability } & 190\end{array}$

$\begin{array}{lll}\text { 5.5.3 Task significance } & 193\end{array}$

5.5.4 Knowledge sharing purposes 195

$\begin{array}{lll}\text { 5.5.5 Knowledge sharing mechanisms } & 196\end{array}$

$\begin{array}{lll}\text { 5.5.6 Task performance } & 198\end{array}$

$\begin{array}{lll}5.6 & \text { Summary of reliability testing } 200\end{array}$

$\begin{array}{lll}5.7 & \text { Path analyses } & 202\end{array}$

$\begin{array}{ll}5.8 & \text { Path analyses with control variables } \\ 5.9 & 216\end{array}$

5.9 Moderating effects of knowledge sharing 223

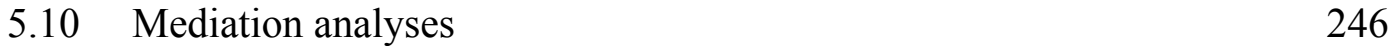

$\begin{array}{lll}5.11 & 265\end{array}$

$\begin{array}{lll}5.11 .1 & \text { Interaction-moderating effects } & 269\end{array}$

5.11.2 Interaction-mediating effects 286

6. Conclusions 299

$\begin{array}{lll}6.1 & \text { Research implications } & 299\end{array}$

6.1.1 Relationships between Task Characteristics, Knowledge 300

Sharing And Task Performance, and the Implications of the Moderating and Mediating Effects of Knowledge Sharing

$\begin{array}{lll}\text { 6.1.1.1 } & \text { Task Newness } & 301\end{array}$

6.1.1.2 Task Difficulty 304

6.1.1.3 Information Required to Perform the Task at Hand 307

6.1.1.4 Task Significance: Task Urgency 309

6.1.1.5 Task Significance: Task Impact 312

6.2 Research Significance and Contributions 316

$\begin{array}{lll}6.3 & \text { Practical Implications } & 317\end{array}$

6.3 Research limitations and future research 319 
VITA 


\section{LIST OF TABLES}

TABLE

PAGE

Table 1. Miami-Dade County Office of Emergency Management: groups 11 and sections

Table 2. Research outline (Adapted from Creswell, 2003 and Xia and

Lee, 2005)

Table 3. Literature review, previous research studies related to task novelty and its task newness dimension

Table 4. Literature review, previous research studies related to task novelty and its task non-routineness dimension

Table 5. Literature review, previous research studies related to task unanalyzability and its task difficulty dimension

Table 6. Literature review, previous research studies related to task unanalyzability and its amount of task information dimension

Table 7. Literature review references, uncertain dynamic disaster management tasks

Table 8. Literature review references, task performance

Table 9. Literature review, knowledge management

Table 10. Literature review, social capital theory: structural capital dimension

Table 11. Literature review, social exchange theory: identity orientations dimensions

Table 12. Literature review, social capital theory: content / cognitive dimension dimensions

Table 13. Literature review, knowledge sharing

Table 14. Literature review references, knowledge sharing, knowledge sharing purposes, and knowledge sharing mechanisms

Table 15. Summary research constructs-dimensions, and definitions 
Table 16. Research instruments used in the generation of measurement items for this research

Table 17. Constructs-Dimensions and Measurement Items

Table 18. Summary of tests to examine non-response bias

Table 19. Reliability estimates (Cronbach's alphas) for the constructs

Table 20. Task newness: factor loadings

Table 21. Task nonroutineness: factor loadings

Table 22. Task difficulty: factor loadings

Table 23. Information equivocality: factor loadings

Table 24. Amount of task information: factor loadings

Table 25. Task urgency: factor loadings

Table 26. Task impact: factor loadings

Table 27. Knowledge sharing for exploration: factor loadings

Table 28. Knowledge sharing for exploitation: factor loadings

Table 29. Knowledge sharing through personal contact: factor loadings

Table 30. Knowledge sharing through written documents: factor loadings

Table 31. Task efficiency: factor loadings

Table 32. Task effectiveness: factor loadings

Table 33. Cronbach's alpha values for reliability testing 200

Table 34. Summary of path analyses, uncertain dynamic disaster management tasks, knowledge sharing, and task performance

Table 35. Summary of path analyses, uncertain dynamic disaster 209 management tasks and knowledge sharing

Table 36. Summary of path analyses hypothesis and findings 
Table 37. Summary of path analyses, uncertain dynamic disaster management tasks, knowledge sharing, and control variables on task performance

Table 38. Summary of path analyses, uncertain dynamic disaster management tasks and control variables on knowledge sharing

Table 39. Summary of path analyses, uncertain dynamic disaster 228 management tasks and knowledge sharing through written documents moderating direct effects on task effectiveness

Table 40. Summary of path analyses, uncertain dynamic disaster management tasks, knowledge sharing for exploitation and knowledge sharing for exploration moderating effects on task effectiveness

Table 41. Summary of path analyses, uncertain dynamic disaster management tasks, knowledge sharing through personal contacts and knowledge sharing through written documents and knowledge sharing for exploration moderating effects on task effectiveness

Table 42. Summary of path analyses, uncertain dynamic disaster management tasks and knowledge sharing through personal contacts moderating direct effects on task efficiency

Table 43. Summary of path analyses, uncertain dynamic disaster management tasks, knowledge sharing for exploitation, knowledge sharing through personal contacts, knowledge sharing through written documents, and knowledge sharing for exploitation moderating effects on task efficiency

Table 44. Summary of low - high moderating effects and findings

Table 45. Summary of mediation analyses, uncertain dynamic disaster management tasks, knowledge sharing for exploitation, and task effectiveness

Table 46. Summary of mediation analyses, uncertain dynamic disaster management tasks, knowledge sharing through written documents, and task effectiveness 
Table 47. Summary of mediation analyses, uncertain dynamic disaster management tasks, knowledge sharing for exploitation, and task efficiency

Table 48. Summary of mediation analyses, uncertain dynamic disaster management tasks, knowledge sharing for exploitation, and task efficiency

Table 49. Summary of path analyses, uncertain dynamic disaster management tasks, knowledge sharing for exploration, knowledge sharing for exploitation, and task performance

Table 50. Summary of mediation effects and findings

Table 51. Results interaction effects, uncertain dynamic disaster management tasks, knowledge sharing, and task performance

Table 52. Summary of interaction-moderating effects and findings

Table 53. Summary of interaction-mediation affects analyses, uncertain dynamic disaster management tasks, knowledge sharing for exploitation, and task effectiveness

Table 54. Summary of interaction-mediation affects analyses, uncertain dynamic disaster management tasks, knowledge sharing through personal contacts, and task effectiveness

Table 55. Summary of interaction-mediation affects analyses, uncertain dynamic disaster management tasks, knowledge sharing for exploitation, and task efficiency

Table 56. Summary of interaction-mediation affects analyses, uncertain dynamic disaster management tasks, knowledge sharing through personal contacts, and task efficiency

Table 57. Summary of interaction-mediation effects and findings

Table 58. Means, standard deviations, and correlations

Table 59. Hurricane Katrina: Situation Report No. 3

Table 60. Hurricane Wilma: Incident Action Plan No. 2 
Table 61. Hurricane Katrina: Incident Action Plan No. 3

Table 62. Hurricane Storm Katrina: Situation Report No. 2

Table 63. Hurricane Katrina: Incident Action Plan No. 2 


\section{LIST OF FIGURES}

FIGURE

PAGE

Figure 1. Miami-Dade Emergency Operations Center, Activation floor plan

Figure 2. Research model

Figure 3. Research model

Figure 4. Uncertain dynamic disaster management tasks and task performance

Figure 5. Uncertain dynamic disaster management tasks, knowledge sharing, and task performance

Figure 6. Uncertain dynamic disaster management tasks and knowledge sharing

Figure 7. Uncertain dynamic disaster management tasks and knowledge sharing moderating direct effects on task effectiveness

Figure 8. Uncertain dynamic disaster management tasks, knowledge sharing for exploitation, knowledge sharing through personal contacts and written documents, and knowledge sharing for exploration moderating effects on task effectiveness

Figure 9. Uncertain dynamic disaster management tasks, knowledge sharing through personal contacts and knowledge sharing through written documents and knowledge sharing for exploration moderating effects on task effectiveness

Figure 10. Uncertain dynamic disaster management tasks and knowledge sharing for exploitation and knowledge sharing through personal contacts moderating direct effects on task efficiency

Figure 11. Uncertain dynamic disaster management tasks, knowledge sharing for exploitation, knowledge sharing through personal contacts, knowledge sharing through written documents, and knowledge sharing for exploitation moderating effects on task efficiency 
Figure 12. Knowledge sharing mediating effects between uncertain dynamic disaster management tasks and task performance

Figure 13. Knowledge sharing moderating-mediating interaction effects between uncertain dynamic disaster management tasks and task performance

Figure 14. Summary of path analyses on task effectiveness

Figure 15. Summary of path analyses on task efficiency

Figure 16. Uncertain dynamic disaster management tasks and knowledge sharing through written documents moderating direct effects on task effectiveness

Figure 17. Uncertain dynamic disaster management tasks, knowledge sharing for exploitation and knowledge sharing for exploration moderating effects on task effectiveness

Figure 18. Uncertain dynamic disaster management tasks, knowledge sharing through personal contacts and knowledge sharing through written documents and knowledge sharing for exploration moderating effects on task effectiveness

Figure 19. Uncertain dynamic disaster management tasks knowledge sharing through personal contacts moderating direct effects on task efficiency

Figure 20. Uncertain dynamic disaster management tasks, knowledge sharing for exploitation, knowledge sharing through personal contacts, knowledge sharing through written documents, and knowledge sharing for exploitation moderating effects on task efficiency

Figure 21. Simple standard trivariate mediation

Figure 22. Uncertain dynamic disaster management tasks, knowledge sharing, and task performance interaction effects

Figures $23 \mathrm{a}$ and $\mathrm{b}$, the moderating effects of knowledge sharing for exploration on amount of task information and task effectiveness 
Figures $24 \mathrm{a}$ and $\mathrm{b}$, the moderating effects of amount of task information on knowledge sharing for exploration and task effectiveness

Figures $25 \mathrm{a}$ and $\mathrm{b}$, the moderating effects of knowledge sharing for exploitation on task newness and task effectiveness

Figures $26 \mathrm{a}$ and $\mathrm{b}$, the moderating effects of task newness on knowledge sharing for exploitation and task effectiveness

Figures $27 \mathrm{a}$ and $\mathrm{b}$, the moderating effects of knowledge sharing for exploitation on task urgency and task effectiveness

Figures $28 \mathrm{a}$ and $\mathrm{b}$, the moderating effects of task urgency on knowledge sharing for exploitation and task effectiveness

Figures $29 \mathrm{a}$ and $\mathrm{b}$, the moderating effects of knowledge sharing for exploitation on task impact and task effectiveness

Figures $30 \mathrm{a}$ and $\mathrm{b}$, the moderating effects of task impact on knowledge sharing for exploitation and task effectiveness

Figures $31 \mathrm{a}$ and $\mathrm{b}$, the moderating effects of knowledge sharing through 275 personal contacts on task urgency and task effectiveness

Figures $32 \mathrm{a}$ and $\mathrm{b}$, the moderating effects of task urgency on knowledge sharing through personal contacts and task effectiveness

Figures $35 \mathrm{a}$ and $\mathrm{b}$, the moderating effects of knowledge sharing through personal contacts on task impact and task effectiveness

Figures $36 \mathrm{a}$ and $\mathrm{b}$, the moderating effects of task impact on knowledge 276 sharing through personal contacts and task effectiveness

Figures $37 \mathrm{a}$ and $\mathrm{b}$, the moderating effects of knowledge sharing trough written documents on task newness and task effectiveness

Figures $38 \mathrm{a}$ and $\mathrm{b}$, the moderating effects of task newness on knowledge sharing trough written documents and task effectiveness

Figures $39 \mathrm{a}$ and $\mathrm{b}$, the moderating effects of knowledge sharing trough written documents on task difficulty and task effectiveness 
Figures $40 \mathrm{a}$ and $\mathrm{b}$, the moderating effects of task difficulty on knowledge sharing trough written documents and task effectiveness

Figures $41 \mathrm{a}$ and $\mathrm{b}$, the moderating effects of knowledge sharing for 280 exploration on task non-routineness and task efficiency

Figures $42 \mathrm{a}$ and $\mathrm{b}$, the moderating effects of task non-routineness on 280 knowledge sharing for exploration and task efficiency

Figures $43 \mathrm{a}$ and $\mathrm{b}$, the moderating effects of knowledge sharing through personal contacts on task non-routineness and task efficiency

Figures $44 \mathrm{a}$ and $\mathrm{b}$, the moderating effects of task non-routineness on knowledge sharing through personal contacts and task efficiency

Figures $45 \mathrm{a}$ and $\mathrm{b}$, the moderating effects of knowledge sharing trough written documents on task newness and task efficiency

Figures $46 \mathrm{a}$ and $\mathrm{b}$, the moderating effects of task newness on knowledge sharing trough written documents and task efficiency

Figures $47 \mathrm{a}$ and $\mathrm{b}$, the moderating effects of knowledge sharing trough written documents on task impact and task efficiency

Figures $48 \mathrm{a}$ and $\mathrm{b}$, the moderating effects of task impact on knowledge sharing trough written documents and task efficiency 


\section{Introduction}

"Emergency Management Capabilities Require Greater Emphasis for Catastrophic Response and Recovery: The experience with Hurricanes Katrina and Rita highlights critical emergency management capabilities that must be ramped up from normal disaster management levels. Our preliminary work suggests that while many organizations provided significant support in these areas during the response and recovery efforts, several key capabilities were not available when needed or with the quantity or quality needed. When catastrophic disaster occurs, significantly more capabilities - in terms of quantity and quality - are needed. Our work is beginning to identify many examples of where the lack of additional response or recovery capabilities, or the delay in getting these capabilities to where they were needed, caused extended suffering" p. 16

\section{GAO-06-442T, March 8, 2006 HURRICANE KATRINA GAO's Preliminary Observations regarding Preparedness, Response, and Recovery: Statement of David M. Walker, Comptroller General of the United States}

"Events preceding and following the attacks of September 11 spotlighted one of our most serious vulnerabilities. We do not share information effectively, particularly when it comes to intelligence, law enforcement, and response activities. If we cannot do a better job of sharing information, we will not be able to effectively identify vulnerabilities, develop needed technology, and coordinate efforts to detect and respond to attacks" p. 8

GAO-02-811T, June 7, 2002 NATIONAL PREPAREDNESS, Integrating New and Existing Technology and Information Sharing into an Effective Homeland Security Strategy: Statement of Randall A. Yim, Managing Director, National Preparedness

\subsection{Research Background}

Because of recent natural disasters such as hurricanes (e.g., Katrina, Rita, and Wilma), wildfires (e.g., in Arizona, California, Florida, and Texas), and tornados (in the American Midwest), as well as the earthquake, tsunami, and nuclear plant disasters in Japan, there is renewed interest in the field of disaster management. In addition, it has 
become evident that public disaster management capabilities need to be enhanced and strengthened in terms of preparedness, response, mitigation, and recovery. Each of these areas represents a different set of challenges based on the impacts of natural disasters and threats such as those mentioned above.

Once a disaster occurs, evolving and dynamic attributes related to time, geography, size, periodicity, circumstances, magnitude, information, knowledge, and people heavily influence decision-making processes and place additional demands on the teams involved in disaster response and recovery efforts. Furthermore, uncertain conditions, role ambiguity, and the need for a situational response increase the complexity of decision-making processes. Indeed, "oftentimes, during the response to a disaster event, unexpected events arise and there is a great deal of uncertainty in figuring out the most efficient and effective ways to perform the task at hand, given that many of the involved tasks are novel, unstructured, and often with conflicting information and interpretation" [Becerra et al., 2008 in Rocha et al., 2009, p. 2].

Consequently, these uncertain, evolving, and dynamic attributes and conditions increase the complexity of decision-making processes and impair the management capabilities of disaster management personnel, which include delegation, communication, and inter-agency co-ordination [Paton and Jackson, 2002]. In fact, research on disaster management events and threats shows that there is a lack of effective cooperation and coordinated action through collaboration and information and knowledge sharing and that these issues are still critical and unresolved problems in the disaster management field [Jenkins 2006; Smith and Dowell, 2000]. Similarly, given these challenges and the difficultly of these situations, the skillful use of information communication technologies, 
the lessons learned from previous disaster events, and comprehensive training in managing disaster events become critical.

Effective cooperation, collaboration, and coordinated action through efficient information and knowledge sharing are also crucial and are especially relevant to decision-making in an environment in which almost everything is an exception to the norm.

Prior research on disaster management has described how the inherently complex tasks related to disaster response and recovery affect performance outcomes [Gudi, 2009]. However, there are no previous studies that measure how disaster management response tasks associated with the decision-maker impact task performance. This study conceptualizes the disaster management tasks associated with the decisionmaker and emphasizes the dynamic characteristics of these tasks [Becerra-Fernandez et al., 2008; Rocha et al., 2009; Xia et al., 2010; Xia et al., 2011]. As noted above, there is currently a lack of understanding and an inability to differentiate the uncertain and dynamic disaster management tasks that are related to task performance. More specifically, there is a gap in the disaster management literature with regard to how to describe and assess uncertain and dynamic disaster management tasks. The inherently dynamic characteristics of uncertain disaster management tasks pose a challenge to the successful completion and performance of these tasks.

Furthermore, the literature on disaster management, knowledge management, and knowledge sharing does not specifically address how knowledge management and knowledge sharing can improve task performance during a disaster management event or threat. Among emergency managers facing a particular disaster or threat, there is a "lack of understanding about what types of knowledge sharing are required for the various 
types of task uncertainties" [Becerra et al., 2008 in Rocha et al., 2009] and how knowledge sharing can improve the outcome of a disaster management event or threat. In summary, there is a lack of appropriate frameworks to conceptualize, assess, and measure the impacts of dynamic disaster management tasks on task performance. Similarly, there is a "critical need to understand and develop effective organizational and procedural mechanisms that can help systematically improve emergency management performance" [Becerra-Fernandez et al.]. Therefore, this research study addresses how knowledge sharing impacts the performance of tasks with uncertain dynamic characteristics.

\subsection{Problem Statement and Research Objectives}

"In the wake of the 2005 Gulf Coast Hurricanes, coordination and collaboration challenges created obstacles during the government's response and recovery efforts"

"Effective collaboration among stakeholders can play a key role in facilitating long-term recovery after a catastrophic event"

GAO-09-811, July 2009 DISASTER RECOVERY: Experiences from Past Disasters Offer Insights for Effective Collaboration after Catastrophic Events

The unstable and changing environmental conditions surrounding a disaster require effective and efficient cooperation, collaboration, and coordinated action through information and knowledge sharing [Kapucu, 2006; Turoff, 2002]. During a disaster 
management response event or threat, resources from multiple actors across different constituencies are required, including public safety, human services, and infrastructure service organizations within cities, counties, states, and federal governments. 
In addition, the activities of non-profit organizations involved in disaster management response also increase. Because of the broad participation associated with all disaster management-related activities, there is a substantial increase in the data, information, and knowledge available both generally and in the context of a specific disaster situation.

Some of the risks associated with the multiple actors that participate in disaster response efforts are related to the dangers of overloading people with data, information, and knowledge that is not relevant to making a decision [Turoff, 2002]. As a result of this broad participation, the actual decision-making processes and performances of disaster management functional groups (e.g., public safety, human services, and infrastructure) are jeopardized in terms of information, knowledge flow, and communication; this challenge significantly impacts "an organization's ability to remain effective in a dynamic disaster environment" [Kapucu, 2006, p. 209]. In other words, there is often no time to determine an optimal solution or to collect the knowledge required to proceed with a course of action. Decision-makers may often be required to operate in contexts that are not within their immediate areas of experience; however, the decision must be made immediately.

Furthermore, disaster management personnel may fail to appropriately identify the uncertain dynamic characteristics of disaster management tasks, and this may prevent them from effectively and efficiently coordinating the actions required to address the tasks at hand. It is also critical to identify the gaps between disaster management response plans and the actual performance of disaster management personnel and functional groups to improve the effectiveness and efficiency of disaster management [Choi and Browner, 2006]. 
Similarly, previous disaster events have revealed a pressing need to enhance and strengthen the decision-making processes and the performance of disaster management response activities [Jenkins, 2006].

This research is based on a review of the literature regarding disaster management, complex tasks, dynamic complexity [Campbell 1988; Wood 1986; Xia and Lee 2005], information processing (Galbraith, 1973; Daft and Lengel, 1986), and knowledge management and sharing, and it uses a combination of qualitative and quantitative methods and multiple field observations and interviews with disaster management personnel. The resulting research has conceptualized the uncertain dynamic characteristics of disaster management tasks along three dimensions: a novelty dimension (task novelty and task nonroutineness), an unanalyzability dimension (task difficulty and the amount of task information), and a significance dimension (task urgency and impact). Furthermore, knowledge sharing is conceptualized as knowledge-sharing purposes (knowledge sharing for exploration and knowledge sharing for exploitation) and knowledge-sharing mechanisms (knowledge sharing through personal contacts and knowledge sharing through written documents). Finally, task performance is conceptualized as task effectiveness and task efficiency.

As a response to the continuing problems in disaster management, as well as the critical and pressing issues mentioned in previous paragraphs, the research objective of this study is driven by the need to better understand the characteristics and dimensions related to the uncertain dynamic characteristics of disaster management tasks and the mediating and moderating effects that knowledge sharing can have on the performance of disaster management tasks. 


\subsection{Research Site}

"State and local governments generally have the primary responsibility for disaster recovery while the federal government provides support when requested. Because there are many parties involved in this process - including all levels of government as well as victims and businesses within the affected communitieseffective collaboration is a key factor for successful recovery"

GAO-09-811, July 2009 DISASTER RECOVERY: Experiences from Past Disasters Offer Insights for Effective Collaboration after Catastrophic

Events

In the United States of America, disaster management is under the jurisdiction of the office of emergency management (OEM). This study was conducted at the MiamiDade County Office of Emergency Management (MD-OEM) in Miami, Florida, USA. Given the number of disaster events faced in Florida each year (mainly tropical depressions, storms, and hurricanes), the MD-OEM is one of the most active, well trained, and prepared offices of emergency management (OEM) and emergency operations centers (EOC) in the world. Each time a disaster threat or event occurs, the office of emergency management activates the emergency operations center (EOC).

According to the significance of the event or threat, the OEM will activate the EOC under one of three different levels. Activation level 1 requires the OEM's personnel and staff to be present on the EOC premises. Level 2 requires the additional presence of selected EOC stakeholders, and level 3 denotes a full EOC activation with the presence of all agencies, organizations, and stakeholders related to the disaster management preparedness, response, mitigation, and recovery activities of the OEM. 
EOCs are organized as follows: the EOC executive group, three functional groups, the EOC support groups, information communication systems, and other related agencies. The functional groups are human services, infrastructure, and public safety. EOC-related agencies include neighboring EOCs from other counties and cities within the EOC county's geographical reach. Table 1 lists the organizations involved in the Miami-Dade County Office of Emergency Management executive and functional groups. The EOC's preparedness, response, mitigation, and recovery activities conducted by these groups and sections follow local response protocols and are supported by disaster management information communication technologies (ICT) such as the incident management system, the incident command system, and the incident management organization system. Furthermore, these ICT systems serve as communication resources to plan, organize, staff, execute, coordinate, and control all of the appropriate activities before, during, and after a disaster event or threat.

In the same way, the EOC has developed schedules and planning guidelines to address disaster threats or events in addition to standard operating procedures. These documents try to predict in advance the different situations that may occur during a disaster event and to suggest possible courses of actions to prepare, respond, mitigate, or recover from such situations. Of particular relevance, these documents outline some of the recurring tasks that must be performed by the diverse stakeholders present during a disaster event. 
The EOC executive group:

- Operations section manager

- Support manager

- Supervisor

- Operations section assistant

- Planning and situation assessment

- Human services supervisor

- Infrastructure supervisor

- Public safety supervisor
The Human services group:

- Agency for health care administration

- American Red Cross

- Department of human services Florida department of children and families

- Greater Miami convention and visitors bureau

- Human services assistant

- Human services manager

- Mental health

- Miami-Dade fire rescue

- Miami-Dade health department

- Miami-Dade housing agency

- Miami-Dade public schools

- Salvation Army

- Special needs coordinator

- Team metro

- Voluntary organizations active in disaster

The public services group:

- Animal department

- Department of environmental resources management

- Florida fish and wildlife commission

- Florida department of law enforcement

- Florida highway patrol

- Florida national guard

- Miami-Dade corrections department

- Miami-Dade fire rescue department

- Miami-Dade police department

- Miami-Dade schools police

- National park service

- Public safety assistant

- Public safety manager

- U.S. coast guard.

- Airport

- Metro bus, Metro mover, Metro rail

- Comcast 


\section{EOC support group:}

- Administrative and finance section

- Answer center supervisor,

- 311 center

- Copy center

- Geographic information systems

- Logistics section
- News media

- Planning and information section

- Radio communications

- Special needs support center

Table 1. Miami-Dade County Office of Emergency Management: groups and sections 


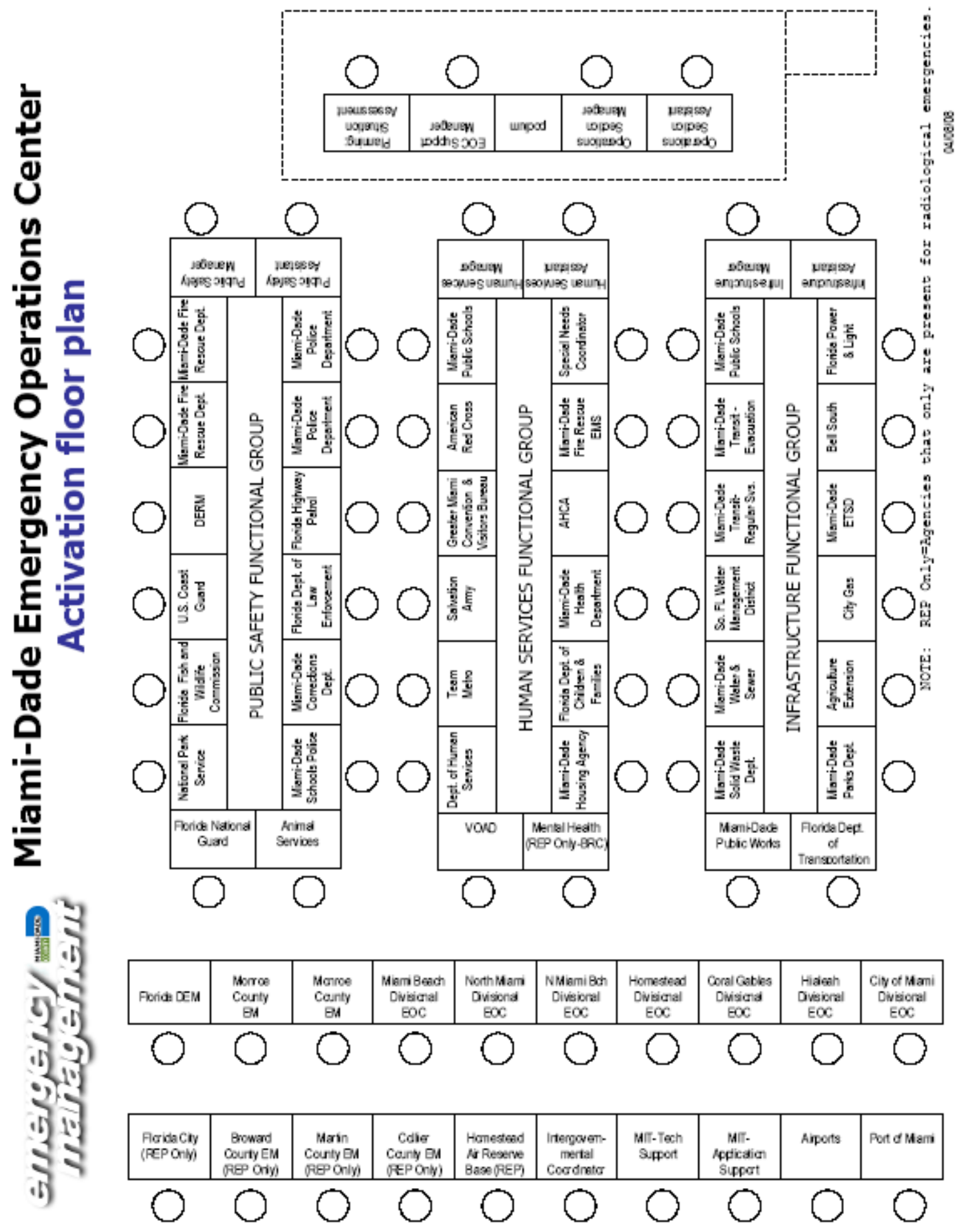

Figure 1. Miami-Dade Emergency Operations Center, Activation floor plan 
During the response to a disaster event, there are two critical documents that are needed to keep the response schedule and planning guidelines on track, namely the current situation report and the incident action plan. The current situation plans/reports and incident action plans/reports describe the current situation, operations, objectives, problems encountered, potential obstacles, assistance required or requested, and projected incident objectives. Similarly, these reports outline the planned and expected tasks required during the response to a disaster event. Additionally, the reports describe the incident characteristics, the possible foreseen tasks, and the potential involvement of the EOC functional groups and their respective agencies. When the EOC personnel encounter previously planned, expected, known, or familiar conditions, they can address them according to the disaster schedule, planning guidelines, standard operating procedures, reports, and expertise and experience of the people at hand. However, when unplanned, unexpected, unknown, or unfamiliar conditions evolve and disrupt the EOC operations, EOC personnel must assess the relevance, impact, and urgency of these conditions to act accordingly and subsequently must guide their operations back to the disaster schedule and plan.

\subsection{Research outline}

To carry out the intended research objectives, this research utilized quantitative methods design according to Creswell [2003] and the "Four-Phase Process of Measure Development and Validation" proposed by Xia and Lee [2005]. These two approaches are summarized in table 2 . 
Phase 0, Research Context

Research Background, Problem Statement and Research Objectives, Research

Significance, and Research Site, Research Outline, and Research Scope and Limitations

Phase 1, Conceptual Development and Initial Item Generation

Literature Review, Field Interviews, Focus Groups, Research Model, Research Questions, and Research Hypothesis

Phase 2, Conceptual Refinement and Item Modification

Sorting Procedure, Pilot Tests, and Final Refinement of Measurement Items

Phase 3, Survey Data Collection

Phase 4, Data Analysis and Measurement Validation

Data Screening and Descriptive Analysis, Confirmatory Factor

Analysis, Factorial Invariance Analysis, and Nomological Validity

Table 2. Research Outline (Adapted from Creswell, 2003 and Xia and Lee, 2005)

To better understand the research context of this study, an in-depth case study coupled with qualitative methods, such as interviews, focus groups, direct and indirect observations, documents, and audiovisual materials, was also implemented. Finally, a qualitative ethnographic research analysis was performed at the Miami Dade OEM-EOC during Tropical Storm Ernesto in August 2006 and during training simulations in May 2007, May 2008, May 2009, and May 2010. As a result of these qualitative research interventions, it was possible to obtain an initial assessment of the knowledge-sharing flows between the EOC stakeholders, functional groups, and organizations that are involved during a disaster event or threat. 
Furthermore, to generate the main research themes, categories, and constructs, an in depth research literature review was conducted using the EOC archives of Standard Operations Procedures, Local Response Protocols, Situation Reports and Incident Reports, Action Plans, the ICT Collaborative Software System, and e-Mail logs of Hurricanes Katrina, Rita, and Wilma.

\subsection{Research Scope and Limitations}

By investigating how decision-making during a disaster event can be improved, this research examines the uncertain dynamic characteristics of disaster management tasks; such tasks are the most suitable unit of analysis. This research focuses on the disaster management activities that occur during the initial response to a disaster event and on how knowledge sharing can moderate or mediate the uncertainty associated with task disposition. Disaster management tasks were analyzed from the perspective of their uncertain dynamic characteristics.

In this context, this research aims to better understand disaster management response activities and knowledge sharing as moderating or mediating variables that affect the effective and efficient performance of a task characterized by decision-making processes in the face of uncertainty and change characteristics. 
To understand the uncertain dynamic characteristics of a disaster management task, this research investigates three dimensions: a novelty dimension (task novelty and task nonroutineness), an unanalyzability dimension (task difficulty and amount of task information), and a significance dimension (task urgency and task impact). Furthermore, knowledge sharing is conceptualized as knowledge-sharing purposes (knowledge sharing for exploration and knowledge sharing for exploitation) and knowledge-sharing mechanisms (knowledge sharing through personal contacts and knowledge sharing through written documents). Finally, task performance is conceptualized as task effectiveness and task efficiency.

An empirical study was used to measure the relationship between the independent variables that comprise uncertain dynamic disaster management tasks, represented by task novelty, unanalyzability, and significance, and the dependent variable of task performance (effectiveness and efficiency) through the moderating and/or mediating variables of knowledge-sharing purposes and mechanisms.

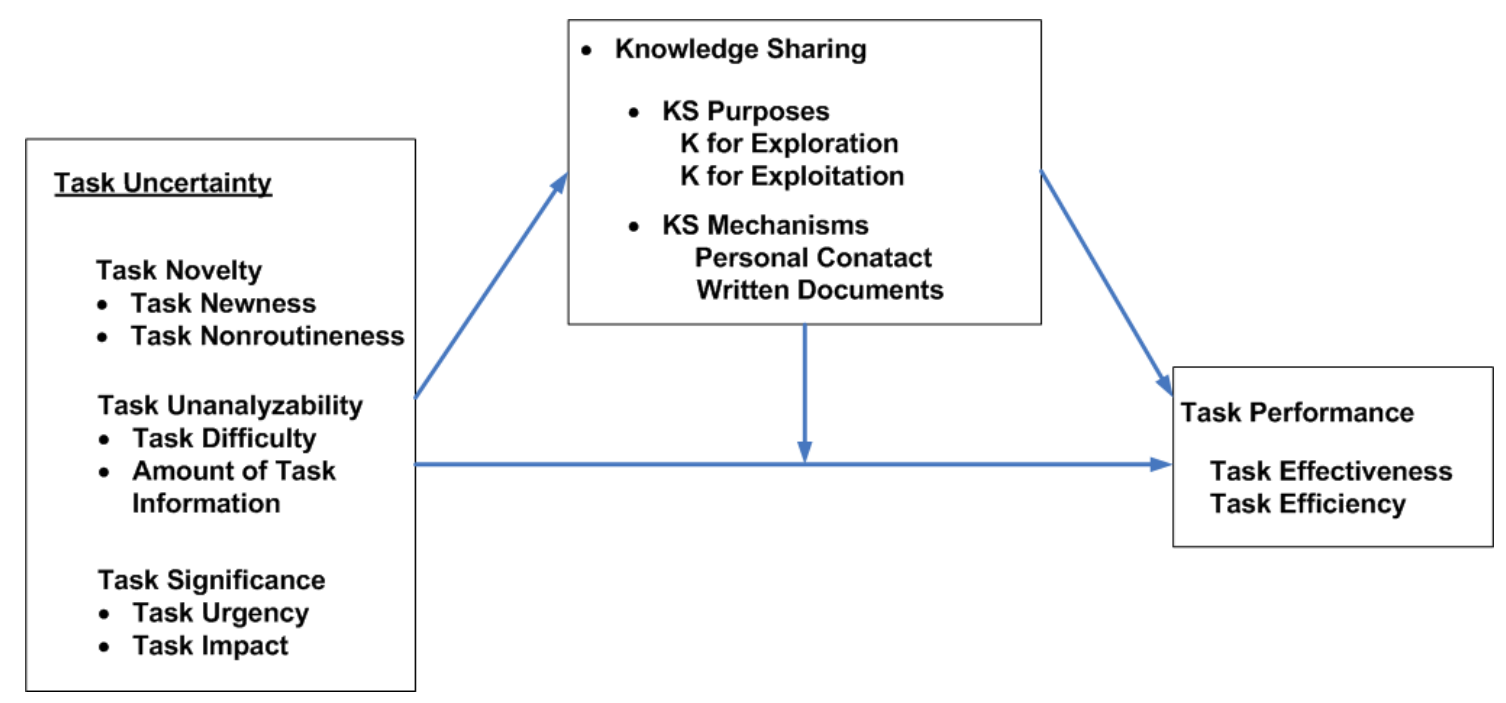

Figure 2. Research Model 
The limitations of this research are inherent to the task characteristics that it addresses. Within the research literature, other task characteristics can be found, including complexity, variety, and interdependence [Dean and Snell, 1991]. However, for the purposes of this research, these task characteristics are considered to be more intrinsic (also referred to as static) to the nature of the task, as opposed to dynamic uncertain task charcteristics. For this reason, this work purposely did not address these intrinsic (static) task characteristics. 


\section{Literature Review}

"The basic goal of emergency preparedness for a major emergency is that first responders should be able to respond swiftly with well-planned, well-coordinated, and effective actions that save lives and property, mitigate the effects of the disaster, and set the stage for a quick, effective recovery. In a major event, coordinated, effective actions are required among responders from different local jurisdictions, levels of government, and nongovernmental entities, such as the Red Cross" p. 4

\section{GAO-06-467T, EMERGENCY PREPAREDNESS AND RESPONSE, Some Issues and Challenges Associated with Major Emergency Incidents: Statement of William O. Jenkins, Jr., Director Homeland Security and Justice Issues}

\subsection{Disaster Management}

Disasters are characterized by a series of dynamic and constantly changing events, with attributes related to time, geography, size, periodicity, circumstances, magnitude, information, knowledge, and people [Kumar, 2000], that heavily influence decisionmaking processes. The unstable and changing environmental conditions surrounding a disaster, in which almost everything is an exception to the norm, call for effective and efficient cooperation, collaboration, and coordinated action through information and knowledge sharing [Kapucu, 2006; Turoff, 2002].

To effectively respond to disaster events or threats, the EOC has developed a set of standard operating procedures and a set of schedule and planning guidelines to address each type of disaster event. Based on past experience, these documents attempt to anticipate and plan for the different circumstances that might arise during a disaster 
event, and they suggest possible courses of actions. These actions are focused on preparedness, response, mitigation, or recovery.

Of particular relevance, these documents outline the tasks that need to be performed by the diverse stakeholders present during a disaster event. Furthermore, in addition to coordinating the activities of the EOC groups during a disaster event, the EOC Executive Group is responsible for keeping the disaster schedule and planning guidelines (the Current Situation Report and the Incident Action Plan) on track.

The Current Situation and Incident Action Plan reports describe the current situation, operations, objectives, problems encountered, potential obstacles, assistance required or requested, and projected incident objectives. Similarly, these reports outline the planned and expected tasks that must be performed following a disaster event as well as the unplanned and unexpected tasks and the involvement of EOC personnel and functional groups and their respective agencies. When EOC personnel are faced with previously planned, expected, known, or familiar tasks, they can address these tasks primarily according to the disaster schedule, planning guidelines, standard operating procedures, reports, and the expertise and experience of the people at hand. However, when the EOC personnel are faced with unplanned, unexpected, unknown, or unfamiliar conditions, they must cope with a great deal of uncertainty in the tasks required for certain response factors, such as the relevance, impact, and urgency of the conditions that determine the required actions.

Given these unplanned, unexpected, unknown, or unfamiliar characteristics of a disaster event, the attention and resources of EOC personnel may be diverted from the course of action dictated by the disaster response schedule and planning guidelines. This 
disruption becomes even more critical when the relevance, impact, and urgency of these conditions jeopardize human lives and have significant economic repercussions.

As a result, a better understanding of unplanned, unexpected, unknown, or unfamiliar tasks during a disaster management event is critical for EOC personnel and functional groups to allow them to effectively and efficiently perform the tasks at hand by returning to the disaster response planning, schedule, and guidelines.

\subsubsection{Critical Issues in Disaster Management}

Given the rarity and dynamic nature of disasters, researchers and practitioners of disaster management emphasize several critical issues and open problems in the response activities. Training and simulations play a significant role in preparing management teams to act before, during, and after a disaster event.

By highlighting the aspects of technology, processes, and people [Sharman et al., 2006], these trainings and simulations take into consideration the disaster "demands (e.g., dynamic and evolving conditions, role uncertainty, and situational responses)", management capabilities, operational demands, and resource allocation [Paton and Jackson, 2002, p. 115]. In particular, regular and ongoing training in communication flows, knowledge sharing, and the use of ICT systems according to pre-established standard operating procedures, schedules, and planning guidelines are critical for an effective and efficient response to a disaster event or threat [Turoff, 2002]. 
Another central issue in disaster management activities is the critical time frame associated with the disaster event. 
The focus and attention of the disaster management team during this time frame is extremely important with regards to the "implementation of plans, and the use of personnel and equipment to achieve the tactical and task requirements" [Perry, 2003, p. 406]. Often, several incidents occur at the same time. As a result, disaster management personnel work under tremendous pressure, demands, and stress, sometimes with shifts of 12 to 18 hours per day [Turoff, 2002]. Therefore, information and knowledge must be managed to effectively and efficiently accomplish the disaster response tasks at hand.

Because of the critical concerns outlined in the previous paragraphs, it is extremely important to comprehensively integrate the issues of whats, whens, whos, whys, and/or hows of disaster management tasks as much and as far in advance as possible. It is also important to explicitly clarify the roles, responsibilities, and information- and knowledge-sharing flows that will play significant roles in the dynamic conditions of the disaster recovery [Turoff, 2002]. Indeed, central to these critical issues is the dynamic allocation and responses of people, resources, and information and knowledge sharing according to the tasks and circumstances that evolve during the disaster recovery [Turoff, 2002].

In summary, disasters are characterized by differing timeframes, geography, sizes, periodicity, circumstances, and magnitude, even within the same category of events. As disaster events evolve, several patterns can be identified; however, there are many "exception[s] to the norm" [Turoff, 2002, p. 29]. The handling of these unforeseen situations by disaster response teams is critical. 
For this reason, the better disaster response teams are prepared to handle unexpected incidents, and the more flexibility they have to readapt their responses and to regroup themselves, the shorter will be the time required for the disaster response team to return their attention to the normally evolving set of disaster response operations.

\subsubsection{Open Problems in Disaster Management}

The popular press and the disaster management literature have highlighted the lack of effective cooperation and coordinated action through collaboration and information and knowledge sharing, as evidenced by the lessons learned from the aftermath of natural disasters such as Hurricane Katrina in 2005 [Jenkins 2006; Smith and Dowell, 2000]. The absence of coordination is usually obvious among both EOC functional groups (human services, infrastructure, and public safety) and among city, county, state, and federal governments and non-profit organizations and businesses [Smith and Dowell, 2000]. Because of the evolving nature of disasters, cooperation and coordinated actions are required in order "to act effectively in disaster situations" [Kapucu, 2006, p. 208]. Indeed, researchers note that the lessons learned from the Gulf Coast disasters suggest that clear rules, policies, roles and responsibilities, as well as training and preparation programs, are essential for effective and efficient coordination among all of the disaster management stakeholders and shareholders involved [Sharman et al.,2006]. 
Adding to these critical issues and open problems in disaster management, there is another critical concern for EOCs around the United States: knowledge erosion at all levels of participating organizations. Because of the renewed interest in the disaster management field as a result of recent disasters around the globe, public and private organizations are engaging in a wide range of activities related to disaster management. On the one hand, public organizations are attempting to strengthen their emergency management capabilities by hiring experienced personnel from other local, county, state, or federal emergency management departments. On the other hand, private organizations are rushing to ride the disaster management wave in search of profitable opportunities; therefore, these organizations are also hiring disaster management experts from the public sector. In addition to these circumstances, because of the dynamic and ever-changing pace of the disaster management industry, experts in this field are seizing opportunities for professional growth and are moving from one organization to another. Furthermore, a considerable percentage of the United States civil servant workforce has been eligible for retirement since 2001 [Kull, 2005], adding to the rapidly shrinking labor force and increased workloads.

At the core of the abovementioned critical issues and open problems is a lack of robust data-, information- and knowledge-communication channels and ICT systems that could support effective coordination and collaboration among disaster management agencies [Choi and Browner, 2006]. 
People, processes, and technology play crucial roles in creating effective inter- and intraorganizational communication, which in turn translates into effective and efficient data-, information- and knowledge sharing that "facilitates collective action in emergencies" during dynamic disaster environments [Kapucu, 2006, p. 208]. Lastly, research studies have demonstrated the importance of the "appropriate design of a socio-technical system" based on data, information, and knowledge sharing through information technology to achieve the appropriate level of coordinated response according to the ever-changing conditions of the disaster event [Confort et al.; 2004, p. 62].

"Assessing, developing, attaining, and sustaining needed emergency preparedness, response, and recovery capabilities is a difficult task that requires sustained leadership, the coordinated efforts of many stakeholders from a variety of first responder disciplines, levels of government, and nongovernmental entities" p. 15-16

GAO-06-467T, EMERGENCY PREPAREDNESS AND RESPONSE, Some Issues and Challenges Associated with Major Emergency Incidents: Statement of William O. Jenkins, Jr., Director Homeland Security and Justice Issues

\subsection{Uncertainty of Disaster Management Tasks}

As disaster events evolve, EOC functional groups and actors address a wide variety of tasks. Most of the time, these tasks have been anticipated and well documented in schedules, planning guidelines, and standard operating procedures, and they have been rehearsed during training and disaster simulation events. 
However, when unexpected events arise during a disaster event, there is a great deal of uncertainty regarding how to approach the tasks at hand because these tasks present themselves as dynamic and novel undertakings.

Most researchers agree that a task is defined as the unit of analysis that is unique and perfectly identifiable for any job [Kim and Dagobert, 2005; Larsen, 2003]. Similarly, every task possesses a set of characteristics that play significant roles in determining the outcomes of the task. According to Kim and Dagobert (2005), these characteristics can be classified as intrinsic and extrinsic characteristics; that is, the characteristics of the task performer and the relationship between the task and performer. Other researchers classify task characteristics as task autonomy, task feedback, task identity, task significance, task difficulty, task variability, task uncertainty, task orientation, and task domain [Piccolo and Jason, 2006; Becerra-Fernandez and Sabherwal, 2001].

In fact, given the unstable and changing environmental conditions surrounding a disaster event, the characteristics of the response activities involved in the task can also be classified as static and dynamic. Static task characteristics are defined as those that are intrinsic to the task itself and that are related to the characteristics of task complexity, variety, and interdependence. The dynamic characteristics of the disaster response task incorporate the decision maker and the cognitive context in which the decision-making process occurs. The dynamic characteristics of the task include novelty (newness and nonroutineness), task unanalyzability (difficulty, equivocality, and the amount of task information), and task significance (urgency and impact); all of these are relative to the person faced with completing the task. 
The concept of task uncertainty during a disaster management event is defined as "the difference between the amount of information [and knowledge] required to perform the task and the amount of information already possessed" [Galbraith, 1973, p. 36-37 in Larsen, 2003, p. 188] and "the absence of information" [Daft and Lengel, 1986, p. 556] required to perform a task. Task uncertainty has a direct relationship with the available information and knowledge; "as information [and knowledge] increases, uncertainty decreases" [Daft and Lengel, 1986, p. 556]. Indeed, for the purposes of this research, task uncertainty is defined as the result of the aggregation of task nonroutineness and task novelty.

Task nonroutineness often is described as "the extent to which a [task] involves performing a number of different [activities] and frequently encountering exceptional circumstances requiring flexibility" [Fields, D.L., 2002, p. 100; Dean and Snell, 1991]. Task newness describes frequent encounters with "unexpected and novel events that occur in performing a task" [Daft and Macintosh, 1981 in Karimi, Somers, and Gupta, 2004, p. 177].

Both task nonroutineness and task newness have direct relationships with task uncertainty; as task nonroutineness and newness increase, so does task uncertainty, making this type of task difficult to predict [Goodhue, 1995; Van de Ven and Delbecq, 1974]

Task unanalyzability denotes "the extent to which workers can follow unambiguous processes to solve task-related problems: that is, the degree to which the task is structured" [Dunegan, Duchon, and Uhlbien, 1992 in Larsen, 2003, p. 185]. 
Furthermore, task unanalyzability is viewed as the opposite of a known cause-and-effect relationship between task requirements and the ability to complete tasks on time. As a result, "task unanalyzability represents the degree to which the task is unstructured and the information required to perform the task is equivocal thus leading to conflicting interpretations" [Daft and Lengel, 1986; Daft and Macintosh, 1981; Dunegan, Duchon, and Uhlbien, 1992]. In other words, task unanalyzability can be interpreted as the circumstances surrounding an unstructured task that make it difficult and challenging to determine a clear course of action. According to these definitions, task unanalyzability can also be seen as the result of task difficulty and information equivocality.

Task difficulty refers to impediments "in seeing into the task and in analyzing it in terms of alternative courses of action, costs, benefits, and outcomes" [Daft and Macintosh, 1981, p. 209]. In fact, task difficulty relates to "the way individuals respond to problems that arise" [Larsen, 2003; Van de Ven and Delbecq, 1974 in Karimi, Somers, and Gupta, 2004, p. 177], and it is directly associated with "the analyzability and predictability of work [and tasks] undertaken by an organization unit" [Van de Ven and Ferry, 1980 in Karimi, Somers, and Gupta, 2004, p. 177].

Another important concept in defining task unanalyzability is information equivocality, which refers to "the multiplicity of meaning conveyed by information about organizational activities" [Daft and Macintosh, 1981, p. 211]. In addition, information equivocality often "lends itself to different and perhaps conflicting interpretations about the work [and task] context" [Daft and Macintosh, 1981, p. 211]. 
As a result, it is evident that when task unanalyzability arises, task uncertainty, as well as task difficulty and information equivocality, increase "in terms of alternative courses of action, costs, benefits, and outcomes" [Daft and Macintosh, 1981, p. 209]. Tables 3, 4, 5, and 6 summarize previous research studies related to task novelty and task unanalyzability and their respective dimensions.

Lastly, other major concept in task uncertainty is the relevance of the significance of the task at hand, which is defined by the aggregation of task urgency and impact. The concept of task significance is primarily defined as "the degree to which the job [and its tasks have ... ] a substantial impact on the lives of other people, whether those people are in the immediate organization or in the world at large" [Hackman and Oldham1980, p. 79 in Larsen, 2003, p. 190].

Similarly, task urgency and impact deal with the same issues as task significance, but there is an additional component measured in terms of economic consequences. Whereas task urgency focuses on the immediate priorities and timeframe in which a task needs to be performed, task impact refers to the analysis and assessment of potential repercussions in order to prioritize tasks.

Table 7 summarizes the literature review references used to conceptualize uncertain dynamic disaster management tasks and its respective constructs and dimensions.

In summary, because of the ever-changing nature of disaster events, it is important for EOC personnel, EOC functional groups and stakeholders to have a deep understanding of uncertain and dynamic disaster management tasks, particularly when these tasks are unplanned and unexpected. 
The uncertain attributes of tasks, such as task novelty, task unanalyzability, and task significance, play important roles in the overall scheme of EOC task performance during a disaster event. In addition, given the unstable conditions of a disaster event and the uncertain task characteristics, the skillful use of knowledge and comprehensive training become critical. Effective cooperation, collaboration, and coordinated action through information- and knowledge sharing are extremely important to make decisions that result in a minimum impact to human life and minimum economic consequences. 


\begin{tabular}{|c|c|c|c|c|}
\hline Construct & Author(s) & $\begin{array}{l}\text { Authors(s) } \\
\text { Construct/Variable } \\
\text { Name } \\
\end{array}$ & Author(s) Definition & $\begin{array}{l}\text { Author(s) } \\
\text { Findings/Relationships }\end{array}$ \\
\hline $\begin{array}{l}\text { Construct: } \\
\text { Task Novelty } \\
\text { Dimension: } \\
\text { Task Newness } \\
\text { Task Novelty captures the } \\
\text { newness (unexpected and } \\
\text { novel events that occur in } \\
\text { performing the task)" } \\
\text { [Fields, 2002; Dean and } \\
\text { Snell, 1991; Daft and } \\
\text { Macintosh, 1981 in } \\
\text { Becerra-Fenandez et al., } \\
\text { 2008, pg. 2, ISCRAM } \\
\text { 2008 Paper] }\end{array}$ & $\begin{array}{l}\text { Daft and } \\
\text { Macintosh, } \\
1981, \text { p. } 208\end{array}$ & Task Variety & $\begin{array}{l}\text { "the frequency of } \\
\text { unexpected and novel } \\
\text { events" }\end{array}$ & $\begin{array}{l}\text { Amount and equivocality of information } \\
\text { processing is related to the variety and } \\
\text { analyzability of work-unit activities } \\
\text { The amount of information processing } \\
\text { increased with task variety and } \\
\text { analyzability }\end{array}$ \\
\hline & $\begin{array}{l}\text { Van de Ven } \\
\text { and Delbecq, } \\
1974\end{array}$ & Task Variability & $\begin{array}{l}\text { "The number of } \\
\text { exceptional cases } \\
\text { encountered in the work } \\
\text { requiring different } \\
\text { methods or procedures } \\
\text { for doing the work" }\end{array}$ & $\begin{array}{l}\text { Task variability and difficulty have a } \\
\text { direct impact on three basic work units } \\
\text { structural modes within a complex } \\
\text { organization: systematized, service, and } \\
\text { group }\end{array}$ \\
\hline
\end{tabular}

Table 3. Literature Review, Previous Research Studies Related to Task Novelty and its Task Newness Dimension 


\begin{tabular}{|c|c|c|c|c|}
\hline Construct & Author(s) & $\begin{array}{l}\text { Authors(s) } \\
\text { Construct/Variable } \\
\text { Name } \\
\end{array}$ & Author(s) Definition & $\begin{array}{l}\text { Author(s) } \\
\text { Findings/Relationships }\end{array}$ \\
\hline & $\begin{array}{l}\text { Blili, } \\
\text { Raymond, and } \\
\text { Rivard, } 1998 \\
\text { Information } \\
\text { and } \\
\text { Management }\end{array}$ & $\begin{array}{l}\text { Task Uncertainty: Task } \\
\text { Complexity and Task } \\
\text { Volatility }\end{array}$ & $\begin{array}{l}\text { "Task uncertainty is the } \\
\text { degree to which work to } \\
\text { be } \\
\text { performed is difficult to } \\
\text { understand and } \\
\text { complex" p. 139. } \\
\text { Along with two } \\
\text { dimensions: " task } \\
\text { complexity } \\
\text { (interdependence, } \\
\text { autonomy, variety, } \\
\text { structurability, } \\
\text { intelligibility) and [ ... } \\
\text { task] volatility (rate of } \\
\text { change, predictability, } \\
\text { exceptions, } \\
\text { controllability)" p. } 139\end{array}$ & $\begin{array}{l}\text { "[end-user computing ] competence and } \\
\text { success are determined by task complexity } \\
\text { and the perceived importance users } \\
\text { attribute to [end-user computing ]" p. } 137 \\
\text { "Task uncertainty is an important factor } \\
\text { affecting user behavior and as a vector of } \\
\text { attitudes and perceptions." p. } 147 \\
\text { "The impact of task uncertainty } \\
\text { demonstrates the importance of } \\
\text { considering this variable in the process } \\
\text { of allocating information processing } \\
\text { resources: those users who have the most } \\
\text { uncertain tasks should have access to } \\
\text { better resources because they have more } \\
\text { important information needs" p. } 147\end{array}$ \\
\hline & $\begin{array}{l}\text { Hopp, Iravani, } \\
\text { and Yuen, } \\
2007 \\
\text { Management } \\
\text { Science }\end{array}$ & $\begin{array}{l}\text { Task Variability } \\
\text { Task Completion }\end{array}$ & $\begin{array}{l}\text { "Task variability } \\
\text { degrades system } \\
\text { performance in } \\
\text { Nondiscretionary Task } \\
\text { Completion Systems"p. } \\
71\end{array}$ & $\begin{array}{l}\text { "Task variability can be beneficial [in } \\
\text { Discretionary Task Completion Systems]. } \\
\text { This is because discretion allows the } \\
\text { server to take advantage of the difference } \\
\text { in task types to increase flexibility" p. } 76\end{array}$ \\
\hline
\end{tabular}

Table 3 (continued ...) 


\begin{tabular}{|c|c|c|c|c|}
\hline Construct & Author(s) & $\begin{array}{l}\text { Authors(s) } \\
\text { Construct/Variable } \\
\text { Name } \\
\end{array}$ & Author(s) Definition & \begin{tabular}{|l|} 
Author(s) \\
Findings/Relationships
\end{tabular} \\
\hline & $\begin{array}{l}\text { Gelderman, } \\
2002 \\
\text { Information } \\
\text { and } \\
\text { Management }\end{array}$ & $\begin{array}{l}\text { Task difficulty } \\
\text { Task variability }\end{array}$ & $\begin{array}{l}\text { "Task variability: the } \\
\text { number of exceptions } \\
\text { encountered } \\
\text { in the characteristics of } \\
\text { the work" p. } 595 \\
\text { "Task difficulty: the } \\
\text { analyzability and } \\
\text { predictability } \\
\text { of the work in an } \\
\text { organization unit" p. } \\
595\end{array}$ & $\begin{array}{l}\text { "Task difficulty does not lead } \\
\text { to problems, as long as the support does } \\
\text { not require that cause-effect relations are } \\
\text { understood but task variability leads to } \\
\text { numerous exceptions when data are } \\
\text { missing or not provided timely enough" p. } \\
593\end{array}$ \\
\hline & $\begin{array}{l}\text { Tatikonda and } \\
\text { Rosenthal, } \\
2000 \\
\text { IEEE } \\
\text { TRANSACTI } \\
\text { ONS ON } \\
\text { ENGINEERIN } \\
\text { G } \\
\text { MANAGEME } \\
\text { NT }\end{array}$ & $\begin{array}{l}\text { Technology novelty } \\
\text { Project complexity } \\
\text { Task uncertainty } \\
\text { Project execution } \\
\text { outcomes }\end{array}$ & $\begin{array}{l}\text { "Task uncertainty is "the } \\
\text { difference } \\
\text { between the amount of } \\
\text { information required to } \\
\text { perform the } \\
\text { task and the amount of } \\
\text { information already } \\
\text { possessed by the } \\
\text { organization" } \\
\text { [Organization Design. } \\
\text { Reading, MA: Addison- } \\
\text { Wesley, 1977, p. 36]" p. } \\
75\end{array}$ & $\begin{array}{l}\text { "Projects with high levels of technology } \\
\text { novelty or project complexity are not } \\
\text { associated with overall project failure, but } \\
\text { are associated with specific project } \\
\text { outcome elements. Technology novelty is } \\
\text { strongly associated with poor unit-cost } \\
\text { and } \\
\text { time-to-market results, and project } \\
\text { complexity is strongly associated } \\
\text { with poor unit-cost outcomes" p. } 74\end{array}$ \\
\hline
\end{tabular}

Table 3 (continued ...) 


\begin{tabular}{|c|c|c|c|c|}
\hline Construct & Author(s) & $\begin{array}{l}\text { Authors(s) } \\
\text { Construct/Variable } \\
\text { Name } \\
\end{array}$ & Author(s) Definition & $\begin{array}{l}\text { Author(s) } \\
\text { Findings/Relationships }\end{array}$ \\
\hline & $\begin{array}{l}\text { Chang, Chang, } \\
\text { and Paper, } \\
2003 \\
\text { Information } \\
\text { and } \\
\text { Management }\end{array}$ & $\begin{array}{l}\text { Task uncertainty: } \\
\text { Task variability } \\
\text { Task analyzability }\end{array}$ & $\begin{array}{l}\text { "Task uncertainty can be } \\
\text { defined as the difference } \\
\text { between the amount of } \\
\text { information needed to } \\
\text { complete a task and the } \\
\text { amount of information } \\
\text { already possessed" p. } \\
692 \\
\text { "Perrow [ ... ] proposes } \\
\text { two basic dimensions of } \\
\text { task uncertainty: } \\
\text { variability } \\
\text { and analyzability" p. } \\
692 \\
\text { "Task variability affects } \\
\text { the amount of } \\
\text { information required to } \\
\text { handle unexpected } \\
\text { events and task } \\
\text { analyzability affects the } \\
\text { form of information } \\
\text { necessary to resolve } \\
\text { ambiguities" p. } 692-693\end{array}$ & $\begin{array}{l}\text { "Broad-scope information (external } \\
\text { environment or future-oriented } \\
\text { information) promotes user satisfaction in } \\
\text { high task variability situations, and [...] in } \\
\text { a highly decentralized organization, } \\
\text { broad-scope, timely, and aggregated } \\
\text { information will also facilitate user } \\
\text { satisfaction" p. } 691\end{array}$ \\
\hline
\end{tabular}

Table 3 (continued ...) 


\begin{tabular}{|c|c|c|c|c|}
\hline Construct & Author(s) & $\begin{array}{l}\text { Authors(s) } \\
\text { Construct/Variable } \\
\text { Name } \\
\end{array}$ & Author(s) Definition & $\begin{array}{l}\text { Author(s) } \\
\text { Findings/Relationships }\end{array}$ \\
\hline \multirow[t]{2}{*}{$\begin{array}{l}\text { Construct: } \\
\text { Task Novelty } \\
\text { Dimension: } \\
\text { Task Non-Routineness } \\
\text { Exceptional } \\
\text { circumstances requiring } \\
\text { flexibility of the task" } \\
\text { [Fields, 2002; Dean and } \\
\text { Snell, 1991; Daft and } \\
\text { Macintosh, 1981 in } \\
\text { Becerra-Fenandez et al., } \\
\text { 2008, pg. 2, ISCRAM } \\
\text { 2008 Paper] }\end{array}$} & $\begin{array}{l}\text { Goodhue, } \\
1995, \text { p. } 1833\end{array}$ & $\begin{array}{l}\text { Task variety, difficult, or } \\
\text { non-routine task }\end{array}$ & $\begin{array}{l}\text { Great variety of issues } \\
\text { or nonroutine, ad hoc } \\
\text { situations will need to } \\
\text { get new types of data } \\
\text { from information } \\
\text { systems, and analyze it } \\
\text { in new ways }\end{array}$ & $\begin{array}{l}\text { Task characteristics affect user evaluation } \\
\text { of task technology fit. }\end{array}$ \\
\hline & $\begin{array}{l}\text { Lillrank, 2003, } \\
\text { p. } 144\end{array}$ & Nonroutine process & $\begin{array}{l}\text { A nonroutine process is } \\
\text { designed to address non- } \\
\text { predictable, surprising } \\
\text { and unfamiliar events } \\
\text { through inquiry and } \\
\text { learning systems, and } \\
\text { capacity for problem } \\
\text { solving } \\
\text { Nonroutine processes } \\
\text { and systems are found in } \\
\text { contexts that are }\end{array}$ & $\begin{array}{l}\text { Nonroutine processes and activities are } \\
\text { directly related to unknown inputs and } \\
\text { target conditions }\end{array}$ \\
\hline
\end{tabular}




\begin{tabular}{|l|l|l|l|}
\hline & & $\begin{array}{l}\text { continuously shifting } \\
\text { and where organizations } \\
\text { must deal with } \\
\text { exceptions, high task } \\
\text { variety, and } \\
\text { unanticipated issues. }\end{array}$ & \\
\hline
\end{tabular}

Table 4. Literature Review, Previous Research Studies Related to Task Novelty and its Task Non-Routineness Dimension

\begin{tabular}{|c|c|c|c|c|}
\hline Construct & Author(s) & $\begin{array}{l}\text { Authors(s) } \\
\text { Construct/Variable } \\
\text { Name } \\
\end{array}$ & Author(s) Definition & $\begin{array}{l}\text { Author(s) } \\
\text { Findings/Relationships }\end{array}$ \\
\hline & $\begin{array}{l}\text { Rowan, } \\
\text { Raudenbush, } \\
\text { and Cheong, } \\
1993 \\
\text { Educational } \\
\text { Administration } \\
\text { Quarterly }\end{array}$ & Non-Routine Task & $\begin{array}{l}\text { "Variability in inputs } \\
\text { and task demands is } \\
\text { seen as creating } \\
\text { technical uncertainty } \\
\text { and adding to the } \\
\text { complexity of work. As } \\
\text { a result, variability } \\
\text { contributes to the } \\
\text { development of non- } \\
\text { routine tasks" p. } 482\end{array}$ & $\begin{array}{l}\text { "Perceived variability }[\ldots] \text { affects the } \\
\text { extent to which [... an activity] becomes a } \\
\text { non-routine task" p. } 496\end{array}$ \\
\hline & $\begin{array}{l}\text { Waller, } 1999 \\
\text { Academy of } \\
\text { Management } \\
\text { Journal }\end{array}$ & $\begin{array}{l}\text { Information collection and } \\
\text { transfer } \\
\text { Task prioritization } \\
\text { Task distribution } \\
\text { Nonroutine events }\end{array}$ & $\begin{array}{l}\text { "information collection } \\
\text { and transfer, task } \\
\text { prioritization, and task } \\
\text { distribution as pivotal in } \\
\text { group's adaptation to } \\
\text { nonroutine vents" p. } 127\end{array}$ & $\begin{array}{l}\text { "the amount of time taken to engage in } \\
\text { adaptive responses after nonroutine events } \\
\text { had a negative association with" } \\
\text { performance, p. } 127 \\
\text { "the frequency of information collection } \\
\text { activities had a positive association with } \\
\text { performance" p. } 127\end{array}$ \\
\hline
\end{tabular}

Table 4 (continued ...) 


\begin{tabular}{|c|c|c|c|c|}
\hline Construct & Author(s) & $\begin{array}{l}\text { Authors(s) } \\
\text { Construct/Variable } \\
\text { Name }\end{array}$ & Author(s) Definition & $\begin{array}{l}\text { Author(s) } \\
\text { Findings/Relationships }\end{array}$ \\
\hline $\begin{array}{l}\text { Construct: } \\
\text { Task Unanalyzability } \\
\text { Dimension: } \\
\text { Task Difficulty } \\
\text { Task Unanalyzability } \\
\text { represents the degree to } \\
\text { which the task is } \\
\text { unstructured and the } \\
\text { information required to } \\
\text { perform the task is } \\
\text { equivocal thus leading to } \\
\text { conflicting } \\
\text { interpretations" [Daft and } \\
\text { Lengel, 1986; Daft and } \\
\text { Macintosh, 1981; } \\
\text { Dunegan, Duchon, and } \\
\text { Uhlbien, 1992 in Becerra- } \\
\text { Fenandez et al., 2008, pg. } \\
\text { 2, ISCRAM 2008 Paper] } \\
\text { Task difficulty relates to } \\
\text { "the way individuals } \\
\text { respond to problems that } \\
\text { arise" [Larsen, 2003; Van } \\
\text { de Ven and Delbecq, } \\
\text { 1974 in Karimi, Somers, }\end{array}$ & $\begin{array}{l}\text { Daft and } \\
\text { Macintosh, } \\
1981, \text { p. } 208- \\
211\end{array}$ & Task analyzability & $\begin{array}{l}\text { Task analyzability [...] } \\
\text { concerns how } \\
\text { individuals respond to } \\
\text { problems that arise. [...] } \\
\text { Participants may have to } \\
\text { spend time thinking } \\
\text { about what to do, and } \\
\text { they may actively search } \\
\text { for solutions beyond } \\
\text { normal procedures } \\
\text { Information equivocality } \\
\text { is defined as the } \\
\text { multiplicity of meaning } \\
\text { conveyed by } \\
\text { information about } \\
\text { organizational activities }\end{array}$ & $\begin{array}{l}\text { Amount and equivocality of information } \\
\text { processing is related to the variety and } \\
\text { analyzability of work-unit activities } \\
\text { The amount of information processing } \\
\text { increased with task variety and } \\
\text { analyzability }\end{array}$ \\
\hline
\end{tabular}




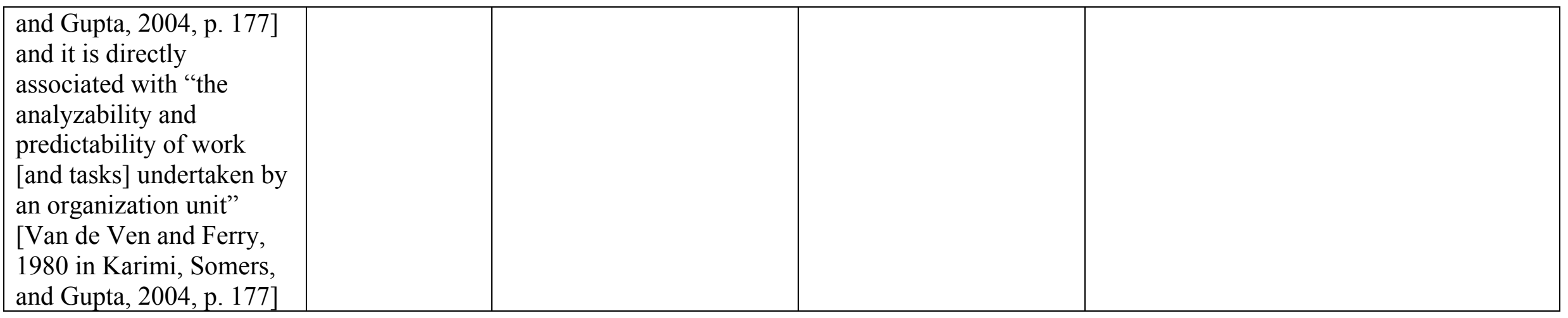

Table 5. Literature Review, Previous Research Studies Related to Task Unanalyzability and its Task Difficulty Dimension 


\begin{tabular}{|c|c|c|c|c|}
\hline Construct & Author(s) & $\begin{array}{l}\text { Authors(s) } \\
\text { Construct/Variable } \\
\text { Name } \\
\end{array}$ & Author(s) Definition & \begin{tabular}{|l|} 
Author(s) \\
Findings/Relationships
\end{tabular} \\
\hline & $\begin{array}{l}\text { Van de Ven } \\
\text { and Delbecq, } \\
1974, \text { p. } 183\end{array}$ & Task Difficulty & $\begin{array}{l}\text { Task Difficulty refers to } \\
\text { the analyzability of the } \\
\text { work itself and the } \\
\text { extent to which there is } \\
\text { a known procedure that } \\
\text { specifies the sequence of } \\
\text { steps to be followed in } \\
\text { performing the task. }\end{array}$ & $\begin{array}{l}\text { Task variability and difficulty have a } \\
\text { direct impact on three basic work units } \\
\text { structural modes within a complex } \\
\text { organization: systematized, service, and } \\
\text { group }\end{array}$ \\
\hline & $\begin{array}{l}\text { Daft and } \\
\text { Macintosh, } \\
1981 \\
\text { Administrative } \\
\text { Science } \\
\text { Quarterly }\end{array}$ & $\begin{array}{l}\text { Amount and equivocality } \\
\text { of information processing } \\
\text { Variety and analyzability } \\
\text { of work-unit activities. }\end{array}$ & $\begin{array}{l}\text { "Task elements are } \\
\text { conceptualized as } \\
\text { stimuli that vary } \\
\text { systematically across } \\
\text { work settings and trans- } \\
\text { late into more or less } \\
\text { uncertainty for } \\
\text { participants" p. } 208 \\
\text { "When work processes } \\
\text { are not analyzable, } \\
\text { participants experience } \\
\text { what might be called } \\
\text { "response" uncertainty. } \\
\text { Un- certainty arises } \\
\text { from difficulty in seeing } \\
\text { into the task and in } \\
\text { analyzing it in terms of } \\
\text { alternative courses of }\end{array}$ & $\begin{array}{l}\text { "Amount of information processing in- } \\
\text { creased with both task variety and } \\
\text { analyzability; the re- ported use of } \\
\text { equivocal information decreased with task } \\
\text { analyzability. The findings suggest a } \\
\text { modification of the previously reported } \\
\text { positive relationship between task un- } \\
\text { certainty and amount of information } \\
\text { processing"p. } 207\end{array}$ \\
\hline
\end{tabular}




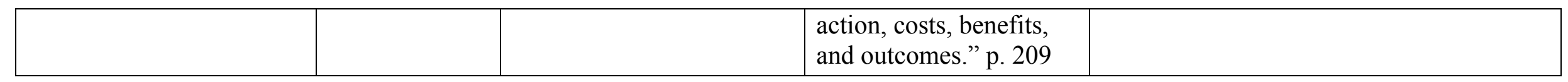

Table 5 (continued ...) 


\begin{tabular}{|c|c|c|c|c|}
\hline Construct & Author(s) & $\begin{array}{l}\text { Authors(s) } \\
\text { Construct/Variable } \\
\text { Name } \\
\end{array}$ & Author(s) Definition & $\begin{array}{l}\text { Author(s) } \\
\text { Findings/Relationships }\end{array}$ \\
\hline & $\begin{array}{l}\text { Edmondson, } \\
\text { Roberto, and } \\
\text { Watkins, 2003 } \\
\text { Leadership } \\
\text { Quarterly }\end{array}$ & Unstructured task & $\begin{array}{l}\text { "Senior teams } \\
\text { face unstructured task } \\
\text { streams-a continual } \\
\text { flow of varying and } \\
\text { overlapping situations. } \\
\text { In } \\
\text { these streams, some } \\
\text { situations may be } \\
\text { familiar and routine, } \\
\text { while others demand } \\
\text { substantial } \\
\text { investments in problem } \\
\text { definition or creation of } \\
\text { new knowledge" p. } 302\end{array}$ & $\begin{array}{l}\text { "the construct of unstructured task streams } \\
\text { and the resulting situation-specific } \\
\text { asymmetries they create suggest that } \\
\text { group-level variables can only provide a } \\
\text { limited } \\
\text { explanation of variation in TMT [Top } \\
\text { Management Team] effectiveness" p. } 316\end{array}$ \\
\hline & $\begin{array}{l}\text { Dunegan, } \\
\text { Duchon, and } \\
\text { Uhl-Bien, } \\
1992 \\
\text { Journal of } \\
\text { Management }\end{array}$ & Task Analyzability & $\begin{array}{l}\text { "Analyzability refers to } \\
\text { the extent to which } \\
\text { workers can follow } \\
\text { unambiguous processes } \\
\text { to solve tasks related } \\
\text { problems: that is, the } \\
\text { degree to which the task } \\
\text { is structured" p. } 62\end{array}$ & $\begin{array}{l}\text { "The quality of leader-member exchange } \\
\text { (LMX) and subordinate performance is } \\
\text { moderated by perceptions of task } \\
\text { analyzability and variety" p. } 59\end{array}$ \\
\hline
\end{tabular}

Table 5 (continued ...) 


\begin{tabular}{|c|c|c|c|c|}
\hline Construct & Author(s) & $\begin{array}{l}\text { Authors(s) } \\
\text { Construct/Variable } \\
\text { Name }\end{array}$ & Author(s) Definition & $\begin{array}{l}\text { Author(s) } \\
\text { Findings/Relationships }\end{array}$ \\
\hline & $\begin{array}{l}\text { Rice, } 1992 \\
\text { Organization } \\
\text { Science }\end{array}$ & Task Analyzability & $\begin{array}{l}\text { "Task analyzability } \\
\text { refers to the way that } \\
\text { individuals are able to } \\
\text { respond to problems that } \\
\text { arise in the process of } \\
\text { task completion. } \\
\text { Analyzable tasks are } \\
\text { those for which } \\
\text { predetermined responses } \\
\text { to potential problems, } \\
\text { and well-known } \\
\text { procedures, are available } \\
\text { and useful, because out- } \\
\text { comes are well } \\
\text { understood" p. } 478 \\
\text { "Unanalyzable tasks } \\
\text { require individuals to } \\
\text { think about, create, or } \\
\text { find satisfactory } \\
\text { solutions to problems } \\
\text { outside of the domain of } \\
\text { facts, rules, or } \\
\text { procedures. Individuals } \\
\text { working in unanalyzable } \\
\text { task environments } \\
\text { cannot rely on more }\end{array}$ & $\begin{array}{l}\text { "Results provide mixed support for the } \\
\text { general hypothesis that task analyzability } \\
\text { influences the relationship between media } \\
\text { usage and performance components" p. } \\
493\end{array}$ \\
\hline
\end{tabular}




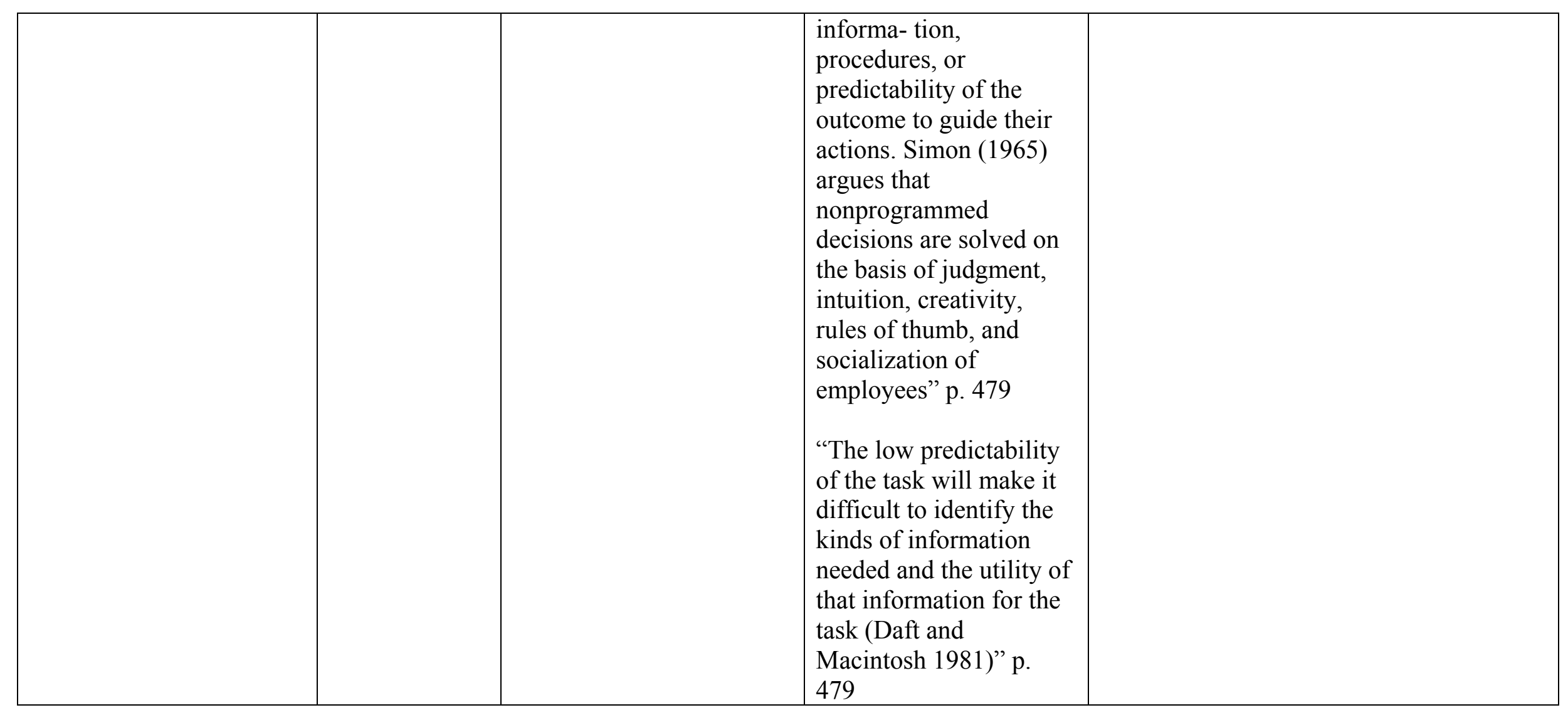

Table 5 (continued ...) 


\begin{tabular}{|c|c|c|c|c|}
\hline Construct & Author(s) & $\begin{array}{l}\text { Authors(s) } \\
\text { Construct/Variable } \\
\text { Name } \\
\end{array}$ & Author(s) Definition & \begin{tabular}{|l|} 
Author(s) \\
Findings/Relationships
\end{tabular} \\
\hline & $\begin{array}{l}\text { Lim and } \\
\text { Benbasat, } \\
2000 \\
\text { MIS Quarterly }\end{array}$ & Task Analyzability & $\begin{array}{l}\text { "An analyzable task is } \\
\text { one in which } \\
\text { 'predetermined response } \\
\text { to potential problems, } \\
\text { and well-known } \\
\text { procedures, are available } \\
\text { and useful' (Rice, 1992, } \\
\text { p. } 478 \text { )" p. } 451\end{array}$ & $\begin{array}{l}\text { "For analyzable tasks, text-based } \\
\text { representation and multimedia } \\
\text { representation are equally effective in } \\
\text { reducing perceived equivocality levels. } \\
\text { For less-analyzable tasks, only multimedia } \\
\text { representation was instrumental in } \\
\text { reducing perceived equivocality levels" p. } \\
449\end{array}$ \\
\hline & $\begin{array}{l}\text { Haerem and } \\
\text { Rau, } 2007 \\
\text { Journal of } \\
\text { Applied } \\
\text { Psychology }\end{array}$ & Task Analyzability & $\begin{array}{l}\text { Analyzability is defined } \\
\text { "as the nature of the } \\
\text { search process that is } \\
\text { undertaken when } \\
\text { exceptions (i.e., } \\
\text { unfamiliar stimuli } \\
\text { encountered during a } \\
\text { task) occur. The search } \\
\text { process depends on } \\
\text { the degree to which the } \\
\text { task is previously } \\
\text { learned or programmed" } \\
\text { p. } 1321\end{array}$ & $\begin{array}{l}\text { "experts and novices pay attention to } \\
\text { different aspects of a task and that this } \\
\text { affects both their perceptions of task } \\
\text { complexity (i.e., task analyzability and } \\
\text { variability) and their performance on the } \\
\text { task" p. } 1320\end{array}$ \\
\hline
\end{tabular}

Table 5 (continued ...) 


\begin{tabular}{|c|c|c|c|c|}
\hline Construct & Author(s) & $\begin{array}{l}\text { Authors(s) } \\
\text { Construct/Variable } \\
\text { Name } \\
\end{array}$ & Author(s) Definition & \begin{tabular}{|l|} 
Author(s) \\
Findings/Relationships
\end{tabular} \\
\hline & $\begin{array}{l}\text { Ito and } \\
\text { Peterson, } 1986 \\
\text { Academy of } \\
\text { Management } \\
\text { Journal }\end{array}$ & Task Difficulty & $\begin{array}{l}\text { "The present study } \\
\text { focuses on the } \\
\text { analyzability component } \\
\text { of task uncertainty, } \\
\text { which we labeled task } \\
\text { difficulty. Task } \\
\text { difficulty refers to } \\
\text { knowledge of cause- } \\
\text { effect relationships (Van } \\
\text { de Ven \& Delbecq, } \\
\text { 1974)" p. } 139 \\
\text { "The more difficult the } \\
\text { tasks, the greater the } \\
\text { vesting of cause-effect } \\
\text { knowledge in } \\
\text { subordinates, hence the } \\
\text { greater their potential } \\
\text { contributions to decision } \\
\text { making" }\end{array}$ & $\begin{array}{l}\text { "The greater the degree of task difficulty, } \\
\text { the greater the amount of boundary- } \\
\text { spanning activity by unit members and the } \\
\text { level of participation in decision making } \\
\text { by unit members, and the greater the } \\
\text { degree of autonomy of unit members"p. } \\
141-142\end{array}$ \\
\hline & $\begin{array}{l}\text { Gelderman, } \\
2002 \\
\text { Information } \\
\text { and } \\
\text { Management }\end{array}$ & Task Difficulty & $\begin{array}{l}\text { "Task difficulty: the } \\
\text { analyzability and } \\
\text { predictability } \\
\text { of the work in an } \\
\text { organization unit" p. } \\
595\end{array}$ & $\begin{array}{l}\text { "The effect of both dimensions of task } \\
\text { structure on this ability differs: task } \\
\text { difficulty does not lead to problems, as } \\
\text { long as the support does not require that } \\
\text { cause-effect relations are understood but } \\
\text { task variability leads to numerous } \\
\text { exceptions when data are missing or not }\end{array}$ \\
\hline
\end{tabular}




\begin{tabular}{|l|l|l|l|}
\hline & & & $\begin{array}{l}\text { provided timely enough. If more features } \\
\text { are build into the system, this situation } \\
\text { tends to get worse" p. 593 }\end{array}$ \\
\hline
\end{tabular}

Table 5 (continued ...) 


\begin{tabular}{|c|c|c|c|c|}
\hline Construct & Author(s) & $\begin{array}{l}\text { Authors(s) } \\
\text { Construct/Variable } \\
\text { Name } \\
\end{array}$ & Author(s) Definition & $\begin{array}{l}\text { Author(s) } \\
\text { Findings/Relationships }\end{array}$ \\
\hline \multirow[t]{2}{*}{$\begin{array}{l}\text { Construct: } \\
\text { Task Unanalyzability } \\
\text { Dimension: } \\
\text { Amount of Task } \\
\text { Information }\end{array}$} & $\begin{array}{l}\text { Daft and } \\
\text { Lengel, 1986, } \\
\text { p. } 559\end{array}$ & $\begin{array}{l}\text { Amount of Task } \\
\text { Information }\end{array}$ & $\begin{array}{l}\text { With respect to } \\
\text { uncertainty, structural } \\
\text { design can facilitate the } \\
\text { amount of information } \\
\text { needed for management } \\
\text { coordination and } \\
\text { control. }[. . .] \text { and } \\
\text { achieve desired task } \\
\text { performance }\end{array}$ & $\begin{array}{l}\text { The amount of task information is } \\
\text { associated with task uncertainty }\end{array}$ \\
\hline & $\begin{array}{l}\text { Daft and } \\
\text { Macintosh, } \\
\text { 1981, p.210 } \\
\text { Administrative } \\
\text { Science } \\
\text { Quarterly }\end{array}$ & $\begin{array}{l}\text { Amount of Information } \\
\text { Processing }\end{array}$ & $\begin{array}{l}\text { "The amount of } \\
\text { information processing } \\
\text { is thus defined as the } \\
\text { volume or quantity of } \\
\text { data about } \\
\text { organizational activities } \\
\text { that is gathered and } \\
\text { interpreted by } \\
\text { organization } \\
\text { participants" p. } 210 \\
\text { "The operational } \\
\text { definition of information } \\
\text { amount is problematic } \\
\text { because information } \\
\text { does not have tangible } \\
\text { properties. Since } \\
\text { information effects a }\end{array}$ & $\begin{array}{l}\text { Amount and equivocality of information } \\
\text { processing is related to the variety and } \\
\text { analyzability of work-unit activities } \\
\text { The amount of information processing } \\
\text { increased with task variety and } \\
\text { analyzability }\end{array}$ \\
\hline
\end{tabular}




\begin{tabular}{|l|l|l|}
\hline & $\mid \begin{array}{l}\text { change in a person's } \\
\text { understanding, the } \\
\text { amount of information } \\
\text { conveyed is the amount } \\
\text { of change in } \\
\text { understanding, which is } \\
\text { extremely difficult to } \\
\text { identify and measure" } \\
\text { p. 210 }\end{array}$ \\
\hline
\end{tabular}

Table 6. Literature Review, Previous Research Studies Related to Task Unanalyzability and its Amount of Task Information Dimension 


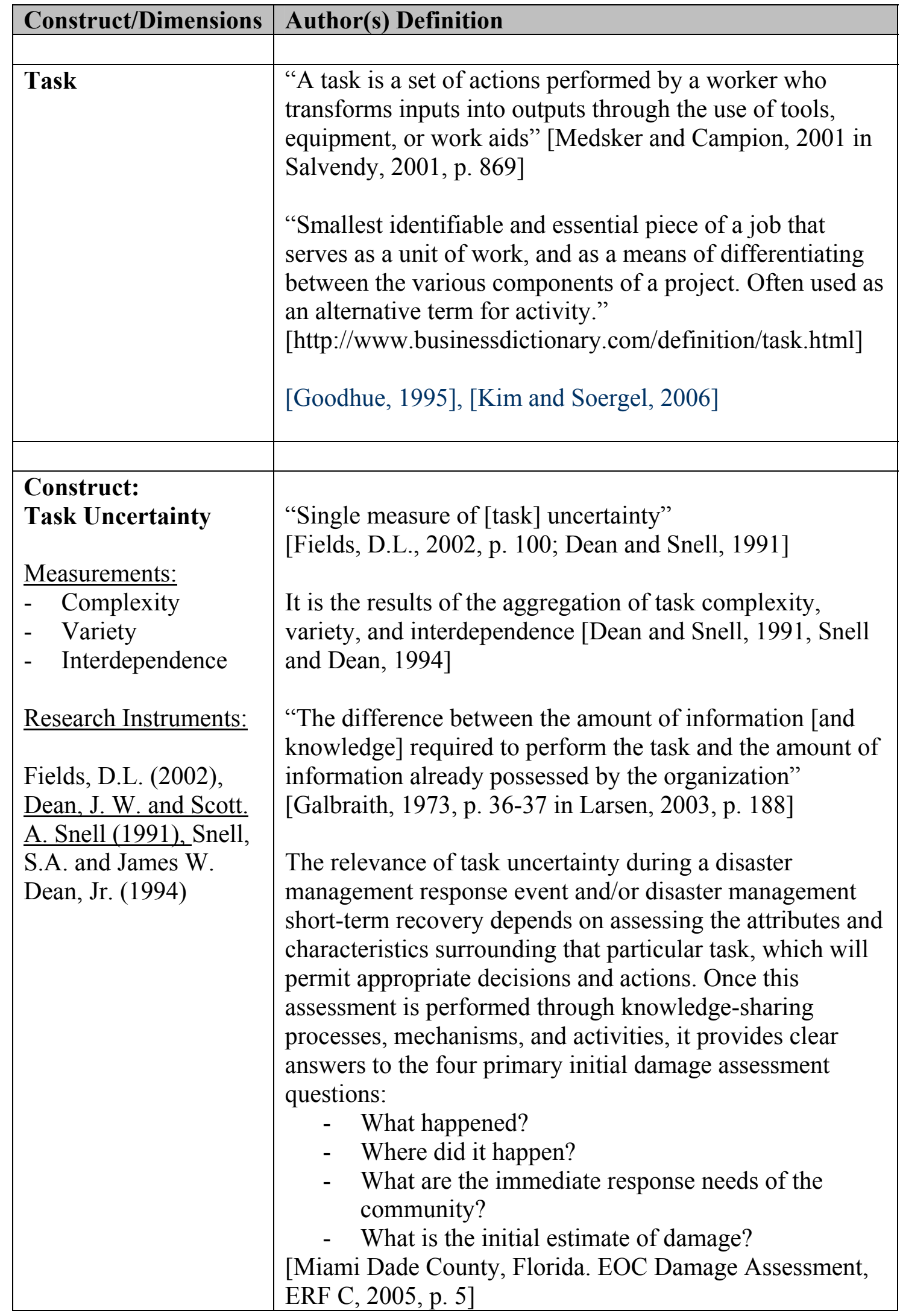


Table 7. Literature Review References, Uncertain Dynamic Disaster Management Tasks 


\begin{tabular}{|c|c|}
\hline Construct/Dimensions & Author(s) Definition \\
\hline Task Complexity & $\begin{array}{l}\text { "The extent a [task] involves mental processes such as } \\
\text { problem solving, applying discretion, and using technical } \\
\text { knowledge" [Fields, D.L., 2002, p. 100; Dean and Snell, } \\
\text { 1991] }\end{array}$ \\
\hline Task Variety & $\begin{array}{l}\text { "The extent to which a [task] involves performing a } \\
\text { number of different tasks [or activities] and frequently } \\
\text { encountering exceptional circumstances requiring } \\
\text { flexibility" } \\
\text { [Fields, D.L., 2002, p. 100; Dean and Snell, 1991] } \\
\text { "The frequency of unexpected and novel events that occur } \\
\text { in performing a task" [Daft and Macintosh, 1981 in Karimi, } \\
\text { Somers, and Gupta, 2004, p. 177] } \\
\text { Low variety = low uncertainty } \\
\text { High variety = tasks difficult to predict } \\
\text { [Goodhue, 1995] [Van de Ven and Delbecq, 1974] } \\
\text { During a disaster management response event and/or } \\
\text { disaster management short-term recovery, task variety is } \\
\text { defined by the changing attributes and characteristics of the } \\
\text { task at hand due to constantly changing conditions. The job } \\
\text { of OEM/EOC organizations and actors is to approach task } \\
\text { variety in the most effective and efficient way possible } \\
\text { through knowledge sharing, which normalizes the task } \\
\text { operations at hand and keeps the comprehensive disaster } \\
\text { management plan on track. }\end{array}$ \\
\hline Task & $\begin{array}{l}\text { "The extent to which people performing a [task] must rely } \\
\text { on or collaborate with others to complete their work [, job, } \\
\text { or task]" } \\
\text { [Fields, D.L., 2002, p. 100; Dean and Snell, 1991] } \\
\text { Interdependent tasks requite more data, information, and } \\
\text { knowledge exchange [Andres and Zmud, } 2002 \text { in Karimi, } \\
\text { Somers, and Gupta, 2004, p. 177] } \\
\text { [Goodhue and Thompson, 1995] } \\
\text { Uncertainty increases task interdependence [Daft and } \\
\text { Macintosh, 1986 in Karimi, Somers, and Gupta, 2004, p. } \\
\text { 177] } \\
\text { Task interdependence is defined under a disaster }\end{array}$ \\
\hline
\end{tabular}




\begin{tabular}{|l|l|}
\hline $\begin{array}{l}\text { management response event and/or disaster management } \\
\text { short-term recovery as the extent to which OEM/EOC } \\
\text { organizations and actors rely on each other in performing } \\
\text { the task at hand. As the degree of task interdependence } \\
\text { increases, so do the number of disaster management } \\
\text { functional groups/people and the relevance of effective and } \\
\text { efficient knowledge-sharing processes, mechanisms, and } \\
\text { activities. }\end{array}$ \\
\hline
\end{tabular}

Table 7 (continued ...)

\begin{tabular}{|c|c|}
\hline Construct/Dimensions & Author(s) Definition \\
\hline $\begin{array}{l}\text { Construct: } \\
\text { Task Novelty } \\
\text { Dimension: } \\
\text { Task } \\
\text { Nonroutineness }\end{array}$ & $\begin{array}{l}\text { It is the results of the aggregation of task variety and task } \\
\text { difficulty [Daft and Macintosh, } 1981 \text { in Karimi, Somers, } \\
\text { and Gupta, 2004, p. 177] } \\
\text { [Goodhue and Thompson, 1995], [Goodhue, 1995] } \\
\text { In the context of a disaster management response event } \\
\text { and/or disaster management short-term recovery, task } \\
\text { nonroutineness refers to the attributes and characteristics of } \\
\text { the task at hand that deviate from the norm. Given these } \\
\text { particular task attributes and characteristics, OEM/EOC } \\
\text { organizations and actors must take the necessary steps to } \\
\text { deal with the task and minimize its divergence. Such a } \\
\text { nonroutine task must be approached, as much as possible, } \\
\text { according to the OEM/EOC comprehensive disaster } \\
\text { management plan, functional plans, and SOPs. }\end{array}$ \\
\hline $\begin{array}{l}\text { Construct: } \\
\text { Task Analyzability }\end{array}$ & $\begin{array}{l}\text { "The extent to which workers can follow unambiguous } \\
\text { processes to solve task-related problems: that is, the degree } \\
\text { to which the task is structured" [Dunegan, Duchon, and } \\
\text { Uhlbien, } 1992 \text { in Larsen, 2003, p. 185]. } \\
\text { This particular construct can be analyzed from two } \\
\text { different perspectives, namely Information Processing } \\
\text { Theory and Organizational Theory. } \\
\text { Some research also relates this construct to } \\
\text { task/information ambiguity (lack of clear rules to make a }\end{array}$ \\
\hline
\end{tabular}




\begin{tabular}{|l|l|}
\hline & $\begin{array}{l}\text { decision) and incorporates this concept into task } \\
\text { uncertainty and variety }\end{array}$ \\
\hline $\begin{array}{l}\text { Lack of Task } \\
\text { Analyzability }\end{array}$ & $\begin{array}{l}\text { [Goodhue and Thompson, 1995], [Goodhue, 1995], [Van } \\
\text { de Ven and Delbecq, 1974] }\end{array}$ \\
\hline
\end{tabular}

Table 7 (continued ...) 


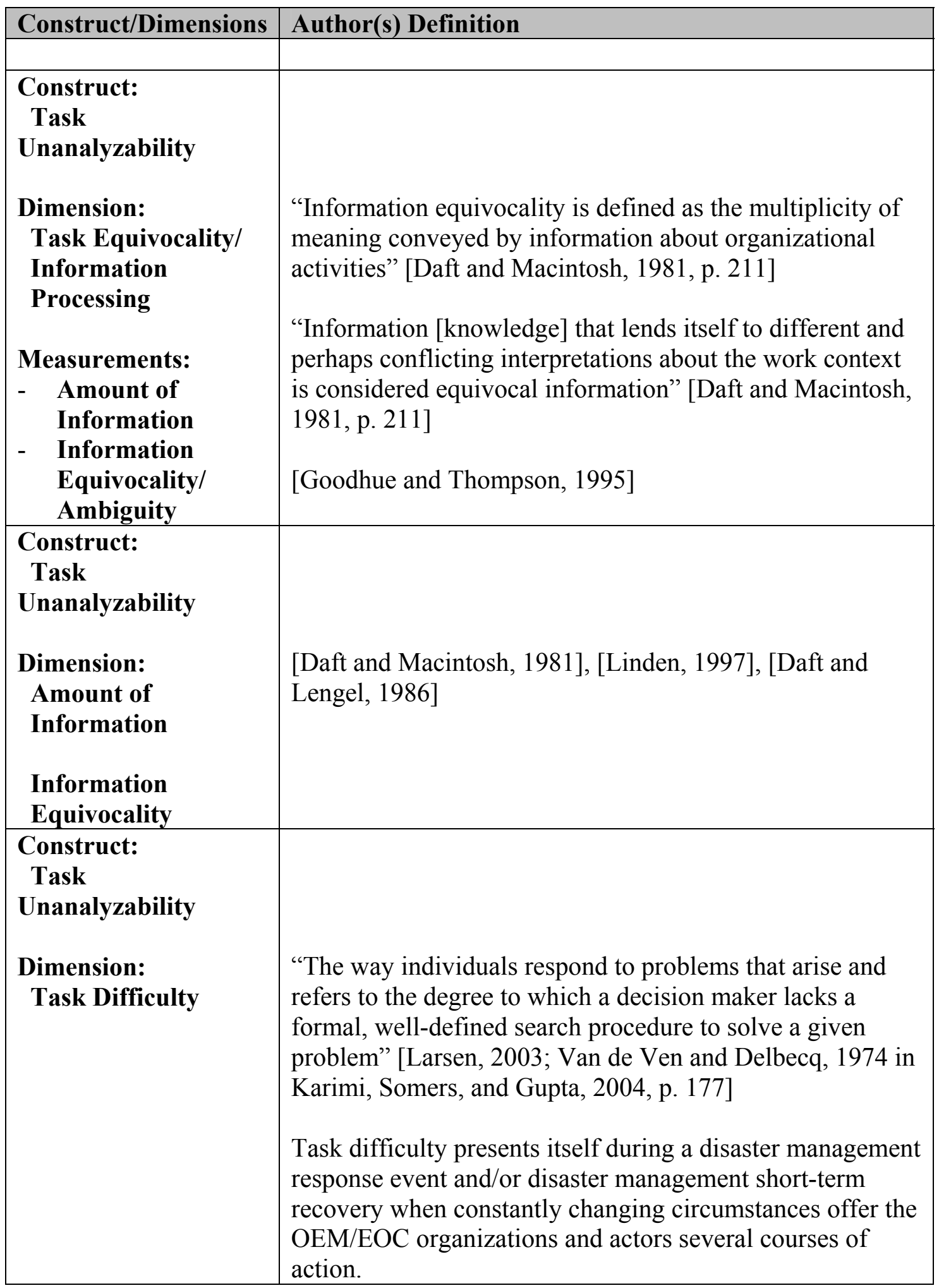

Table 7 (continued ...) 


\begin{tabular}{|c|c|}
\hline Construct/Dimensions & Author(s) Definition \\
\hline $\begin{array}{l}\text { Construct: } \\
\text { Task } \\
\text { Unanalyzability } \\
\text { Dimension: } \\
\text { Lack of Information }\end{array}$ & $\begin{array}{l}\text { "Uncertainty has come to mean the absence of } \\
\text { information" [Daft and Lengel, 1986, p. 556] } \\
\text { "The difference between the amount of information } \\
\text { required to perform the task and the amount of information } \\
\text { already possessed by the organization" [Galbraith, } 1977 \text { in } \\
\text { Daft and Lengel, 1986, p. 556] }\end{array}$ \\
\hline $\begin{array}{l}\text { Construct: } \\
\text { Task Significance } \\
\text { Dimensions: } \\
\text { Task } \\
\text { Urgency/Impact } \\
\text { (Task Demands) }\end{array}$ & $\begin{array}{l}\text { "The degree to which the job has a substantial impact on } \\
\text { the lives of other people, whether those people are in the } \\
\text { immediate organization or in the world at large" [Hackman } \\
\text { and Oldham1980, p. } 79 \text { in Larsen, 2003, p. 190] } \\
\text { [Kim and Soergel, 2006] } \\
\text { Task significance under a disaster management response } \\
\text { event and/or disaster management short term recovery is } \\
\text { proportionally related to } \\
\text { - Preserve human and animal lives, } \\
\text { - Give giving immediate relief and support to people } \\
\text { affected [Queensland Disaster Management } \\
\text { - Planning Guidelines, 2005 for Local Government], } \\
\text { - Minimize the disaster effects, and }\end{array}$ \\
\hline
\end{tabular}

Table 7 (continued ...)

In summary, because of the dynamic nature of disaster events, it is important for EOC functional groups and stakeholders to have a deep understanding of the uncertain and dynamic task characteristics involved in disaster response activities. The uncertain 
and dynamic attributes of tasks, such as task novelty, task unanalyzability, and task significance, play important roles in the overall performance of the disaster response. In addition, given the unstable conditions of disaster events and the uncertain task characteristics, the skillful use of knowledge and comprehensive training regarding issues of what, when, why, and how become critical.

\begin{tabular}{|l|l|}
\hline Construct/Dimensions & Author(s) Definition \\
\hline $\begin{array}{l}\text { Construct: } \\
\text { Task Performance } \\
\text { Dimension: } \\
\text { Task Effectiveness }\end{array}$ & $\begin{array}{l}\text { "Refers to the extent to which the disaster task } \\
\text { requirements were met. It represents the extent to which } \\
\text { the task outcome was satisfactory and how well the task } \\
\text { was executed without disrupting other tasks according to } \\
\text { the perception of the OEM/EOC actors" [Gudi, Becerra- } \\
\text { Fernández, and Xia, 2007] }\end{array}$ \\
\hline $\begin{array}{l}\text { Construct: } \\
\text { Dimension: } \\
\text { Task Efficiency }\end{array}$ & $\begin{array}{l}\text { "Refers to the extent to which the task was completed in } \\
\text { the required time frame and within the allocated budget and } \\
\text { resources. The efficiency will depend on whether the task } \\
\text { was completed on time using the available resources" } \\
\text { [Gudi, Becerra-Fernández, and Xia, 2007] }\end{array}$ \\
\hline
\end{tabular}

Table 8. Literature Review References, Task Performance 


\subsection{Knowledge Management (KM)}

"KM needs to be applied to the development of Emergency Response Systems. Lessons learned from each disaster and exercise need to be captured and disseminated to those responsible for creating formal or ad hoc emergency response systems" P. 206

Murphy and Jennex, 2006

Knowledge is defined as "the set of justified beliefs that enhance an entity's capability for effective action" [Alavi and Leidner, 2001, p. 109; Nonaka, 1994]. Knowledge is also defined as "the whole set of insights, experiences, and procedures that are considered correct and true and that therefore guide the thoughts, behaviors, and communications of people" [Van der Spek and Spijkervet in Beckman, 1999, pg. 1-3]. Furthermore, knowledge can be approached from several dimensions such as "storage media, accessibility, typology, and hierarchy" [Beckman, 1999, pg. 1-3].

Knowledge is commonly classified into types such as know-what (declarative knowledge), know-how (procedural knowledge), know-where, know-why, and care-why knowledge [Quinn cited in Beckman, 1999, pg. 1-4] as well as individual, group, and organizational knowledge [Becerra-Fernandez and Sabherwal, 2003] and subjective, objective, tacit and explicit knowledge [Polanyi, 1966].

Explicit knowledge refers to the knowledge that is captured and readily available in tangible forms such as books, documents, manuals, or through ICT systems. 
Tacit knowledge is "by definition, uncaptured. People carry tacit knowledge around in their heads in the forms of insight, judgment, craftsmanship and creative talents - this knowledge can be expressed or represented in some way, but never fully captured" [Harris, 2003, pg. 3].

According to a previous definition of knowledge, knowledge management is generally defined as "doing what is needed to get the most out of knowledge resources" [Becerra Fernandez, Gonzalez, and Sabherwal, 2004, p. 3]. Additionally, knowledge management is approached as a business process for managing intellectual assets and as a discipline that promotes an integrated approach to the creation, capture, organization, access and use of the enterprise's knowledge and information assets [Harris, 2003]. Similarly, knowledge management is described as a "conscious strategy of getting the right knowledge to the right people at the right time and helping people share and put information into action in ways that strive to improve organizational performance" [O’Dell and Jackson, 1998, p. 4]. Furthermore, most knowledge management definitions incorporate at least one of the following distinctive concepts: business processes, information communication technologies, knowledge repositories and human behaviors [Eschenfelder et al, 1998]. Table 9 summarizes some of the knowledge management studies that are most relevant to this research. 


\begin{tabular}{|c|c|}
\hline Aut & $\begin{array}{l}\text { ithor(s) } \\
\text { idings/Relationships }\end{array}$ \\
\hline $\begin{array}{l}\text { Becerra Fernandez, } \\
\text { Gonzalez, and } \\
\text { Sabherwal, 2004, }\end{array}$ & $\begin{array}{l}\text { Knowledge management is defined as "performing the } \\
\text { activities involved in discovering, capturing, sharing, and } \\
\text { applying knowledge in terms of resources, documents, and } \\
\text { people skills, so as to enhance, in a cost-effective fashion, } \\
\text { the impact of knowledge on the unit's goal achievement" [p. } \\
\text { 372] }\end{array}$ \\
\hline $\begin{array}{l}\text { Beckman, } 1999 \\
\text { Knowledge } \\
\text { Management, } \\
\text { Handbook, 1st Edition }\end{array}$ & $\begin{array}{l}\text { Created a comprehensive map of knowledge management } \\
\text { concepts, processes, technologies, organizational } \\
\text { implications, management issues, and implementation } \\
\text { challenges and problems. The importance of this study lies } \\
\text { in the many different perspectives through which the field } \\
\text { of knowledge management can be seen, analyzed and } \\
\text { approached. }\end{array}$ \\
\hline $\begin{array}{l}\text { Kakabadse, } \\
\text { Kakabadse, and } \\
\text { Kouzmin, } 2003 \\
\text { Journal of Knowledge } \\
\text { Management }\end{array}$ & $\begin{array}{l}\text { Reviewed and summarized the latest knowledge } \\
\text { management taxonomy model literature. The authors pay } \\
\text { particular attention to the network and community of } \\
\text { practice models that emphasize the importance of acquiring, } \\
\text { sharing and transferring tacit knowledge. }\end{array}$ \\
\hline $\begin{array}{l}\text { McElroy, } 2000 \\
\text { Journal of Knowledge } \\
\text { Management }\end{array}$ & $\begin{array}{l}\text { Investigated knowledge management as a key enabler of } \\
\text { organizational learning within organizations. When these } \\
\text { two areas come together, they can be an important factor } \\
\text { associated with knowledge use, transfer, and reuse and } \\
\text { ultimately, the creation of new knowledge. }\end{array}$ \\
\hline $\begin{array}{l}\text { Alavi and Leinder, } \\
2001 \\
\text { MIS Quarterly }\end{array}$ & $\begin{array}{l}\text { Provided a comprehensive knowledge management } \\
\text { literature review identifying relevant research issues for the } \\
\text { field of information communication technologies (ICT). } \\
\text { Identifying the basic concepts of knowledge management as } \\
\text { well as the potential role of ICT, this research paper } \\
\text { concluded with a list of pressing research questions } \\
\text { regarding knowledge creation, storage, retrieval, transfer, } \\
\text { and application, as well as the use of ICT. }\end{array}$ \\
\hline $\begin{array}{l}\text { Grover and } \\
\text { Davenport, } 2001 \\
\text { Journal of } \\
\text { Management } \\
\text { Information Systems }\end{array}$ & $\begin{array}{l}\text { Focused on mapping several knowledge management } \\
\text { research projects currently being undertaken. Furthermore, } \\
\text { the authors summarized useful knowledge management } \\
\text { concepts, paying particular attention to knowledge transfer, } \\
\text { communities of practice and knowledge markets. }\end{array}$ \\
\hline
\end{tabular}

Table 9. Literature Review, Knowledge Management 


\subsubsection{Knowledge Creation Theory}

The knowledge creation theory proposed by IIkujiro Nonaka supports paradigms that viewed knowledge creation as a "continuous dialogue between tacit and explicit knowledge" [Nonaka, 1994, pg. 14]. This theory departs from the assumption that knowledge creation begins and ends with the individual, and therefore, the key to this process is the interaction of individuals, organizations, and the environment. Nonaka's four basic combinations of tacit and explicit knowledge are tacit to tacit, tacit to explicit, explicit to explicit, and explicit to tacit.

For each combination, there is a suitable knowledge conversion process, namely socialization, externalization, combination, and internalization, respectively. Indeed, the ultimate goal of knowledge creation theory is to provide the appropriate conditions for the organization to "consistently create new knowledge, disseminate it widely throughout the organization, and quickly embody it in new technologies and products" [Nonaka, 1991, pg. 96]. In this process, individuals ultimately play a key role in discovering, capturing, sharing, and applying tacit and explicit knowledge. The challenge lies in conducting these processes in the most effective and efficient way. 


\subsubsection{Knowledge-Based Theory of the Firm}

There are many theories of firms that try to "explain and predict [its] structure and behaviors" [Grant, 1996, p. 109]. However, a literature review of the field reveals that there is no single, comprehensive theory of the firm that encompasses all of the general and specific aspects related to the firm's knowledge-sharing activities. Nevertheless, many researchers appear to agree that there is a set of common and most-representative theories of the firm that includes economic-, neoclassical-, organizational-, transaction cost-, behavior-, strategic management-, resource-, and knowledge-based theories.

One of the most accepted definitions of knowledge-based theory is the "platform for a new view of the firm as a dynamic, evolving, quasi-autonomous system of knowledge production and application" [Truch, 2004 , p. 14]. In similar manner, the knowledge-based view of the firm "focuses upon knowledge as the most strategically important of the firm's resources [and] knowledge is central to several quite distinct research traditions, notably organizational learning, the management of technology, and managerial cognition" [Grant, 1996, p. 110].

Under these assumptions, the knowledge-based theory of the firm explains how knowledge creates value at the strategic, tactical, and operational levels of any organization. Because of its particular attributes, such as transferability, capacity for aggregation, appropriability, specialization in acquisition, and production, knowledge becomes an important source of competitive and comparative advantage for the firm and individuals [Grant, 1996]. 


\subsubsection{Social Capital Theory Stepping-Stone for Knowledge Management and Knowledge Sharing}

Social capital has been defined by Coleman [1990] as "people and organizations with some characteristics in common which form a social structure which allows them to act within that particular social structure". Similarly, other authors expand this definition to include the "networks, norms, trust, and mutual understanding that bind together the members of human networks and communities, and enable participants to act together more effectively to pursue shared objectives" [Baron, Field, and Schuller, 2000; Fukuyama 1995; in Widén and Ginman 2004, p. 449] and "resources embedded in a social structure that are accessed and/or mobilized in purposive action" [Lin 2001, p.29]. Furthermore, according to Hazleton and Kennan [2000], social capital can be approached from three different perspectives: structural, content, and relational. The structural perspective involves access to entities (people and organizations) and the availability, reference, and time of information and knowledge [Hazleton and Kennan, 2000] according to actors, activities, and resources in social environments [Choo, 1998].

The content perspective relates to the communication functions of informationexchange (people-knowledge-organization) problem identification through experience and expertise on the field, behavior regulation, and conflict management; such information exchange results in the development of social capital [Hazleton and Kennan, 2000]. The relational perspective is mainly concerned with social capital expectations, obligations, trust, identification, and social system closure [Hazleton and Kennan, 2000]. 
Social capital strengthens knowledge management processes and activities through information and knowledge channels, social norms, identity, obligations and expectations, and moral infrastructure [Hoffman, Hoelscher, and Karma, 2005].

Similarly, knowledge creation is supported by the "development of collective intellectual capital by affecting the conditions necessary for exchange and combination to occur" [Hoffman, Hoelscher, and Karma, 2005, p. 98]. Knowledge sharing is encouraged by the connections among people and the connections of people with their environment, communities, and organizations [Putnam, 1995] with "high interdependence, frequent interaction, and closed structures" [Nahapiet and Ghoshai 1998, Nohria and Eccles 1992 in Wasko and Faraj 2005, p. 38]. As a result, social capital provides the necessary attributes to enhance and strengthen knowledge management processes and activities "because it makes collective action more efficient" [Hoffman, Hoelscher, and Karma, 2005, p. 98].

Furthermore, in recent years, researchers such as Nahapiet and Ghoshal [1998], Lesser [2000], Cohen and Prusak [2001], and Adler and Kwon [2002] have incorporated the social capital theory into their knowledge management research [Huysman and Wulf, 2006]. Additionally, the research community has observed a substantial increase of knowledge management programs, processes, and activities in relation to casual and people-to-people knowledge management and sharing initiatives [Huysman and Wulf, 2006]. 
Indeed, the relevance of social capital to the knowledge-sharing field lies in approaching the "knowledge sharing research questions of who shares knowledge and how is knowledge shared?, what knowledge is shared?, and why and when is knowledge shared?" [Huysman and Wulf, 2006, p. 44]. Tables 10, 11, and 12 summarize some of the literature on social capital theory that is most relevant to this research.

\begin{tabular}{|c|c|}
\hline $\begin{array}{l}\text { Social Capital } \\
\text { Theory: } \\
\text { Structural Capital }\end{array}$ & Literature Review References \\
\hline Social Capital & $\begin{array}{l}\text { People and organizations with some characteristics in } \\
\text { common that form a social structure that allows them to act } \\
\text { within that particular social structure [Coleman, 1990] } \\
\text { "networks, norms, trust, and mutual understanding that bind } \\
\text { together the members of human networks and communities, } \\
\text { and enable participants to act together more effectively to } \\
\text { pursue shared objectives" [Baron, Field, and Schuller, 2000; } \\
\text { Fukuyama 1995; in Widén and Ginman 2004, p. 449] }\end{array}$ \\
\hline
\end{tabular}

Table 10. Literature Review, Social Capital Theory: Structural Capital Dimension 


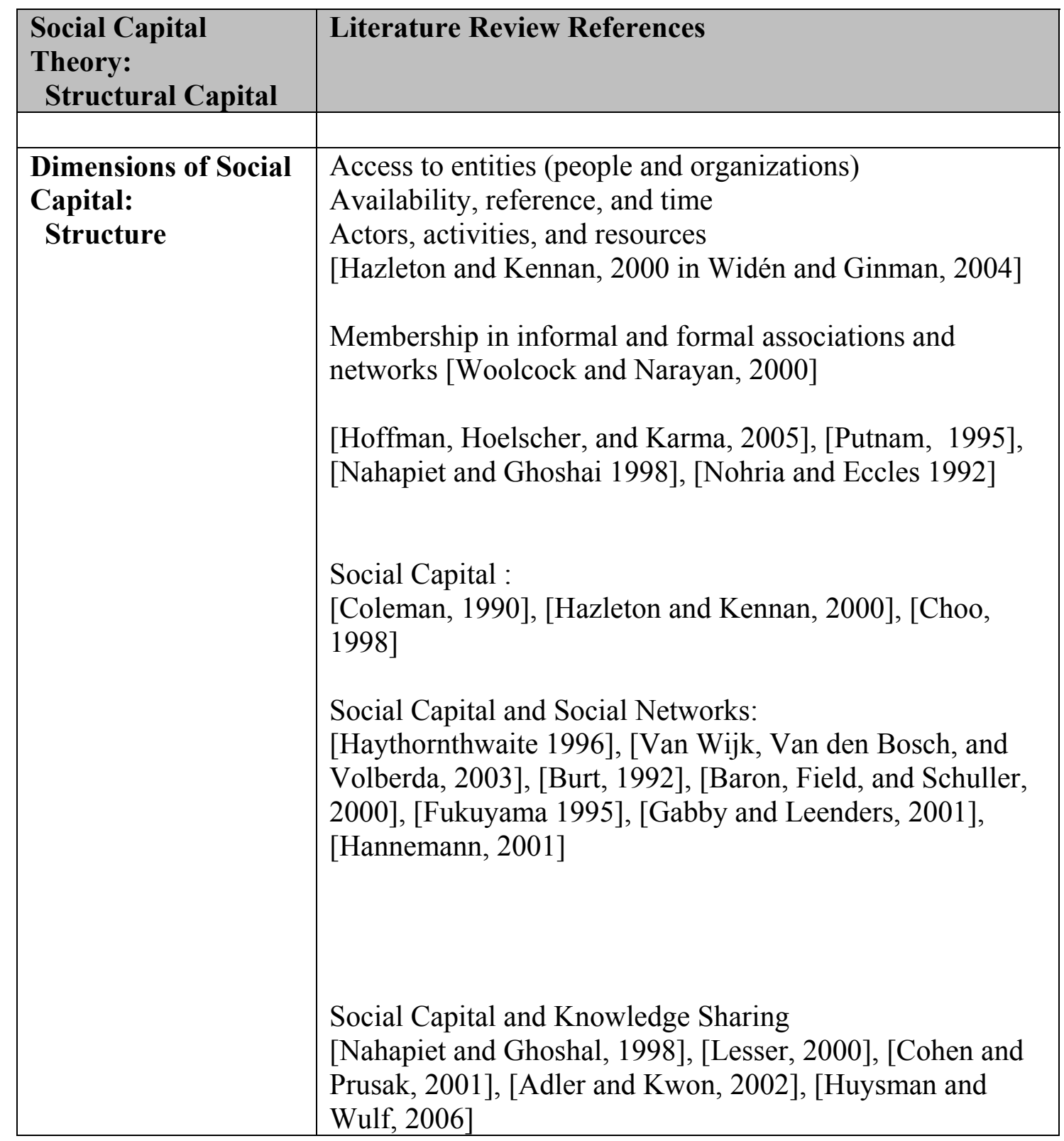

Table 10. (continued ...) 


\begin{tabular}{|c|c|}
\hline $\begin{array}{l}\text { Social Exchange } \\
\text { Theory: } \\
\text { Identity } \\
\text { Orientations }\end{array}$ & Literature Review References \\
\hline $\begin{array}{l}\text { Knowledge Sharing } \\
\text { through Codifiability }\end{array}$ & $\begin{array}{l}\text { It "reflects the extent to which knowledge can be articulated } \\
\text { or codified, even if the resulting codified knowledge might } \\
\text { be difficult to impart to other individual" [Becerra- } \\
\text { Fernandez, González, and Sabherwal, 2004, p. 24] } \\
\text { In the context of a disaster management response event } \\
\text { and/or disaster management short-term recovery, } \\
\text { codifiability refers to the extent to which OEM/EOC actors } \\
\text { are able to explicitly share their knowledge through writing, } \\
\text { documents, diagrams, pictures, and voice recordings. Such } \\
\text { sharing usually occurs through information/knowledge } \\
\text { communication/collaborative systems and documents (e.g., } \\
\text { e-mail, e-Team, IAP, SitReps, EOC TV screens, and so on) }\end{array}$ \\
\hline Identity Orientation & $\begin{array}{l}\text { The concept of identity orientation rests on people's social } \\
\text { interactions and how "individuals define themselves in } \\
\text { terms of their relationships to others and to social groups" } \\
\text { [Markus and Kitayama, 1991, Triadis et al., } 1988 \text { in Brewer } \\
\text { and Gardner, 1996, p. 83] }\end{array}$ \\
\hline Personal & $\begin{array}{l}\text { Relational identity orientation is defined by the individual } \\
\text { when he or she sees himself or herself as a different and } \\
\text { unique individual [Brewer and Gardner, 1996, and Flynn, } \\
\text { 2005] } \\
\text { Self Concept : Personal } \\
\text { Level of Analysis: Individual } \\
\text { Personal identity orientation refers to the extent to which } \\
\text { OEM/EOC actors perceive themselves as sole and } \\
\text { distinctive entities to respond to the task at hand during a } \\
\text { disaster management response event and/or disaster } \\
\text { management short-term recovery. In this case, actors with } \\
\text { personal identity orientations will tend to seek information } \\
\text { and knowledge to perform the task at hand. }\end{array}$ \\
\hline
\end{tabular}

Table 11. Literature Review, Social Exchange Theory: Identity Orientations Dimensions 


\begin{tabular}{|c|c|}
\hline $\begin{array}{l}\text { Social Exchange } \\
\text { Theory: } \\
\text { Identity } \\
\text { Orientations }\end{array}$ & Literature Review References \\
\hline Relational & $\begin{array}{l}\text { Personal identity orientation is defined by the individual } \\
\text { when he or she sees himself or herself as part of } \\
\text { interpersonal relationships and connections related to others } \\
\text { [Brewer and Gardner, 1996, and Flynn, 2005] } \\
\text { Self Concept : Relational } \\
\text { Level of Analysis: Interpersonal } \\
\text { Relational identity orientation refers to the extent to which } \\
\text { OEM/EOC actors perceive themselves as people with } \\
\text { personal relationships and connections during a disaster } \\
\text { management response event and/or disaster management } \\
\text { short-term recovery with the objective of better responding } \\
\text { to the task at hand. }\end{array}$ \\
\hline Collective & $\begin{array}{l}\text { Collective identity orientation is defined by the individual } \\
\text { when he or she sees himself or herself as part of a social } \\
\text { group [Brewer and Gardner, 1996, and Flynn, 2005] } \\
\text { Self Concept : Collective } \\
\text { Level of Analysis: Group } \\
\text { Collective identity orientation refers to the extent to which } \\
\text { OEM/EOC actors perceive themselves as part of their own } \\
\text { functional group and the OEM/EOC so that the entire team } \\
\text { can better respond to the task at hand during a disaster } \\
\text { management response event and/or disaster management } \\
\text { short-term recovery. }\end{array}$ \\
\hline
\end{tabular}

Table 11 (continued ...) 


\begin{tabular}{|l|l|}
\hline $\begin{array}{l}\text { Social Capital } \\
\text { Theory: } \\
\text { Content / Cognitive }\end{array}$ & Literature Review References \\
\hline $\begin{array}{l}\text { Dimensions of Social } \\
\text { Capital: } \\
\text { Content /Cognitive }\end{array}$ & $\begin{array}{l}\text { Communication functions } \\
\text { Information exchange (people-knowledge-organization), } \\
\text { problem identification, behavior regulation, and conflict } \\
\text { management } \\
\text { [Hazleton and Kennan, 2000 in Widén and Ginman, 2004] }\end{array}$ \\
\hline Expertise on the field & $\begin{array}{l}\text { Cognitive capital is developed through [Wasko and Faraj, } \\
\text { 2005] : } \\
\text { Experience on the field } \\
\text { The constant learning and knowledge (expertise) applied on } \\
\text { the field } \\
\text { Frequent interactions with others } \\
\text { Similar contexts, information, skills, and organizational } \\
\text { environment }\end{array}$ \\
\hline $\begin{array}{l}\text { Experience on the } \\
\text { field }\end{array}$ & $\begin{array}{l}\text { People's experience and expertise increase the chances of } \\
\text { individuals to engage in knowledge sharing activities } \\
\text { [Constant et al. 1996, Wasko and Faraj, 2005 ] }\end{array}$ \\
\hline
\end{tabular}

Table 12. Literature Review, Social Capital Theory: Content / Cognitive Dimension Dimensions

\subsection{The EOC as Knowledge-Based Organization}

The relevance of knowledge in today's organizations cannot be overemphasized.

Peter Drucker highlighted the importance of knowledge as becoming "a key economic resource and the dominant—and perhaps the only—source of competitive advantage" [cited in Norris et al. , 2003, p. VI]. In a similar fashion, knowledge is "a key success factor" [Bennet, 2004, p. 513], and therefore, organizations are looking to enhance their one sure source of lasting competitive advantage: knowledge [Nonaka, 1999]. 
Because of the importance of the characteristics, attributes, information, and knowledge of the EOC, it can be classified as a knowledge-based organization. 
A knowledge-based organization uses knowledge on an everyday basis or when it is needed for customer interactions, stakeholder relationships, business insights, organizational memory, processes, products, services, and people. For knowledge-based organizations, knowledge is a vital resource [Lytras and Pouloudi, 2003] along with people, capital, physical assets and information technology systems. Like any of these resources, knowledge must be managed and used at the right times and places. However, knowledge per se does not provide organizations with lasting sustainable comparative and competitive advantages. "Knowledge, experience, and expertise must be formalized, distributed, shared, and applied" to become a key source of knowledge, customer value, organizational performance, and business profitability as well as a lasting comparative and competitive advantage. Like any other organizational resource, knowledge must be managed in order to contribute to the organization's performance [Beckman, 1999, p. I-7].

The broader concept of knowledge management is defined as the systematic, explicit, and deliberate building, renewal, and application of knowledge to maximize an enterprise's knowledge-related effectiveness and to maximize returns from its knowledge assets [Wiig, 1997]. For organizations to be as effective and efficient as possible, knowledge management (KM) must be supported by the processes of discovery, capture, sharing and application [Becerra, Gonzalez, and Sabherwal, 2004]. When these KM activities are performed properly, knowledge through aggregation gains appreciation, which ultimately enhances the performance of the organization. 
Consequently, most organizations, particularly those that are knowledge-based like the EOC, are well aware of the self-reinforcing cycle of knowledge: the more it is used and shared, the more valuable it becomes [Clarke, 2001]. However, only when knowledge is created and leveraged through effective knowledge sharing can the overall performance of the organization benefit [Majchrzak, Cooper, and Neece, 2004].

\subsection{Knowledge Sharing}

"Communication and connectivity form the cornerstones of knowledge sharing and can be described as the enablement of flow of the bright knowledge to the right person at the right timeQ [26] that allow organizations and individuals to explore the inherent challenges that arise from the operational core of knowledge and to design and approach in concrete ways strategies for a response" p. 1074

A business process context for Knowledge Management, Raghu and Vinze

"the problem of information sharing is much more extensive than just sharing information about an impending attack - it extends from the early stages of research and development, to collecting data, preventing and detecting attacks, and responding to attacks" p. 9

GAO-02-811T, June 7, 2002 NATIONAL PREPAREDNESS, Integrating New and Existing Technology and Information Sharing into an Effective Homeland Security Strategy: Statement of Randall A. Yim, Managing Director, National Preparedness

Knowledge management in public organizations such as the EOC is relevant to their attempts to manage their intellectual assets and to promote an integrated approach to 
the creation, capture, organization, access and use of the organization's knowledge and information assets [Harris, 2003]. 
In fact, knowledge management processes are a "conscious strategy of getting the right knowledge to the right people at the right time and helping people share and put information into action in ways that strive to improve organizational performance" where knowledge-sharing processes and activities play a key role [O'dell and Jackson, 1998, p. 4].

The concept of knowledge sharing is defined as "the process through which one unit (e.g., an individual, group, department, or division) is affected by the experience of another" [Argote et al., 2000, p. 3]. Similarly, knowledge sharing focuses on the set of activities and processes learned by individuals within a particular context and situation and applied in a different context and situation [Argote and Ingram, 2000]. Knowledgesharing processes and activities are an important part of new knowledge creation. In the same manner, knowledge-sharing facilitates and enhances the use and reuse of current knowledge.

Knowledge-sharing activities include knowledge transfer, exchange and distribution. Through traditional apprentice models, learning networks, best practices and lessons-learned programs, storytelling, interviews, training, after-action reviews, knowledge-exchange sites and facilities (e.g., e-shops, knowledge e-markets, share fairs, corridors, break rooms and brown bag seminars), socialization programs, cross-functional teams, social networks, and support communities, knowledge-sharing strategies, practices and activities are reinforced at all levels of the organization.

In addition, strategies, practices and activities related to knowledge sharing require three very important components: people, processes and technology. 
In each of these three components, organizations are taking advantage of the most fundamental part of knowledge, namely people. Table 13 summarizes some of the knowledge-sharing literature most relevant to this research.

\begin{tabular}{|l|l|}
\hline Author(s) & $\begin{array}{l}\text { Author(s) } \\
\text { Findings/Relationships }\end{array}$ \\
\hline $\begin{array}{l}\text { Huysman and de Wit, } \\
2004\end{array}$ & $\begin{array}{l}\text { Identified the differences between the first wave of } \\
\text { knowledge management, which focused on knowledge } \\
\text { acquisition, exchange and creation by knowledge workers, } \\
\text { and the second wave of knowledge management, which } \\
\text { Pefined knowledge management as an everyday activity } \\
\text { conducted by networks and communities of people focusing } \\
\text { on knowledge sharing. The key finding of this research } \\
\text { paper is the importance of tacit knowledge sharing during } \\
\text { daily interactions where emergent communities of practice } \\
\text { play a significant role. }\end{array}$ \\
\hline $\begin{array}{l}\text { Argote, Ingram, } \\
\text { Levine and Moreland, }\end{array}$ & $\begin{array}{l}\text { Highlighted the relevance of knowledge sharing as a matter } \\
\text { of productivity, performance, and ultimately, survival, in } \\
\text { organizations. }\end{array}$ \\
$\begin{array}{l}\text { Organizational } \\
\text { Behavior and Human } \\
\text { Decision Processes }\end{array}$ & $\begin{array}{l}\text { Approached the research topic of knowledge creation and } \\
\text { sharing in high-tech industry. The organizational context } \\
\text { and nature of work heavily influences the process of } \\
\text { knowledge sharing. A key aspect in this process is the social } \\
\text { dimension of collaboration for knowledge sharing. }\end{array}$ \\
\hline Kim and King, 2004 & $\begin{array}{l}\text { Looked at the knowledge-sharing processes of Toyota to } \\
\text { determine why this company is so efficient and effective in } \\
\text { these processes relative to its competitors. Learning and } \\
\text { knowledge networks have played pivotal roles in } \\
\text { knowledge sharing activities. The synergy created by these } \\
\text { networks is the main cause of Toyota's ability to share } \\
\text { knowledge in the most effective and efficient way. The } \\
\text { dynamic knowledge-sharing activities of Toyota result in } \\
\text { productivity and learning advantages in very short periods } \\
\text { of time. In other words, Toyota has had the ability to create } \\
\text { a knowledge-sharing self-reinforcing cycle. }\end{array}$ \\
\hline Management & Addressed how technological knowledge flows across \\
\hline $\begin{array}{l}\text { Dyer and Nobeoka, } \\
\text { 2000 }\end{array}$ \\
$\begin{array}{l}\text { Strategic Management } \\
\text { Journal }\end{array}$
\end{tabular}




\begin{tabular}{|l|l|}
\hline $\begin{array}{l}\text { Journal of Knowledge } \\
\text { Management }\end{array}$ & $\begin{array}{l}\text { multinational companies. Relevant organizational, cultural } \\
\text { and informal issues can heavily determine knowledge- } \\
\text { sharing activities. In a similar manner, co-operative and } \\
\text { collaborative environments are conducive to successful } \\
\text { technological knowledge flows among knowledge workers } \\
\text { and business units. }\end{array}$ \\
\hline
\end{tabular}

Table 13. Literature Review, Knowledge Sharing 


\begin{tabular}{|l|l|}
\hline Author(s) & $\begin{array}{l}\text { Author(s) } \\
\text { Findings/Relationships }\end{array}$ \\
\hline Yang, 2004 & $\begin{array}{l}\text { Reported a high correlation between knowledge-sharing } \\
\text { collaboration culture and performance. Factors such as } \\
\text { collaborative environments, trust and team-group- } \\
\text { community achievement are essential for knowledge } \\
\text { sharing. In addition, motivation programs, effective } \\
\text { communication, and readily available knowledge from } \\
\text { training programs and social interactions are crucial to } \\
\text { encourage a knowledge-sharing culture. }\end{array}$ \\
\hline $\begin{array}{l}\text { Majchrzak, Cooper, } \\
\text { and Neece, 2004 }\end{array}$ & $\begin{array}{l}\text { Asserted the challenges of knowledge transfer through } \\
\text { knowledge sharing and reuse. Familiarity with the source of } \\
\text { knowledge plays a critical role in using that particular } \\
\text { knowledge source. In addition, tacit knowledge is better } \\
\text { shared and reused in organizations when there are common } \\
\text { places to identify, capture, select, store, share, apply and } \\
\text { create new knowledge. The knowledge reuse process for } \\
\text { innovation proposed in this research paper, along with } \\
\text { concepts such as recombinative integration, are major } \\
\text { contributions to the field of knowledge transfer, sharing and } \\
\text { reuse. }\end{array}$ \\
\hline $\begin{array}{l}\text { Malhent Science } \\
\text { Majchrzak, 2004 }\end{array}$ & $\begin{array}{l}\text { ldentified the importance of knowledge-sharing norms for } \\
\text { task coordination, external connectivity, distributed } \\
\text { cognition, and interactivity in teams geographically } \\
\text { distributed around the world. }\end{array}$ \\
\hline $\begin{array}{l}\text { Journal of Knowledge } \\
\text { Management }\end{array}$ & $\begin{array}{l}\text { Covered several knowledge management strategies to } \\
\text { prevent knowledge erosion in small and medium-sized } \\
\text { firms with less than 500 employees. Many of these } \\
\text { strategies focused on knowledge-sharing activities such as } \\
\text { repositories of lessons learned, mentoring and best practices } \\
\text { sharing. }\end{array}$ \\
\hline $\begin{array}{l}\text { Wickert and Herschel } \\
\text { 2001 }\end{array}$ \\
\hline Management
\end{tabular}

Table 13 (continued ...) 


\subsection{Why Share Knowledge?}

"Knowledge sharing, especially, in inter-organizational mission-critical decisionmaking scenarios, is critical to timely and effective resolution to decisional problems [... and ] building communities of decision-makers that interact often is a necessity to create effective knowledge sharing processes" p. 1076 A business process context for Knowledge Management, Raghu and Vinze

The motivations to share knowledge are addressed in the research literature by content theories that identify the diverse factors that motivate people to share knowledge [Hendriks, 1999]. These theories, such as needs hierarchy motivation theory [Maslow, 1954], motivation theory X and theory Y [McGregor, 1960], Expectancy theory [Vroom, 1964], motivation-hygiene theory [Herzberg, 1968, 1987], and the theory of needs [McClelland, 1971], provide several motivations to share knowledge. These motivations include the incentive of being paid a salary, the engagement in the production chain of goods and services, the personal satisfaction of interacting with others and belonging to a group, team, or organization of people, social status, recognition, and respect, and a sense of accomplishment [Hendriks, 1999]. Additionally, in the late 1960s and 1980s, Frederick Herzberg [Herzberg, 1968, 1987] proposed the two-factor (motivation-hygiene) theory to explain human behaviors such as knowledge sharing [Hendriks, 1999]. Hygiene factors do not provide employees with a sense of fulfillment and contentment, but their absence produces profound discontent and frustration [Herzberg, 1968, 1987]. 
Some of these typical hygiene factors are compensation packages, job security and conditions, organizational environment, culture, and climate, social working relations, management and employee relations [Herzberg, 1968, 1987 in Hendriks, 1999].

Motivating factors are those "sources of satisfaction included, a sense of achievement, recognition, the work itself, the opportunity to take responsibility and prospects for advancement" [Bassett-Jones and Lloyd, 2005, p. 932]. People share knowledge most readily when there is a perception that knowledge sharing enhances professional prestige, when they have previously worked in knowledge-sharing environments, and/or when they are organizationally placed in social networks [Wasko and Faraj, 2005].

\subsection{Knowledge-Sharing Mechanisms and Purposes}

According to Ikujiro Nonaka [1994], knowledge leverages the creation, sharing, use, and reuse of knowledge through the continuous interaction and conversion of tacit and explicit knowledge. These interactions are characterized by the knowledge-sharing mechanisms of socialization (tacit to tacit), externalization (tacit to explicit), internalization (explicit to tacit), and combination (explicit to explicit). Key to these mechanisms is "the process through which explicit and tacit knowledge is communicated to other individuals" [Becerra-Fernández et al, 2004, p. 3] in the most effective and efficient manner. In fact, the interaction among individuals, organizations, and the 
environment, along with the availability of knowledge, tacit or explicit, will determine which knowledge-sharing mechanism to use.

\subsubsection{Knowledge-Sharing Mechanisms}

"Perhaps more useful than the sharing of reports and other written accounts of recovery lessons and experiences is the ability to directly network with other recovery officials who can answer questions and relate insights first-hand"

"Through one-on-one exchanges like these, state and local officials involved in recovery can obtain tailored advice from individuals who have addressed similar challenges themselves"

GAO-09-811, July 2009 DISASTER RECOVERY: Experiences from Past Disasters Offer Insights for Effective Collaboration after

Catastrophic Events

Knowledge-sharing mechanisms have been defined as "the formal and informal [ways] for sharing, integrating, interpreting and applying know-what, know-how, and know-why embedded in individuals and groups that will aid in the performance of project tasks" [Boh, 2007, p. 28]. Indeed, the informal-casual and formal methods of sharing knowledge can be summarized as knowledge sharing though personal interactions and written documents, respectively [Becerra-Fernandez, González, and Sabherwal, 2004; Kogut and Zander, 1992; Zander and Kogut, 1995; Yi, 2005]. Each type of knowledge sharing will be used according to the extent to which knowledge can be taught through person-to-person communications or codified in written documents. Knowledge teachability "reflects the extent to which the knowledge can be taught to other 
individuals, through training, apprenticeship, and so on" [Becerra-Fernandez, González, and Sabherwal, 2004, p. 24]. Similarly, knowledge codifiability is "the extent to which knowledge can be articulated or codified, even if the resulting codified knowledge might be difficult to impart to other individual" [Becerra-Fernandez, González, and Sabherwal, 2004, p. 24; Kogut and Zander, 1992; Zander and Kogut, 1995].

Knowledge sharing through personal interactions is appropriate for knowledge that "has not been formally articulated [via] writing, and usually is shared in the form of personal advice" [Hansen, Nohria, and Tierney, 1999 in Hansen and Hass, 2001, p. 1]. Frequently, these interactions are through person-to-person channels, informal social exchanges, and organizational exchanges through "teams or project groups ... [in] regular meetings for brainstorming or problem-solving by seeking ideas" [Yi, 2005, p. 41]. Most of these interactions are conducted in the form of traditional apprentice models, learning networks, storytelling, interviews, training, after-action reviews, cross-functional team assignments, social networks, and social communities at sites of knowledge exchange (e.g., knowledge e-shops, knowledge e-markets, share fairs, corridors, break rooms, and brown bag seminars) [Nonaka, 1991, 1994; Nonaka and Toyama 2003; Plunkett, 2001; Weber, Aha, and Becerra-Fernandez, 2001].

In the same way, knowledge sharing through written documents is used with knowledge that has been codified and "written down and is usually shared in the form of electronic documents" [Hansen, Nohria, and Tierney, 1999 in Hansen and Hass, 2001, p. 1] or through printed paper documents. Some of these written documents are found in planning guidelines, standard operating procedures, best practices, lessons learned, and 
after-action reports. This explicitness of knowledge combines with "ideas, information, and expertise" [Yi, 2005, p. 41] to facilitate, in the most efficient and effective way, the availability and diffusion of knowledge wherever people have access to these written documents. 
Under unstable and changing environments, the type of knowledge sharing plays a significant role, particularly when faced with dynamic tasks. However, in many instances, given the significance, urgency, and impact of tasks, the preference for knowledge via exploration or exploitation is not easy to predict and identify.

Therefore, choosing the type of knowledge is critical when faced with the challenge of identifying the appropriate knowledge-sharing purpose (exploration or exploitation) for the task at hand.

\subsubsection{Knowledge-Sharing Purposes}

"This country has tremendous resources at its disposal, leading edge technologies, a superior research and development base, and extensive expertise and experience of human capital resources. However, there are substantial challenges to leveraging these tools, including getting the right information at the right time and sharing it and getting the right technologies, and developing a construct that makes sure not only that the right information goes to the right people, but that we can prevent, detect, and respond to attacks in a concerted, effective manner" p. 3

GAO-02-811T, June 7, 2002 NATIONAL PREPAREDNESS, Integrating New and Existing Technology and Information Sharing into an Effective Homeland Security Strategy: Statement of Randall A. Yim, Managing Director, National Preparedness

"Knowledge-sharing purpose" refers to those activities used to identify the knowledge that subsequently will need to be shared. The purpose of knowledge sharing is either knowledge exploration or knowledge exploitation. Knowledge sharing via exploration refers to searching for new alternatives by generating variation [March, 1991, McGrath, 2001]. 
Exploration activities can be summarized as "search, variation, risk taking, experimentation, play, flexibility, discovery, or innovation" [March, 1991 in Schildt, Maula, and Keil, 2005, p. 494]. Indeed, due to the intrinsic characteristics of knowledge sharing for exploration, low-density networks of people with high degrees of connectivity and access to other people and resources outside the core group, team, or network are far more effective in knowledge-exploration activities [Kane and Alavi, 2005]

Knowledge sharing for exploitation is defined as "a directed search emphasizing limiting variety and building closely on the existing knowledge base" [Schildt, Maula, and Keil, 2005, p. 495, McGrath, 2001]. In addition, knowledge exploitation activities focus on "refinement, choice, production, efficiency, selection, implementation, and execution" of knowledge [March, 1991 in Schildt, Maula, and Keil, 2005, p. 494]. In fact, given that the knowledge needed to tackle the tasks at hand is already known, organized, and available, networks of people with high degrees of connectivity are most effective for conducting knowledge sharing for exploitation [Kane and Alavi, 2005, p.235].

In summary, knowledge sharing can be for the "exploration of new possibilities and the exploitation of old certainties" [March, 1991, p. 71] to take action on the tasks at hand. The knowledge-sharing purpose will primarily be determined by the significance, urgency, and impact of tasks. However, once the most appropriate knowledge-sharing purpose is defined, it is crucial to decide the required mechanism of knowledge sharing. Table 14 summarizes some of the knowledge-sharing literature used to support the conceptualization of knowledge-sharing purposes and knowledge-sharing mechanisms used in this research. 


\begin{tabular}{|c|c|}
\hline Construct/Dimensions & Author(s) Definition \\
\hline $\begin{array}{l}\text { Construct: } \\
\text { Knowledge Sharing }\end{array}$ & 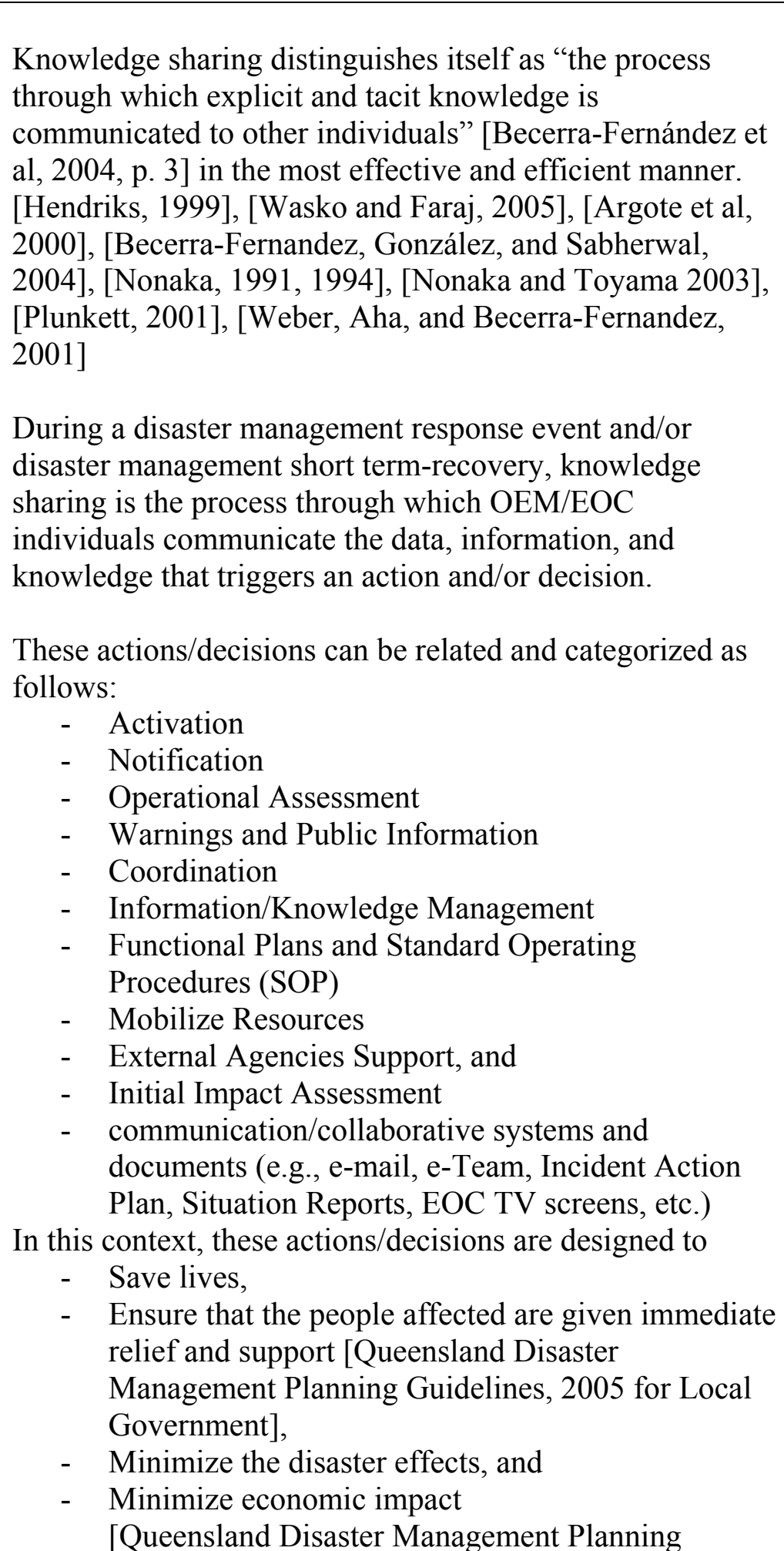 \\
\hline
\end{tabular}




\begin{tabular}{|l|l|}
\hline & $\begin{array}{c}\text { Guidelines, 2005 } \\
\text { for Local Government] } \\
\text { These knowledge-sharing interactions can be categorized } \\
\text { as follows: } \\
-\quad \text { person to person (one person talking to another } \\
\text { person at the EOC floor) } \\
-\quad \text { person to group (formal and informal meetings such } \\
\text { as the planning and/or briefings meetings and } \\
\text { activities performed at the EOC floor or perimeter } \\
\text { offices) } \\
-\quad \text { person to information/knowledge }\end{array}$ \\
\hline
\end{tabular}

Table 14. Literature Review References, Knowledge Sharing, Knowledge Sharing Purposes, and Knowledge Sharing Mechanisms

\begin{tabular}{|l|l|}
\hline Construct/Dimensions & Author(s) Definition \\
\hline $\begin{array}{l}\text { Knowledge Sharing } \\
\text { Activities }\end{array}$ & $\begin{array}{l}\text { Knowledge transfer activities include knowledge sharing, } \\
\text { exchange and distribution [Argote et al, 2000, Becerra- } \\
\text { Fernandez, González, and Sabherwal, 2004]. }\end{array}$ \\
$\begin{array}{l}\text { Knowledge-transfer strategies, practices, and activities are } \\
\text { reinforced at all levels of the organization through } \\
\text { traditional apprentice models, learning networks, best } \\
\text { practices and lessons-learned programs, storytelling, } \\
\text { interviews, training, after-action reviews, knowledge } \\
\text { exchange sites and facilities (e.g., K e-shops, K e-markets, } \\
\text { share fairs, corridors, break rooms and brown bag } \\
\text { seminars), socialization programs, cross functional teams, } \\
\text { social networks, and communities of practice [Nonaka, } \\
\text { 1991, 1994; Nonaka and Toyama 2003; Plunkett, 2001; } \\
\text { Weber, Aha, and Becerra-Fernandez, 2001]. }\end{array}$ \\
$\begin{array}{l}\text { Knowledge sharing (KS) activities can be empirically } \\
\text { researched and tested through the following set of } \\
\text { constructs: written contributions, organizational } \\
\text { communications, personal interactions, and communities of } \\
\text { practice [Yi, 2005] }\end{array}$ \\
\hline Knowledge Sharing \\
Effectiveness & $\begin{array}{l}\text { It occurs "when relevant, useful, or meaningful knowledge } \\
\text { is distributed between individuals within the environment, } \\
\text { that is, the process of knowledge sharing did in fact take } \\
\text { place" [Bosua and Scheepers, 2007, p. 97] }\end{array}$ \\
$\begin{array}{l}\text { KS effectiveness refers to the extent to which the } \\
\text { knowledge being shared to perform a particular task during }\end{array}$ \\
\hline
\end{tabular}




\begin{tabular}{|l|l|}
\hline & $\begin{array}{l}\text { a disaster management response event and/or disaster } \\
\text { management short-term recovery was "relevant, useful, } \\
{[\ldots] \text { meaningful" [Bosua and Scheepers, 2007, p. 97], and }} \\
\text { satisfactory for the people involved. }\end{array}$ \\
\hline $\begin{array}{l}\text { Knowledge Sharing } \\
\text { (Behavior metrics) }\end{array}$ & $\begin{array}{l}\text { Measurements: } \\
-\quad \text { Written Contributions } \\
-\quad \text { Organizational Communications } \\
- \text { Personal Interactions } \\
\text { Research Instruments: } \\
{[\text { Yi, J., 2005] }}\end{array}$ \\
\hline $\begin{array}{l}\text { Knowledge Sharing } \\
\text { Efficiency }\end{array}$ & $\begin{array}{l}\text { It is when "the sharing of knowledge [happens] with the } \\
\text { minimum wasted time, effort, or expense" [Bosua and } \\
\text { Scheepers, 2007, p. 97] }\end{array}$ \\
& $\begin{array}{l}\text { KS Efficiency refers to the extent to which knowledge } \\
\text { sharing to perform a particular task during a disaster } \\
\text { management response event and/or disaster management } \\
\text { short term recovery took place in the required time, } \\
\text { resources, and budget. }\end{array}$ \\
\hline
\end{tabular}

Table 14 (continued ...)

\begin{tabular}{|l|l|}
\hline Construct/Dimensions & Author(s) Definition \\
\hline $\begin{array}{l}\text { Construct: } \\
\text { Knowledge Sharing } \\
\text { Purposes } \\
\text { Dimension: } \\
\text { Knowledge } \\
\text { Exploration }\end{array}$ & \\
& $\begin{array}{l}\text { Knowledge exploration often refers to the exploration of } \\
\text { new alternatives by generating variation [March, 1991, } \\
\text { McGrath, 2001] }\end{array}$ \\
& $\begin{array}{l}\text { "Exploration activities include search, variation, risk } \\
\text { taking, experimentation, play, flexibility, discovery, or } \\
\text { innovation" [March, 1991 in Schildt, Maula, and Keil, } \\
\text { 2005, p. 494] }\end{array}$ \\
& $\begin{array}{l}\text { "Low density networks [are] more effective for knowledge } \\
\text { exploration" [Kane and Alavi, 2005, p.235] }\end{array}$ \\
\hline $\begin{array}{l}\text { Konstruct: } \\
\text { Purposes } \\
\text { Dimension: } \\
\text { Knowledge } \\
\text { Exploitation }\end{array}$ & $\begin{array}{l}\text { Knowledge exploitation refers to "a directed search } \\
\text { emphasizing limiting variety and building closely on the }\end{array}$ \\
\hline
\end{tabular}




\begin{tabular}{|l|l|}
\hline $\begin{array}{l}\text { existing knowledge base" [Schildt, Maula, and Keil, 2005, } \\
\text { p. 495, McGrath, 2001] }\end{array}$ \\
$\begin{array}{l}\text { "Exploitation activities include refinement, choice, } \\
\text { production, efficiency, selection, implementation, and } \\
\text { execution" [March, 1991 in Schildt, Maula, and Keil, 2005, } \\
\text { p. 494] }\end{array}$ \\
$\begin{array}{l}\text { "High density networks [are] more effective for knowledge } \\
\text { exploitation" [Kane and Alavi, 2005, p.235] }\end{array}$ \\
\hline
\end{tabular}

Table 14 (continued ...) 


\begin{tabular}{|c|c|}
\hline Construct/Dimensions & Author(s) Definition \\
\hline $\begin{array}{l}\text { Construct: } \\
\text { Knowledge Sharing } \\
\text { Mechanisms }\end{array}$ & $\begin{array}{l}\text { "Knowledge Sharing Mechanisms are defined as the formal } \\
\text { and informal mechanisms for sharing, integrating, } \\
\text { interpreting and applying know-what, know-how, and } \\
\text { know-why embedded in individuals and groups that will } \\
\text { aid in the performance of project tasks" [Boh, 2007, p. 28] } \\
\text { Knowledge-sharing mechanisms are the methods through } \\
\text { which knowledge is being shared during a disaster } \\
\text { management response event and/or disaster management } \\
\text { short-term recovery to perform a particular task, most often } \\
\text { answering the following questions: } \\
\text { - What happened? Where did it happen? } \\
\text { - What are the immediate response needs of the } \\
\quad \text { community? } \\
\text { - What is the initial estimate of damage? } \\
\text { [Miami Dade County, Florida. EOC Damage Assessment, } \\
\text { ERF C, 2005, p. 5] }\end{array}$ \\
\hline $\begin{array}{l}\text { Construct: } \\
\text { Knowledge Sharing } \\
\text { Mechanisms }\end{array}$ & \\
\hline $\begin{array}{l}\text { Dimension: } \\
\text { Personal Contact }\end{array}$ & $\begin{array}{l}\text { This is a mechanism to share knowledge that "has not been } \\
\text { formally articulated in writing, and usually is shared in the } \\
\text { form of personal advice" [Hansen, Nohria, and Tierney, } \\
1999 \text { in Hansen and Hass, 2001, p. 1] } \\
\text { Informal social interactions } \\
\text { Person to person channels } \\
\text { "The larger the personal networks [...] the greater the } \\
\text { chance that the individual will share knowledge with } \\
\text { people [within his or her] social network" [Yi, 2005, p.45] } \\
\text { Formal interactions through "teams or project groups ... } \\
\text { [in] regular meetings for brainstorming }\end{array}$ \\
\hline
\end{tabular}

Table 14 (continued ...) 


\begin{tabular}{|c|c|}
\hline Construct/Dimensions & Author(s) Definition \\
\hline $\begin{array}{l}\text { Knowledge Sharing } \\
\text { through Teachability }\end{array}$ & $\begin{array}{l}\text { It "reflects the extent to which the knowledge can be taught } \\
\text { to other individuals, through training, apprenticeship, and } \\
\text { so on" [Becerra-Fernandez, González, and Sabherwal, } \\
\text { 2004, p. 24] } \\
\text { Teachability refers to extent to which OEM/EOC actors } \\
\text { engage in one-to-one or one-to-many knowledge-sharing } \\
\text { activities through personal interactions and observations } \\
\text { during a disaster management response event and/or } \\
\text { disaster management short-term recovery. These } \\
\text { knowledge-sharing activities can also be performed at other } \\
\text { times through apprentice models and formal training } \\
\text { programs. }\end{array}$ \\
\hline Pers & $\begin{array}{l}\text { Informal social interactions } \\
\text { Person to person channels } \\
\text { Knowledge Sharing Mechanism: Personalization } \\
\text { "The larger the personal networks [...] the greater the } \\
\text { chance that the individual will share knowledge with } \\
\text { people [within his or her] social network" [Yi, 2005, p.45] }\end{array}$ \\
\hline $\begin{array}{l}\text { Construct: } \\
\text { Knowledge Sharing } \\
\text { Mechanisms } \\
\text { Dimension: } \\
\text { Written-Electronic } \\
\text { Documents }\end{array}$ & $\begin{array}{l}\text { This is a mechanism to share knowledge that has been } \\
\text { codifies and "written down and is usually shared in the } \\
\text { form of electronic documents" [Hansen, Nohria, and } \\
\text { Tierney, } 1999 \text { in Hansen and Hass, 2001, p. 1] } \\
\text { Contribution of "ideas, information, and expertise through } \\
\text { written documentation" [Yi, 2005, p. 41] }\end{array}$ \\
\hline $\begin{array}{l}\text { Knowledge Sharing } \\
\text { through Codifiability }\end{array}$ & $\begin{array}{l}\text { It "reflects the extent to which knowledge can be } \\
\text { articulated or codified, even if the resulting codified } \\
\text { knowledge might be difficult to impart to other individual" } \\
\text { [Becerra-Fernandez, González, and Sabherwal, 2004, p. } \\
\text { 24] } \\
\text { In the context of a disaster management response event } \\
\text { and/or disaster management short-term recovery, } \\
\text { codifiability refers to the extent to which OEM/EOC actors } \\
\text { are able to explicitly share their knowledge through } \\
\text { writing, documents, diagrams, pictures, and voice } \\
\text { recordings. This knowledge is most often shared through } \\
\text { information/knowledge communication/collaborative }\end{array}$ \\
\hline
\end{tabular}




\begin{tabular}{|l|l|}
\hline & $\begin{array}{l}\text { systems and documents (e.g., e-mail, e-Team, IAP, } \\
\text { SitReps, EOC TV screens, and so on). }\end{array}$ \\
\hline Written & Contribution of "ideas, information, and expertise through \\
Contributions & $\begin{array}{l}\text { written documentation" [Yi, 2005, p. 41] } \\
\text { Person to document channels } \\
\text { Knowledge Sharing Mechanism: Codification }\end{array}$ \\
\hline
\end{tabular}

Table 14 (continued ...) 


\begin{tabular}{|l|l|}
\hline Construct/Dimensions & Author(s) Definition \\
\hline & \\
\hline $\begin{array}{l}\text { Organizational } \\
\text { Communications }\end{array}$ & $\begin{array}{l}\text { Formal interactions through "teams or project groups ... } \\
\text { [in] regular meetings for brainstorming or problem- solving } \\
\text { by seeking ideas from employees" [Yi, 2005, p. 41] } \\
\text { Person to group channels } \\
\text { Knowledge Sharing Mechanism: Personalization }\end{array}$ \\
\hline
\end{tabular}

Table 14 (continued ...) 


\section{Research model and hypotheses}

\subsection{Research Model}

Uncertain dynamic disaster management tasks are highly unpredictable and often involve the work of several EOC functional groups and organizations that attend to specific characteristics of a given task. To resolve these types of tasks, EOC functional groups and organizations must interact with one another, sharing data, information, and knowledge, to successfully perform a given task within the needed timeframe. According to the uncertain dynamic disaster management task characteristics that disaster management personnel face, different knowledge-sharing strategies in terms of knowledge-sharing purposes or mechanisms may be employed to increase the possibility of effective and efficient task performance.

As discussed in earlier sections, no prior studies have correlated uncertain dynamic disaster management tasks, knowledge sharing, and task performance. Consequently, this research study aims to understand better the interaction of these three constructs through the proposed research model shown in Figure 3. 


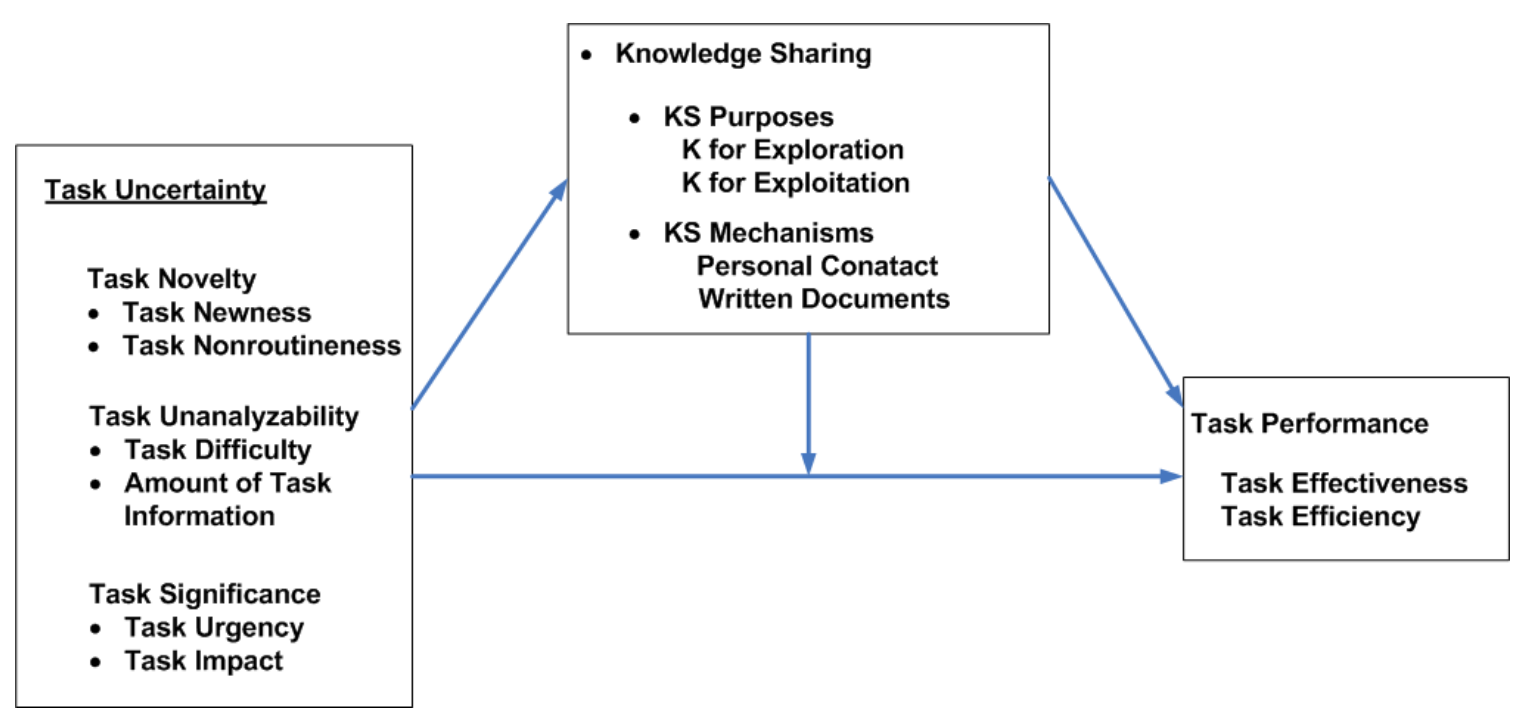

Figure 3. Research Model

Furthermore, this research study attempts to determine which knowledge-sharing purposes and mechanisms are most appropriate for use by EOC and disaster management personnel according to uncertain dynamic disaster management task characteristics.

Moreover, in terms of effectiveness and efficiency, this research study aims to measure the mediating and moderating effects of knowledge-sharing purposes and mechanisms in relation to task performance.

\subsection{Research Questions}

The motivation behind this research study is driven by the need to better understand how knowledge sharing can mediate and/or moderate uncertain dynamic task characteristics in the context of disaster management. 
This study is based on a review of relevant theoretical and empirical studies of effective knowledge sharing and disaster management [Becerra-Fernandez et al., 2008; Rocha et al., 2009; Xia et al., 2010; Xia et al., 2011].

Some research questions that are related to this topic are as follows:

Facing uncertain dynamic task characteristics:

- What is the direct effect of uncertain dynamic disaster management tasks on task performance?

- How can knowledge be effectively and efficiently transferred among disaster management intra- and inter-agency organizations so as to have a positive effect on task performance?

- To what extent does the mediating effect of knowledge sharing positively impact task performance during a disaster management event?

- To what extent does the moderating effect of knowledge sharing positively impact task performance during a disaster management event?

- To what degree do appropriate knowledge-sharing purposes help increase cooperation, collaboration, and coordination among disaster management team members and among disaster management teams so as to influence task performance?

- To what degrees do appropriate knowledge-sharing mechanisms help increase cooperation, collaboration, and coordination among disaster management team members and among disaster management teams so as to influence task performance? 
- To what extent does the control effect of people's levels of expertise and experience in disaster management events influence knowledge sharing and thus task performance?

\subsection{Research Hypotheses}

Based on a literature review of case study research analyses that have been performed using the EOC archives of standard operations procedures, local response protocols, situation reports and incidents, action plans, ICT collaborative software systems, and e-mail logs of hurricanes Katrina, Rita, and Wilma; the qualitative ethnographic research analysis performed at the Miami-Dade OEM and EOC during Tropical Ernesto in 2006 and several training simulations between 2007 and 2010; and multiples interviews, focus groups, direct and indirect observations with the EOC personnel, functional groups, and related agencies and organizations that were mentioned in previous sections, this research study developed the following hypotheses to address the research questions that were stated in previous sections. 


\subsubsection{Research Hypotheses for Direct Effects}

Because of the uncertain evolution and dynamic attributes and conditions of disaster management tasks that impair management capabilities and decision-making processes of disaster management personnel, uncertain dynamic disaster management tasks are predisposed to failure in terms of task performance [Becerra-Fernandez et al., 2008; Rocha et al., 2009]. Higher levels of uncertain dynamic task characteristics with novelty dimensions (task newness, task nonroutineness) and the unanalyzability dimension of task difficulty in disaster management tasks imply a greater uncertainty and complication facing a given task, and therefore, the probability of an unsatisfactory outcome increases. Nevertheless, higher levels of uncertain dynamic task characteristics in the contexts of an unanalyzable quantity of task information and task significance (task urgency and task impact) increase the pressure to complete these tasks within reasonable levels of satisfaction for all of the disaster management stakeholders who are involved in a given task [Rocha et al., 2009; Xia et al., 2010]. Consequently, this research study conceptualized hypotheses $\mathrm{H} 1$ and $\mathrm{H} 2$, as shown in Figure 4 and outlined in the following paragraphs. 


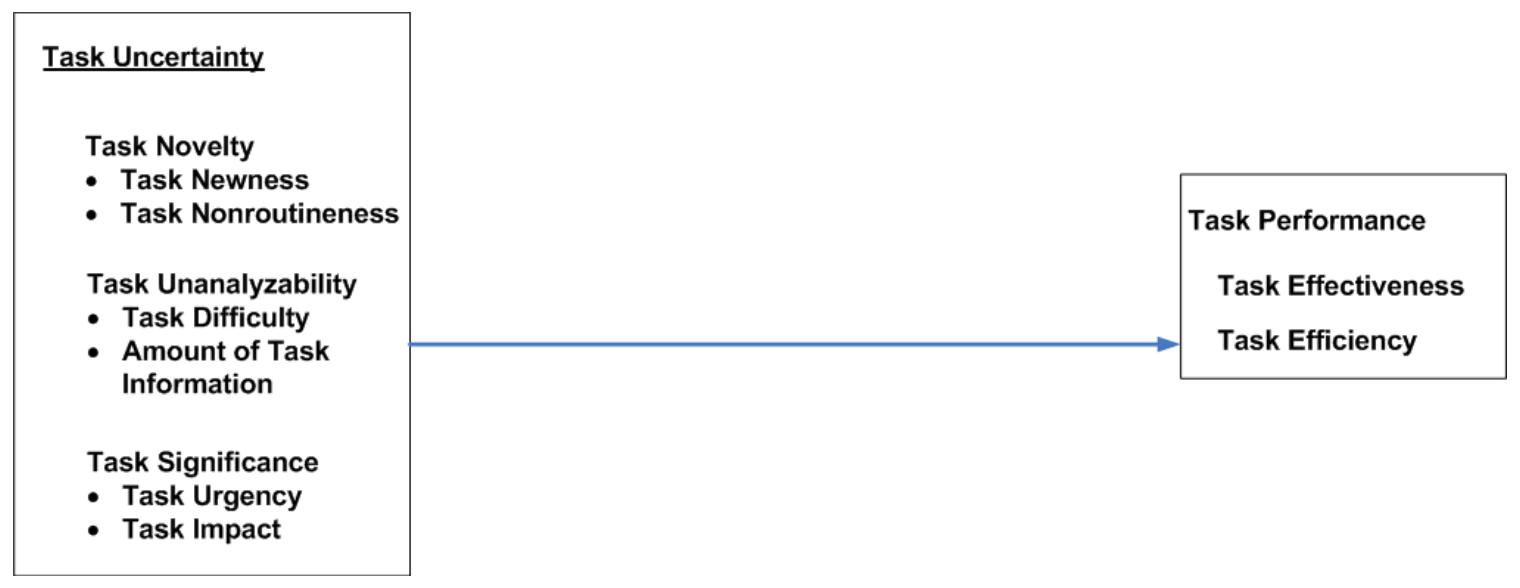

Figure 4. Uncertain dynamic disaster management tasks and task performance

Uncertain dynamic disaster management tasks and task performance hypotheses

H1. Uncertain dynamic task characteristics with novelty dimensions (task newness, task nonroutineness), and unanalyzability dimension of task difficulty are negatively associated with task effectiveness

H1a. Task newness is negatively associated with task effectiveness $\mathrm{H} 1 \mathrm{~b}$. Task nonroutineness is negatively associated with task effectiveness H1c. Task difficulty is negatively associated with task effectiveness

H2. Uncertain dynamic task characteristics with unanalyzability dimension of amount of task information, and significance dimensions (task urgency and task impact) are positively associated with task effectiveness

H2a. Amount of task information is positively associated with task effectiveness

H2b. Task urgency is positively associated with task effectiveness

H2c. Task impact is positively associated with task effectiveness 
Similarly, disaster management tasks, which feature higher levels of uncertain dynamic task characteristics with novelty dimensions (task newness, task nonroutineness) and an unanalyzability dimension of task difficulty, that must be performed within a specified period, budget, and set of resources are prone to failure due to the lack of previous experiences in performing these tasks. On the contrary, despite higher levels of uncertain dynamic task characteristics with dimensions of unanalyzable task information quantities and task significance (task urgency and task impact) in compliance with the required timeframes, budgets, and resources, these tasks must be successfully completed [Rocha et al., 2009; Xia et al., 2010]. Consequently, this research study conceptualized the following hypotheses $\mathrm{H} 3$ and H4, as shown in Figure 4 and as outlined in the following paragraphs.

H3. Uncertain dynamic task characteristics with novelty dimensions (task newness, task nonroutineness), and unanalyzability dimension of task difficulty are negatively associated with task efficiency

H3a. Task newness is negatively associated with task efficiency H3b. Task nonroutineness is negatively associated with task efficiency H3c. Task difficulty is negatively associated with task efficiency

H4. Uncertain dynamic task characteristics with unanalyzability dimension of amount of task information, and significance dimension (task urgency and task impact) are positively associated with task efficiency

H4a. Amount of task information is positively associated with task efficiency

H4b. Task urgency is positively associated with task efficiency

H4c. Task impact is positively associated with task efficiency 
As previously described, when uncertain dynamic disaster management tasks are presented to disaster management personnel, the approach and decision-making processes to perform these tasks often exceed the person's experience, expertise, and problemsolving skills. Knowledge sharing becomes critical to quickly assess, handle, and successfully perform the given task [Becerra-Fernandez et al., 2008; Xia et al., 2011]. Consequently, this research study conceptualized hypotheses $\mathrm{H} 5$ and $\mathrm{H} 6$, as shown in Figure 5 and outlined in the following paragraphs.

Given the uncertainty, novelty, and ever-changing characteristics of task novelty with task newness and task nonroutineness dimensions, in addition to the mounting challenges of task unanalyzability with task difficulty dimensions, knowledge-sharing purposes and mechanisms help to predict the performance of these tasks; however, when these types of knowledge sharing are being simultaneously employed without discriminating among them for specific uncertain dynamic disaster management tasks and dimensions, a given task is doomed to failure (task requirements not being met and unsatisfactory task outcomes for the disaster management personnel and organizations that are involved with a given task) [Becerra-Fernandez et al., 2008; Rocha et al., 2009; Xia et al., 2010; Xia et al., 2011]. Consequently, this research study conceptualized hypotheses H5a, H5b, and H5c, as shown in Figure 5 and as outlined in the following paragraphs. 


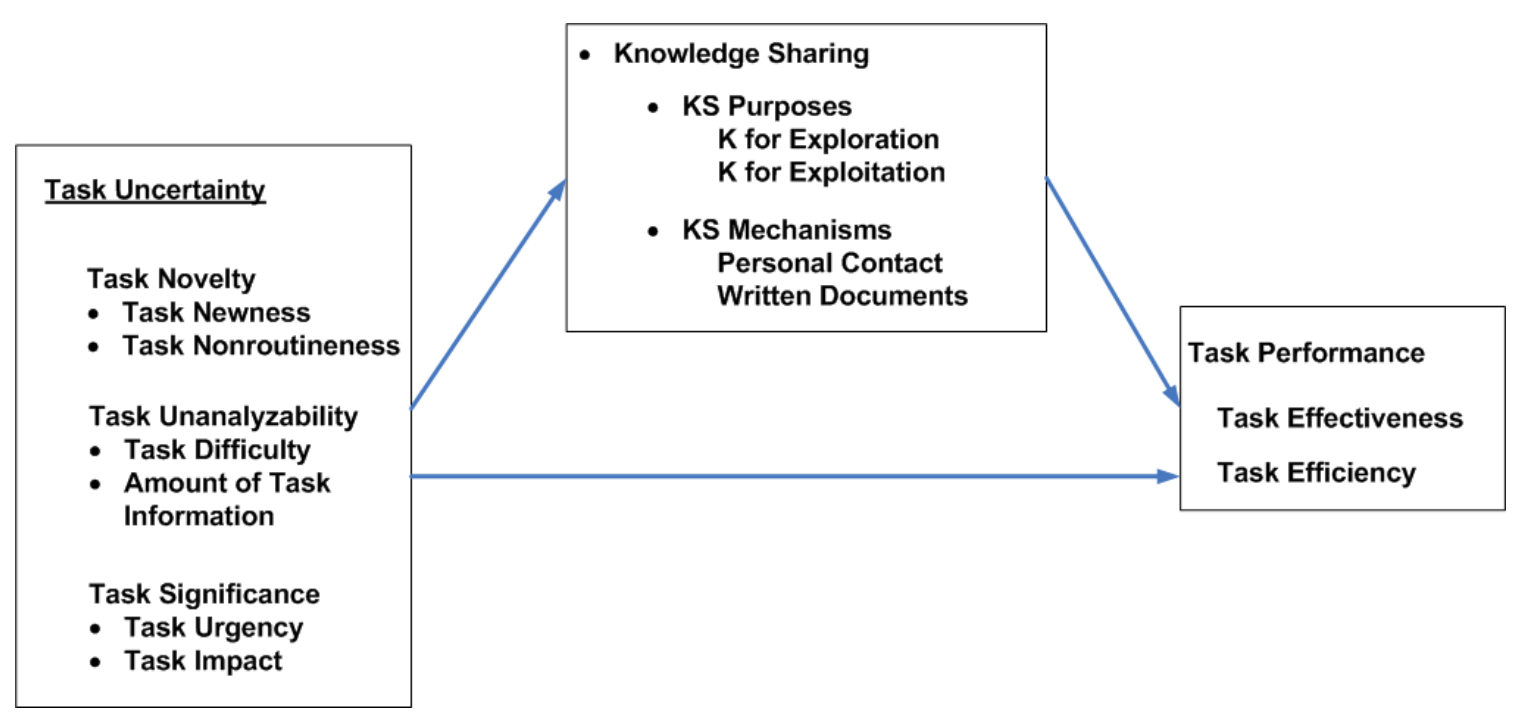

Figure 5. Uncertain dynamic disaster management tasks, knowledge sharing, and task performance

\section{Uncertain dynamic disaster management tasks, knowledge sharing and task performance hypotheses}

H5. Uncertain dynamic task characteristics with novelty dimensions (task newness, task nonroutineness), and unanalyzability dimension of task difficulty along with, knowledge sharing purposes and its dimensions (knowledge sharing for exploration and knowledge sharing for exploitation), and knowledge sharing mechanisms and its dimensions (knowledge sharing through personal contacts and knowledge sharing through written documents) are negatively associated with task effectiveness

H5a. Task newness is negatively associated with task effectiveness H5b. Task nonroutineness is negatively associated with task effectiveness H5c. Task difficulty is negatively associated with task effectiveness

When uncertain dynamic disaster management tasks characteristics are presented as task unanalyzability regarding the amount of task information and task significance with task urgency and task impact dimensions, the need for EOC personnel and disaster management functional groups and organizations to obtain as much data, information, and knowledge as possible so as to successfully perform a given task is crucial. 
Furthermore, when EOC personnel and disaster management functional groups and organizations face uncertain dynamic disaster management tasks with significance characteristics and task urgency and impact dimensions, the pressure to successfully perform the task increases with no room for failure [Rocha et al., 2009; Xia et al., 2010]. Consequently, EOC personnel and disaster management functional groups and organizations pursue different combinations of knowledge-sharing purposes and mechanisms to contribute to the successful completion of these tasks so as to meet the requirements of a given task and ensure that the task results are satisfactory for all parties involved. Consequently, this research study conceptualized hypotheses H5d, H5e, and H5f, as shown in Figure 5 and as outlined in the following paragraphs.

H5. Uncertain dynamic task characteristics with unanalyzability dimension of amount of task information, and significance dimension (task urgency and task impact) difficulty along with, knowledge sharing purposes and its dimensions (knowledge sharing for exploration and knowledge sharing for exploitation), and knowledge sharing mechanisms and its dimensions (knowledge sharing through personal contacts and knowledge sharing through written documents) are positively associated with task effectiveness

H5d. Amount of task information is positively associated with task effectiveness

H5e. Task urgency is positively associated with task effectiveness H5f. Task impact is positively associated with task effectiveness

When EOC personnel and disaster management functional groups and organizations face uncertain dynamic disaster management tasks, knowledge-sharing purposes and mechanisms can be used to successfully meet the requirements of a given task through satisfactory outcomes for all stakeholders who are participating in the execution of the task. 
Given the novelty, unanalyzability, and significance dimensions of the task and its pressing requirements to be met and satisfy all related parties who are involved in a relatively short time span, a combination of knowledge-sharing purposes and mechanisms is needed to successfully perform a given task [Becerra-Fernandez et al., 2008; Rocha et al., 2009; Xia et al., 2010; Xia et al., 2011].

However, not all combinations of knowledge-sharing purposes and mechanisms are positively associated with task performance and its dimension of task effectiveness. According to the limited timeframe to fulfill the task requirements, the different demands of the stakeholders who are involved in the task, and a literature review and conceptualization of knowledge sharing for exploration in terms of discovering new data, information, and knowledge sharing, the practices of knowledge sharing for exploitation in terms of directly searching and using existing knowledge, knowledge sharing through personal contacts in terms of the individual who possesses experience and expertise that is not easily articulated and formally codified in writing and that is easier and faster to share through personal interactions about the task being performed, knowledge sharing through written documents in terms of knowledge that has been formally codified in writing and is available to be searched and put to work, knowledge sharing for exploration, and knowledge sharing through personal contacts are positively associated with task performance and its dimension of task effectiveness, whereas knowledge sharing for exploitation and knowledge sharing through written documents are negatively associated with task performance and its dimension of task effectiveness [BecerraFernandez et al., 2008; Xia et al., 2011]. 
Consequently, this research study conceptualized hypotheses $\mathrm{H} 5 \mathrm{~g}, \mathrm{H} 5 \mathrm{~h}, \mathrm{H} 5 \mathrm{i}$, and $\mathrm{H} 5 \mathrm{j}$, as shown in Figure 5 and outlined in the following paragraphs.

H5. Knowledge sharing purpose with exploration dimension and knowledge sharing mechanism with personal contacts dimension along with uncertain dynamic task characteristics are positively associated with task effectiveness

H5g. Knowledge sharing purpose for exploration is positively associated with task effectiveness

$\mathrm{H} 5 \mathrm{~h}$. Knowledge sharing mechanism through personal contacts is positively associated with task effectiveness

H5. Knowledge sharing purpose with exploitation dimension and knowledge sharing mechanism with written documents dimension along with uncertain dynamic task characteristics are negatively associated with task effectiveness

H5i. Knowledge sharing purpose for exploitation is negatively associated with task effectiveness

H5j. Knowledge sharing mechanism through written documents is negatively associated with task effectiveness

As previously stated, because of the uncertainty, novelty, and ever-changing characteristics of task novelty with task newness and task nonroutineness dimensions, in addition to the mounting challenges of task unanalyzability with task difficulty dimensions, knowledge-sharing purposes and mechanisms help to predict the performance of these tasks; however, when these types of knowledge sharing are simultaneously employed without discriminating among them for specific uncertain dynamic disaster management tasks and dimensions, the task performance and its dimension of task efficiency are doomed to failure, particularly when the task requires specific timeframes to be met and when there are limited budgets and scarce resources to complete a given task [Becerra-Fernandez et al., 2008; Rocha et al., 2009; Xia et al., 2010; Xia et al., 2011]. 
Consequently, this research study conceptualizes hypotheses H6a, H6b, and H6c shown in Figure 5 and outlined in the following paragraphs.

H6. Uncertain dynamic task characteristics with novelty dimensions (task newness, task nonroutineness), and unanalyzability dimension of task difficulty along with, knowledge sharing purposes and its dimensions (knowledge sharing for exploration and knowledge sharing for exploitation), and knowledge sharing mechanisms and its dimensions (knowledge sharing through personal contacts and knowledge sharing through written documents) are negatively associated with task efficiency

H6a. Task newness is negatively associated with task efficiency H6b. Task nonroutineness is negatively associated with task efficiency H6c. Task difficulty is negatively associated with task efficiency

Similarly, when uncertain dynamic disaster management task characteristics are presented as task unanalyzability regarding the amount of task information and task significance with task urgency and task impact dimensions, the need for EOC personnel and disaster management functional groups and organizations to obtain as much data, information, and knowledge as possible to successfully perform current given task within specific timeframes as well as with limited budgets and scarce resources is crucial. Furthermore, when EOC personnel and disaster management functional groups and organizations face uncertain dynamic disaster management tasks with significance characteristics and task urgency and impact dimensions, the pressure to successfully perform the task increases with no room for failure, even if there are restrictions in terms of specific timeframes, limited budgets, and scarce resources [Becerra-Fernandez et al., 2008; Rocha et al., 2009; Xia et al., 2010; Xia et al., 2011]. 
Therefore, EOC personnel and disaster management functional groups and organizations pursue different combinations of knowledge-sharing purposes and mechanisms so as to contribute to the successful performance of these tasks in terms of effectively performing a given task within specific timeframes, with limited budgets, and with scarcely available resources [Becerra-Fernandez et al., 2008; Xia et al., 2011]. Consequently, this research study conceptualized hypotheses H6d, H6e, and H6f, as shown in Figure 5 and as outlined in the following paragraphs.

H6. Uncertain dynamic task characteristics with unanalyzability dimension of amount of task information, and significance dimension (task urgency and task impact) difficulty along with, knowledge sharing purposes and its dimensions (knowledge sharing for exploration and knowledge sharing for exploitation), and knowledge sharing mechanisms and its dimensions (knowledge sharing through personal contacts and knowledge sharing through written documents) are positively associated with task efficiency

H6d. Amount of task information is positively associated with task efficiency

H6e. Task urgency is positively associated with task efficiency

H6f. Task impact is positively associated with task efficiency

When EOC personnel and disaster management functional groups and organizations face uncertain dynamic disaster management tasks, knowledge-sharing purposes and mechanisms can be used to successfully meet the requirements of current given task within specific timeframes, with limited budgets, and with scarcely available resources. 
Because of the novelty, unanalyzability, and significance dimensions of the task and its pressing requirements to be completed within a specified timeframe, budget, and existing resources, a combination of knowledge-sharing purposes and mechanisms is needed to successfully perform a given task [Rocha et al., 2009; Xia et al., 2010].

According to the constraints faced by EOC personnel and disaster management functional groups and organizations, in addition to a literature review and conceptualization of knowledge sharing for exploration in terms of discovering new data, information, and knowledge, the practices of knowledge sharing for exploitation in terms of directly searching and using existing knowledge, knowledge sharing through personal contacts in terms of the individual who possesses experience and expertise is difficult to articulate and formally codify in writing (this particular type of knowledge is easier and faster to share through personal interactions) and knowledge sharing through written documents in terms of knowledge that has been formally codified in writing and it is available to be searched and put to work [Becerra-Fernandez et al., 2008; Rocha et al., 2009; Xia et al., 2010; Xia et al., 2011]. With the objective to perform current given task according to its timeframe, budget, and existing resources, EOC personnel and disaster management functional groups and organizations combine these four dimensions of knowledge sharing to successfully accomplish the task. Consequently, this research study conceptualized hypotheses H6g, H6h, H6i, and H6j, as shown in Figure 6 and as outlined in the following paragraphs. 
H6. Knowledge sharing purpose with exploration and exploitation dimensions and knowledge sharing mechanisms with personal contacts and written documents dimensions along with uncertain dynamic task characteristics are positively associated with task efficiency

H6g. Knowledge sharing purpose for exploration is positively associated with task efficiency

H6h. Knowledge sharing purpose for exploitation is positively associated with task efficiency

H6i. Knowledge sharing mechanism through personal contacts is positively associated with task efficiency

H6j. Knowledge sharing mechanism through written documents is positively associated with task efficiency

Disaster management tasks are highly uncertain, and depending on the particular dimensions of current given task, disaster management personnel may need to share knowledge for different purposes and through different mechanisms [Becerra-Fernandez et al., 2008; Rocha et al., 2009]. Consequently, this research study conceptualized hypotheses H7, H8, H9, and H10, as shown in Figure 6 and outlined in the following paragraphs.

According to the novelty, unanalyzability, and significance dimensions of uncertain dynamic disaster management tasks, the dimensions of knowledge-sharing purposes can reveal new knowledge that is needed to perform a given task by examining previously completed tasks. Through knowledge-sharing activities, such as searching, experimentation, discovery, and innovation, uncertain dynamic disaster management tasks are positively associated with knowledge sharing for exploration [Rocha et al., 2009; Xia et al., 2010]. Consequently, this research study conceptualized hypotheses H7a, H7b, H7c, H7d, H7e, and H7f, as shown in Figure 6 and outlined in the following paragraphs. 


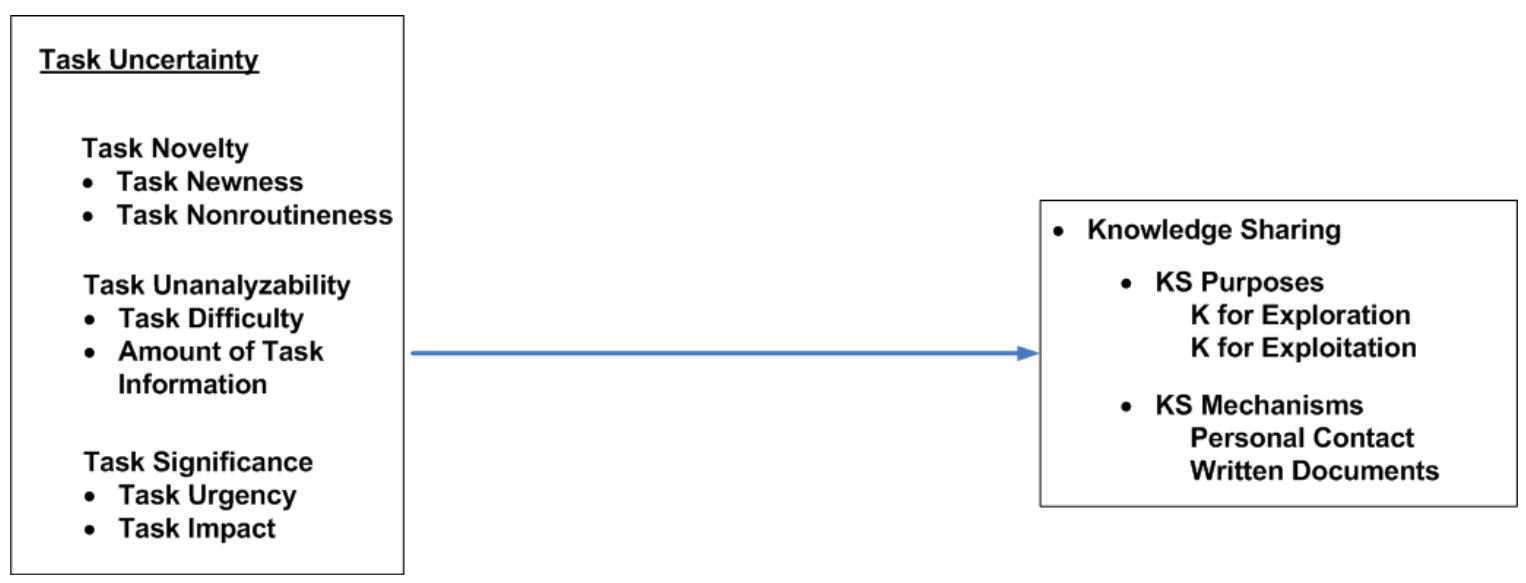

Figure 6. Uncertain dynamic disaster management tasks and knowledge sharing

\section{Uncertain dynamic disaster management tasks and knowledge sharing hypotheses}

H7. Uncertain dynamic task characteristics with novelty dimensions (task newness and task nonroutineness), unanalyzability dimension (task difficulty and amount of task information), and significance dimensions (task urgency and task impact) are positively associated with knowledge sharing for exploration

H7a. Task newness is positively associated with knowledge sharing for exploration

H7b. Task nonroutineness is positively associated with knowledge sharing for exploration

H7c. Task difficulty is positively associated with knowledge sharing for exploration

H7d. Amount of task information is positively associated knowledge sharing for exploration

H7e. Task urgency is positively associated with knowledge sharing for exploration

H7f. Task impact is positively associated with knowledge sharing for exploration 
Knowledge sharing for exploitation plays a slightly different role with respect to uncertain dynamic disaster management tasks. Knowledge sharing for exploitation is used by EOC personnel and disaster management functional groups and organizations when there is existing knowledge that is related to the task being performed. Types of knowledge sharing activities for exploitation include refinement, choice, selection, and the use of existing data, information, and knowledge [Rocha et al., 2009; Xia et al., 2010]. Usually, this knowledge is found through EOC schedule and planning guidelines, standard operating procedures, best practices, lessons learned, and after-action reports.

Given the characteristics of uncertain dynamic disaster management tasks with task novelty dimensions, as previously described, there is no previous knowledge to be shared through knowledge-sharing purposes for exploitation. For this reason, task novelty dimensions of task newness and task nonroutineness are negatively associated with knowledge sharing for exploitation [Rocha et al., 2009; Xia et al., 2010]. Consequently, this research study conceptualized hypotheses H8a and H8b, as shown in Figure 6 and outlined in the following paragraphs.

For the uncertain dynamic disaster management tasks with unanalyzability and significance dimensions, the knowledge that can be mined through knowledge sharing for exploitation through direct searching activities among others is crucial to assist EOC personnel and functional groups and related organizations in successfully performing a given task [Rocha et al., 2009; Xia et al., 2010]. 
Consequently, this research study conceptualizes hypotheses H8c, H8d, H8e, and H8f shown in Figure 6 and outlined in the following paragraphs.

H8. Uncertain dynamic task characteristics with novelty dimensions (task newness and task nonroutineness), unanalyzability dimensions (task difficulty and amount of task information), and significance dimensions (task urgency and task impact) are positively associated with knowledge sharing for exploitation

H8a. Task newness is negatively associated with knowledge sharing for exploitation

H8b. Task nonroutineness negatively associated with knowledge sharing for exploitation

H8c. Task difficulty is positively associated with knowledge sharing for exploitation

H8d. Amount of task information is positively associated knowledge sharing for exploitation

H8e. Task urgency is positively associated with knowledge sharing for exploitation

H8f. Task impact is positively associated with knowledge sharing for exploitation

Knowledge-sharing mechanisms through personal contacts are employed when EOC personnel and functional groups and related organizations need to share knowledge that is difficult to articulate in writing and is based on the experience and expertise of people. Furthermore, because of the uncertain dynamic characteristics of a given task and the pressure to successfully perform the task, tasks with novelty, unanalyzability, and significance dimensions are positively related to knowledge sharing through personal contacts [Becerra-Fernandez et al., 2008; Xia et al., 2011]. 
Consequently, this research study conceptualizes hypotheses H9a, H9b, H9c, H9d, H9e, and H9f shown in Figure 6 and outlined in the following paragraphs.

H9. Uncertain dynamic task characteristics with novelty dimensions (task newness and task nonroutineness), unanalyzability dimensions (task difficulty and amount of task information), and significance dimensions (task urgency and task impact) are positively associated with knowledge sharing through personal contacts

H9a. Task newness is positively associated with knowledge sharing through personal contacts

H9b. Task nonroutineness positively associated with knowledge sharing through personal contacts

H9c. Task difficulty is positively associated with knowledge sharing through personal contacts

H9d. Amount of task information is positively associated knowledge sharing through personal contacts

H9e. Task urgency is positively associated with knowledge sharing through personal contacts

H9f. Task impact is positively associated with knowledge sharing through personal contacts

Knowledge-sharing mechanisms through personal contacts are employed when EOC personnel and functional groups and related organizations need to share knowledge that has been previously codified through EOC schedule and planning guidelines, standard operating procedures, best practices, lessons learned, and after-action reports. 
Additionally, given the uncertainty dynamic task characteristics of task novelty, wherein there is no previous information or knowledge that is available for that particular task, or task significance, wherein the performance and consequences of the task are highly related to reduced and limited time constraints, task novelty and task significance are negatively associated with knowledge sharing through written documents [BecerraFernandez et al., 2008; Xia et al., 2011]. Consequently, this research study conceptualized hypotheses H10a, H10b, H10e, and H10f, as shown in Figure 6 and outlined in the following paragraphs.

In opposition to task novelty and task significance, task unanalyzability and its dimensions of task difficulty and the amount of task information that benefits from information and knowledge that have been previously codified through EOC schedule and planning guidelines, standard operating procedures, best practices, lessons learned, and after-action reports, EOC personnel and functional groups and related organizations heavily rely on knowledge sharing through written documents so as to attempt to find the best information and knowledge that supports their decision-making processes to successfully perform a given task [Becerra-Fernandez et al., 2008; Xia et al., 2010; Xia et al., 2011]. Consequently, this research study conceptualized hypotheses H10c and H10d, as shown in Figure 6 and outlined in the following paragraphs. 
H10. Uncertain dynamic task characteristics with novelty dimensions (task newness and task nonroutineness) and significance dimensions (task urgency and task impact) are negatively associated with knowledge sharing through written documents

H10a. Task newness is negatively associated with knowledge sharing through written documents

H10b. Task nonroutineness negatively associated with knowledge sharing through written documents

H10e. Task urgency is negatively associated with knowledge sharing through written documents

H10f. Task impact is negatively associated with knowledge sharing through written documents

H10. Uncertain dynamic task characteristics with unanalyzability dimensions (task difficulty and amount of task information) are positively associated with knowledge sharing through written documents

H10c. Task difficulty is positively associated with knowledge sharing through written documents

H10d. Amount of task information is positively associated knowledge sharing through written documents

\subsubsection{Research Hypotheses for Moderating Effects}

Given the characteristics and dimensions of uncertain disaster management tasks, it is expected that the relationship between uncertain disaster management tasks and task performance could be affected by the moderating effects and levels of knowledge sharing that are utilized in assessing, approaching, and successfully resolving a given task. 
The use of knowledge sharing to moderate the relationship between uncertain disaster management tasks and task performance is expected to change the strength and/or direction of this relationship.

When EOC personnel and functional groups and related organizations face uncertain dynamic disaster management tasks, they must appropriately respond so as to meet the task requirements and achieve reasonable levels of satisfaction for all disaster management stakeholders who are involved in a given task. Therefore, EOC personnel and functional groups and related organizations utilize different knowledge-sharing purposes and mechanisms to effectively accomplish the task being performed.

According to the literature review that was performed for this research and interviews and field observations that were performed by the EOC, it appears that knowledge sharing activities for exploration (discovering new data, information, and knowledge) and knowledge sharing activities through written documents (knowledge that has been formally codified in writing and is available to be searched and put to work) can moderate the relationship between uncertain dynamic disaster management tasks and task performance [Becerra-Fernandez et al., 2008; Rocha et al., 2009; Xia et al., 2010; Xia et al., 2011].

Knowledge sharing for exploration can positively moderate the relationships among uncertain dynamic disaster management tasks with task novelty dimensions (newness and nonroutineness) because there is no previous knowledge available to perform a given task. 
Furthermore, the same positive moderation applies between uncertain dynamic disaster management tasks and task unanalyzability dimensions (the task difficulty and amount of task information) because EOC personnel and functional groups and related organizations want to have as much available knowledge so as to make a sound decision to successfully perform a given task in terms of task effectiveness [Becerra-Fernandez et al., 2008;

Rocha et al., 2009; Xia et al., 2011].

However, this positive moderation through knowledge sharing for exploration does not hold for those uncertain dynamic disaster management tasks with task significance dimensions (urgency and impact) because these tasks must be accomplished as soon as possible so as to prevent the loss of human life, serious infrastructure damage, and economic impact [Rocha et al., 2009]. Consequently, this research study conceptualized hypotheses H11 and H12, as shown in Figure 7 and outlined in the following paragraphs.

Knowledge sharing through written documents is conceptualized as knowledge that has been formally codified in writing and is available to be searched and put to work. For uncertain dynamic disaster management tasks with task novelty dimensions (newness and nonroutineness), knowledge-sharing mechanisms through written documents cannot positively moderate the relationship with task performance because there is no previous knowledge that is available to be shared through written documents [Becerra-Fernandez et al., 2008; Rocha et al., 2009; Xia et al., 2011]. 
Similarly, for uncertain dynamic disaster management tasks with the unanalyzability dimension of task difficulty, knowledge sharing through written documents cannot positively moderate this relationship with task performance because of the impediments "in seeing into the task and in analyzing it in terms of alternative courses of action, costs, benefits, and outcomes" [Daft and Macitosh, 1981, p. 209]. Given the extent of task difficulty, EOC personnel and functional groups and related organizations cannot immediately identify and apply the knowledge that is most applicable to a given task.

For uncertain dynamic disaster management tasks that feature the unanalyzability dimension of task information quantity and significance dimension (task urgency and task impact), knowledge sharing through written documents can positively moderate the relationship with task performance because increasing amounts information and knowledge that are available to perform the task improve the possibility of making sound decisions and meeting the requirements of the task being performed [Becerra-Fernandez et al., 2008; Xia et al., 2010; Xia et al., 2011]. Consequently, this research study conceptualized hypotheses H13 and H14, as shown in Figure 7 and outlined in the following paragraphs. 


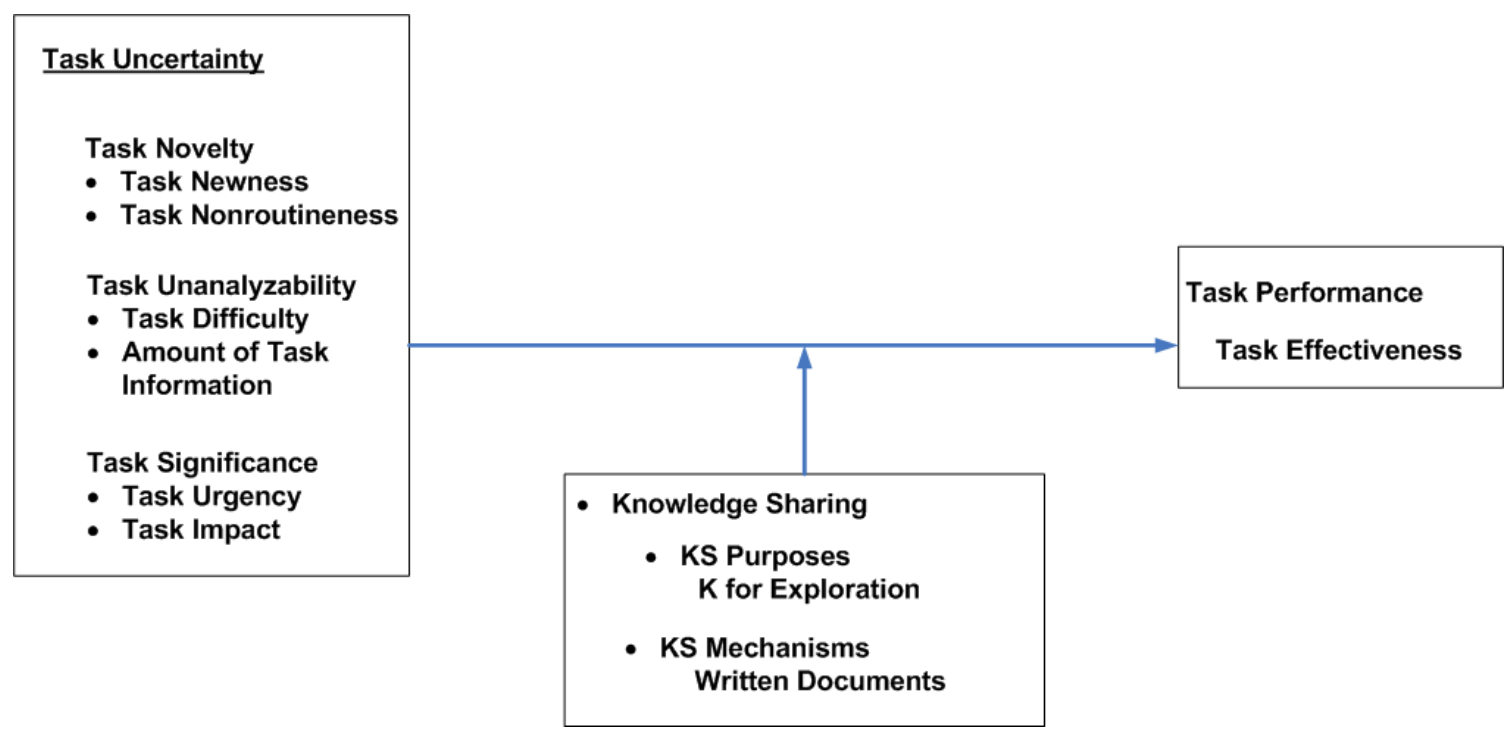

Figure 7. Uncertain dynamic disaster management tasks and knowledge sharing moderating direct effects on task effectiveness

Knowledge sharing moderating effects hypotheses

H11. Knowledge sharing for exploration positively moderates the relationship between uncertain dynamic task characteristics with novelty dimensions (task newness and task nonroutineness) and unanalyzability dimension (task difficulty and amount of task information) with task effectiveness

H12. Knowledge sharing for exploration negatively moderates the relationship between uncertain dynamic task characteristics with significance dimensions (task $\underline{\text { urgency }}$ and task impact) and task effectiveness

H13. Knowledge sharing through written documents negatively moderates the relationship between uncertain dynamic task characteristics with novelty dimensions (task newness and task nonroutineness) and unanalyzability dimension (task difficulty) with task effectiveness

H14. Knowledge sharing through written documents positively moderates the relationship between uncertain dynamic task characteristics with unanalyzability dimension (amount of task information) and significance dimensions (task urgency and task impact) and task effectiveness 
When EOC personnel and functional groups and related organizations face uncertain dynamic disaster management tasks, a combination of knowledge-sharing purposes and mechanisms can be used to meet the requirements of the task and the satisfaction levels of the stakeholders who are involved in the task being performed. According to the literature review that was performed for this research and interviews and field observations performed by the EOC, it appears that knowledge-sharing purposes through the dimension of knowledge sharing for exploration activities (discovering new data, information, and knowledge) can moderate the relationship between uncertain dynamic disaster management tasks and task performance when knowledge-sharing purposes through the dimension of knowledge sharing for exploitation and knowledge sharing mechanisms (personal contacts and written documents) help to predict this relationship [Becerra-Fernandez et al., 2008; Rocha et al., 2009; Xia et al., 2011].

Knowledge sharing for exploration cannot positively moderate the relationship of uncertain dynamic disaster management tasks with task novelty dimensions (newness and nonroutineness), task unanalyzability dimensions (task difficulty and the amount of task information), knowledge-sharing purposes through its dimension of knowledge sharing for exploitation and knowledge sharing mechanisms (personal contacts and written documents) because there is no previous information and knowledge about a given task, and the unstructured and equivocal degree of the task being performed leads to conflicting interpretations [Daft and Lengel, 1986; Daft and Macintosh, 1981; Dunegan, Duchon, and Uhlbien, 1992]. 
Therefore, there is no information or knowledge to share, whereas, if there is, EOC personnel and functional groups and related organizations cannot identify the pertinent information to share so as to support the decision-making process to successfully meet the requirements of a given task [Rocha et al., 2009]. Consequently, this research study conceptualized hypothesis H15, as shown in Figure 8 and outlined in the following paragraphs.

However, for the combination of uncertain dynamic disaster management tasks with task significance dimensions (urgency and significance), knowledge sharing for exploitation, and knowledge-sharing mechanisms (personal contacts and written documents), the moderating effect of knowledge sharing for exploration tends to positively affect the relationship with task performance. This positive moderation effect occurs because of the use of knowledge sharing for exploitation and knowledge-sharing mechanisms (personal contacts and written documents) for the exploration of a significance task wherein there is little or no room for failure [Rocha et al., 2009]. Consequently, this research study conceptualized hypothesis H16, as shown in Figure 8 and outlined in the following paragraphs. 


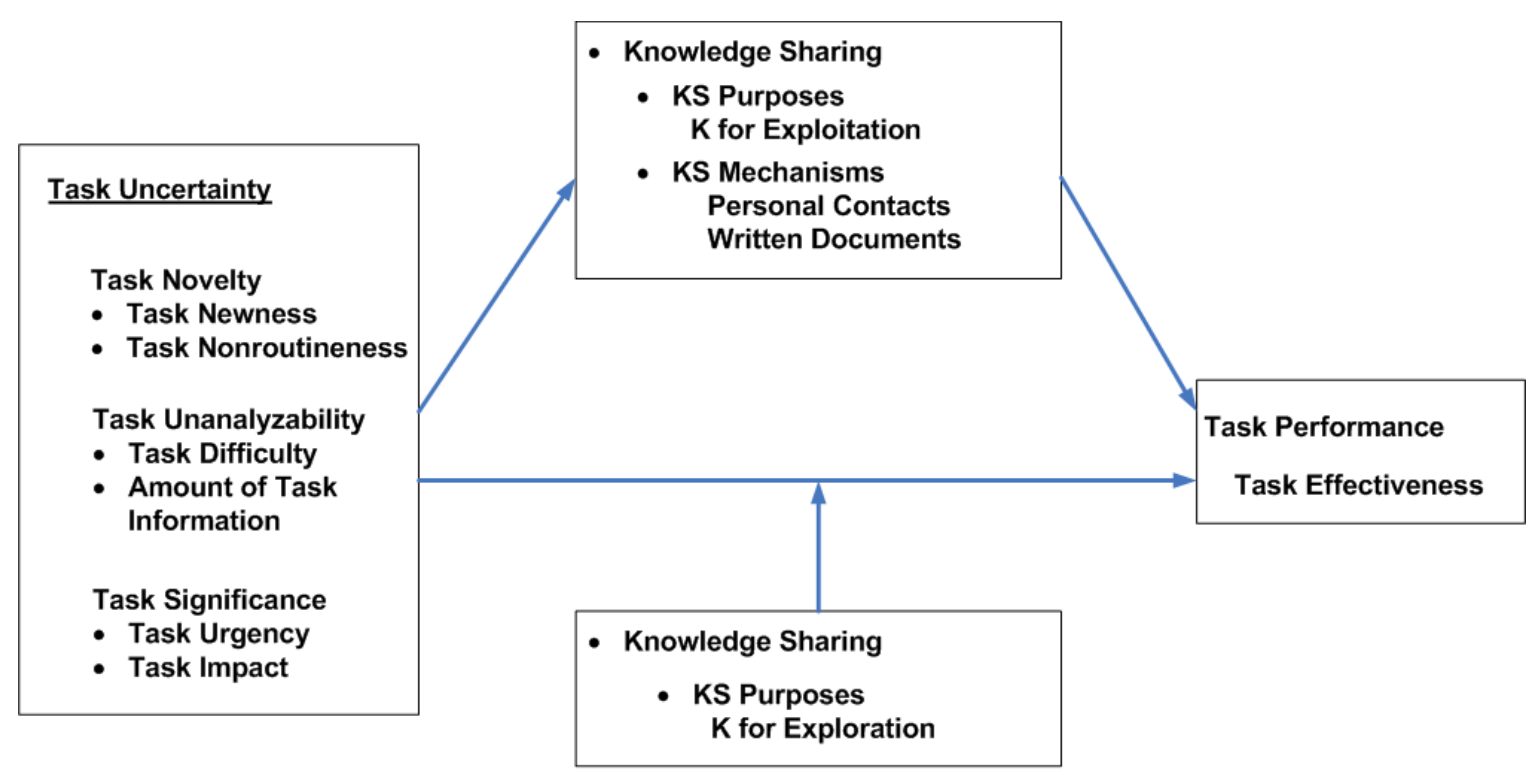

Figure 8. Uncertain dynamic disaster management tasks, knowledge sharing for exploitation, knowledge sharing through personal contacts and written documents, and knowledge sharing for exploration moderating effects on task effectiveness

Knowledge sharing moderating effects hypotheses

H15. Knowledge sharing for exploration negatively moderates the relationship between uncertain dynamic task characteristics with novelty dimensions (task newness and task nonroutineness) and unanalyzability dimension (task difficulty and amount of task information) along with knowledge sharing purposes (knowledge sharing for exploitation) and knowledge sharing mechanisms (knowledge sharing through personal contacts and knowledge sharing through written documents) with task effectiveness

H16. Knowledge sharing for exploration positively moderates the relationship between uncertain dynamic task characteristics with significance dimensions (task urgency and task impact) along with knowledge sharing purposes (knowledge sharing for exploitation) and knowledge sharing mechanisms (knowledge sharing through personal contacts and knowledge sharing through written documents) with task effectiveness 
Similarly as the previous set of hypotheses, the moderation effect of knowledge sharing for exploration can be assessed when uncertain dynamic disaster management tasks are being performed together with knowledge-sharing mechanisms (personal contacts and written documents) but without the time-consuming mining of information and knowledge of knowledge-sharing purposes through the dimension of knowledge sharing for exploitation. According to the literature review that was performed for this research and interviews and field observations that were performed by the EOC, EOC personnel and functional groups and related organizations often share knowledge on the "good enough" premises without mining for information and knowledge, given the uncertain dynamic characteristics of a given task and the pressing requirements of the task to be performed [Becerra-Fernandez et al., 2008; Rocha et al., 2009; Xia et al., 2010; Xia et al., 2011]. Consequently, this research study conceptualized hypotheses H17 and H18, as shown in Figure 9 and outlined in the following paragraphs. 


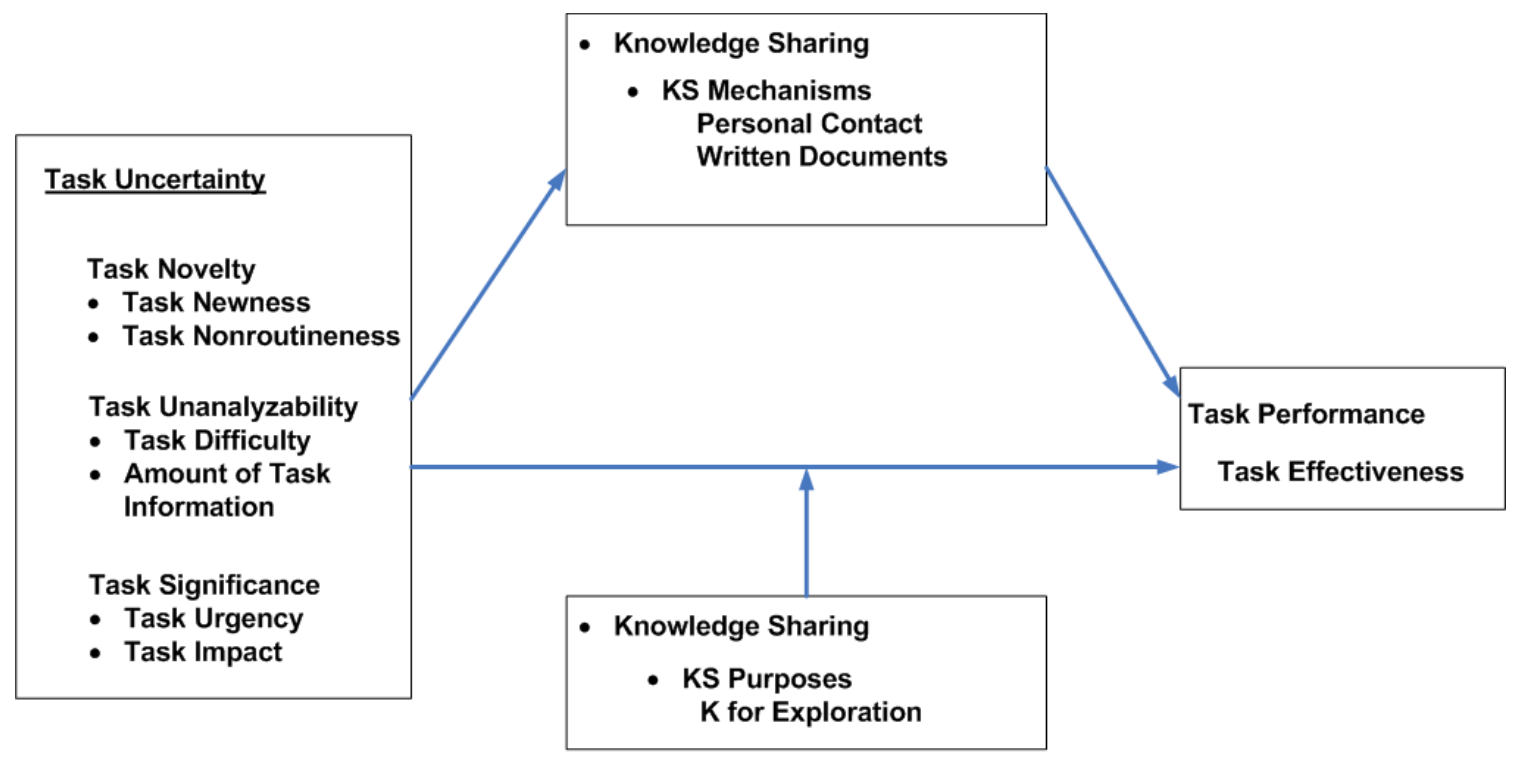

Figure 9. Uncertain dynamic disaster management tasks, knowledge sharing through personal contacts and knowledge sharing through written documents and knowledge sharing for exploration moderating effects on task effectiveness

Knowledge sharing moderating effects hypotheses

H17. Knowledge sharing for exploration negatively moderates the relationship between uncertain dynamic task characteristics with novelty dimensions (task newness and task nonroutineness) and unanalyzability dimension (task difficulty and amount of task information) along with knowledge sharing mechanisms (knowledge sharing through personal contacts and knowledge sharing through written documents) with task effectiveness

H18. Knowledge sharing for exploration positively moderates the relationship between uncertain dynamic task characteristics with significance dimensions (task urgency and task impact) along with knowledge sharing mechanisms (knowledge sharing through personal contacts and knowledge sharing through written documents) with task effectiveness 
When EOC personnel and functional groups and related organizations face uncertain dynamic disaster management tasks that must be completed within specific timeframes and there are limited budgets and scarce resources to accomplish a given task, a different combination of knowledge-sharing purposes and mechanisms is needed to moderate this relationships with task performance [Becerra-Fernandez et al., 2008; Xia et al., 2011]. According to the literature review that was performed for this research and interviews and field observations that were performed by the EOC, knowledge sharing for exploitation and through personal contacts can positively mediate the relationship between uncertain dynamic disaster management tasks and task performance with its dimension of task efficiency.

During a disaster management event or threat and according to the EOC schedule and planning guidelines, standard operating procedures, best practices, lessons learned, and after-action reports, good estimates of similar timeframes, budgets, and resources can be used to successfully perform a given task. The activities of knowledge sharing for exploitation, such as searching, experimenting, discovering, and innovating positively, support the performance of uncertain dynamic disaster management tasks to perform a given task with the available timeframes, budgets, and resources [Rocha et al., 2009; Xia et al., 2010]. Consequently, this research study conceptualized hypothesis H19, as shown in Figure 10 and outlined in the following paragraphs. 
Similarly, oftentimes, to comply with specific timeframes, budgets, and resources, sharing mechanisms through the dimension of knowledge sharing through personal contacts often play a significant role when EOC personnel, infrastructure groups, and related organizations utilize the experience and expertise of others to address the uncertain dynamic disaster management task being performed [Becerra-Fernandez et al., 2008; Xia et al., 2010; Xia et al., 2011]. Consequently, this research study conceptualized hypothesis H20, as shown in Figure 10 and outlined in the following paragraphs. 


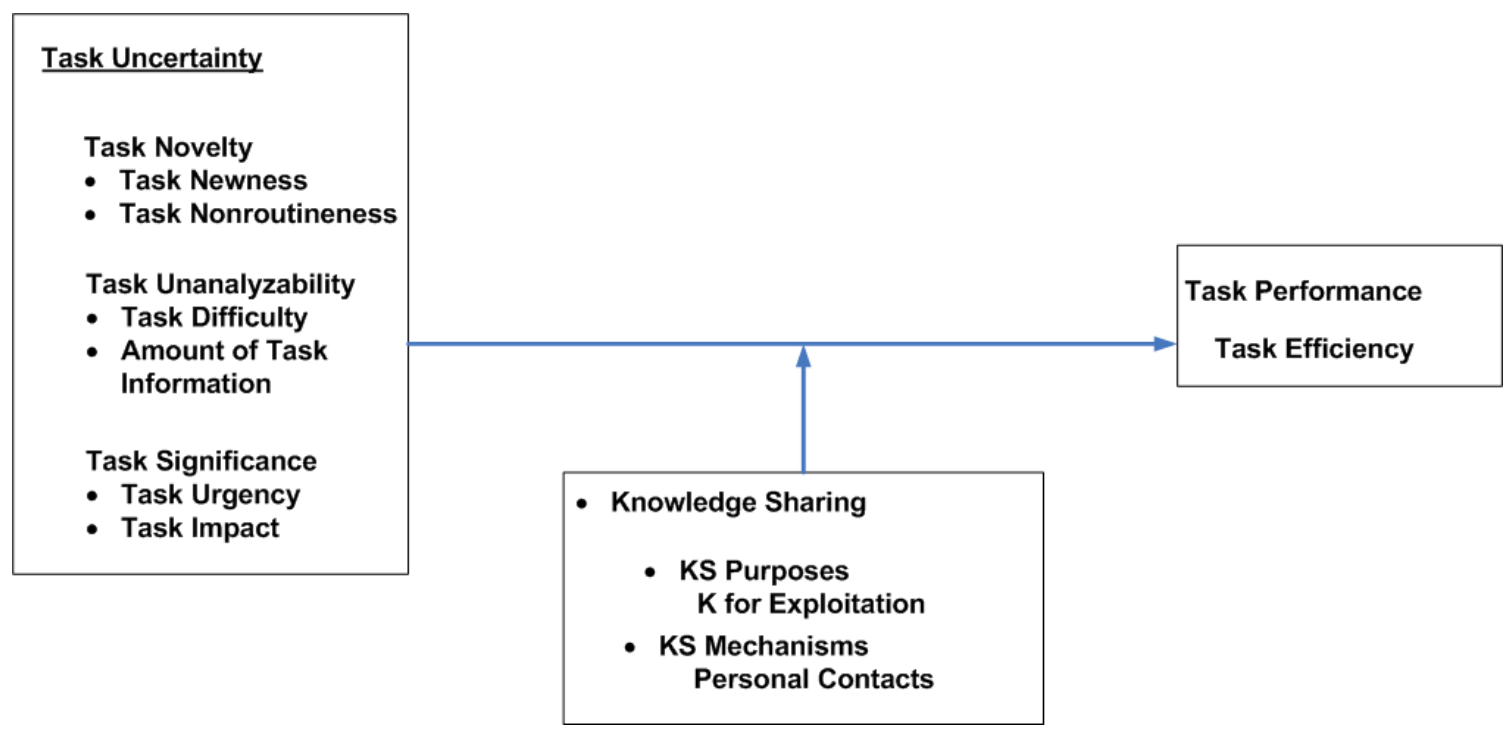

Figure 10. Uncertain dynamic disaster management tasks and knowledge sharing for exploitation and knowledge sharing through personal contacts moderating direct effects on task efficiency

\section{Knowledge sharing moderating effects hypotheses}

H19. Knowledge sharing for exploitation positively moderates the relationship between uncertain dynamic task characteristics with novelty dimensions (task newness and task nonroutineness), unanalyzability dimension (task difficulty and amount of task information), and significance dimensions (task urgency and task impact) with task efficiency

H20. Knowledge sharing through personal contacts positively moderates the relationship between uncertain dynamic task characteristics with novelty dimensions (task newness and task nonroutineness), unanalyzability dimension (task difficulty and amount of task information), and significance dimensions (task urgency and task impact) with task efficiency 
Similarly as the previous set of hypotheses (H15 and H17), the moderating effects of knowledge sharing for exploration can be assessed when uncertain dynamic disaster management tasks are being performed together with knowledge sharing for exploitation and knowledge-sharing mechanisms (personal contacts and written documents) [BecerraFernandez et al., 2008; Xia et al., 2011]. In assessing the moderating effect between knowledge-uncertain dynamic disaster management tasks and task performance and its dimension of task efficiency, specific timeframes, budgets, and resources are critical to the performing of a given task.

When EOC personnel and functional groups and related organizations face uncertain dynamic disaster management tasks, a combination of knowledge-sharing purposes and mechanisms can be used to meet the restricted timeframes and limited budgets and resources that apply to the task being performed. According to the literature review that was performed for this research and interviews and field observations that were performed by the EOC, it appears that activities of knowledge sharing for exploration (discovering new data, information, and knowledge) can moderate the relationship between uncertain dynamic disaster management tasks and task performance and its dimension of task efficiency when knowledge sharing for exploitation and knowledge-sharing mechanisms (personal contacts and written documents) help to predict this relationship [Becerra-Fernandez et al., 2008; Rocha et al., 2009; Xia et al., 2011]. 
Knowledge sharing for exploration positively moderates the relationship of uncertain dynamic disaster management tasks with task novelty dimensions (newness and nonroutineness), task unanalyzability dimensions (task difficulty and amount of task information), task significance dimensions (urgency and impact), and knowledge sharing for exploitation and knowledge-sharing mechanisms (personal contacts and written documents) [Becerra-Fernandez et al., 2008; Rocha et al., 2009; Xia et al., 2010; Xia et al., 2011]. This positive moderation effect occurs because the use of knowledge sharing for exploitation and knowledge-sharing mechanisms (personal contacts and written documents) through the activities of knowledge sharing for exploration help EOC personnel and functional groups and related organizations to share as much data, information, and knowledge as possible so as to maximize the performance of a given task within the restricted timeframes, controlled budgets, and limited resources available [Rocha et al., 2009; Xia et al., 2010]. Consequently, this research study conceptualized hypothesis H21, as shown in Figure 11 and outlined in the following paragraphs. 


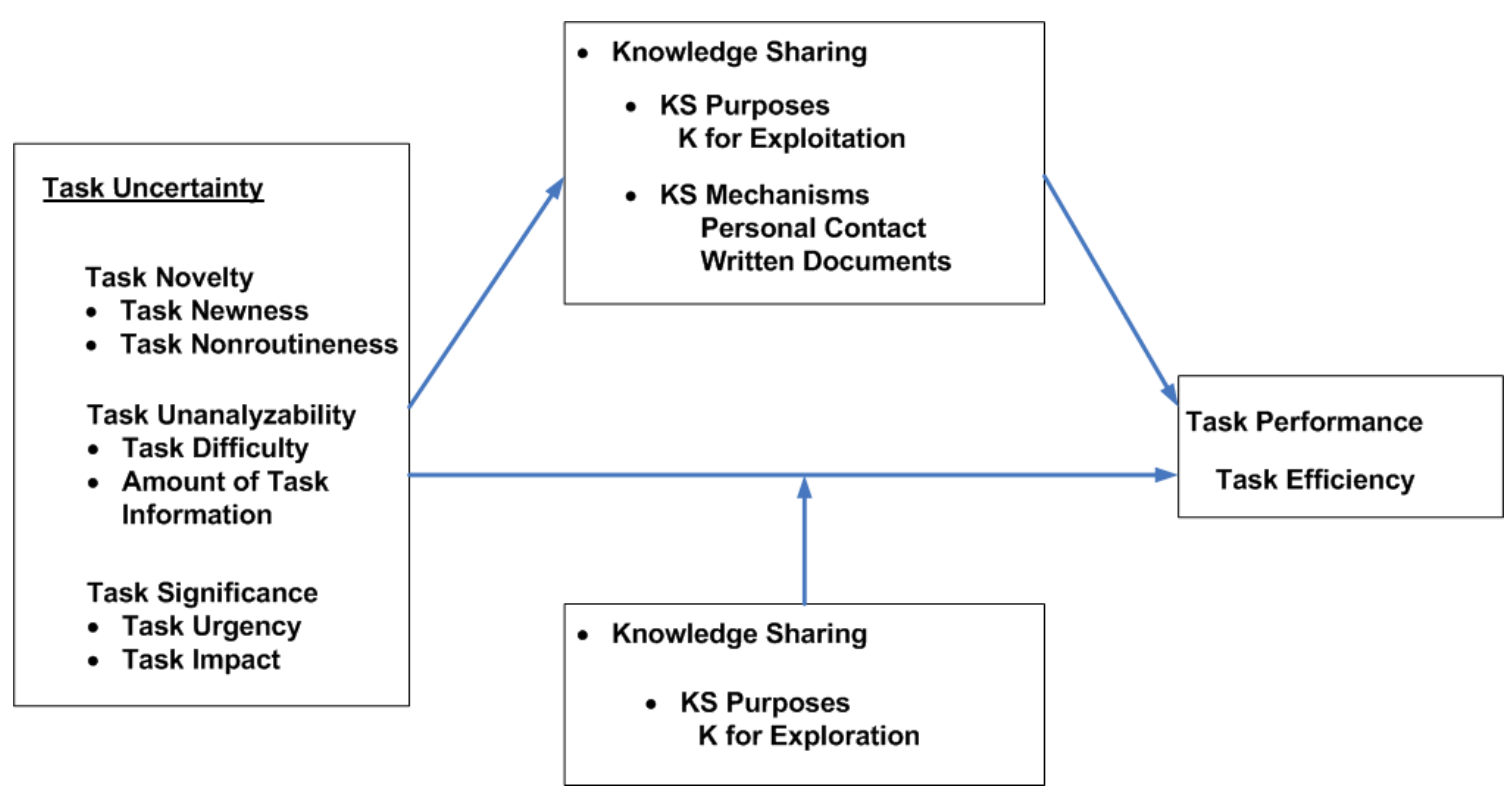

Figure 11. Uncertain dynamic disaster management tasks, knowledge sharing for exploitation, knowledge sharing through personal contacts, knowledge sharing through written documents, and knowledge sharing for exploitation moderating effects on task efficiency

Knowledge sharing moderating effects hypothesis

H21. Knowledge sharing for exploration positively moderates the relationship between uncertain dynamic task characteristics with novelty dimensions (task newness and task nonroutineness), unanalyzability dimension (task difficulty and amount of task information), and significance dimensions (task urgency and task impact) along with knowledge sharing purposes (knowledge sharing for exploitation) and knowledge sharing mechanisms (knowledge sharing through personal contacts and knowledge sharing through written documents) with task efficiency 


\subsubsection{Research Hypotheses for Mediating Effects}

Given the relationships that were described in previous sections between uncertain disaster management tasks and task performance, it is expected that these relationships could be affected by a mediator-intervening variable, such as knowledge sharing. Consequently, this research study conceptualized hypotheses H22, H23, H24, $\mathrm{H} 25,26, \mathrm{H} 27, \mathrm{H} 28$, and H29, as shown in Figure 12 and outlined in the following paragraphs.

Mediation effects are given by the inclusion of a third explanatory variable that helps to predict the relationship between an independent set of variables and a dependent variable. In order to assess the mediation effects between dependent and independent variables, the inclusion of a mediating variable in this relationship should significantly reduce the direct effect of the relationship between the independent and dependent variables. As a result, the mediator variable helps to explain the significant relationship between the independent variable(s) and the dependent variable [Iacobucci, 2008, p. 1].

As previously described, because of the nature of uncertain dynamic disaster management tasks, they are prone to failure in terms of task performance. Nevertheless, according to the literature review, interviews, and field observations that were conducted for this research, knowledge sharing through the dimensions of knowledge-sharing purposes and mechanisms can enable a significant relationship between uncertain dynamic disaster management tasks and task performance. 
When EOC personnel and functional groups and related organizations face uncertain dynamic disaster management tasks, a combination of knowledge-sharing purposes and mechanisms could be used as a means to exert a significant effect on task performance.

The inclusion of knowledge sharing for exploration in terms of discovering new data, information, and knowledge; knowledge sharing for exploitation in terms of directly searching and using existing knowledge; knowledge sharing through personal contacts in terms of the individual who possesses experience and expertise that is not easily articulated and formally codified in writing and is easier and faster to share this through personal interactions about the task being performed; and knowledge sharing through written documents in terms of knowledge that has been formally codified in writing and is available to be searched and put to work as a mediator of activities between uncertain dynamic disaster management tasks and task performance could help to explain the significant relationships between these two variables [Becerra-Fernandez et al., 2008; Rocha et al., 2009; Xia et al., 2010; Xia et al., 2011]. Specifically, these mediation effects can explain why uncertain dynamic disaster management tasks have a significant relationship with the requirements and levels of satisfaction for all disaster management stakeholders who are involved in performing a given task. 
As result, it is expected that the dimensions of knowledge-sharing purposes (exploration and exploitation) and mechanisms (personal contacts and written documents) can significantly reduce the direct effects of uncertain dynamic disaster management tasks and their dimensions of task novelty (newness and nonroutineness), task unanalyzability (task difficulty and amount of task information), and task significance (urgency and impact) on task performance and its dimension of task effectiveness [Becerra-Fernandez et al., 2008; Rocha et al., 2009; Xia et al., 2010; Xia et al., 2011]. Consequently, this research study conceptualized hypotheses H22, H23, H24, and H25, as shown in Figure 12 and outlined in the following paragraphs.

Similarly as the previous set of hypotheses (H22, H23, H24, and H25), the mediating effects of knowledge sharing for exploration and exploitation and knowledge sharing through personal contacts and written documents can be assessed through the relationship between knowledge-uncertain dynamic disaster management tasks and task performance with its dimension of task efficiency in terms of specific timeframes, budgets, and resources in performing a given task.

Similarly, when EOC personnel and functional groups and related organizations face uncertain dynamic disaster management tasks and their dimensions of task novelty (newness and nonroutineness), task unanalyzability (task difficulty and amount of task information), and task significance (urgency and impact), these people and organizations use a combination of knowledge-sharing purposes and mechanisms to respond to a given task [Becerra-Fernandez et al., 2008; Rocha et al., 2009; Xia et al., 2010; Xia et al., 2011]. 
This specifically occurs when uncertain dynamic disaster management tasks are influenced by restricted timeframes, controlled budgets, and limited resources for performing a given task. As a result, it is expected that the dimensions of knowledgesharing purposes (exploration and exploitation) and mechanisms (personal contacts and written documents) can significantly reduce the direct effects of uncertain dynamic disaster management tasks and their dimensions of task novelty (newness and nonroutineness), task unanalyzability (task difficulty and amount of task information), and task significance (urgency and impact) on task performance and its dimension of task efficiency [Becerra-Fernandez et al., 2008; Rocha et al., 2009; Xia et al., 2010; Xia et al., 2011]. Consequently, this research study conceptualizes hypotheses H26, H27, H28, and H29 shown in Figure 12 and outlined in the following paragraphs 


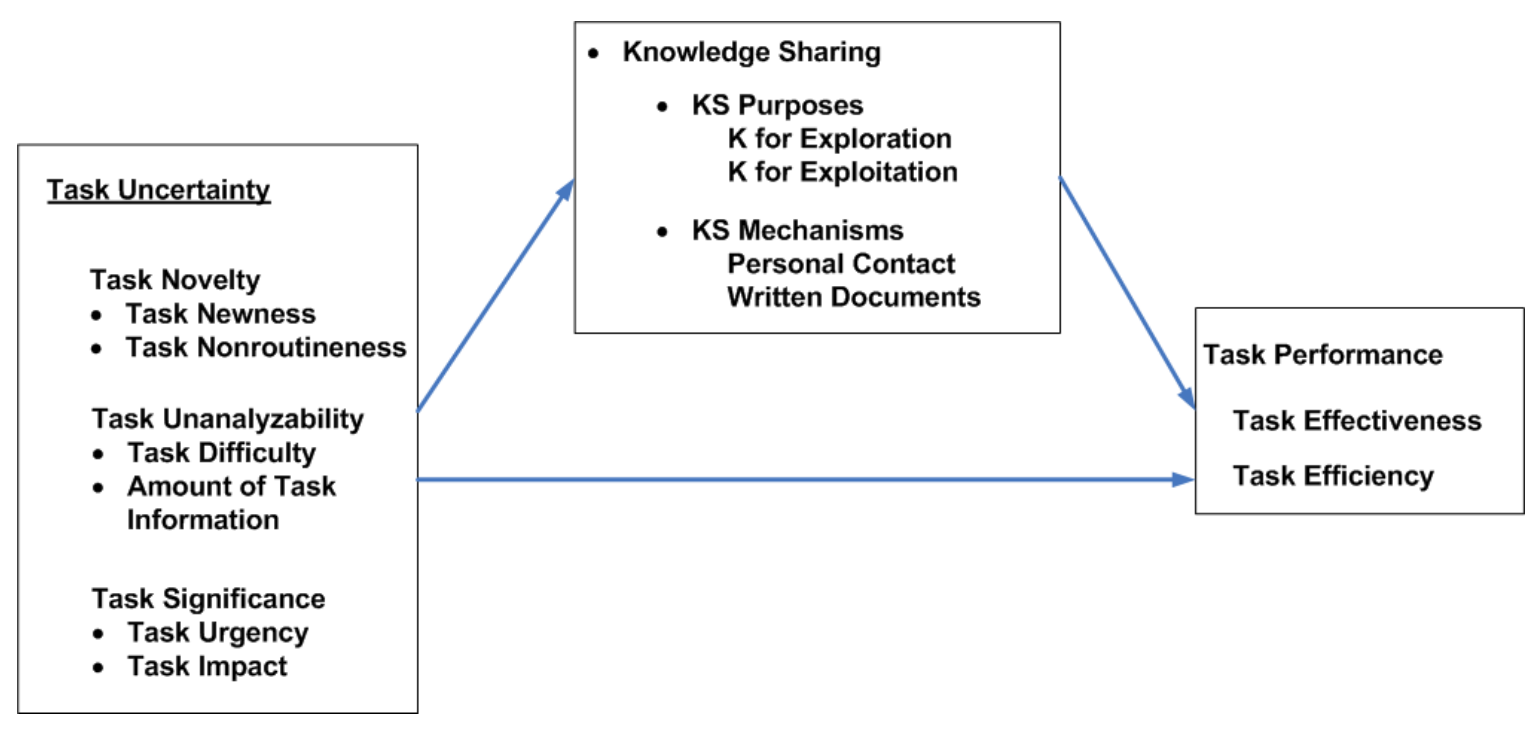

Figure 12. Knowledge sharing mediating effects between uncertain dynamic disaster management tasks and task performance

Knowledge sharing mediates the relationship between uncertain dynamic disaster management tasks and task performance hypotheses

H22. Knowledge sharing purposes and its dimension of knowledge sharing for exploration mediates the relationship between uncertain dynamic disaster management tasks and task effectiveness

H23. Knowledge sharing purposes and its dimension of knowledge sharing for exploitation mediates the relationship between uncertain dynamic disaster management tasks and task effectiveness

H24. Knowledge sharing mechanisms and its dimension of knowledge sharing through personal contacts mediates the relationship between uncertain dynamic disaster management tasks and task effectiveness

H25. Knowledge sharing mechanisms and its dimension of knowledge sharing through written documents mediates the relationship between uncertain dynamic disaster management tasks and task effectiveness 
H26. Knowledge sharing purposes and its dimension of knowledge sharing for exploration mediates the relationship between uncertain dynamic disaster management tasks and task efficiency

H27. Knowledge sharing purposes and its dimension of knowledge sharing for exploitation mediates the relationship between uncertain dynamic disaster management tasks and task efficiency

H28. Knowledge sharing mechanisms and its dimension of knowledge sharing through personal contacts mediates the relationship between uncertain dynamic disaster management tasks and task efficiency

H29. Knowledge sharing mechanisms and its dimension of knowledge sharing through written documents mediates the relationship between uncertain dynamic disaster management tasks and task efficiency

\subsubsection{Research Hypotheses for Knowledge Sharing Moderating-Mediating Interaction Effects between Uncertain Dynamic Disaster Management Tasks and Task Performance}

\subsubsection{Research Hypotheses for Moderating-Interaction Effects}

According to the literature review that was performed for this research and interviews and field observations that were performed by the EOC, the previous sections of this manuscript addressed the direct, moderating, and mediating hypotheses effects in a piecemeal approach between uncertain dynamic disaster management tasks, knowledge sharing, and task performance. 
This piecemeal approach to formulating the previous hypotheses intended to isolate the direct, moderating, and mediating effects between uncertain dynamic disaster management tasks and task performance through each knowledge sharing dimension: knowledge-sharing purposes (exploration and exploitation) and knowledge-sharing mechanisms (personal contacts and written documents); however, when EOC personnel and functional groups and related organizations face uncertain dynamic disaster management tasks, combinations of knowledge-sharing purposes (exploration and exploitation) and mechanisms (personal contacts and written documents) are available for use according to the uncertain dynamic characteristics of the task being performed [Becerra-Fernandez et al., 2008; Rocha et al., 2009; Xia et al., 2010; Xia et al., 2011].

According to previous paragraphs, during a disaster management event or threat, unexpected and significant circumstances can occur, and knowledge sharing can play a simultaneous role in moderating and mediating the relationship between uncertain disaster management tasks and task performance. These assessments can be conducted through simultaneous interaction effects between each dimension of uncertain disaster management tasks (task novelty, task unanalyzability, and task significance), knowledge sharing (knowledge-sharing purposes and mechanisms), and task performance (task effectiveness and task efficiency) [Becerra-Fernandez et al., 2008; Rocha et al., 2009; Xia et al., 2010]. 
As previously stated, given the characteristics and dimensions of uncertain disaster management tasks, it is expected that the relationship between uncertain disaster management tasks and task performance could be affected by the moderating effects and the levels of knowledge sharing that are utilized in assessing, approaching, and successfully resolving a given task. The use of knowledge sharing to moderate the relationship between uncertain disaster management tasks and task performance is expected to change the strength and/or direction of this relationship.

When EOC personnel and functional groups and related organizations face uncertain dynamic disaster management tasks, they must appropriately respond to meet the task requirements and achieve reasonable levels of satisfaction among all disaster management stakeholders who are involved in a given task. Therefore, EOC personnel and functional groups and related organizations utilize different knowledge-sharing purposes and mechanisms to effectively accomplish the task being performed [BecerraFernandez et al., 2008; Xia et al., 2011].

According to the literature review performed for this research and interviews and field observations that were performed by the EOC, it appears that the activities of knowledge sharing for exploration (discovering new data, information, and knowledge) and knowledge sharing through personal contact (an individual who possesses experience and expertise that is difficult to articulate and formally codify in writing and is more easily and rapidly shared through personal interactions regarding the task being performed) can moderate the relationship between uncertain dynamic disaster management tasks and task performance [Becerra-Fernandez et al., 2008; Xia et al., 2011]. 
Knowledge sharing for exploration can positively moderate the relationship between uncertain dynamic disaster management tasks with task novelty dimensions (newness and nonroutineness) and task effectiveness because there is no previous knowledge available to perform a given task in terms of meeting the task requirements and ensuring that the task results are satisfactory for all parties involved [Rocha et al., 2009]. Furthermore, the same positive moderation applies between uncertain dynamic disaster management tasks and task unanalyzability dimensions (task difficulty and the amount of task information) because EOC personnel and functional groups and related organizations want to have as much available knowledge as possible so as to make a sound decision and successfully perform a given task in terms of task effectiveness. Similarly, the same positive moderation holds between uncertain dynamic disaster management tasks, task significance dimensions (task urgency and task impact), and task effectiveness, given the high stakes of task significance in terms of human lives and economic repercussions [Rocha et al., 2009].

Consequently, this research study conceptualized hypothesis H30, as shown in Figure 13 and outlined in the following paragraphs.

In addition, knowledge sharing through personal contacts can positively moderate the relationships between uncertain dynamic disaster management tasks, task novelty dimensions (newness and nonroutineness), and task effectiveness because there is no previous knowledge that is available to perform a given task; therefore, EOC personnel and functional groups and related organizations want to integrate as much of the experiences and expertise of others as possible so as to make a sound decision. 
Similarly, the same positive moderation applies between uncertain dynamic disaster management tasks, task unanalyzability dimensions (task difficulty and the amount of task information), and task effectiveness because EOC personnel and functional groups and related organizations want to have as much data, information, and knowledge as possible so as to meet the requirements of the task and ensure that the task results are satisfactory for all of the stakeholders who are involved. Furthermore, the moderating role of knowledge sharing through personal contacts plays a relevant role between uncertain dynamic disaster management tasks and task significance dimensions (task urgency and task impact) and task effectiveness due to the significant nature of these tasks in terms of risk and consequences [Becerra-Fernandez et al., 2008; Xia et al., 2011].

For this reason, EOC personnel and functional groups and related organizations take advantage of knowledge sharing through personal contacts so as to support one another's decisions in terms of data, information, and knowledge in the fastest possible way (i.e., face-to-face) so as to successfully accomplish a given task. Consequently, this research study conceptualized hypothesis H32, as shown in Figure 13 and outlined in the following paragraphs. 
However, when EOC personnel and functional groups and related organizations simultaneously use knowledge-sharing purposes and mechanisms, according to the literature review performed for this research and interviews and field observations performed by the EOC, knowledge sharing for exploitation and through personal contacts negatively moderates the relationship between uncertain dynamic disaster management tasks and task performance [Becerra-Fernandez et al., 2008; Rocha et al., 2009; Xia et al., 2010; Xia et al., 2011].

During a disaster management event or threat, EOC personnel and infrastructure groups and related organizations tend to rely on knowledge sharing activities for exploitation, such as searching, experimenting, discovering, and innovating according to the EOC schedule and planning guidelines, in addition to standard operating procedures, best practices, lessons learned, and after-action reports [Rocha et al., 2009].

Often, these activities are time consuming, specifically when facing uncertain dynamic disaster management tasks with task novelty dimensions (newness and nonroutineness), task unanalyzability dimensions (task difficulty and the amount of task information), and task significance dimensions (task urgency and task impact). Given the characteristics of these tasks and their novelty, analyzability, and significance, there is a limited amount of time to perform a given task, and knowledge sharing activities for exploitation require time to obtain all of the necessary data, information, and knowledge so as to make a decision in regards to meeting the requirements of a given task and ensuring that the task results are satisfactory for all of the stakeholders who are involved [Becerra-Fernandez et al., 2008; Rocha et al., 2009; Xia et al., 2010; Xia et al., 2011]. 
Consequently, this research study conceptualized hypothesis H31, as shown in Figure 13 and outlined in the following paragraphs.

Knowledge-sharing mechanisms through written documents are conceptualized as knowledge that has been formally codified in writing and is available to be searched and put to work. For uncertain dynamic disaster management tasks with task novelty dimensions (newness and nonroutineness), knowledge-sharing mechanisms through written documents cannot positively moderate the relationship with task performance because there is no previous knowledge available that can be shared through written documents [Becerra-Fernandez et al., 2008; Xia et al., 2011]. Similarly, for uncertain dynamic disaster management tasks with the unanalyzability dimensions of task difficulty and task information amount, knowledge sharing through written documents cannot positively moderate the relationship with task performance because of the impediments "in seeing into the task and in analyzing it in terms of alternative courses of action, costs, benefits, and outcomes" [Daft and Macitosh, 1981, p. 209]. For uncertain dynamic disaster management tasks with task significance (urgency and impact) dimensions, the reduced time to accomplish the task plays a relevant role that cannot be supported by the moderating effect of knowledge sharing through written documents [Becerra-Fernandez et al., 2008; Xia et al., 2011]. Consequently, this research study conceptualized hypothesis H33, as shown in Figure 13 and outlined in the following paragraphs. 


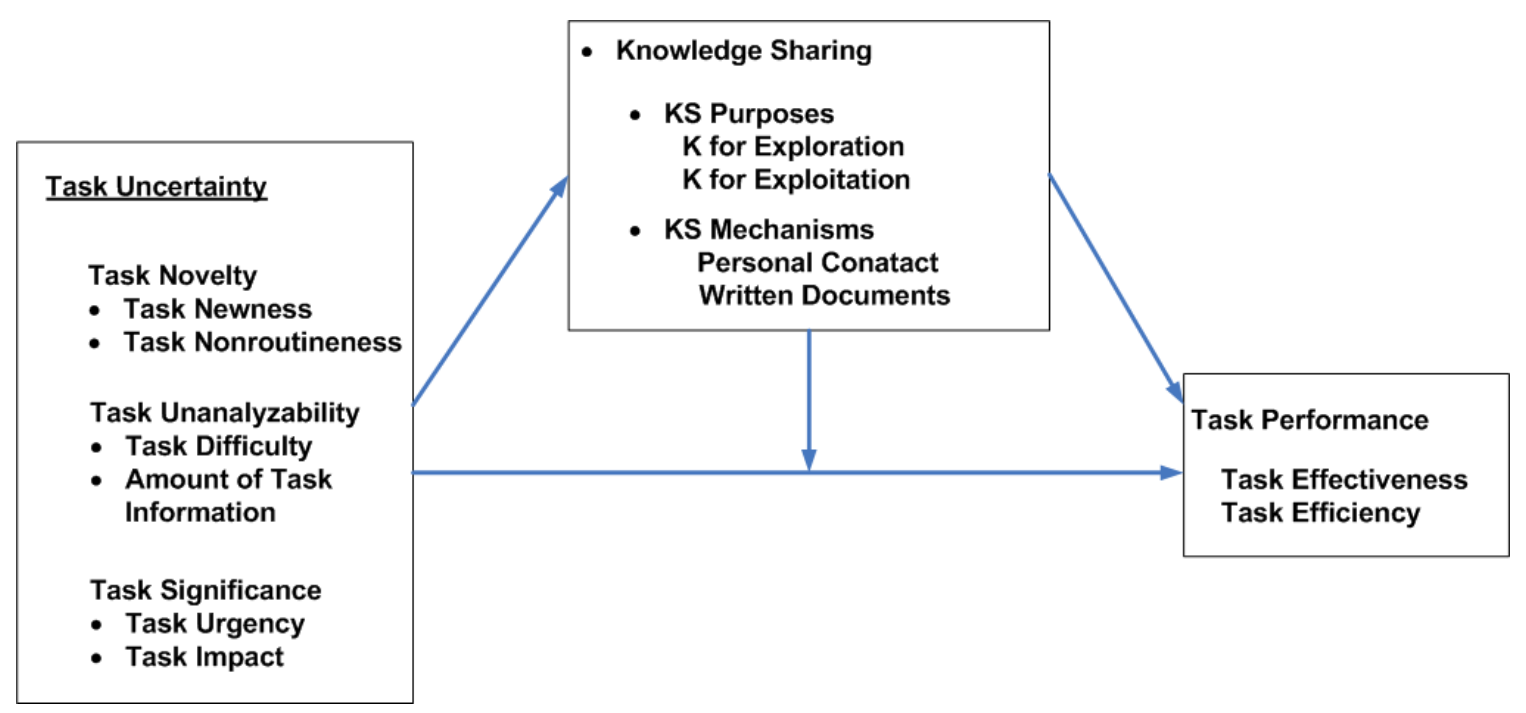

Figure 13. Knowledge sharing moderating-mediating interaction effects between uncertain dynamic disaster management tasks and task performance

Knowledge sharing moderating-interaction effects hypotheses between uncertain dynamic disaster management tasks and task performance

H30. Knowledge sharing for exploration positively moderates the relationship between uncertain dynamic task characteristics with novelty dimensions (task newness and task nonroutineness), unanalyzability dimension (task difficulty and amount of task information), and significance dimensions (task urgency and task impact) with task effectiveness

H31. Knowledge sharing for exploitation negatively moderates the relationship between uncertain dynamic task characteristics with novelty dimensions (task newness and task nonroutineness), unanalyzability dimension (task difficulty and amount of task information), and significance dimensions (task urgency and task impact) with task effectiveness

H32. Knowledge sharing through personal contacts positively moderates the relationship between uncertain dynamic task characteristics with novelty dimensions (task newness and task nonroutineness), unanalyzability dimension (task difficulty and amount of task information), and significance dimensions (task urgency and task impact) with task effectiveness

H33. Knowledge sharing through written documents negatively moderates the relationship between uncertain dynamic task characteristics with novelty dimensions (task newness and task nonroutineness), unanalyzability dimension (task difficulty and amount of task information), and significance dimensions (task urgency and task impact) with task effectiveness 
When EOC personal and functional groups and related organizations face uncertain dynamic disaster management tasks in terms of task performance and its dimension of task efficiency, a given task must be accomplished in compliance with the required timeframes, budgets, and resources available and/or allocated for the task being performed. As a result, EOC personnel and functional groups and related organizations can make use of a combination of knowledge-sharing purposes and mechanisms so as to have a significant effect on task performance and its dimension of task efficiency. The use of knowledge sharing for exploration in terms of discovering new data, information, and knowledge; knowledge sharing for exploitation in terms of directly searching and using existing knowledge; knowledge sharing through personal contacts in terms of the individual who possesses experience and expertise that is difficult to articulate and formally codify in writing and is more easily and rapidly shared through personal interactions regarding the task being performed; and knowledge sharing through written documents in terms of knowledge that has been formally codified in writing and is available to be searched and put to work as a positive mediator of activities between uncertain dynamic disaster management tasks and task performance and its dimension of task efficiency could help explain the significant relations between these two variables [Becerra-Fernandez et al., 2008; Rocha et al., 2009; Xia et al., 2010; Xia et al., 2011]. 
Specifically, these knowledge-sharing mediation effects could explain why uncertain dynamic disaster management tasks have a significant relationship in meeting the required timeframes, budgets, and resources in performing a given task.

Based on EOC schedule and planning guidelines, standard operating procedures, best practices, lessons learned, and after-action reports, EOC personal and functional groups and related organizations have a good estimate of the needed timeframes, budgets, and resources that a mix of uncertain dynamic disaster management tasks might require to be efficiently performed. The relevance for EOC personal and functional groups and related organizations to meet the required timeframes, restricted budgets, and limited resources of the task being performed is derived from the fact that there are other tasks that need to be performed, either at the same time or on a waiting queue, and they will require the same pool of budgets and available resources [Becerra-Fernandez et al., 2008; Xia et al., 2011].

According to the literature review that was performed for this research and interviews and field observations that were performed by the EOC, it is expected that the dimensions of knowledge-sharing purposes (exploration and exploitation) and mechanisms (personal contacts and written documents) can positively moderate the relationship between uncertain dynamic disaster management tasks and their dimensions of task novelty (newness and nonroutineness), task unanalyzability (task difficulty and the amount of task information), task significance (urgency and impact), and task performance and its dimension of task efficiency [Becerra-Fernandez et al., 2008; Rocha et al., 2009; Xia et al., 2010; Xia et al., 2011]. 
Consequently, this research study conceptualized the moderating-interaction effects

hypotheses of the dimensions of knowledge-sharing purposes (exploration and

exploitation) and knowledge-sharing mechanisms (personal contacts and written

documents) for the relationship between uncertain disaster management tasks and task

performance and its dimension of task efficiency via hypotheses $\mathrm{H} 34, \mathrm{H} 35, \mathrm{H} 36$, and

H37, as shown in Figure 13 and outlined in the following paragraphs.

H34. Knowledge sharing for exploration positively moderates the relationship between uncertain dynamic task characteristics with novelty dimensions (task newness and task nonroutineness), unanalyzability dimension (task difficulty and amount of task information), and significance dimensions (task urgency and task impact) with task efficiency

H35. Knowledge sharing for exploitation positively moderates the relationship between uncertain dynamic task characteristics with novelty dimensions (task newness and task nonroutineness), unanalyzability dimension (task difficulty and amount of task information), and significance dimensions (task urgency and task impact) with task efficiency

H36. Knowledge sharing through personal contacts positively moderates the relationship between uncertain dynamic task characteristics with novelty dimensions (task newness and task nonroutineness), unanalyzability dimension (task difficulty and amount of task information), and significance dimensions (task urgency and task impact) with task efficiency

H37. Knowledge sharing through written documents positively moderates the relationship between uncertain dynamic task characteristics with novelty dimensions (task newness and task nonroutineness), unanalyzability dimension (task difficulty and amount of task information), and significance dimensions (task urgency and task impact) with task efficiency 


\subsubsection{Research Hypotheses for Mediating Effects}

As previously stated in the earlier research hypotheses of mediating effects, given the relationships that were described in the prior sections between uncertain disaster management tasks and task performance, it is expected that these relationships could be affected by a mediator-intervening variable, such as knowledge sharing. Consequently, through interaction effects, this research study conceptualized hypotheses H38, H39, $\mathrm{H} 40, \mathrm{H} 41, \mathrm{H} 42, \mathrm{H} 43, \mathrm{H} 44$, and H45, as shown in Figure 13 and outlined in the following paragraphs.

Mediation effects are given by the inclusion of a third explanatory variable that helps to predict the relationship between an independent set of variables and a dependent variable. To assess the mediation effects between independent and dependent variables, the inclusion of the mediating variable in this relationship should significantly reduce the direct effect in the relationship between the independent and dependent variables.

As a result, the mediator variable helps to explain the significant relationship between the independent variable(s) and the dependent variable [Iacobucci, 2008].

As previously described, because of the nature of uncertain dynamic disaster management tasks, they are prone to failure in terms of task performance. Nevertheless, according to the literature review, interviews, and field observations that were conducted for this research, knowledge sharing through its dimensions of knowledge-sharing purposes and knowledge-sharing mechanisms can enable a significant relationship between uncertain dynamic disaster management tasks and task performance. 
When EOC personnel and functional groups and related organizations face uncertain dynamic disaster management tasks, a combination of knowledge-sharing purposes and mechanisms could be used as a means to exert a significant effect on task performance [Becerra-Fernandez et al., 2008; Rocha et al., 2009; Xia et al., 2010; Xia et al., 2011].

The inclusion of knowledge sharing for exploration in terms of discovering new data, information, and knowledge; knowledge sharing for exploitation in terms of directly searching and using existing knowledge; knowledge sharing through personal contacts in terms of the individual who possesses experience and expertise that is difficult to articulate and formally codify in writing and is easier and faster to share through personal interactions about the task being performed; and knowledge sharing through written documents in terms of knowledge that has been formally codified in writing and is available to be searched and put to work as a mediator of activities between uncertain dynamic disaster management tasks and task performance could help to explain the significant relations between these two variables [Becerra-Fernandez et al., 2008; Rocha et al., 2009; Xia et al., 2011]. Specifically, these mediation effects can explain why uncertain dynamic disaster management tasks have a significant relationship with the requirements and the levels of satisfaction for all disaster management stakeholders who are involved in performing a given task. 
As result, it is expected that the dimensions of knowledge-sharing purposes (exploration and exploitation) and mechanisms (personal contacts and written documents) can significantly reduce the direct effects of uncertain dynamic disaster management tasks and their dimensions of task novelty (newness and nonroutineness), task unanalyzability (task difficulty and amount of task information), and task significance (urgency and impact) on task performance and its dimension of task effectiveness [Becerra-Fernandez et al., 2008; Rocha et al., 2009; Xia et al., 2010; Xia et al., 2011]. Consequently, this research study conceptualized hypotheses H38, H39, H40, and H41, as shown in Figure 13 and outlined in the following paragraphs.

Knowledge sharing mediating-interaction effects hypotheses between uncertain dynamic disaster management tasks and task performance

H38. Knowledge sharing purposes and its dimension of knowledge sharing for exploration mediates the relationship between uncertain dynamic disaster management tasks and task effectiveness

H39. Knowledge sharing purposes and its dimension of knowledge sharing for exploitation mediates the relationship between uncertain dynamic disaster management tasks and task effectiveness

H40. Knowledge sharing mechanisms and its dimension of knowledge sharing through personal contacts mediates the relationship between uncertain dynamic disaster management tasks and task effectiveness

H41. Knowledge sharing mechanisms and its dimension of knowledge sharing through written documents mediates the relationship between uncertain dynamic disaster management tasks and task effectiveness 
Similarly as in the previous set of hypotheses (H38, H39, H40, and H41), the mediating effects of knowledge sharing for exploration and exploitation, in addition to knowledge sharing mechanisms, through personal contacts and written documents can be assessed through the relationship between knowledge-uncertain dynamic disaster management tasks and task performance with its dimension of task efficiency in terms of specific timeframes, budgets, and available resources for performing a given task [Becerra-Fernandez et al., 2008; Rocha et al., 2009; Xia et al., 2010; Xia et al., 2011].

Similarly, when EOC personnel and functional groups and related organizations face uncertain dynamic disaster management tasks and its dimensions of task novelty (newness and nonroutineness), task unanalyzability (task difficulty and amount of task information), and task significance (urgency and impact), these people and organizations use a combination of knowledge-sharing purposes and mechanisms to respond to a given task. This is specifically true when uncertain dynamic disaster management tasks are subject to restricted timeframes, controlled budgets, and limited available resources to perform a given task. 
As a result, it is expected that the dimensions of knowledge-sharing purposes (exploration and exploitation) and mechanisms (personal contacts and written documents) can significantly reduce the direct effects of uncertain dynamic disaster management tasks and their dimensions of task novelty (newness and nonroutineness), task unanalyzability (task difficulty and amount of task information), and task significance (urgency and impact) on task performance and its dimension of task efficiency [Becerra-Fernandez et al., 2008; Rocha et al., 2009; Xia et al., 2010; Xia et al., 2011]. Consequently, this research study conceptualized hypotheses H42, H43, H44, and H45, as shown in Figure 13 and outlined in the following paragraphs.

H42. Knowledge sharing purposes and its dimension of knowledge sharing for exploration mediates the relationship between uncertain dynamic disaster management tasks and task efficiency

H43. Knowledge sharing purposes and its dimension of knowledge sharing for exploitation mediates the relationship between uncertain dynamic disaster management tasks and task efficiency

H44. Knowledge sharing mechanisms and its dimension of knowledge sharing through personal contacts mediates the relationship between uncertain dynamic disaster management tasks and task efficiency

H45. Knowledge sharing mechanisms and its dimension of knowledge sharing through written documents mediates the relationship between uncertain dynamic disaster management tasks and task efficiency 


\section{Research Design and Methodology}

\subsection{Research Design and Methodology}

The research design and methodology used to conduct this research study were based on the quantitative research methods of Creswell [2003] and the "Four-Phase Process of Measure Development and Validation" proposed by Xia and Lee [2005]. The research design proposed for this work was conceptualized in five relevant phases. Phase zero describes the research context of this work, including research background, problem statement and research objectives, research significance, research site, research outline, and research scope and limitations. Phase one reviews the conceptual development and initial item generation, which consist of the following research activities: literature review, field interviews, focus groups, research model, research questions, and research hypothesis. Phase two deals with conceptual refinement and item modification through sorting procedures, pilot tests, and the final refinement of measurement items [Xia and Lee, 2005]. Phase three relates to survey data collection. Finally, phase four performs the data analysis and measurement validation along with data screening and descriptive analysis, confirmatory factor analysis, factorial invariance analysis, and nomological validity. 
To generate the primary research themes, categories, and constructs, a thorough literature review and case study research analyses were performed based on EOC archives of standard operations procedures, local response protocols, situation reports and incident reports, action plans, ICT collaborative software system and e-mail logs of hurricanes Katrina, Rita, and Wilma. Additionally, a qualitative ethnographic research analysis was performed at the Miami-Dade OEM and EOC during Tropical Storm Ernesto in 2006 and during training simulations in May 2007, May 2008, May 2009, and May 2010. To allow for an initial assessment of knowledge-sharing flows during these disaster management threats, events, and trainings, EOC stakeholders and functional groups were identified to determine the number of people and agencies involved during a disaster event or threat. Lastly, in-depth case study research coupled with qualitative methods was performed through interviews, focus groups, direct and indirect observations, documents, and audiovisual materials to set the comprehensive stage for this research.

\subsection{Data Collection Instrument Design, Measurement Items Generation, and Sorting Procedure}

\subsubsection{Survey Questionnaire Design}

The survey designed for this research study asked respondents from EOC functional groups, agencies, or related organizations to answer the entire questionnaire with no missing values. 
The survey instrument consisted of four sections.

The first section is related to the uncertain and dynamic characteristics of disaster management tasks that EOC personnel might face during a disaster event.

In this section, the survey provides a sample list and brief descriptions of typical tasks that can be classified according to their uncertain and dynamic characteristics. The list intends to cover tasks with different degrees of uncertainty and change in terms of novelty, unanalyzability, and significance. Furthermore, this list was not intended to be exhaustive but to depict a broad range of uncertain and dynamic disaster management tasks.

The respondents were asked to select a task from the above-mentioned list in which they were involved during a recent disaster management event or threat. If the respondent could not identify any involvement in the tasks mentioned above, there was an option to specify a similar task in terms of the uncertain and dynamic characteristics of disaster management tasks.

In addition, there was a survey question aimed at precisely identifying the organization that was leading the chosen task. The survey designed for this research study is included in Appendix A.

Additionally, in this section, there were questions designed to assess the experiences of disaster management personnel and their expertise regarding the chosen task. Finally, the rest of the items in this section were intended to measure the uncertain and dynamic disaster management constructs and their appropriate dimensions as defined in previous sections and paragraphs. 
According to the research design of this study, the second and third sections assessed the roles of knowledge-sharing purposes and knowledge-sharing mechanisms as critical mediating and moderating factors in the successful performance of uncertain and dynamic disaster management tasks. Finally, the fourth and final section covered the respondents' background information such as job title, EOC functional group, education, and number of years of employment within that particular organization, within the disaster management field, and within the EOC.

Table 15 summarizes the uncertain dynamic disaster management constructs and dimensions along with their definitions conceptualized for this research.

\begin{tabular}{|c|l|}
\hline Construct & Definition \\
\hline $\begin{array}{l}\text { Uncertain Dynamic } \\
\text { Disaster } \\
\text { Management Tasks }\end{array}$ & $\begin{array}{l}\text { "Dynamic uncertainty captures the ad hoc unpredictable } \\
\text { nature of the tasks" [Becerra-Fenandez et al., 2008, pg. 2] }\end{array}$ \\
\hline Task Novelty & $\begin{array}{l}\text { Task Novelty captures the newness (unexpected and novel } \\
\text { events that occur in performing the task) and nonroutineness } \\
\text { (exceptional circumstances requiring flexibility) of the task } \\
\text { [Fields, 2002; Dean and Snell, 1991; Daft and Macintosh] }\end{array}$ \\
\hline Task Newness & $\begin{array}{l}\text { Unexpected and novel events that occur in performing the } \\
\text { task [Fields, 2002; Dean and Snell, 1991; Daft and } \\
\text { Macintosh, 1981] }\end{array}$ \\
\hline $\begin{array}{l}\text { Task } \\
\text { Nonroutinene }\end{array}$ & $\begin{array}{l}\text { "Exceptional circumstances requiring flexibility of the task" } \\
\text { [Fields, 2002; Dean and Snell, 1991; Daft and Macintosh, } \\
\text { 1981] }\end{array}$ \\
\hline $\begin{array}{l}\text { Task } \\
\text { Unanalyzability }\end{array}$ & $\begin{array}{l}\text { Task Unanalyzability represents the degree to which the task } \\
\text { is unstructured and the information required to perform the } \\
\text { task is equivocal thus leading to conflicting interpretations }\end{array}$ \\
\hline
\end{tabular}


[Daft and Lengel, 1986; Daft and Macintosh, 1981;

Dunegan, Duchon, and Uhlbien, 1992]

Table 15. Summary research constructs-dimensions, and definitions 


\begin{tabular}{|c|l|}
\hline Construct & Definition \\
\hline $\begin{array}{c}\text { Task } \\
\text { Difficulty }\end{array}$ & $\begin{array}{l}\text { Task difficulty refers to the impediments "in seeing into the } \\
\text { task and in analyzing it in terms of alternative courses of } \\
\text { action, costs, benefits, and outcomes" [Daft and Macintosh, } \\
\text { 1981, p. 209] }\end{array}$ \\
\hline Information & $\begin{array}{l}\text { The information required to perform the task is equivocal } \\
\text { thus leading to conflicting interpretations [Daft and Lengel, } \\
\text { 1986; Daft and Macintosh, 1981; Dunegan, Duchon, and } \\
\text { Uhlbien, 1992] }\end{array}$ \\
\hline Task Significance & $\begin{array}{l}\text { Task Significance captures the urgency and impact of the } \\
\text { task [Becerra-Fenandez et al., 2008, pg. 2] }\end{array}$ \\
\hline Task Urgency & $\begin{array}{l}\text { Task urgency focuses on the immediate priority and } \\
\text { timeframe a task is needed to be done" [Becerra-Fenandez } \\
\text { et al., 2008, pg. 2] }\end{array}$ \\
\hline Task Impact & $\begin{array}{l}\text { Task impact refers to the analysis and assessment of the } \\
\text { extent of potential repercussions to prioritize when a task } \\
\text { needs to be done [Becerra-Fenandez et al., 2008, pg. 2] }\end{array}$ \\
\hline $\begin{array}{l}\text { Knowledge exploration refers to situations where discovery } \\
\text { of new knowledge is required because there is no existing } \\
\text { knowledge for performing the tasks at hand [March, 1991; } \\
\text { McGrath, 2001] }\end{array}$ \\
\hline $\begin{array}{c}\text { Knowledge for } \\
\text { Exploration }\end{array}$ & $\begin{array}{l}\text { Knowledge exploitation refers to a directed search and } \\
\text { utilization of existing knowledge" [Schildt et al., 2005; } \\
\text { McGrath, 2001] }\end{array}$ \\
\hline Personal Contact & $\begin{array}{l}\text { Knowledge sharing through personal interactions is } \\
\text { appropriate for knowledge that is difficult to codify and hard } \\
\text { to formally articulate in writing, and as a result, such } \\
\text { knowledge often resides in individuals based on their tacit } \\
\text { experiences and social context [Hansen, Nohria, and } \\
\text { Tierney, 1999; Becerra-Fernandez et al., 2004] }\end{array}$ \\
\hline Exploitation & $\begin{array}{l}\text { Knowledge sharing through written documents is } \\
\text { appropriate for explicit knowledge that has been formally } \\
\text { codified and written down, and as a result, is available for } \\
\text { search and use in the forms of planning guidelines, standard }\end{array}$ \\
\hline Knowledge for Documents
\end{tabular}




\begin{tabular}{|l|l|}
\hline & $\begin{array}{l}\text { operating procedures, best practices, lessons learned, and } \\
\text { after action reports [Yi, 2005] }\end{array}$ \\
\hline
\end{tabular}

Table 15 (continued ...) 


\begin{tabular}{|l|l|}
\hline Construct & Definition \\
\hline Task Effectiveness & $\begin{array}{l}\text { Refers to the extent to which the disaster task requirements } \\
\text { were met. It represents the extent to which the task outcome } \\
\text { was satisfactory and how well the task was executed without } \\
\text { disrupting other tasks according to the perception of the } \\
\text { OEM/EOC actors [Gudi, Becerra-Fernández, and Xia, 2007] }\end{array}$ \\
\hline Task Efficiency & $\begin{array}{l}\text { Refers to the extent to which the task was completed in the } \\
\text { required time frame and within the allocated budget and } \\
\text { resources. The efficiency will depend on whether the task was } \\
\text { completed on time using the available resources" [Gudi, } \\
\text { Becerra-Fernández, and Xia, 2007] }\end{array}$ \\
\hline
\end{tabular}

Table 15 (continued ...)

\subsubsection{Generation and Refinement of Measurement Items}

According to the research model described in previous paragraphs, the generation and refinement of the measurement items for each construct used in this research included the following steps. First, initial measurement items were generated through an extensive literature review and field observations. Second, specific sections research instruments were selected from among several relevant research papers found in the literature that addressed constructs to similar to this research study. Third, the initial measurement items were thoroughly evaluated against each construct definition, and definitions that could capture the intended assessment and measurement of each construct were selected. 
Fourth, the reviewed set of measurement items was then carefully analyzed through numerous meetings, interviews, and observations with disaster management researchers, experts related to the field of disaster management, and EOC personnel to validate each construct and their respective measurement items. In this process, some of these measurement items needed to be adapted so that they fully captured the construct concept that they were designed to assess and measure. Table 16 summarizes the research constructs list with their respective research instruments references found in the literature.

\begin{tabular}{|c|c|}
\hline Construct & $\begin{array}{l}\text { References of Research Instrument Items Adapted } \\
\text { from }\end{array}$ \\
\hline \multicolumn{2}{|l|}{$\begin{array}{l}\text { Uncertain Dynamic } \\
\text { Disaster Management } \\
\text { Tasks }\end{array}$} \\
\hline \multicolumn{2}{|l|}{ Task Novelty } \\
\hline $\begin{array}{ll}\text { - } & \text { Task } \\
& \text { Nonroutineness }\end{array}$ & $\begin{array}{l}\text { Adapted from Daft and Macintosh, } 1981 \text { in Karimi, } \\
\text { Somers, and Gupta, 2004, p. } 177\end{array}$ \\
\hline - Task Newness & $\begin{array}{l}\text { Adapted from Fields, D.L., 2002, Dean, J. W. and Scott. } \\
\text { A. Snell, 1991, Snell, S.A. and James W. Dean, Jr., } \\
\text { 1994, Daft and Macintosh, } 1981 \text { in Karimi, Somers, and } \\
\text { Gupta, 2004, p. } 177\end{array}$ \\
\hline \multicolumn{2}{|c|}{ Task Unanalyzability } \\
\hline - Task Difficulty & Adapted from Van de Ven and Delbecq, 1974, p. 183 \\
\hline $\begin{array}{l}\text { - Information } \\
\text { Equivocality }\end{array}$ & $\begin{array}{l}\text { Adapted from Daft and Macintosh, 1981, p. } 215 \text { and } \\
\text { Adapted from Daft and Lengel, } 1986\end{array}$ \\
\hline \multicolumn{2}{|l|}{ Task Significance } \\
\hline $\begin{array}{l}\text { - } \quad \text { Task Urgency } \\
\text { - Task Impact }\end{array}$ & $\begin{array}{l}\text { Adapted from Karasek, } 1979 \text { in Fields, 2002, p. } 82 \\
\text { Adapted from Hackman and Oldham, } 1974 \text { in Fields, } \\
\text { 2002, p. } 73\end{array}$ \\
\hline
\end{tabular}


Table 16. Research instruments used in the generation of measurement items for this research

\begin{tabular}{|c|c|}
\hline Construct & $\begin{array}{l}\text { References of Research Instrument Items Adapted } \\
\text { from }\end{array}$ \\
\hline \multicolumn{2}{|l|}{ Knowledge Sharing } \\
\hline \multicolumn{2}{|l|}{$\begin{array}{l}\text { Knowledge Sharing } \\
\text { Purposes }\end{array}$} \\
\hline $\begin{array}{ll}\text { - } & \text { Knowledge for } \\
\text { Exploration } \\
\text { - } \\
\text { Knowledge for } \\
\text { Exploitation }\end{array}$ & $\begin{array}{l}\text { Adapted from Tom J. M. Mom, Frans A. J. Van Den } \\
\text { Bosch and Henk W. Volberda, 2007, Yi } 2005 \\
\text { Adapted from Tom J. M. Mom, Frans A. J. Van Den } \\
\text { Bosch and Henk W. Volberda, 2007, Becerra-Fernandez } \\
\text { and Sabherwal, 2001, March, 1991 }\end{array}$ \\
\hline \multicolumn{2}{|l|}{$\begin{array}{l}\text { Knowledge Sharing } \\
\text { Mechanisms }\end{array}$} \\
\hline $\begin{array}{l}\text { - Personal Contact } \\
\text { - Written Documents }\end{array}$ & $\begin{array}{l}\text { Adapted from Zander and Kogut, } 1995 \\
\text { Adapted from Zander and Kogut, 1995, Yi } 2005\end{array}$ \\
\hline \multicolumn{2}{|l|}{ Task Performance } \\
\hline $\begin{array}{l}\text { - Task Effectiveness } \\
\text { - Task Efficiency }\end{array}$ & $\begin{array}{l}\text { Gudi, Becerra-Fernandez, and Xia, } 2007 \\
\text { Gudi, Becerra-Fernandez, and Xia, } 2007\end{array}$ \\
\hline Experience on the field & Adapted from Wasko and Faraj, 2005 \\
\hline Expertise on the subject & Adapted from Wasko and Faraj, 2005 \\
\hline
\end{tabular}

Table 16 (continued ...) 


\subsubsection{Sorting Procedure}

Once the initial refinement of measurement items was completed, a sorting procedure was conducted to validate the constructs, the measurement items, and the relationships between these two. To conduct a sorting procedure session, the following preliminary steps were needed. 
First, an introduction script was developed to present this sorting procedure to the participant(s). This script covered the sorting procedure objectives, process, and methodology. Second, a brief presentation of the research work was performed in which the research model and constructs were explained in detail. To facilitate the presentation, a two-page summary was handed to the participant(s) in which the abstract of the research work was presented, the research model was depicted, and each construct concept was defined. Third, a set of $5 \frac{1}{2} \times 8^{1 / 2}$-inch banner cards were printed, each with the research construct heading in bold followed by the construct definition, and they were placed side-by-side on a flat surface such as a meeting or conference room table. Fourth, a set of 3x5-inch index cards was created, and each card displayed one measurement item from the measurement items described in the previous paragraphs. Fifth, a constructvalidity recording table was created to keep track of these sorting process outcomes.

The construct-validity recording table columns represent each of the constructs of the research model, whereas the rows represent each of the measurement items for each construct. In addition, the intersection of each construct and its corresponding measurement item is clearly identified for accurate recording purposes.

After the previous steps were completed, the sorting procedure sessions were conducted according to the following steps. First, an initial pool of four to ten sorting respondents was selected. These sorting respondents were selected based on their knowledge, expertise, and experience of the research subject as well as their individual interest in participating in these sorting procedure sessions. Second, a meeting room with multimedia capabilities and a large meeting and/or conference table was selected. 
Third, the sorting procedure session began according to the sorting procedure protocol script with a brief presentation of the research work and model at hand and a detailed explanation of the research constructs involved. At the end of each presentation, a twopage summary of the research work presented was handed to the sorting respondent, including a detailed description and definition of the constructs related to the research model of this study. Fourth, the respondent was asked to carefully read each measurement item printed on each $3 \times 5$-inch index card and to sort these cards according to the $5 \frac{1}{2} \times 8^{1 / 2}$ inch banner cards with the construct heading definitions, which were set side by side on the meeting or conference table. It is important to note that an additional $5 \frac{1}{2} \times 8^{1 / 2-1 n c h}$ banner card was created for those measurement items that, according to the sorting respondent, did not belong to any of the construct heading-definition banners laid on the table. This additional banner card was categorized as ambiguous or unclear measurement items. Fifth, once the sorting process was completed, the measurement items placed on each construct were individually compared with their corresponding construct and measurement item with the help of the construct-validity recording table . Sixth, for those constructs that did not match the original construct and corresponding measurement item, an open discussion and feedback session was conducted to review any discrepancies and evaluate possible changes in the measurement items. As a result, the constructs and measurement items in question were slightly modified in terms of wording, emphasis on certain terms, and/or construct-measurement-item categorization. The same process was followed for those measurement items placed under the ambiguous or unclear category. 
Finally, the sorting respondent was asked to provide additional feedback, if any, and the sorting procedure session was finalized.

With the sorting procedure session notes and feedback in hand, the constructvalidity recording table was completed. Then, the matching numbers of sorted constructs and measurement items were evaluated to assess the percentage of items that were correctly placed. A commonly accepted threshold is a percentage equal to or greater than eighty.

The results were then analyzed, and pertinent changes to the measurement items were made so that the understanding and clarity of each measurement item would be improved for the next sorting procedure session. Finally, the sorting procedure process ended when at least four respondents had completed the process and when constructs and measurement items were consistently matched with eighty percent accuracy. Table 17 summarizes the end results of the sorting procedures conducted in terms of constructs, dimensions, and measurement items. 


\begin{tabular}{|c|c|}
\hline $\begin{array}{l}\text { Construct- } \\
\text { Dimensions }\end{array}$ & Measurement Items \\
\hline $\begin{array}{l}\text { Experience and } \\
\text { Expertise on the } \\
\text { Field }\end{array}$ & \\
\hline Experien & $\begin{array}{l}\text { 2. For this particular task, how many years of experience did } \\
\text { you have the last time you coordinated/performed this task? } \\
\text { Scale: } \\
\bullet \quad \text { Years, Months }\end{array}$ \\
\hline Expertis & $\begin{array}{l}\text { 3. For this particular task, what was your level of expertise } \\
\text { the last time you coordinated/performed this task? } \\
\text { Scale: } \\
\text { - Seven point Likert scale from } 1 \text { (novice) to } 7 \text { (expert) }\end{array}$ \\
\hline Task Efficiency & \\
\hline PLTime4 & $\begin{array}{l}\text { 4. What was the planned time for the task completion (in } \\
\text { hours): hours } \\
\text { Scale: } \\
\qquad \text { Hours }\end{array}$ \\
\hline AcTime5 & $\begin{array}{l}\text { 5. What was the actual time required for completing the task } \\
\text { (in hours): } \\
\text { Scale: } \\
\bullet \text { Hours }\end{array}$ \\
\hline PLBudg6 & $\begin{array}{l}\text { 6. What was the planned budget/cost for the task: } \$ \\
\text { Scale: } \\
\bullet \quad \text { Dollars }\end{array}$ \\
\hline AcBudg7 & $\begin{array}{l}\text { 7. What was the actual budget/cost for the task: } \$ \\
\text { Scale: } \\
- \text { Dollars }\end{array}$ \\
\hline
\end{tabular}

Table 17. Constructs-Dimensions and Measurement Items 


\begin{tabular}{|c|c|}
\hline & $\begin{array}{l}\text { For the following measurement items, the measurement } \\
\text { scale used was a: } \\
\text { - Seven point Likert scale from } 1 \text { (strongly disagree) to } \\
\quad 7 \text { (strongly agree) } \\
\end{array}$ \\
\hline $\begin{array}{l}\text { Construct- } \\
\text { Dimensions }\end{array}$ & Measurement Items \\
\hline TEfcy8 & 8. The task was completed within the planned time schedule \\
\hline TEfcy9 & 9. The task was completed within the allocated budget \\
\hline TEfcy10 & $\begin{array}{l}\text { 10. The task was completed within the planned number of } \\
\text { person-hours }\end{array}$ \\
\hline TEfcy11 & $\begin{array}{l}\text { 11. The task was completed with efficient use of all available } \\
\text { resources }\end{array}$ \\
\hline TEfcy12 & $\begin{array}{l}\text { 12. Completing the task did not required additional } \\
\text { unanticipated resources }\end{array}$ \\
\hline \multicolumn{2}{|l|}{ Task Effectiveness } \\
\hline TEfss13 & 13. The task was completed satisfactorily for all participants \\
\hline TEfss14 & $\begin{array}{l}\text { 14. All incident requirements were met when the task was } \\
\text { completed }\end{array}$ \\
\hline TEfss15 & $\begin{array}{l}\text { 15. The task was completed successfully without negatively } \\
\text { impacting other tasks }\end{array}$ \\
\hline TEfss16 & $\begin{array}{l}\text { 16. The task was effectively completed despite any conflicting } \\
\text { task requirements }\end{array}$ \\
\hline \multicolumn{2}{|l|}{ Task Novelty } \\
\hline \multicolumn{2}{|l|}{ Task Newness } \\
\hline TNvNew1 & $\begin{array}{l}\text { Setting the objectives of this new task required answering } \\
\text { questions that have not been asked before }\end{array}$ \\
\hline TNvNew2 & $\begin{array}{l}\text { Coordinating/performing the activities of this new task } \\
\text { required answering questions that have not been asked before }\end{array}$ \\
\hline TNvNew3 & $\begin{array}{l}\text { Setting the objectives for this new task required adopting new } \\
\text { procedures }\end{array}$ \\
\hline TNvNew4 & $\begin{array}{l}\text { Coordinating/performing the activities of this new task } \\
\text { required adopting new ways of doing things }\end{array}$ \\
\hline TNvNew5 & $\begin{array}{l}\text { This predefined task is not always required when the EOC is } \\
\text { activated }\end{array}$ \\
\hline
\end{tabular}

Table 17 (continued ...) 


\begin{tabular}{|c|c|}
\hline & $\begin{array}{l}\text { For the following measurement items, the measurement } \\
\text { scale used was a: } \\
\text { - Seven point Likert scale from } 1 \text { (strongly disagree) to } \\
\quad 7 \text { (strongly agree) }\end{array}$ \\
\hline $\begin{array}{l}\text { Construct- } \\
\text { Dimensions }\end{array}$ & Measurement Items \\
\hline \multicolumn{2}{|l|}{$\begin{array}{l}\text { Task } \\
\text { Nonroutineness }\end{array}$} \\
\hline TNvNoR6 & $\begin{array}{l}\text { The objectives for this predefined task are not the same every } \\
\text { time the EOC is activated }\end{array}$ \\
\hline TNvNoR7 & $\begin{array}{l}\text { The activities involved in this predefined task are not the same } \\
\text { for every EOC activation }\end{array}$ \\
\hline TNvNoR8 & $\begin{array}{l}\text { This task involves activities that are not previously specified } \\
\text { in existing standard operating procedures }\end{array}$ \\
\hline TNvNoR9 & This predefined task requires changing the required activities \\
\hline \multicolumn{2}{|l|}{ Task Unanalyzability } \\
\hline \multicolumn{2}{|l|}{ Task Difficulty } \\
\hline TUnDif10 & $\begin{array}{l}\text { It is difficult to see clearly the sequence of steps that can be } \\
\text { followed to coordinate/perform the activities of this task }\end{array}$ \\
\hline TUnDif11 & $\begin{array}{l}\text { You came across specific difficult problems that you were not } \\
\text { sure how to solve immediately }\end{array}$ \\
\hline TUnDif12 & $\begin{array}{l}\text { Coordinating/performing the task required you to spend } \\
\text { additional time to think and solve specific problems }\end{array}$ \\
\hline TUnDif13 & $\begin{array}{l}\text { While coordinating/performing the task, it was difficult to } \\
\text { know whether the results of your efforts would be correct }\end{array}$ \\
\hline \multicolumn{2}{|l|}{$\begin{array}{l}\text { Information } \\
\text { Equivocality }\end{array}$} \\
\hline TUnInE14 & $\begin{array}{l}\text { The objectives set for this task were not clearly defined } \\
\text { according to existing standard operating procedures }\end{array}$ \\
\hline TUnInE15 & $\begin{array}{l}\text { Before you started this task, the information used for setting } \\
\text { the objectives of this task meant different things to different } \\
\text { people }\end{array}$ \\
\hline TUnInE16 & $\begin{array}{l}\text { During the execution of this task, the information used to } \\
\text { accomplish the task objectives meant different things to } \\
\text { different people }\end{array}$ \\
\hline TUnInE17 & $\begin{array}{l}\text { There were multiple possible ways to interpret how to achieve } \\
\text { the objectives of this task }\end{array}$ \\
\hline TUnInE18 & There were multiple ways to interpret the possible outcomes \\
\hline
\end{tabular}


for this task

TUnInE19 There were no clear measures to evaluate the task outcomes and performance

Table 17 (continued ...) 


\begin{tabular}{|c|c|}
\hline & $\begin{array}{l}\text { For the following measurement items, the measurement } \\
\text { scale used was a: } \\
\text { - Seven point Likert scale from } 1 \text { (strongly disagree) to } \\
\quad 7 \text { (strongly agree) }\end{array}$ \\
\hline $\begin{array}{l}\text { Construct- } \\
\text { Dimensions }\end{array}$ & Measurement Items \\
\hline \multicolumn{2}{|l|}{$\begin{array}{l}\text { Amount of Task } \\
\text { Information }\end{array}$} \\
\hline TUnIEA30 & $\begin{array}{l}\text { You waited until all relevant information was examined } \\
\text { before deciding a course of action to execute the activities for } \\
\text { this task }\end{array}$ \\
\hline TUnIEA31 & $\begin{array}{l}\text { You kept gathering data until an excellent solution emerged } \\
\text { before deciding a course of action to execute the activities for } \\
\text { this task }\end{array}$ \\
\hline TUnIEA32 & $\begin{array}{l}\text { You acquired all possible information before making a final } \\
\text { decision to execute the activities for this task }\end{array}$ \\
\hline TUnIEA33 & $\begin{array}{l}\text { You went over all the available information until an excellent } \\
\text { solution appeared before deciding a course of action to } \\
\text { execute the activities for this task }\end{array}$ \\
\hline \multicolumn{2}{|l|}{ Task Significance } \\
\hline \multicolumn{2}{|l|}{ Task Urgency } \\
\hline TSgUrg20 & This task required your immediate attention \\
\hline TSgUrg21 & $\begin{array}{l}\text { The pressure to complete this task did not allow you time to } \\
\text { think }\end{array}$ \\
\hline TSgUrg22 & $\begin{array}{l}\text { The task did not have built-in slack time which allowed you } \\
\text { time to think }\end{array}$ \\
\hline TSgUrg23 & The activities of this task must be done as fast as possible \\
\hline TSgUrg24 & $\begin{array}{l}\text { You were primarily focused on achieving the immediate } \\
\text { objectives for this task }\end{array}$ \\
\hline \multicolumn{2}{|r|}{ 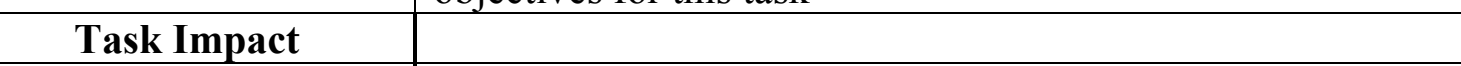 } \\
\hline TSgImp25 & $\begin{array}{l}\text { Failure to complete this task would significantly impact the } \\
\text { lives or well-being of people }\end{array}$ \\
\hline TSgImp26 & $\begin{array}{l}\text { Failure to complete this task would have significant economic } \\
\text { impact }\end{array}$ \\
\hline TSgImp27 & $\begin{array}{l}\text { Failure to complete this task would incur significant } \\
\text { infrastructure loss during the disaster }\end{array}$ \\
\hline TSgImp28 & $\begin{array}{l}\text { Failure to complete this task would create a pile-up of } \\
\text { activities in your own work }\end{array}$ \\
\hline
\end{tabular}


TSgImp29 $\mid$ Failure to complete this task would slow down or create a bottleneck for other people

Table 17 (continued ...) 


\begin{tabular}{|c|c|}
\hline & $\begin{array}{l}\text { For the following measurement items, the measurement } \\
\text { scale used was a: } \\
\text { - Seven point Likert scale from } 1 \text { (strongly disagree) to } \\
7 \text { (strongly agree) }\end{array}$ \\
\hline $\begin{array}{l}\text { Construct- } \\
\text { Dimensions }\end{array}$ & Measurement Items \\
\hline \multicolumn{2}{|l|}{\begin{tabular}{|l|} 
Knowledge Sharing \\
Purposes
\end{tabular}} \\
\hline \multicolumn{2}{|l|}{$\begin{array}{l}\text { Knowledge for } \\
\text { Exploration }\end{array}$} \\
\hline KSPExor1 & $\begin{array}{l}\text { You searched for new ways to coordinate/perform the } \\
\text { activities of this task }\end{array}$ \\
\hline KSPExor2 & $\begin{array}{l}\text { You had to modify existing procedures to coordinate/perform } \\
\text { the activities of this task }\end{array}$ \\
\hline KSPExor3 & $\begin{array}{l}\text { You had to learn new skills or knowledge to } \\
\text { coordinate/perform the activities of this task }\end{array}$ \\
\hline KSPExor4 & $\begin{array}{l}\text { You discovered different procedures to coordinate/perform } \\
\text { this task }\end{array}$ \\
\hline \multicolumn{2}{|l|}{$\begin{array}{l}\text { Knowledge for } \\
\text { Exploitation }\end{array}$} \\
\hline KSPExit5 & $\begin{array}{l}\text { To coordinate/perform this task, you used the experience you } \\
\text { gained from coordinating/performing similar tasks in the past }\end{array}$ \\
\hline KSPExit6 & To coordinate/perform this task, you used your expertise \\
\hline KSPExit7 & $\begin{array}{l}\text { You applied the needed knowledge you obtained from } \\
\text { existing standard operating procedures }\end{array}$ \\
\hline KSPExit8 & $\begin{array}{l}\text { There is a defined body of knowledge which can guide you in } \\
\text { doing the activities for this task }\end{array}$ \\
\hline
\end{tabular}

Table 17 (continued ...) 


\begin{tabular}{|c|c|}
\hline & $\begin{array}{l}\text { For the following measurement items, the measurement } \\
\text { scale used was a: } \\
\text { - Seven point Likert scale from } 1 \text { (strongly disagree) to } \\
\quad 7 \text { (strongly agree) }\end{array}$ \\
\hline $\begin{array}{l}\text { Construct- } \\
\text { Dimensions }\end{array}$ & Measurement Items \\
\hline \multicolumn{2}{|l|}{$\begin{array}{l}\text { Knowledge Sharing } \\
\text { Mechanisms } \\
\end{array}$} \\
\hline \multicolumn{2}{|l|}{ Personal Contact } \\
\hline KSMPC1 & $\begin{array}{l}\text { New personnel can acquire the required knowledge for this } \\
\text { task by talking to skilled employees }\end{array}$ \\
\hline KSMPC2 & $\begin{array}{l}\text { New personnel can acquire the required knowledge for this } \\
\text { task by face-to-face on-the-job training }\end{array}$ \\
\hline KSMPC3 & $\begin{array}{l}\text { Personal contact interactions were required to execute the } \\
\text { activities for this task }\end{array}$ \\
\hline KSMPC4 & $\begin{array}{l}\text { You were able to interact with others when } \\
\text { coordinating/performing this task }\end{array}$ \\
\hline KSMPC5 & $\begin{array}{l}\text { People were available for personal interaction during the } \\
\text { execution of this task }\end{array}$ \\
\hline KSMPC6 & $\begin{array}{l}\text { You had access to experts when you needed their knowledge } \\
\text { and advice to execute this task }\end{array}$ \\
\hline \multicolumn{2}{|c|}{\begin{tabular}{|l|l|} 
Written Documents &
\end{tabular}} \\
\hline KSMWD7 & $\begin{array}{l}\text { The knowledge required to coordinate/perform this task was } \\
\text { captured in documents }\end{array}$ \\
\hline KSMWD8 & $\begin{array}{l}\text { The knowledge required to coordinate/perform this task was } \\
\text { stored in computer systems }\end{array}$ \\
\hline KSMWD9 & $\begin{array}{l}\text { An extensive documentation describing critical parts of the } \\
\text { knowledge is required to coordinate/perform this task }\end{array}$ \\
\hline KSMWD10 & Standard operating procedures exist to support this task \\
\hline KSMWD11 & $\begin{array}{l}\text { You were able to access to existing standard operating } \\
\text { procedures when coordinating/performing this task }\end{array}$ \\
\hline KSMWD12 & $\begin{array}{l}\text { Standard operating procedures were available to support this } \\
\text { task }\end{array}$ \\
\hline KSMWD13 & $\begin{array}{l}\text { New employees can learn how to coordinate/perform this task } \\
\text { by studying existing standard operating procedures }\end{array}$ \\
\hline
\end{tabular}

Table 17 (continued ...) 


\section{Data Analysis and Results}

\subsection{Survey Data Collection}

The target survey respondents included those who were directly involved in disaster management response activities at the Miami-Dade Office of Emergency Management. The respondents were members of various emergency executive groups, functional groups (human services, infrastructure, and public safety), support groups (311 answer center, geographic information systems, logistics section, planning and information section, and special needs support center), information communication systems, and other related public agencies and private corporations. The targeted 734 potential respondents were individuals with experience in disaster management response events.

Before the respondents answered questions related to task uncertainty dynamic disaster management measures, they were asked to identify a specific disaster response task that they had been recently involved with and were asked to refer to that specific task when answering all relevant questions. To make the interpretation of tasks consistent, a list of typical disaster management response tasks was provided as a resource of examples. Respondents first answered questions that were related to measures of the different dimensions of task uncertainty. 
They then assessed the extent to which they were engaged in knowledge sharing for the purpose of knowledge exploration and knowledge exploitation. They also provided respondent background information, such as job title, education, the specific emergency functional group to which they belonged, the number of years they have worked in their current organization, and the number of years they have worked in the disaster management field. A total of 168 usable responses were received and used in our data analysis, representing an overall response rate of $22.9 \%$. The characteristics of the respondents who were included in the sample are as follows:

- Years of experience had to coordinated and/or performed this task: 9.41 Years

- Years worked in the emergency management field:

- Years worked at current organization 1: 10.09 Years

- Years worked at the Emergency Operations Center:

- Organizational Level
- Senior Management:
$41.70 \%$
- Middle Management:
$30.40 \%$
○ Operations Management: $\quad 28.00 \%$

- People belonging to the following Office of Emergency Management and/or Emergency Operations Center functional groups:

○ Infrastructure Group $23.80 \%$

○ Human Services Group $\quad 14.30 \%$

○ Public Safety Group 35.70\%

O Other:

- Hospitals/Health Care $\quad 3.57 \%$

- Planning and Logistics $\quad 3.57 \%$

- Staff and Support Organizations $\quad 2.97 \%$

- Operations $2.38 \%$

- City/Municipal $\quad 1.78 \%$

- Other $11.90 \%$ 


\subsection{Pre-Analysis and Data Screening}

Once a minimum of 168 completed survey responses was reached, a preliminary analysis process was performed, and data screening procedures were initiated. The objective of these procedures was to evaluate the quality of the collected data collected prior to the subsequent statistical and multivariate tests. The four data screening purposes that were suggested for this research study dealt with data accuracy, missing data, extreme data values, normality, linearity, and homoscedasticity so as to "assess the adequacy of fit between the data and the assumptions" [Mertler and Vannatta, 2005, p. 25 ] of the multivariate statistical methods that were planned to be used to analyze this data.

Data accuracy and missing data were assessed for each variable. Using SPSS statistical software, missing data were determined. In addition, extreme data values, also known as outliers, were identified as values that were beyond the variable mean plus/minus three standard deviations. No missing values were found because one of the requisites was to completely answer the survey so as to avoid having any missing values. Furthermore, very few cases were found to have outlier values, and after careful analysis and feedback from the respondents, it was determined that the outlier value was not an error but was the intended response of the survey respondent. 


\subsection{Non-Response Bias Analysis}

To examine the nonresponse bias for this study, the data were assessed based on the dates that the surveys were completed according to early and late replies on key constructs and demographic variables. The data were divided in two groups according to the date that the survey was completed. Each group represented the early and late respondents, and the late group served as a proxy for those potential respondents who took the survey. Independent-sample $t$ tests were conducted on the following constructs and variables: 


\section{Constructs:}

- Task nonroutineness

- Task newness

- Task difficulty

- Amount of task information

- $\quad$ Task urgency

- Task impact

- Knowledge sharing for exploration

- Knowledge sharing for exploitation

- Knowledge sharing through written documents

- Knowledge sharing through personal contacts

- Task Efficiency

- Task Effectiveness

Demographic Variables:

- Years worked in the disaster management field

- Years worked in current organization

- Level of expertise 


\begin{tabular}{|l|l|l|}
\hline \multicolumn{1}{|c|}{ Construct } & \multicolumn{1}{|c|}{ Result of $\boldsymbol{t}$ test } & \multicolumn{1}{c|}{ Comments } \\
\hline $\begin{array}{l}\text { Years worked in the } \\
\text { disaster management field }\end{array}$ & Significant at .05 level & $\begin{array}{l}\text { Mean difference is: -3.10 } \\
\text { Mean values: 11.95 and } \\
15.05\end{array}$ \\
\hline $\begin{array}{l}\text { Years worked in current } \\
\text { organization }\end{array}$ & Not Significant & \\
\hline Level of expertise & Not Significant & \\
\hline Task nonroutineness & Not Significant & \\
\hline Task newness & Significant at .05 level & $\begin{array}{l}\text { Mean difference is: } 0.6191 \\
\text { Mean values: } 4.3889 \text { and }\end{array}$ \\
\hline Task difficulty & Not Significant & \\
\hline $\begin{array}{l}\text { Amount of task } \\
\text { information }\end{array}$ & Not Significant & \\
\hline Task urgency & Not Significant & \\
\hline Task impact & Not Significant & \\
\hline $\begin{array}{l}\text { Knowledge sharing for } \\
\text { exploration }\end{array}$ & Not Significant & \\
\hline $\begin{array}{l}\text { Knowledge sharing for } \\
\text { exploitation }\end{array}$ & Not Significant & \\
\hline $\begin{array}{l}\text { Knowledge sharing } \\
\text { through written documents }\end{array}$ & Not Significant & Not Significant \\
\hline $\begin{array}{l}\text { Knowledge sharing } \\
\text { through personal contacts }\end{array}$ & Not Significant & \\
\hline Task efficiency & Not Significant & \\
\hline Task effectiveness & & \\
\hline
\end{tabular}

Table 18. Summary of tests to examine non-response bias

According to the independent-sample $t$ test results, eleven of twelve key constructs of this study indicated that the differences in their mean values were not significant. In addition, two of the three demographic variables of this study indicated that the differences in their mean values were not significant at 0.05 level. 
These results are a reasonable measure to indicate that this survey data set is not likely to possess response bias.

\subsection{Validity and Reliability Issues}

To assess whether the measurement items were reliable, this research study used internal consistency estimates of reliability based on Cronbach's alpha statistical test. Cronbach's alpha statistical test determines the "consistency in scores among equivalent items" [Green and Salkind, 2004, p. 325].

To conduct Cronbach's alpha statistical reliability test, the following steps were followed. First, the underlying internal consistency reliability procedure assumptions were met. The underlying internal consistency reliability procedure assumptions are as follows: the components of the measurement are equivalent, the errors in the measurements between parts are unrelated, and an item is a sum of its true and erroneous scores. Second, it was determined that all items used the same scale, and that if any items were needed, these were to be reverse-scaled. Third, using SPSS, a reliability analysis was conducted for Cronbach's alpha statistical reliability test according to the assumptions met in the first step of this process. Fourth, once the appropriate reliability analyses were performed, a Cronbach's alpha coefficient was reported to assess the coefficient alpha reliability test. Cronbach's alpha corrected correlation coefficients usually range from 0 to 1 , and the reliability of these scale scores increases as the coefficient values approach 1 . 
Internal consistency estimates of reliability, which are described by Cronbach's alpha values, were computed for the three dimensions of uncertain dynamic disaster management tasks (novelty, unanalyzability, and significance), two purposes for knowledge sharing (exploration and exploitation), two mechanisms for knowledge sharing (personal contacts and written documents), and task performance. As shown in Table 19 , the reliability estimates for all variables are above 0.60 , indicating satisfactory levels of reliability (Hair, Anderson, Tatham \& Black, 1998).

\begin{tabular}{|l|r|r|r|}
\hline Task Uncertainty Dimensions & $\begin{array}{r}\text { Cronbach's } \\
\text { Alpha } \\
\text { Cronbach's } \\
\text { Alpha }\end{array}$ & $\begin{array}{r}\text { Sumber } \\
\text { Standardized } \\
\text { Items Alpha }\end{array}$ & $\begin{array}{r}\text { of } \\
\text { Items }\end{array}$ \\
\hline Task Novelty & & & \\
Task Newness & 0.773 & 0.775 & 6 \\
\hline TNvNew2, TNvNew3, & 0.826 & 0.826 & 3 \\
TNvNew4 & & & \\
Task Nonroutineness & 0.768 & 0.768 & 3 \\
\hline TNvNew5, TNvNoR6, TNvNoR7 & & & \\
\hline & & & \\
\hline Task Unanazability & 0.681 & 0.683 & \\
Task Difficulty & 0.792 & 0.793 & 5 \\
TUnDif10, TUnDif1 1, TUnDif12, & & & \\
TUnDif13,TUnInE14 & & & \\
Amount of Information & 0.797 & 0.797 & 3 \\
\hline TUnIEA30,TUnIEA31,TUnIEA33 & & & \\
\hline
\end{tabular}

Table 19. Reliability estimates (Cronbach's alphas) for the constructs 


\begin{tabular}{|c|c|c|c|}
\hline & $\begin{array}{r}\text { Cronbach's } \\
\text { Alpha }\end{array}$ & $\begin{array}{r}\text { Cronbach's } \\
\text { Alpha } \\
\text { Standardized } \\
\text { Items Alpha } \\
\end{array}$ & $\begin{array}{r}\text { Number } \\
\text { of } \\
\text { Items }\end{array}$ \\
\hline Task Significance & 0.659 & 0.659 & 6 \\
\hline$\frac{\text { Task Urgency }}{\text { TSgUrg20, TSgUrg23, TSgUrg24 }}$ & 0.647 & 0.644 & 3 \\
\hline$\frac{\text { Task Impact }}{\text { TSgImp25, TSgImp26, TSgImp28 }}$ & 0.654 & 0.654 & 3 \\
\hline \multicolumn{4}{|l|}{ Knowledge Sharing Dimensions } \\
\hline Knowledge Sharing Purposes & 0.703 & 0.707 & 8 \\
\hline $\begin{array}{l}\text { KS for Exploration } \\
\text { KSPExor1, KSPExor2, KSPExor3, } \\
\text { KSPExor4, }\end{array}$ & 0.813 & 0.813 & 4 \\
\hline $\begin{array}{l}\text { KS for Exploitation } \\
\text { KSPExit5, KSPExit6, KSPExit7, } \\
\text { KSPExit8 }\end{array}$ & 0.776 & 0.780 & 4 \\
\hline $\begin{array}{l}\text { Knowledge Sharing Mechanisms } \\
\text { KS through Personal Contact } \\
\text { KSMPC2, KSMPC3, KSMPC4, } \\
\text { KSMPC5 }\end{array}$ & 0.884 & $\begin{array}{l}0.880 \\
0.765\end{array}$ & $\begin{array}{r}11 \\
4\end{array}$ \\
\hline $\begin{array}{l}\text { KS through Written Documents } \\
\text { KSMWD7, KSMWD88, KSMWD9, } \\
\text { KSMWD10, KSMWD11, KSMWD12, } \\
\text { KSMWD13 }\end{array}$ & 0.910 & 0.910 & 7 \\
\hline \multicolumn{4}{|l|}{ Task Performance Dimensions } \\
\hline Task Performance & 0.762 & 0.768 & 6 \\
\hline$\frac{\text { Task Efficiency }}{\text { TEfcy8, TEfcy9, TEfcy } 10}$ & 0.764 & 0.761 & 3 \\
\hline$\frac{\text { Task Effectiveness }}{\text { TEfss } 13, \text { TEfss } 14, \text { TEfss } 16,}$ & 0.757 & 0.768 & 3 \\
\hline
\end{tabular}


Table 19. (continued ...)

\subsection{Measurement Validation}

Construct validity is commonly defined as the agreement between the construct along with its conceptual definition and the items that are used to measure the construct [Schwab, 1980]. Two relevant concepts in construct validity include convergent validity and discriminant validity. Convergent validity refers to "the degree to which two or more attempts to measure the same concept [...] are in agreement" [Bagozzi and Phillips, 1982, p. 468]. Discriminant validity is defined as "the degree to which measures of distinct concepts differ" [Bagozzi and Phillips, 1982, p. 469].

For this research study, each construct was measured by different dimensions according to the following list: uncertain dynamic disaster management tasks including task novelty (task nonroutineness and task newness), task unanalyzability (task difficulty and the amount of task information), and task significance (task urgency and task impact); knowledge sharing by purpose (exploration and exploitation) and mechanism (personal contact and written documents); and task performance (in terms of effectiveness and efficiency). Based on these constructs and their respective measurement dimensions, it was expected to have a high degree of convergent validity, or large common variance, for those items that were measuring their intended constructs and a lower degree of discriminant validity, or little common variance, for those items that were intended to measure other constructs with no cross loadings observed [Schwab, 1980, Bagozzi and Phillips, 1982]. 
Construct validity was assessed via the multivariate statistical procedure of factor analysis. Factor analysis identifies the "factors that statistically explain the variation and covariation among measures" [Green and Salkind, 2004, p. 312]. In addition, this method reduces the data by obtaining together those variables that measure the same construct [Mertler and Vannatta, 2005]. The factor analysis statistical procedure was developed through factor extraction and factor rotation. Factor extraction uses principal component analysis to assess "all sources of variability for each variable" [Mertler and Vannatta, 2005, p. 275] and extract from a correlation matrix those factors that "account for the largest amount of the variability among the measured variables" [Green and Salkind, 2004, p. 314].

After obtaining these extracted factors, "the number of factors underlying a set of measured variables" [Green and Salkind, 2004, p. 314] can be determined. The variability of a factor is also known as the eigenvalue. The criterion to chose those extracted factors is commonly based on eigenvalues that are greater than 1 (for a total number of variables that is less than 30) and communalities that are greater than 0.70 . Another criterion used is to choose those extracted factors that "account for at least 70\% total variability" [Mertler and Vannatta, 2005, p. 277].

Once the factor extraction procedure was completed, factor rotation must be considered. The objective of factor rotation is to "statistically manipulate (i.e., to rotate factors) the results to make the factors more interpretable" [Green and Salkind, 2004, p. 313]. Varimax is the most commonly used rotation method, reporting orthogonal or uncorrelated factors. 
The varimax factor rotation method produces a rotated factor matrix, which is also known as the factor-loading matrix. After acquiring these results the component loadings with higher absolute coefficients are analyzed in terms of strength and direction so as to assess commonalties and assign a representative grouping name to each component.

As a result, those component loadings with higher absolute coefficients should correspond to the intended constructs and measurement items, and they can be determined to have convergent validity. Additionally, those component loadings with lower absolute coefficients should correspond to other intended constructs and measurement items, and they can be determined to have discriminant validity.

The tables below summarize the results of the factor analyses that were conducted for the following uncertain dynamic disaster management task dimensions: task novelty (task nonroutineness and task newness), task unanalyzability (task difficulty and the amount of task information), and task significance (task urgency and task impact); knowledge-sharing purpose (exploration and exploitation) and knowledge-sharing mechanisms (personal contact and written documents); and task performance (in terms of effectiveness and efficiency).

\subsubsection{Task Novelty}

The dimensionality of the 9 items used to measure task novelty was analyzed using maximum likelihood factor analysis. The number of factors to rotate was determined on the a priori hypothesis that the construct was bidimensional (task newness and task nonroutinenes), the eigenvalues, and the interpretability of the factor solution. 
The initial hypothesis of bi-dimensionality was supported and the rotated solution yielded two interpretable factors. Tables 20 and 21 show the final result obtained for task newness and nonroutineness. For the task newness dimension, given the high variance shown by its item TNvNew1, it was decided to drop this item. Finally, for the task nonroutineness dimension, two items, TNvNoR8 and TNvNoR8, cross loaded with the task newness dimension, so it was decided to delete these items.

\begin{tabular}{|l|l|}
\hline \multicolumn{1}{|c|}{ Task Newness Items } & Factor Loadings \\
\hline $\begin{array}{l}\text { TNvNew2 } \\
\text { Coordinating/performing the activities of this new task } \\
\text { required answering questions that have not been asked } \\
\text { before }\end{array}$ & .563 \\
\hline $\begin{array}{l}\text { TNvNew3 } \\
\text { Setting the objectives for this new task required adopting } \\
\text { new procedures }\end{array}$ & .892 \\
\hline $\begin{array}{l}\text { TNvNew4 } \\
\text { Coordinating/performing the activities of this new task } \\
\text { required adopting new ways of doing things }\end{array}$ & .865 \\
\hline $\begin{array}{l}\text { Deleted High Variance } \\
\text { TNvNew1 }\end{array}$ & \\
$\quad \begin{array}{l}\text { Setting the objectives of this new task required } \\
\text { answering questions that have not been asked } \\
\text { before }\end{array}$ & \\
\hline $\begin{array}{l}\text { Note: } \\
\text { Extraction Method: Maximum Likelihood } \\
\text { Rotation Method: Varimax with Kaiser Normalization }\end{array}$ \\
\hline
\end{tabular}

Table 20. Task newness: factor loadings 


\begin{tabular}{|l|l|}
\hline \multicolumn{1}{|c|}{ Task Nonroutineness Items } & Factor Loadings \\
\hline $\begin{array}{l}\text { TNvNew5 } \\
\text { This predefined task is not always required when the EOC } \\
\text { is activated }\end{array}$ & .564 \\
\hline $\begin{array}{l}\text { TNvNoR6 } \\
\text { The objectives for this predefined task are not the same } \\
\text { every time the EOC is activated }\end{array}$ & .974 \\
\hline $\begin{array}{l}\text { TNvNoR7 } \\
\text { The activities involved in this predefined task are not the } \\
\text { same for every EOC activation }\end{array}$ & .611 \\
\hline $\begin{array}{l}\text { Deleted Cross Loadings } \\
\text { TNvNoR8 }\end{array}$ & \\
This task involves activities that are not previously \\
specified in existing standard operating procedures \\
TNvNoR9 \\
This predefined task requires changing the \\
required activities
\end{tabular}

Table 21. Task nonroutineness: factor loadings

\subsubsection{Task Unanalyzability}

The dimensionality of the 14 items used to measure task unanalyzability was analyzed using maximum likelihood factor analysis. The number of factors to rotate was determined on the a priori hypothesis that the construct was tri-dimensional (task difficulty, information equivocality, and amount of task information), the eigenvalues, and the interpretability of the factors solution. The initial hypothesis of tri-dimensionality was not supported and the rotated solution yielded just two interpretable factors. 
Tables 22, 23, and 24 show the final result obtained for task difficulty, information equivocality, and amount of task information. For the information equivocality dimension, five items, TUnInE15, TUnInE16, TUnInE17, TUnInE18, and TUnInE19, cross loaded with the task difficulty dimension, so it was decided to delete these items. Finally, the amount of task information dimension, given the high variance shown by item TUnIEA32, it was decided to drop this item.

\begin{tabular}{|l|l|}
\hline \multicolumn{1}{|c|}{ Task Difficulty Items } & Factor Loadings \\
\hline $\begin{array}{l}\text { TUnDif10 } \\
\text { It is difficult to see clearly the sequence of steps that can } \\
\text { be followed to coordinate/perform the activities of this } \\
\text { task }\end{array}$ & .692 \\
\hline $\begin{array}{l}\text { TUnDif11 } \\
\text { You came across specific difficult problems that you were } \\
\text { not sure how to solve immediately }\end{array}$ & .766 \\
\hline $\begin{array}{l}\text { TUnDif12 } \\
\text { Coordinating/performing the task required you to spend } \\
\text { additional time to think and solve specific problems }\end{array}$ & .746 \\
\hline $\begin{array}{l}\text { TUnDif13 } \\
\text { While coordinating/performing the task, it was difficult to } \\
\text { know whether the results of your efforts would be correct }\end{array}$ & .660 \\
\hline $\begin{array}{l}\text { TUnInE14 } \\
\text { The objectives set for this task were not clearly defined } \\
\text { according to existing standard operating procedures }\end{array}$ & .540 \\
\hline $\begin{array}{l}\text { Note: } \\
\text { Extraction Method: Maximum Likelihood } \\
\text { Rotation Method: Varimax with Kaiser Normalization }\end{array}$ & \\
\hline
\end{tabular}

Table 22. Task difficulty: factor loadings 


\begin{tabular}{|l|l|}
\hline \multicolumn{1}{|c|}{ Information Equivocality Items } & Factor Loadings \\
\hline Deleted Cross Loadings & \\
TUnInE15 & \\
Before you started this task, the information used \\
for setting the objectives of this task meant & \\
different things to different people & \\
TUnInE16 & \\
During the execution of this task, the information & \\
used to accomplish the task objectives meant & \\
different things to different people & \\
TUnInE17 & \\
There were multiple possible ways to interpret & \\
how to achieve the objectives of this task & \\
TUnInE18 & \\
There were multiple ways to interpret the possible & \\
outcomes for this task & \\
TUnInE19 & \\
There were no clear measures to evaluate the task & \\
outcomes and performance & \\
\hline Note: & \\
Extraction Method: Maximum Likelihood \\
Rotation Method: Varimax with Kaiser Normalization
\end{tabular}

Table 23. Information equivocality: factor loadings

\begin{tabular}{|l|l|}
\hline \multicolumn{1}{|c|}{ Amount of Task Information Items } & Factor Loadings \\
\hline $\begin{array}{l}\text { TUnIEA30 } \\
\text { You waited until all relevant information was examined } \\
\text { before deciding a course of } \\
\text { action to execute the activities for this task }\end{array}$ & .680 \\
\hline $\begin{array}{l}\text { TUnIEA31 } \\
\text { You kept gathering data until an excellent solution } \\
\text { emerged before deciding a course of } \\
\text { action to execute the activities for this task }\end{array}$ & .803 \\
\hline $\begin{array}{l}\text { TUnIEA33 } \\
\text { You went over all the available information until an } \\
\text { excellent solution appeared before } \\
\text { deciding a course of action to execute the activities for } \\
\text { this task }\end{array}$ & \\
\hline
\end{tabular}

Table 24. Amount of task information: factor loadings 


\begin{tabular}{|l|c|}
\hline \multicolumn{1}{|c|}{ Amount of Task Information Items } & Factor Loadings \\
\hline $\begin{array}{l}\text { Deleted High Variance } \\
\text { TUnIEA32 }\end{array}$ & \\
& $\begin{array}{l}\text { You acquired all possible information before } \\
\text { making a final decision to execute the activities for } \\
\text { this task }\end{array}$ \\
\hline $\begin{array}{l}\text { Note: } \\
\text { Extraction Method: Maximum Likelihood } \\
\text { Rotation Method: Varimax with Kaiser Normalization }\end{array}$ \\
\hline
\end{tabular}

Table 24 (continued ...)

\subsubsection{Task Significance}

The dimensionality of the 10 items used to measure task significance was analyzed using maximum likelihood factor analysis. The number of factors to rotate was determined on the a priori hypothesis that the construct was bi-dimensional (task urgency and task significance), the eigenvalues, and the interpretability of the factors solution. The initial hypothesis of bi-dimensionality was supported and the rotated solution yielded two interpretable factors. Tables 25 and 26 show the final result obtained for task urgency and task significance. For the task urgency dimension, just two items, TsgUrg21 and TsgUrg22, loaded into the other task significance dimension so it was decided to delete these items. Finally, for the task impact, item TSgImp29 cross loaded with the task urgency dimension and item TSgImp27 showed a high variance so it was decided to drop these two items. 


\begin{tabular}{|l|l|}
\hline \multicolumn{1}{|c|}{ Task Urgency Items } & Factor Loadings \\
\hline TSgUrg20 & .567 \\
This task required your immediate attention & \\
\hline $\begin{array}{l}\text { TsgUrg23 } \\
\text { The activities of this task must be done as fast as possible }\end{array}$ & .851 \\
\hline $\begin{array}{l}\text { TsgUrg24 } \\
\text { You were primarily focused on achieving the immediate } \\
\text { objectives for this task }\end{array}$ & .428 \\
\hline $\begin{array}{l}\text { Deleted Factor belonging to "Other" Significant construct } \\
\text { TsgUrg21 }\end{array}$ & \\
The pressure to complete this task did not allow \\
$\quad$ you time to think \\
$\quad$ TsgUrg22 \\
$\quad \begin{array}{l}\text { The task did not have built-in slack time which } \\
\text { allowed you time to think }\end{array}$ \\
\hline $\begin{array}{l}\text { Note: } \\
\text { Extraction Method: Maximum Likelihood } \\
\text { Rotation Method: } \text { Varimax with Kaiser Normalization }\end{array}$ \\
\hline
\end{tabular}

Table 25. Task urgency: factor loadings

\begin{tabular}{|c|c|}
\hline Task Impact Items & Factor Loadings \\
\hline $\begin{array}{l}\text { TSgImp } 25 \\
\text { Failure to complete this task would significantly impact } \\
\text { the lives or well-being of people }\end{array}$ & .470 \\
\hline $\begin{array}{l}\text { TSgImp } 26 \\
\text { Failure to complete this task would have significant } \\
\text { economic impact }\end{array}$ & .947 \\
\hline $\begin{array}{l}\text { TSgImp } 28 \\
\text { Failure to complete this task would create a pile-up of } \\
\text { activities in your own work }\end{array}$ & .512 \\
\hline $\begin{array}{l}\text { Deleted Cross Loadings } \\
\text { TSgImp29 } \\
\text { Failure to complete this task would slow down or } \\
\text { create a bottleneck for other people }\end{array}$ & \\
\hline $\begin{array}{l}\text { Deleted High Variance } \\
\text { TSgImp27 } \\
\text { Failure to complete this task would incur } \\
\text { significant infrastructure loss during the disaster }\end{array}$ & \\
\hline $\begin{array}{l}\text { Note: } \\
\text { Extraction Method: Maximum Likelihood } \\
\text { Rotation Method: Varimax with Kaiser Normalization }\end{array}$ & \\
\hline
\end{tabular}

Table 26. Task impact: factor loadings 


\subsubsection{Knowledge Sharing Purposes}

The dimensionality of the 8 items used to measure knowledge sharing purposes was analyzed using maximum likelihood factor analysis. The number of factors to rotate was determined on the a priori hypothesis that the construct was bi-dimensional (knowledge sharing for exploration and knowledge sharing for exploitation), the eigenvalues, and the interpretability of the factors solution. The initial hypothesis of bidimensionality was supported and the rotated solution yielded two interpretable factors. Tables 27 and 28 show the final result obtained knowledge sharing for exploration and knowledge sharing for exploitation.

\begin{tabular}{|l|l|}
\hline \multicolumn{1}{|c|}{ Knowledge Sharing for Exploration Items } & Factor Loadings \\
\hline $\begin{array}{l}\text { KSPExor1 } \\
\text { You searched for new ways to coordinate/perform the } \\
\text { activities of this task }\end{array}$ & .591 \\
\hline $\begin{array}{l}\text { KSPExor2 } \\
\text { You had to modify existing procedures to } \\
\text { coordinate/perform the activities of this task }\end{array}$ & .795 \\
\hline $\begin{array}{l}\text { KSPExor3 } \\
\text { You had to learn new skills or knowledge to } \\
\text { coordinate/perform the activities of this task }\end{array}$ & .706 \\
\hline $\begin{array}{l}\text { KSPExor4 } \\
\text { You discovered different procedures to } \\
\text { coordinate/perform this task }\end{array}$ & .822 \\
\hline $\begin{array}{l}\text { Note: } \\
\text { Extraction Method: Maximum Likelihood } \\
\text { Rotation Method: Varimax with Kaiser Normalization }\end{array}$ & \\
\hline
\end{tabular}

Table 27. Knowledge sharing for exploration: factor loadings 


\begin{tabular}{|l|l|}
\hline \multicolumn{1}{|c|}{ Knowledge Sharing for Exploitation Items } & Factor Loadings \\
\hline $\begin{array}{l}\text { KSPExit1 } \\
\text { To coordinate/perform this task, you used the experience } \\
\text { you gained from coordinating/ performing similar tasks in } \\
\text { the past }\end{array}$ & .791 \\
\hline $\begin{array}{l}\text { KSPExit2 } \\
\text { To coordinate/perform this task, you used your expertise }\end{array}$ & .796 \\
\hline $\begin{array}{l}\text { KSPExit3 } \\
\text { You applied the needed knowledge you obtained from } \\
\text { existing standard operating procedures }\end{array}$ & .571 \\
\hline $\begin{array}{l}\text { KSPExit4 } \\
\text { There is a defined body of knowledge which can guide } \\
\text { you in doing the activities for this task }\end{array}$ & .561 \\
\hline $\begin{array}{l}\text { Note: } \\
\text { Extraction Method: Maximum Likelihood } \\
\text { Rotation Method: Varimax with Kaiser Normalization }\end{array}$ & \\
\hline
\end{tabular}

Table 28. Knowledge sharing for exploitation: factor loadings

\subsubsection{Knowledge Sharing Mechanisms}

The dimensionality of the 13 items used to measure knowledge sharing mechanisms was analyzed using maximum likelihood factor analysis. The number of factors to rotate was determined on the a priori hypothesis that the construct was bidimensional (knowledge sharing through personal contacts and knowledge sharing through written documents), the eigenvalues, and the interpretability of the factors solution. The initial hypothesis of bi-dimensionality was supported and the rotated solution yielded two interpretable factors. Tables 29 and 30 show the final result obtained for knowledge sharing through personal contacts and knowledge sharing through written documents. 
For the knowledge sharing through written documents dimension, one item, KSMPC1, fell below the threshold of .3 and item KSMPC6 cross loaded cross loaded with the knowledge sharing through personal contacts so it was decided to drop these two items.

\begin{tabular}{|l|l|}
\hline \multicolumn{1}{|c|}{ Knowledge Sharing through Personal Contact Items } & Factor Loadings \\
\hline $\begin{array}{l}\text { KSMPC2 } \\
\text { New personnel can acquire the required knowledge for } \\
\text { this task by face-to-face on-the-job training }\end{array}$ & .449 \\
\hline $\begin{array}{l}\text { KSMPC3 } \\
\text { Personal contact interactions were required to execute the } \\
\text { activities for this task }\end{array}$ & .630 \\
\hline $\begin{array}{l}\text { KSMPC4 } \\
\text { You were able to interact with others when } \\
\text { coordinating/performing this task }\end{array}$ & .936 \\
\hline $\begin{array}{l}\text { KSMPC5 } \\
\text { People were available for personal interaction during the } \\
\text { execution of this task }\end{array}$ & .625 \\
\hline $\begin{array}{l}\text { Note: } \\
\text { Extraction Method: Maximum Likelihood } \\
\text { Rotation Method: Varimax with Kaiser Normalization }\end{array}$ & \\
\hline
\end{tabular}

Table 29. Knowledge sharing through personal contact: factor loadings

\begin{tabular}{|l|l|}
\hline Knowledge Sharing through Written Documents Items & Factor Loadings \\
\hline $\begin{array}{l}\text { KSMWD7 } \\
\text { The knowledge required to coordinate/perform this task } \\
\text { was captured in documents }\end{array}$ & .747 \\
\hline $\begin{array}{l}\text { KSMWD8 } \\
\text { The knowledge required to coordinate/perform this task } \\
\text { was stored in computer systems }\end{array}$ & .623 \\
\hline $\begin{array}{l}\text { KSMWD9 } \\
\text { An extensive documentation describing critical parts of } \\
\text { the knowledge is required to coordinate/perform this task }\end{array}$ & .565 \\
\hline $\begin{array}{l}\text { KSMWD10 } \\
\text { Standard operating procedures exist to support this task }\end{array}$ & .861 \\
\hline $\begin{array}{l}\text { KSMWD11 } \\
\text { You were able to access to existing standard operating } \\
\text { procedures when coordinating/performing this task }\end{array}$ & .852 \\
\hline
\end{tabular}

Table 30. Knowledge sharing through written documents: factor loadings 


\begin{tabular}{|c|c|}
\hline $\begin{array}{l}\text { KSMWD12 } \\
\text { Standard operating procedures were available to support } \\
\text { this task }\end{array}$ & .907 \\
\hline $\begin{array}{l}\text { KSMWD13 } \\
\text { New employees can learn how to coordinate/perform this } \\
\text { task by studying existing standard operating procedures }\end{array}$ & .599 \\
\hline $\begin{array}{l}\text { Deleted Factor Loading }<.3 \\
\text { KSMPC1 } \\
\text { New personnel can acquire the required } \\
\text { knowledge for this task by talking to skilled } \\
\text { employees }\end{array}$ & \\
\hline $\begin{array}{l}\text { Deleted Cross Loadings } \\
\text { KSMPC6 } \\
\text { You had access to experts when you needed their } \\
\text { knowledge and advice to execute this task }\end{array}$ & \\
\hline
\end{tabular}

Table 30 (continued ...)

\subsubsection{Task Performance}

The dimensionality of the 9 items used to measure task performance was analyzed using maximum likelihood factor analysis. The number of factors to rotate was determined on the a priori hypothesis that the construct was bi-dimensional (task efficiency and task effectiveness), the eigenvalues, and the interpretability of the factors solution. The initial hypothesis of bi-dimensionality was supported and the rotated solution yielded two interpretable factors. Tables 31 and 32 show the final result obtained for task efficiency and task effectiveness. For the task efficiency dimension, one item, TEfcy 11, cross loaded with the tasl effectiveness dimension so it was decided to drop this item. For the task effectiveness dimension, one item, TEfcy12, fell below the threshold of .3 and item TEfss 15 showed a high variance so it was decided to drop these two items. 


\begin{tabular}{|l|l|}
\hline \multicolumn{1}{|c|}{ Task Efficiency Items } & Factor Loadings \\
\hline $\begin{array}{l}\text { TEfcy8 } \\
\text { The task was completed within the planned time schedule }\end{array}$ & .722 \\
\hline $\begin{array}{l}\text { TEfcy9 } \\
\text { The task was completed within the allocated budget }\end{array}$ & .472 \\
\hline $\begin{array}{l}\text { TEfcy10 } \\
\text { The task was completed within the planned number of } \\
\text { person-hours }\end{array}$ & .931 \\
\hline $\begin{array}{l}\text { Deleted Cross Loadings } \\
\text { TEfcy11 } \\
\text { The task was completed with efficient use of all } \\
\text { available resources }\end{array}$ & \\
\hline $\begin{array}{l}\text { Note: } \\
\text { Extraction Method: Maximum Likelihood } \\
\text { Rotation Method: Varimax with Kaiser Normalization }\end{array}$ \\
\hline
\end{tabular}

Table 31. Task efficiency: factor loadings

\begin{tabular}{|c|c|}
\hline Task Effectiveness Items & Factor Loadings \\
\hline $\begin{array}{l}\text { TEfss } 13 \\
\text { The task was completed satisfactorily for all participants }\end{array}$ & .622 \\
\hline $\begin{array}{l}\text { TEfss } 14 \\
\text { All incident requirements were met when the task was } \\
\text { completed }\end{array}$ & .875 \\
\hline $\begin{array}{l}\text { TEfss16 } \\
\text { The task was effectively completed despite any } \\
\text { conflicting task requirements }\end{array}$ & .635 \\
\hline $\begin{array}{l}\text { Deleted Factor Loading }<.3 \\
\text { TEfcy12 } \\
\text { Completing the task did not required additional } \\
\text { unanticipated resources }\end{array}$ & \\
\hline $\begin{array}{l}\text { Deleted High Variance } \\
\text { TEfss15 } \\
\text { The task was completed successfully without } \\
\text { negatively impacting other tasks } \\
\end{array}$ & \\
\hline $\begin{array}{l}\text { Note: } \\
\text { Extraction Method: Maximum Likelihood } \\
\text { Rotation Method: Varimax with Kaiser Normalization }\end{array}$ & \\
\hline
\end{tabular}

Table 32. Task effectiveness: factor loadings 
5.6 Summary of Reliability Testing

Table 33 summarizes these results:

\begin{tabular}{|c|c|c|c|c|}
\hline $\begin{array}{l}\text { Construct and } \\
\text { Measures }\end{array}$ & $\begin{array}{c}\text { Cronbach's } \\
\text { Alpha }\end{array}$ & $\begin{array}{l}\text { Standardized } \\
\text { Item Alpha }\end{array}$ & $\begin{array}{c}\mathrm{N} \\
\text { number } \\
\text { of items }\end{array}$ & Comments \\
\hline Task Novelty & 0.773 & 0.775 & 6 & Satisfactory \\
\hline $\begin{array}{l}\text { Task Newness } \\
\text { TNvNew2, } \\
\text { TNvNew3, } \\
\text { TNvNew4 }\end{array}$ & 0.826 & 0.826 & 3 & Satisfactory \\
\hline $\begin{array}{l}\text { Task Nonroutineness } \\
\text { TNvNew5, } \\
\text { TNvNoR6, } \\
\text { TNvNoR7 }\end{array}$ & 0.768 & 0.768 & 3 & Satisfactory \\
\hline Task Unanazability & 0.681 & 0.683 & 8 & $\begin{array}{l}\text { Marginally } \\
\text { acceptable }\end{array}$ \\
\hline $\begin{array}{r}\text { Task Difficulty } \\
\text { TUnDif10, } \\
\text { TUnDif11, } \\
\text { TUnDif12, } \\
\text { TUnDif13, } \\
\text { TUnInE14 }\end{array}$ & 0.792 & 0.793 & 5 & Satisfactory \\
\hline $\begin{array}{l}\text { Amount of Task } \\
\text { Information } \\
\text { TUnIEA30,TUnIEA31, } \\
\text { TUnIEA33 }\end{array}$ & 0.797 & 0.797 & 3 & Satisfactory \\
\hline Task Significance & 0.659 & 0.659 & 6 & $\begin{array}{l}\text { Marginally } \\
\text { acceptable }\end{array}$ \\
\hline $\begin{array}{l}\text { Task Urgency } \\
\text { TSgUrg20, TSgUrg23, } \\
\text { TSgUrg24 }\end{array}$ & 0.647 & 0.644 & 3 & $\begin{array}{l}\text { Marginally } \\
\text { acceptable }\end{array}$ \\
\hline $\begin{array}{l}\text { Task Impact } \\
\text { TSgImp25, TSgImp26, } \\
\text { TSgImp28 }\end{array}$ & 0.654 & 0.654 & 3 & $\begin{array}{l}\text { Marginally } \\
\text { acceptable }\end{array}$ \\
\hline
\end{tabular}

Table 33. Cronbach's alpha values for reliability testing 


\begin{tabular}{|c|c|c|c|c|}
\hline $\begin{array}{l}\text { Construct and } \\
\text { Measures }\end{array}$ & $\begin{array}{c}\text { Cronbach's } \\
\text { Alpha }\end{array}$ & $\begin{array}{l}\text { Standardized } \\
\text { Item Alpha }\end{array}$ & $\begin{array}{c}\mathrm{N} \\
\text { number } \\
\text { of items }\end{array}$ & Comments \\
\hline $\begin{array}{l}\text { Knowlede Sharing } \\
\text { Purposes }\end{array}$ & 0.703 & 0.707 & 8 & Satisfactory \\
\hline $\begin{array}{c}\text { KS for Exploration } \\
\text { KSPExor1, } \\
\text { KSPExor2, } \\
\text { KSPExor3, } \\
\text { KSPExor4 }\end{array}$ & 0.813 & 0.813 & 4 & Satisfactory \\
\hline $\begin{array}{c}\text { KS for Exploitation } \\
\text { KSPExit5, } \\
\text { KSPExit6, } \\
\text { KSPExit7, } \\
\text { KSPExit8 } \\
\end{array}$ & 0.776 & 0.780 & 4 & Satisfactory \\
\hline $\begin{array}{l}\text { Knowlede Sharing } \\
\text { Mechanisms }\end{array}$ & 0.884 & 0.880 & 11 & Satisfactory \\
\hline $\begin{array}{l}\text { KS through Persornal } \\
\text { Contact } \\
\text { KSMPC2, } \\
\text { KSMPC3, } \\
\text { KSMPC4, } \\
\text { KSMPC5 }\end{array}$ & 0.750 & 0.765 & 4 & Satisfactory \\
\hline $\begin{array}{l}\text { KS through Written } \\
\text { Documents } \\
\text { KSMWD7, } \\
\text { KSMWD88, } \\
\text { KSMWD9, } \\
\text { KSMWD10, } \\
\text { KSMWD11, } \\
\text { KSMWD12, } \\
\text { KSMWD13 }\end{array}$ & 0.910 & 0.910 & 7 & Satisfactory \\
\hline Task Performance & 0.762 & 0.768 & 6 & Satisfactory \\
\hline $\begin{array}{l}\text { Task Efficiency } \\
\text { TEfcy8, TEfcy9, } \\
\text { TEfcy } 10 \\
\end{array}$ & 0.764 & 0.761 & 3 & Satisfactory \\
\hline $\begin{array}{c}\text { Task Effectiveness } \\
\text { TEfss } 13 \text {, TEfss } 14 \text {, } \\
\text { TEfss } 16 \\
\end{array}$ & 0.757 & 0.768 & 3 & Satisfactory \\
\hline
\end{tabular}


Table 33. (continued ...)

\subsection{Path Analyses}

Sets of multiple regression analyses were conducted to explore the relationships between uncertain dynamic disaster management tasks, knowledge sharing, and task performance.

In the first set, the independent variables included the uncertain dynamic disaster management tasks and their respective constructs (task novelty, task unanalyzability, and task significance), whereas the dependent variable included task performance and its respective dimensions (task efficiency and task effectiveness). In the second set, knowledge sharing with its respective constructs, knowledge-sharing purposes and their dimensions (knowledge sharing for exploration and knowledge sharing for exploitation), and knowledge-sharing mechanisms and their dimensions (knowledge sharing through personal contacts and knowledge sharing through written documents) were included as independent variables along with the three constructs for the uncertain dynamic disaster management tasks (task novelty, task unanalyzability, and task significance), whereas the dependent variable included task performance and its respective dimensions (task efficiency and task effectiveness). In the third set, the independent variables included the uncertain dynamic disaster management tasks and their respective constructs (task novelty, task unanalyzability, and task significance), whereas the dependent variables included knowledge-sharing purposes and their dimensions (knowledge sharing for exploration and knowledge sharing for exploitation) and knowledge-sharing mechanisms 
and their dimensions (knowledge sharing through personal contacts and knowledge sharing through written documents).

These three sets are represented by the following equations:

Set 1. Uncertain dynamic disaster management tasks and task performance

$$
\begin{aligned}
& \text { Effectiveness = } \quad \begin{array}{l}
\text { (Newness, Nonroutineness, Difficulty, Amount of Task } \\
\text { Inf., Urgency, Impact) }
\end{array} \\
& \text { Efficiency }=\quad \begin{array}{c}
\text { (Newness, Nonroutineness, Difficulty, Amount of Task } \\
\text { Inf., Urgency, Impact) }
\end{array}
\end{aligned}
$$

Set 2. Uncertain dynamic disaster management tasks, knowledge sharing, and task performance

$$
\begin{array}{ll}
\text { Effectiveness }= & f \begin{array}{l}
\text { (Newness, Nonroutineness, Difficulty, Amount of Task } \\
\text { Inf., Urgency, Impact, Exploration, Exploitation, PC, }
\end{array} \\
\text { Efficiency }= & \begin{array}{l}
\text { WD) } \\
\text { (Newness, Nonroutineness, Difficulty, Amount of Task } \\
\text { Inf., Urgency, Impact, Exploration, Exploitation, PC, } \\
\text { WD) }
\end{array}
\end{array}
$$

Set 3. Uncertain dynamic disaster management tasks and knowledge sharing

Knowledge Sharing Purposes

$$
\begin{aligned}
& \text { Exploration }=f \begin{array}{l}
\text { (Newness, Nonroutineness, Difficulty, Amount of Task } \\
\text { Inf., Urgency, Impact) }
\end{array} \\
& \text { Exploitation }=f \begin{array}{l}
\text { (Newness, Nonroutineness, Difficulty, Amount of Task } \\
\text { Inf., Urgency, Impact) }
\end{array}
\end{aligned}
$$

Knowledge Sharing Mechanisms

$$
\begin{aligned}
& \text { Personal Contacts }=f \text { (Newness, Nonroutineness, Difficulty, Amount } \\
& \text { of Task Inf., Urgency, Impact) }
\end{aligned}
$$




\section{Written Documents $=f$ (Newness, Nonroutineness, Difficulty, Amount of Task Inf., Urgency, Impact)}

Table 34 summarizes set of equations 1 and 2 showing the individual values of standardized beta coefficients, t-statistic, and the statistically significant level, and table 35 summarizes set of equations 3 showing the individual values of standardized beta coefficients, t-statistic, and the statistically significant level. 


\begin{tabular}{|c|c|c|c|c|c|c|c|c|}
\hline & \multicolumn{2}{|l|}{ Effectiveness } & \multicolumn{2}{|l|}{ Effectiveness } & \multicolumn{2}{|l|}{ Efficiency } & \multicolumn{2}{|l|}{ Efficiency } \\
\hline & $\begin{array}{l}\text { Standardized } \\
\beta \text { coefficient }\end{array}$ & t-statistic & $\begin{array}{l}\text { Standardized } \\
\beta \text { coefficient }\end{array}$ & t-statistic & $\begin{array}{l}\text { Standardized } \\
\beta \text { coefficient }\end{array}$ & t-statistic & $\begin{array}{l}\text { Standardized } \\
\beta \text { coefficient }\end{array}$ & t-statistic \\
\hline Task Newness & -0.087 & -1.015 & -0.059 & -0.580 & -0.117 & -1.310 & -0.073 & -0.708 \\
\hline $\begin{array}{l}\text { Task } \\
\text { Nonroutineness }\end{array}$ & 0.087 & 1.110 & 0.072 & 0.917 & 0.049 & 0.597 & 0.040 & 0.500 \\
\hline Task Difficulty & -0.177 & $\begin{array}{l}-2.084^{*} \\
\text { H1c }\end{array}$ & -0.184 & $\begin{array}{l}-2.048 * \\
\text { H5c }\end{array}$ & -0.146 & $\begin{array}{l}-1.659+ \\
\mathrm{H} 3 \mathrm{c}\end{array}$ & -0.054 & -0.596 \\
\hline $\begin{array}{l}\text { Amount of } \\
\text { Task } \\
\text { Information }\end{array}$ & 0.065 & 0.884 & 0.067 & 0.890 & 0.226 & $\begin{array}{l}2.973 * * \\
\mathrm{H} 4 \mathrm{a}\end{array}$ & 0.161 & $\begin{array}{l}2.093^{*} \\
\text { H6d }\end{array}$ \\
\hline Task Urgency & 0.285 & $\begin{array}{l}3.777 * * * \\
\mathrm{H} 2 \mathrm{~b}\end{array}$ & 0.238 & $\begin{array}{l}3.066^{* *} \\
\mathrm{H} 5 \mathrm{e}\end{array}$ & 0.049 & 0.627 & -0.006 & -0.070 \\
\hline Task Impact & 0.178 & $\begin{array}{l}2.331^{*} \\
\mathrm{H} 2 \mathrm{c}\end{array}$ & 0.195 & $\begin{array}{l}2.304^{*} \\
\text { H5f }\end{array}$ & 0.044 & 0.554 & -0.035 & -0.407 \\
\hline KS Exploration & & & -0.018 & -0.174 & & & -0.046 & -0.447 \\
\hline $\begin{array}{l}\text { KS } \\
\text { Exploitation }\end{array}$ & & & 0.177 & $\begin{array}{l}1.867+ \\
\text { H5i }\end{array}$ & & & 0.269 & $\begin{array}{l}2.794 * * \\
\text { H6h }\end{array}$ \\
\hline $\begin{array}{l}\text { KS Personal } \\
\text { Contact }\end{array}$ & & & 0.021 & 0.242 & & & 0.038 & 0.439 \\
\hline $\begin{array}{l}\text { KS Written } \\
\text { Documents }\end{array}$ & & & -0.184 & $\begin{array}{l}-2.007^{*} \\
\mathrm{H} 5 \mathrm{j}\end{array}$ & & & 0.041 & 0.442 \\
\hline
\end{tabular}


$F=\mathbf{3 . 2 4 7} * * *$

Note: ${ }^{* * *} p<0.001 ;{ }^{* *} p<0.01 ;{ }^{*} p<0.05 ;{ }^{+} p<0.1$

Table 34. Summary of path analyses, uncertain dynamic disaster management tasks, knowledge sharing, and task performance 
Based on the results of Table 34 , the standardized $\beta$ coefficient between task difficulty and task effectiveness was negative and significant $(-1.177, p<*)$. This result provides support for the hypothesis that task difficulty is negatively associated with task effectiveness. The standardized $\beta$ coefficient between task urgency and task effectiveness was positive and significant $(0.285, p<* * *)$. This result provides support for the hypothesis that task urgency is positively associated with task effectiveness. The standardized $\beta$ coefficient between task impact and task effectiveness was positive and significant $\left(0.178, p<^{*}\right)$. This result provides support for the hypothesis that task impact is positively associated with task effectiveness.

Furthermore, the standardized $\beta$ coefficient between task difficulty and task efficiency was negative and significant $(-0.146, p<+)$. This result provides support for the hypothesis that task difficulty is negatively associated with task efficiency. And, the standardized $\beta$ coefficient between amount of task information and task efficiency was positive and significant $(0.226, p<* *)$. This result provides support for the hypothesis that the amount of task information is positively associated with task efficiency.

Similarly, Table 34 shows the results when the variable of knowledge sharing along with its constructs, knowledge sharing purpose and its dimensions (knowledge sharing for exploration and knowledge sharing for exploitation), and knowledge sharing mechanisms and its dimensions (knowledge sharing through personal contacts and knowledge sharing through written documents), are added as independent variables along with dynamic disaster management tasks and their respective constructs (task novelty, task unanazability, and task significance) and the dependent variable of task performance and its respective dimensions (task efficiency and task effectiveness). 
According to the results of Table 34, the standardized $\beta$ coefficient between task difficulty and task effectiveness was negative and significant $\left(-0.184, p<^{*}\right)$. This result provides support for the hypothesis that task difficulty is negatively associated with task effectiveness. The standardized $\beta$ coefficient between task urgency and task effectiveness was positive and significant $(0.238, p<* *)$. This result provides support for the hypothesis that task urgency is positively associated with task effectiveness. The standardized $\beta$ coefficient between task impact and task effectiveness was positive and significant $(0.195, p<*)$. This result provides support for the hypothesis that task impact is positively associated with task effectiveness.

The standardized $\beta$ coefficient between knowledge sharing for exploitation and task effectiveness was positive and significant $(0.177, p<+)$. This result provides support for the hypothesis that knowledge sharing for exploitation is positively associated with task effectiveness. The standardized $\beta$ coefficient between knowledge sharing through written documents and task effectiveness was negative and significant $\left(-0.184, p<^{*}\right)$. This result provides support for the hypothesis that knowledge sharing through written documents is negatively associated with task effectiveness.

Furthermore, the standardized $\beta$ coefficient between amount of task information and task efficiency was positive and significant $(0.161, p<*)$. This result provides support for the hypothesis that amount of task information is positively associated with task efficiency. The standardized $\beta$ coefficient between knowledge sharing for exploitation and task efficiency was positive and significant $(0.269, p<* *)$. This result provides support for the hypothesis that knowledge sharing for exploitation is positively associated with task efficiency. 


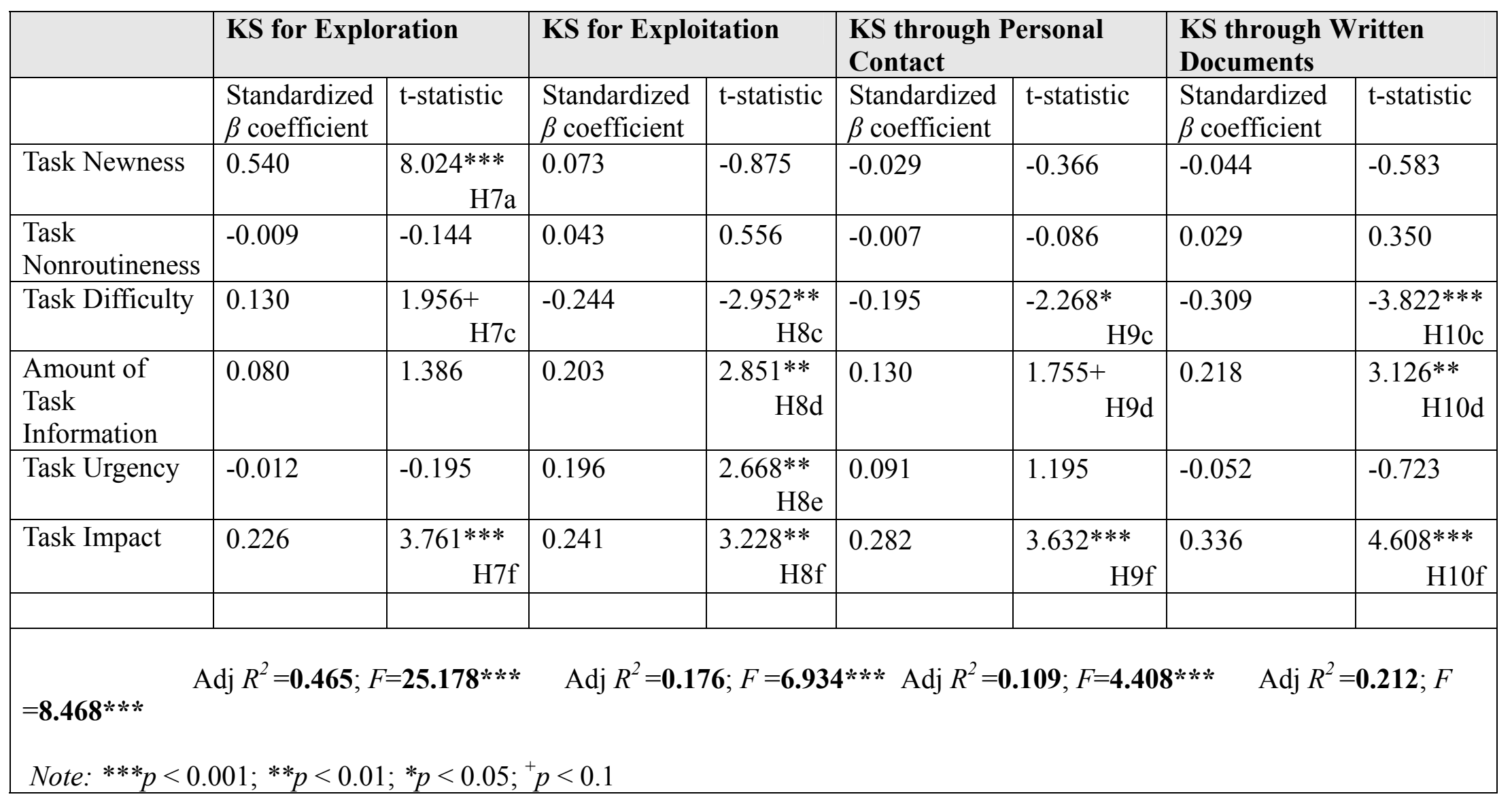

Table 35. Summary of path analyses, uncertain dynamic disaster management tasks and knowledge sharing 
To explore the relationships between uncertain dynamic disaster management tasks and knowledge sharing, sets of multiple regression analyses were conducted, as previously described. Table 35 summarizes the third set of equations, showing the individual values of standardized beta coefficients, t-statistics, and levels of statistical significance.

The standardized $\beta$ coefficient between task newness and knowledge sharing for exploration was positive and significant $(0.540, p<* *)$. This result provides support for the hypothesis that task newness is positively associated with knowledge sharing for exploration. The standardized $\beta$ coefficient between task difficulty and knowledge sharing for exploration was positive and significant $(0.130, p<+)$. This result provides support for the hypothesis that task difficulty is positively associated with knowledge sharing for exploration. The standardized $\beta$ coefficient between task impact and knowledge sharing for exploration was positive and significant $(0.226, p<* * *)$. This result provides support for the hypothesis that task impact is positively associated with knowledge sharing for exploration.

The standardized $\beta$ coefficient between task difficulty and knowledge sharing for exploitation was negative and significant $(-0.244, p<* *)$. This result did not provide support for the hypothesis that task difficulty is positively associated with knowledge sharing for exploitation. The standardized $\beta$ coefficient between amount of task information and knowledge sharing for exploitation was positive and significant $(0.203, p<* *)$. This result provides support for the hypothesis that amount of task information is positively associated with knowledge sharing for exploitation. 
The standardized $\beta$ coefficient between task urgency and knowledge sharing for exploitation was positive and significant $(0,196, p<* *)$. This result provides support for the hypothesis that task urgency is positively associated with knowledge sharing for exploitation. The standardized $\beta$ coefficient between task impact and knowledge sharing for exploitation was positively and significant $(0.241, p<* *)$. This result provides support for the hypothesis that task impact is positively associated with knowledge sharing for exploitation.

The standardized $\beta$ coefficient between task difficulty and knowledge sharing through personal contacts was negative and significant $(-0.195, p<*)$. This result did not provide support for the hypothesis that task difficulty is positively associated with knowledge sharing through personal contacts. The standardized $\beta$ coefficient between amount of task information and knowledge sharing through personal contacts was positive and significant $(0.130, p<+)$. This result provides support for the hypothesis that amount of task information is positively associated with knowledge sharing through personal contacts.

The standardized $\beta$ coefficient between task impact and knowledge sharing through personal contacts was positive and significant $(0.282, p<* * *)$. This result provides support for the hypothesis that task impact is positively associated with knowledge sharing through personal contacts.

The standardized $\beta$ coefficient between task difficulty and knowledge sharing through written documents was negative and significant $(-0.309, p<* * *)$. This result did not provide support for the hypothesis that task difficulty is positively associated with knowledge sharing through written documents. 
The standardized $\beta$ coefficient between amount of task information and knowledge sharing through written documents was positive and significant $(0.218, p<* *)$. This result provides support for the hypothesis that amount of task information is positively associated with knowledge sharing through written documents. The standardized $\beta$ coefficient between task impact and knowledge sharing through written documents was positive and significant $(0.336, p<* * *)$. This result provides support for the hypothesis that task impact is positively associated with knowledge sharing through written documents.

The table below summarizes the hypothesis and the finding of this study through path analysis.

\begin{tabular}{|l|l|l|}
\hline H1c. & $\begin{array}{l}\text { Task difficulty is negatively associated with } \\
\text { task effectiveness }\end{array}$ & $\begin{array}{l}\text { Marginally Supported: } \\
{ }^{*} p<0.05\end{array}$ \\
\hline H2b. & $\begin{array}{l}\text { Task urgency is positively associated with task } \\
\text { effectiveness }\end{array}$ & $\begin{array}{l}\text { Strongly Supported: } \\
{ }^{* * *} p<0.001\end{array}$ \\
\hline H2c. & $\begin{array}{l}\text { Task impact is positively associated with task } \\
\text { effectiveness }\end{array}$ & $\begin{array}{l}\text { Marginally Supported: } \\
{ }^{*} p<0.05\end{array}$ \\
\hline H3c. & $\begin{array}{l}\text { Task difficulty is negatively associated with } \\
\text { task efficiency }\end{array}$ & $\begin{array}{l}\text { Marginally Not Supported: } \\
{ }_{p} p<0.1\end{array}$ \\
\hline H4a. & $\begin{array}{l}\text { Amount of task information is positively } \\
\text { associated with task efficiency }\end{array}$ & $\begin{array}{l}\text { Supported: } \\
{ }_{*} p p<0.01\end{array}$ \\
\hline H5c. & $\begin{array}{l}\text { Task difficulty is negatively associated with } \\
\text { task effectiveness }\end{array}$ & $\begin{array}{l}\text { Marginally Supported: } \\
{ }^{*} p<0.05\end{array}$ \\
\hline H5e. & $\begin{array}{l}\text { Task urgency is positively associated with task } \\
\text { effectiveness }\end{array}$ & $\begin{array}{l}\text { Supported: } \\
{ }^{* *} p<0.01\end{array}$ \\
\hline H5f. & $\begin{array}{l}\text { Task impact is positively associated with task } \\
\text { effectiveness }\end{array}$ & $\begin{array}{l}\text { Marginally Supported: } \\
{ }^{*} p<0.05\end{array}$ \\
\hline H5i. & $\begin{array}{l}\text { Knowledge sharing purpose for exploitation is } \\
\text { negatively associated with task effectiveness }\end{array}$ & $\begin{array}{l}\text { Marginally Not Supported: } \\
{ }^{+} p<0.1\end{array}$ \\
\hline
\end{tabular}

Table 36. Summary of path analyses hypothesis and findings 


\begin{tabular}{|c|c|c|}
\hline $\mathrm{H} 5 \mathrm{j}$. & $\begin{array}{l}\text { Knowledge sharing mechanism through written } \\
\text { documents is negatively associated with task } \\
\text { effectiveness }\end{array}$ & $\begin{array}{l}\text { Marginally Supported: } \\
*_{p}<0.05\end{array}$ \\
\hline H6d. & $\begin{array}{l}\text { Amount of task information is positively } \\
\text { associated with task efficiency }\end{array}$ & $\begin{array}{l}\text { Marginally Supported: } \\
*_{p}<0.05\end{array}$ \\
\hline H6h. & $\begin{array}{l}\text { Knowledge sharing purpose for exploitation is } \\
\text { positively associated with task efficiency }\end{array}$ & $\begin{array}{l}\text { Supported: } \\
* * p<0.01\end{array}$ \\
\hline H7a. & $\begin{array}{l}\text { Task newness is positively associated with } \\
\text { knowledge sharing for exploration }\end{array}$ & $\begin{array}{l}\text { Strongly Supported: } \\
* * * p<0.001\end{array}$ \\
\hline H7c. & $\begin{array}{l}\text { Task difficulty is positively associated with } \\
\text { knowledge sharing for exploration }\end{array}$ & $\begin{array}{l}\text { Marginally Not Supported: } \\
{ }_{p}^{+}<0.1\end{array}$ \\
\hline H7f. & $\begin{array}{l}\text { Task impact is positively associated with } \\
\text { knowledge sharing for exploration }\end{array}$ & $\begin{array}{l}\text { Strongly Supported: } \\
* * * p<0.001\end{array}$ \\
\hline H8c. & $\begin{array}{l}\text { Task difficulty is positively associated with } \\
\text { knowledge sharing for exploitation }\end{array}$ & $\begin{array}{l}\text { Supported: } \\
* * p<0.01 \\
\text { but reverse direction }\end{array}$ \\
\hline H8d. & $\begin{array}{l}\text { Amount of task information is positively } \\
\text { associated knowledge sharing for exploitation }\end{array}$ & $\begin{array}{l}\text { Supported: } \\
* *_{p}<0.01\end{array}$ \\
\hline H8e. & $\begin{array}{l}\text { Task urgency is positively associated with } \\
\text { knowledge sharing for exploitation }\end{array}$ & $\begin{array}{l}\text { Supported: } \\
* * p<0.01\end{array}$ \\
\hline H8f. & $\begin{array}{l}\text { Task impact is positively associated with } \\
\text { knowledge sharing for exploitation }\end{array}$ & $\begin{array}{l}\text { Supported: } \\
* *_{p}<0.01\end{array}$ \\
\hline H9c. & $\begin{array}{l}\text { Task difficulty is positively associated with } \\
\text { knowledge sharing through personal contacts }\end{array}$ & $\begin{array}{l}\text { Marginally Supported: } \\
*_{p}<0.05 \\
\text { but reverse direction }\end{array}$ \\
\hline H9d. & $\begin{array}{l}\text { Amount of task information is positively } \\
\text { associated knowledge sharing through personal } \\
\text { contacts }\end{array}$ & $\begin{array}{l}\text { Marginally Not Supported: } \\
{ }^{+} p<0.1\end{array}$ \\
\hline H9f. & $\begin{array}{l}\text { Task impact is positively associated with } \\
\text { knowledge sharing through personal contacts }\end{array}$ & $\begin{array}{l}\text { Strongly Supported: } \\
* * * p<0.001\end{array}$ \\
\hline H10c. & $\begin{array}{l}\text { Task difficulty is positively associated with } \\
\text { knowledge sharing through written documents }\end{array}$ & $\begin{array}{l}\text { Strongly Supported: } \\
* * * p<0.001 \\
\text { but reverse direction }\end{array}$ \\
\hline H10d. & $\begin{array}{l}\text { Amount of task information is positively } \\
\text { associated knowledge sharing through written } \\
\text { documents }\end{array}$ & $\begin{array}{l}\text { Supported: } \\
* * p<0.01\end{array}$ \\
\hline H10f. & $\begin{array}{l}\text { Task impact is negatively associated with } \\
\text { knowledge sharing through written documents }\end{array}$ & $\begin{array}{l}\text { Strongly Supported: } \\
* * * p<0.001\end{array}$ \\
\hline
\end{tabular}

Table 36. (continued ...) 


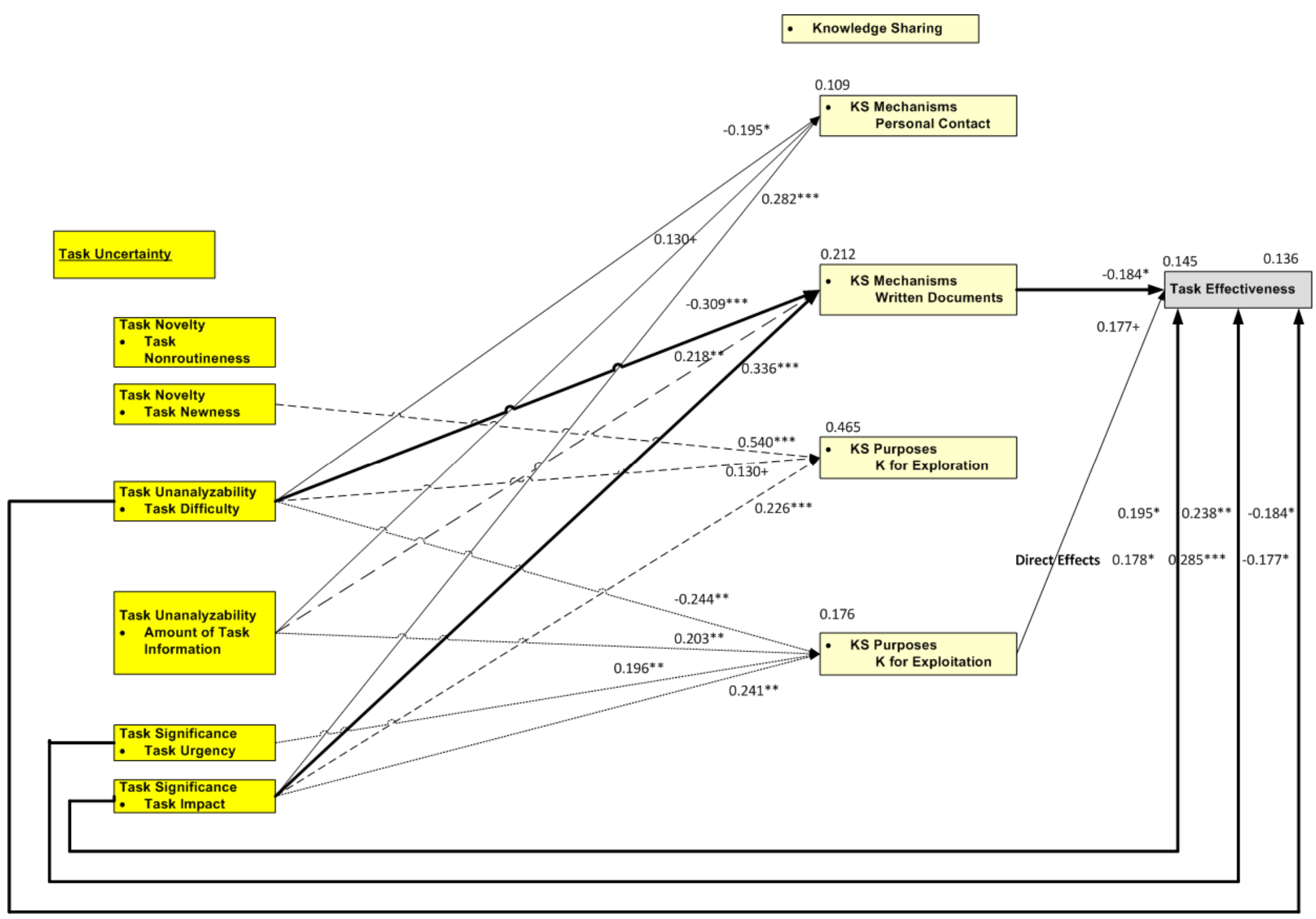

Figure 14. Summary of path analyses on task effectiveness 


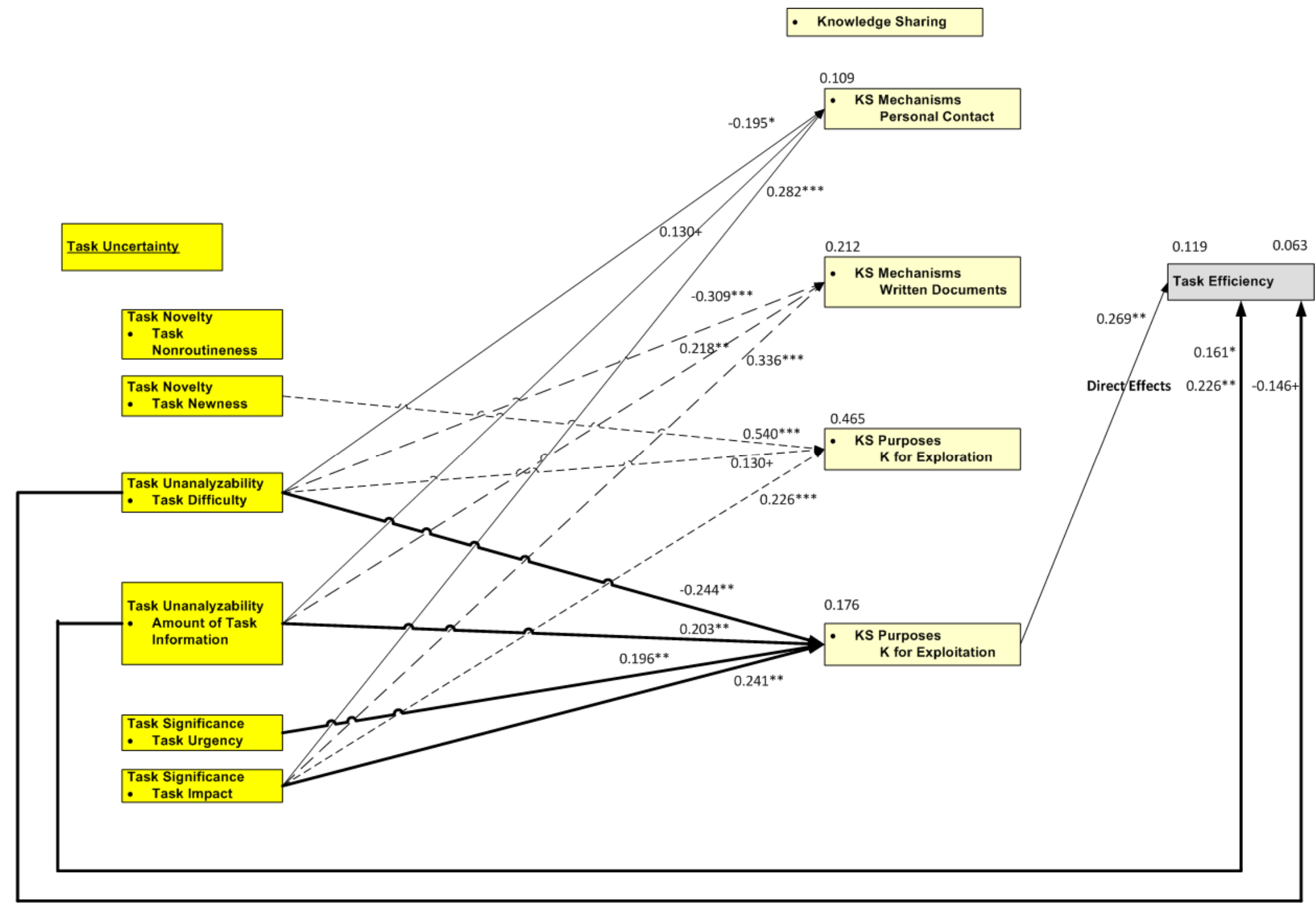

Figure 15. Summary of path analyses on task efficiency 


\subsection{Path Analyses with Control Variables}

Sets of multiple regression analyses were conducted to explore the relationships between uncertain dynamic disaster management tasks, knowledge sharing, and task performance and control variables that were taken from the research instrument responses and demographic attributes. The control variables that were used in this study were as follows:

1. Years of experience the respondent had the last time he/she coordinated/performed the emergency task chosen to respond this research survey.

2. Level of expertise, from novice to expert, the respondent had the last time he/she coordinated/performed the emergency task chosen to respond this research survey.

3. Number of years worked in the current organization.

4. Number of years worked in the emergency management field.

In the first set, the independent variables included the uncertain dynamic disaster management tasks and their respective constructs (task novelty, task unanalyzability, and task significance) and the control variables of years of experience, level of expertise, years worked in the current organization, and years worked in the emergency management field; however, the dependent variable included task performance and its respective dimensions (task efficiency and task effectiveness). 
In the second set, knowledge sharing with its respective constructs, knowledgesharing purposes and their dimensions (knowledge sharing for exploration and knowledge sharing for exploitation), and knowledge-sharing mechanisms and their dimensions (knowledge sharing through personal contacts and knowledge sharing through written documents) were included as independent variables, and the control variables included years of experience, level of expertise, years worked in the current organization, and years worked in the emergency management field, along with the three constructs for the uncertain dynamic disaster management tasks (task novelty, task unanalyzability, and task significance). Conversely, the dependent variable included task performance and its respective dimensions (task efficiency and task effectiveness). In the third set, the independent variables included the uncertain dynamic disaster management tasks and their respective constructs (task novelty, task unanalyzability, and task significance) and the control variables of years of experience, level of expertise, years worked in the current organization, and years worked in the emergency management field, whereas the dependent variables included knowledge-sharing purposes and their dimensions (knowledge sharing for exploration and knowledge sharing for exploitation) and knowledge-sharing mechanisms and their dimensions (knowledge sharing through personal contacts and knowledge sharing through written documents). 
These three sets are represented by the following equations:

Set 1. Uncertain dynamic disaster management tasks and task performance

\begin{tabular}{|c|c|}
\hline Effectiveness $=$ & $\begin{array}{l}f \text { (Newness, Nonroutineness, Difficulty, Amount of Task } \\
\text { Inf., Urgency, Impact, Experience, Expertise, } \\
\text { Years Worked Current Organization, Years Worked } \\
\text { Emergency Management Field) }\end{array}$ \\
\hline Efficiency $=$ & $\begin{array}{l}f \text { (Newness, Nonroutineness, Difficulty, Amount of Task } \\
\text { Inf., Urgency, Impact, Experience, Expertise, } \\
\text { Years Worked Current Organization, Years Worked } \\
\text { Emergency Management Field) }\end{array}$ \\
\hline
\end{tabular}

Set 2. Uncertain dynamic disaster management tasks, knowledge sharing, and task performance

$\begin{array}{ll}f \text { Effectiveness }= & \text { (Newness, Nonroutineness, Difficulty, Amount of Task } \\ & \text { Inf., Urgency, Impact, Exploration, Exploitation, PC, } \\ & \text { WD, Experience, Expertise, Years Worked Current } \\ & \text { Organization, Years Worked Emergency Management } \\ & \text { Field) } \\ f & \text { (Newness, Nonroutineness, Difficulty, Amount of Task } \\ \text { Efficiency }= & \text { Inf., Urgency, Impact, Exploration, Exploitation, PC, } \\ & \text { WD, Experience, Expertise, Years Worked Current } \\ & \text { Organization, Years Worked Emergency Management } \\ & \text { Field) }\end{array}$


Set 3. Uncertain dynamic disaster management tasks and knowledge sharing

Knowledge Sharing Purposes

Exploration $=f$ (Newness, Nonroutineness, Difficulty, Amount of Task Inf., Urgency, Impact, Experience, Expertise, Years Worked Current, Organization, Years Worked Emergency Management Field)

Exploitation $=f$ (Newness, Nonroutineness, Difficulty, Amount of Task Inf., Urgency, Impact, Experience, Expertise, Years Worked Current, Organization, Years Worked Emergency Management Field)

Knowledge Sharing Mechanisms

Personal Contacts $=f$ (Newness, Nonroutineness, Difficulty, Amount of Task Inf., Urgency, Impact, Experience, Expertise, Years Worked Current, Organization, Years Worked Emergency Management Field)

Written Documents $=f$ (Newness, Nonroutineness, Difficulty, Amount of Task Inf., Urgency, Impact, Experience, Expertise, Years Worked Current, Organization, Years Worked Emergency Management Field)

Table 37 summarizes set of equations 1 and 2 showing the individual values of standardize beta coefficients, t-statistic, and the statistically significant level, and table 38 summarizes set of equations 3 showing the individual values of standardize beta coefficients, t-statistic, and the statistically significant level. 


\begin{tabular}{|c|c|c|c|c|c|c|c|c|}
\hline & \multicolumn{2}{|c|}{ Effectiveness } & \multicolumn{2}{|c|}{ Effectiveness } & \multicolumn{2}{|c|}{ Efficiency } & \multicolumn{2}{|c|}{ Efficiency } \\
\hline & $\begin{array}{l}\text { Standardized } \\
\beta \text { coefficient }\end{array}$ & t-statistic & $\begin{array}{l}\text { Standardized } \\
\beta \text { coefficient }\end{array}$ & t-statistic & $\begin{array}{l}\text { Standardized } \\
\beta \text { coefficient }\end{array}$ & t-statistic & $\begin{array}{l}\text { Standardized } \\
\beta \text { coefficient }\end{array}$ & t-statistic \\
\hline Task Newness & -0.083 & -0.958 & -0.051 & -0.497 & -0.094 & -1.025 & -0.062 & -0.585 \\
\hline $\begin{array}{l}\text { Task } \\
\text { Nonroutineness }\end{array}$ & 0.084 & 1.062 & 0.072 & 0.905 & 0.053 & 0.633 & 0.053 & 0.655 \\
\hline Task Difficulty & -0.182 & $-2.102^{*}$ & -0.167 & $-1.826+$ & -0.149 & -1.634 & -0.059 & -0.625 \\
\hline $\begin{array}{l}\text { Amount of } \\
\text { Task } \\
\text { Information }\end{array}$ & 0.076 & 1.032 & 0.069 & 0.911 & 0.219 & $2.814 * *$ & 0.157 & $2.000 *$ \\
\hline Task Urgency & 0.282 & $3.720 * * *$ & 0.234 & $2.983 * *$ & 0.042 & 0.527 & -0.015 & -0.185 \\
\hline Task Impact & 0.170 & $2.186^{*}$ & 0.187 & $2.128 *$ & 0.047 & 0.572 & -0.038 & -0.423 \\
\hline KS Exploration & & & -0.045 & -0.435 & & & -0.048 & -0.458 \\
\hline $\begin{array}{l}\text { KS } \\
\text { Exploitation }\end{array}$ & & & 0.183 & 1.875 & & & 0.263 & 2.623 \\
\hline $\begin{array}{l}\text { KS Personal } \\
\text { Contact }\end{array}$ & & & 0.029 & 0.342 & & & 0.043 & 0.487 \\
\hline $\begin{array}{l}\text { KS Written } \\
\text { Documents }\end{array}$ & & & -0.158 & -1.648 & & & 0.060 & 0.610 \\
\hline Experience & -0.168 & $-1.887+$ & -0.164 & $-1.807+$ & -0.040 & -0.427 & -0.028 & -0.306 \\
\hline Expertise & 0.000 & 0.003 & -0.014 & -0.159 & 0.051 & 0.556 & -0.034 & -0.363 \\
\hline $\begin{array}{l}\text { Worked Years } \\
\text { Current Org. }\end{array}$ & 0.067 & 0.872 & 0.033 & 0.414 & 0.092 & 1.135 & 0.080 & 0.993 \\
\hline $\begin{array}{l}\text { Worked Years } \\
\text { in Emergency } \\
\text { Management }\end{array}$ & 0.097 & 1.232 & 0.081 & 1.017 & -0.052 & -0.628 & -0.022 & -0.270 \\
\hline$F=2.377 * *$ & Adj $R^{2}=0.14$ & $F=3.843$ & $\operatorname{Adj} R^{2}=0$. & $52 ; F=3$. & *** $\quad \operatorname{Adj} R^{2}$ & $0.050 ; F=$ & $\operatorname{Adj} R$ & $=0.104$ \\
\hline
\end{tabular}


Note: ${ }^{* * *} p<0.001 ;{ }^{* *} p<0.01 ;{ }^{*} p<0.05 ;{ }^{+} p<0.1$

Table 37. Summary of path analyses, uncertain dynamic disaster management tasks, knowledge sharing, and control variables on task performance 


\begin{tabular}{|c|c|c|c|c|c|c|c|c|}
\hline & \multicolumn{2}{|c|}{ KS for Exploration } & \multicolumn{2}{|c|}{ KS for Exploitation } & \multicolumn{2}{|c|}{$\begin{array}{c}\text { KS through Personal } \\
\text { Contact }\end{array}$} & \multicolumn{2}{|c|}{$\begin{array}{c}\text { KS through Written } \\
\text { Documents }\end{array}$} \\
\hline & $\begin{array}{l}\text { Standardized } \\
\beta \text { coefficient }\end{array}$ & t-statistic & $\begin{array}{l}\text { Standardized } \\
\beta \text { coefficient }\end{array}$ & t-statistic & $\begin{array}{l}\text { Standardized } \\
\beta \text { coefficient }\end{array}$ & t-statistic & $\begin{array}{l}\text { Standardized } \\
\beta \text { coefficient }\end{array}$ & t-statistic \\
\hline Task Newness & 0.545 & $7.955 * * *$ & -0.027 & -0.323 & 0.004 & 0.044 & 0.019 & 0.237 \\
\hline $\begin{array}{l}\text { Task } \\
\text { Nonroutineness }\end{array}$ & -0.020 & -0.325 & 0.016 & 0.209 & -0.045 & -0.555 & -0.062 & -0.852 \\
\hline Task Difficulty & 0.153 & $2.246^{*}$ & -0.231 & $-2.795 * *$ & -0.178 & $-2.008^{*}$ & -0.246 & $-3.080 * *$ \\
\hline $\begin{array}{l}\text { Amount of } \\
\text { Task } \\
\text { Information }\end{array}$ & 0.071 & 1.221 & 0.190 & $2.695 * *$ & 0.120 & 1.582 & 0.179 & $2.633 * *$ \\
\hline Task Urgency & -0.010 & -0.167 & 0.207 & $2.872 * *$ & 0.101 & 1.301 & -0.041 & -0.587 \\
\hline Task Impact & 0.234 & $3.832 * * *$ & 0.235 & $3.178 * *$ & 0.284 & $3.578 * * *$ & 0.371 & $5.182 * * *$ \\
\hline Experience & -0.162 & $-2.307^{*}$ & -0.071 & -0.838 & -0.004 & -0.047 & -0.008 & -0.100 \\
\hline Expertise & 0.119 & $1.731+$ & 0.274 & $3.288 * * *$ & 0.138 & 1.547 & 0.216 & $2.684 * *$ \\
\hline $\begin{array}{l}\text { Worked Years } \\
\text { Current Org. }\end{array}$ & 0.021 & 0.344 & 0.083 & 1.124 & -0.020 & -0.256 & -0.133 & $-1.871+$ \\
\hline $\begin{array}{l}\text { Worked Years } \\
\text { in Emergency } \\
\text { Management }\end{array}$ & -0.007 & -0.110 & -0.065 & -0.871 & -0.048 & -0.600 & -0.182 & $-2.505^{*}$ \\
\hline $\begin{array}{l}F=7.276 * * * \\
\text { Note: } * * * p<0 .\end{array}$ & $1 ; * * p<0.0$ & $*_{p}<0.0$ & $* * \operatorname{Adj} R^{2}=0$ & $22 ; F=5.7$ & $* * * \operatorname{Adj} R^{2}=$ & $.105 ; F=$ & $62 * * \quad \operatorname{Adj} F$ & $=0.273$ \\
\hline
\end{tabular}

Table 38. Summary of path analyses, uncertain dynamic disaster management tasks and control variables on knowledge sharing 
For the first and second sets of equations, based on the results of Table 37, there were no major differences in the magnitudes and directions of the relationships between the independent variables of uncertain dynamic disaster management tasks, knowledge sharing, the control variables, and the dependent variable of task performance. Similarly, for the third set of equations based on the results of Table 38, there were no major differences in the magnitudes and directions of the relationships between the independent variables of uncertain dynamic disaster management tasks, the control variables, and the dependent variable of knowledge sharing. In other words, the findings remained the same.

\subsection{Moderating Effects of Knowledge Sharing}

To assess the levels of knowledge-sharing purposes (exploration and exploitation) and mechanisms (personal contacts and written documents) that were required to have a positive or negative relationship between uncertain dynamic tasks and their novelty dimensions (task newness and task nonroutineness), unanalyzability dimensions (task difficulty and amount of task information), and significance dimensions (task urgency and task impact) and task performance (task effectiveness and task performance), two moderating effects methodologies were adopted. First, the median values for knowledgesharing purposes (exploration and exploitation) and mechanisms (personal contacts and written documents) were estimated. 
Then, the survey data were divided into two groups: the first group contained those cases for which the values of the specific knowledge-sharing purpose (exploration and exploitation) and mechanisms (personal contacts and written documents) were less than the median values, and the second group contained those cases for which the values of the specific knowledge-sharing purpose (exploration and exploitation) and mechanisms (personal contacts and written documents) were equal or greater than the median values.

Therefore, it is assumed that the first group of uncertain dynamic tasks was performed using relatively low levels of knowledge-sharing purposes (exploration and exploitation) and mechanisms (personal contacts and written documents), and the second group of uncertain dynamic tasks was performed using relatively high levels of knowledge-sharing purposes and mechanisms.

Second, the moderated relationships that were described above can be determined through multiple regressions, wherein the relationship between independent and dependent variables is moderated by a moderating variable. These interaction effects occur when the "effect of the independent variable on the dependent variable differs depending on the value of a third variable, called the moderator variable" [Jaccard and Turrisi, 2003, p. 3]. Simple regression analyses were performed with the independent variables, the moderating variables, and the cross-product terms that were formed from the interaction effects of the independent variables and the moderating variables. 
Therefore, it is assumed that the moderating variables, knowledge sharingpurposes (exploration and exploitation) and mechanisms (personal contacts and written documents) within the cross-product terms that were formed through the interaction effects with the uncertain dynamic tasks, novelty dimensions (task newness and task nonroutineness), unanalyzability dimensions (task difficulty and the amount of task information), and significance dimensions (task urgency and task impact) will influence task performance (task effectiveness and task performance).

Corresponding to the first moderating effects methodology cited above and the first set of moderating hypotheses, wherein knowledge sharing for exploration and knowledge sharing through written documents moderate the relationship between uncertain dynamic task characteristics and task performance, two sets of multiple regression analyses were performed according to the following equations:

1. Knowledge sharing for exploration less than its median value Effectiveness $=f$ (Newness, Nonroutineness, Difficulty, Amount of Task Inf., Urgency, Impact)

2. Knowledge sharing for exploration equal or greater than its median value Effectiveness $=f$ (Newness, Nonroutineness, Difficulty, Amount of Task Inf., Urgency, Impact)

3. Knowledge sharing through written documents less than its median value Effectiveness $=f$ (Newness, Nonroutineness, Difficulty, Amount of Task Inf., Urgency, Impact)

4. Knowledge sharing through written documents equal or greater than its median value Effectiveness $=f$ (Newness, Nonroutineness, Difficulty, Amount of Task Inf., Urgency, Impact)

The significant results are depicted in Figure 16 and Table 39. 
The standardized $\beta$ coefficient between task difficulty and task effectiveness was negative and significant $(-0.289, p<*)$ when the level of knowledge sharing through written documents was equal or above its median value. However, when the level of knowledge sharing through written documents was below its median value, this relationship was not significant. This result indicates that when the level of knowledge sharing through written documents is equal or greater than its median value, the negative impact of task difficulty is greater on task effectiveness as compared to the impact when knowledge sharing through written documents is below its median value. This result provide support for the hypothesis that knowledge sharing through written documents negatively moderates the relationship between uncertain dynamic task characteristics with unanalyzability dimension (task difficulty) with task effectiveness.

The standardized $\beta$ coefficient between task urgency and task effectiveness was positive and significant $(0.415, p<* * *)$ when the level of knowledge sharing through written documents was below its median value. It was also positive and significant $(0.205, p<+)$ when the level of knowledge sharing through written documents was equal or greater than its median value. However, these results indicate that task urgency has a greater positive effect on effectiveness at lower levels of knowledge sharing through written documents than higher levels of knowledge sharing through written documents. This result provide support for the hypothesis that knowledge sharing through written documents positively moderates the relationship between uncertain dynamic task characteristics with and significance dimensions (task urgency) and task effectiveness. 
The standardized $\beta$ coefficient between task impact and task effectiveness was positive and significant $(0.269, p<*)$ when the level of knowledge sharing through written documents was equal or above its median value. However, when the level of knowledge sharing through written documents was below its median value, this relationship was not significant. These results indicate that task impact has a greater positive effect on effectiveness at higher levels of knowledge sharing through written documents than lower levels of knowledge sharing through written documents. This result provide support for the hypothesis that knowledge sharing through written documents positively moderates the relationship between uncertain dynamic task characteristics with and significance dimensions (task impact) and task effectiveness.

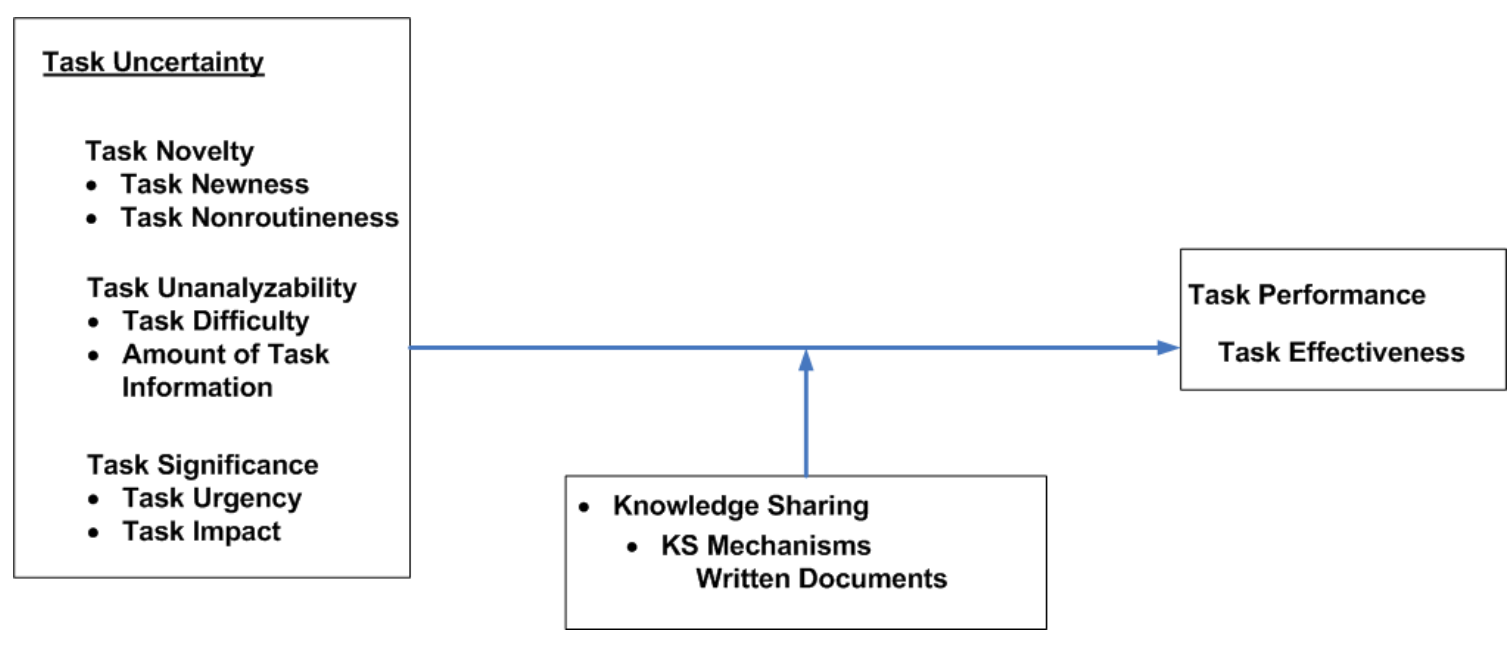

Figure 16. Uncertain dynamic disaster management tasks and knowledge sharing through written documents moderating direct effects on task effectiveness 


\begin{tabular}{|c|c|c|c|c|}
\hline \multirow{3}{*}{$\begin{array}{l}\text { Independent } \\
\text { Variable } \\
\end{array}$} & \multicolumn{4}{|c|}{ Dependent Variable Task Effectiveness } \\
\hline & \multicolumn{2}{|c|}{ KS Written Documents $<4.857$} & \multicolumn{2}{|c|}{ KS Written Documents $>=4.85$} \\
\hline & $\begin{array}{l}\begin{array}{l}\text { Standardized } \beta \\
\text { coefficient }\end{array} \\
\end{array}$ & t-statistic & \begin{tabular}{|l}
$\begin{array}{l}\text { Standardized } \beta \\
\text { coefficient }\end{array}$ \\
\end{tabular} & t-statistic \\
\hline Task Newness & -0.149 & -1.106 & -0.052 & -0.448 \\
\hline $\begin{array}{l}\text { Task } \\
\text { Nonroutineness }\end{array}$ & 0.126 & 1.108 & 0.088 & 0.783 \\
\hline Task Difficulty & -0.030 & -0.243 & -0.289 & $-2.320 * \mathrm{H} 13$ \\
\hline $\begin{array}{l}\text { Amount of } \\
\text { Task Inf. }\end{array}$ & 0.033 & 0.313 & 0.072 & 0.686 \\
\hline Task Urgency & 0.415 & $3.874 * * * \quad \mathrm{H} 14$ & 0.205 & $1.808+\mathrm{H} 14$ \\
\hline Task Impact & 0.106 & 0.947 & 0.269 & 2.467* H14 \\
\hline Note: $* * * p<0$ & $\begin{array}{l}\operatorname{Adj} R^{2}=\mathbf{0 . 1 6 1} \\
01 ; * * p<0.01\end{array}$ & $\begin{array}{l}=\mathbf{3 . 5 5 3 * *} \\
<0.05 ;{ }^{+} p<0.1\end{array}$ & Adj $R^{2}=\mathbf{0 . 1 0 8}$ & $=2.740 *$ \\
\hline
\end{tabular}
Effectiveness $=\quad f$ (Newness, Nonroutineness, Difficulty, Amount of Task Inf., Urgency, Impact)

Table 39. Summary of path analyses, uncertain dynamic disaster management tasks and knowledge sharing through written documents moderating direct effects on task effectiveness

According to the second set of moderating hypotheses, knowledge sharing for exploration moderates the relationship of uncertain dynamic task characteristics with knowledge-sharing purposes (knowledge sharing for exploitation) and mechanisms (knowledge sharing through personal contacts and knowledge sharing through written documents) and task performance. 
For this group of data, two sets of multiple regression analysis were performed according to the following equations:

1. Knowledge sharing for exploration less than its median value

$$
\begin{aligned}
& \text { Effectiveness }=f \text { (Newness, Nonroutineness, Difficulty, Amount of Task Inf., } \\
& \text { Urgency, Impact, Exploitation) } \\
& \text { Effectiveness }=f \text { (Newness, Nonroutineness, Difficulty, Amount of Task Inf., } \\
& \text { Urgency, Impact, Personal Contacts) } \\
& \text { Effectiveness }=f \text { (Newness, Nonroutineness, Difficulty, Amount of Task Inf., } \\
& \text { Urgency, Impact, Written Documents) } \\
& \text { Effectiveness }=f \text { (Newness, Nonroutineness, Difficulty, Amount of Task Inf., } \\
& \text { Urgency, Impact, Personal Contacts, Written Documents) }
\end{aligned}
$$

2. Knowledge sharing for exploration equal or greater than its median value

$$
\begin{aligned}
& \text { Effectiveness }=f \text { (Newness, Nonroutineness, Difficulty, Amount of Task Inf., } \\
& \text { Urgency, Impact, Exploitation) } \\
& \text { Effectiveness }=f \text { (Newness, Nonroutineness, Difficulty, Amount of Task Inf., } \\
& \text { Urgency, Impact, Personal Contacts) } \\
& \text { Effectiveness }=f \text { (Newness, Nonroutineness, Difficulty, Amount of Task Inf., } \\
& \text { Urgency, Impact, Written Documents) } \\
& \text { Effectiveness }=f \text { (Newness, Nonroutineness, Difficulty, Amount of Task Inf., } \\
& \text { Urgency, Impact, Personal Contacts, Written Documents) }
\end{aligned}
$$

The significant results are depicted in figures 17 and 18 and tables 40 and 41.

For equation:

Effectiveness $=\quad f$ (Newness, Nonroutineness, Difficulty, Amount of Task Inf. , Urgency, Impact, Exploitation), 
the standardized $\beta$ coefficient between task newness and task effectiveness was negative and significant $(-0.182, p<+)$ when the level of knowledge sharing for exploration was below its median value. However, when the level of knowledge sharing for exploration was equal or above its median value, this relationship was not significant. This result indicates that when the level of knowledge sharing for exploration is less than its median value, the negative impact of task newness is greater on task effectiveness as compared to the impact when knowledge sharing for exploration is equal or above its median value. This result provide support for the hypothesis that knowledge sharing for exploration negatively moderates the relationship between uncertain dynamic task characteristics with novelty dimensions (task newness) along with knowledge sharing purposes (knowledge sharing for exploitation) with task effectiveness.

The standardized $\beta$ coefficient between task difficulty and task effectiveness was negative and significant $(-0.327, p<*)$ when the level of knowledge sharing for exploration was equal or above its median value. However, when the level of knowledge sharing for exploration was below its median value, this relationship was not significant. This result indicates that when the level of knowledge sharing for exploration is equal or greater than its median value, the negative impact of task difficulty is greater on task effectiveness as compared to the impact when knowledge sharing for exploration is less than its median value. 
This result provide support for the hypothesis that knowledge sharing for exploration negatively moderates the relationship between uncertain dynamic task characteristics with and unananazability dimension (task difficulty) along with knowledge sharing purposes (knowledge sharing for exploitation) with task effectiveness.

The standardized $\beta$ coefficient between task urgency and task effectiveness was positive and significant $(0.284, p<* *)$ when the level of knowledge sharing for exploration was below its median value. Also, when the level of knowledge sharing for exploration was equal or above its median value, this relationship was still positive significant $(0.194, p<+)$. This result indicates that when the level of knowledge sharing for exploration is less than its median value, the positive impact of task urgency is greater on task effectiveness as compared to the impact when knowledge sharing for exploration is equal or above its median value.

This result provide support for the hypothesis that knowledge sharing for exploration positively moderates the relationship between uncertain dynamic task characteristics with significant dimensions (task urgency) along with knowledge sharing purposes (knowledge sharing for exploitation) with task effectiveness.

The standardized $\beta$ coefficient between task impact and task effectiveness was positive and significant $(0.225, p<+)$ when the level of knowledge sharing for exploration was below its median value. However, when the level of knowledge sharing for exploration was equal or above its median value, this relationship was not significant. 
This result indicates that when the level of knowledge sharing for exploration is less than its median value, the positive impact of task impact is greater on task effectiveness as compared to the impact when knowledge sharing for exploration is equal or above its median value. This result provide support for the hypothesis that knowledge sharing for exploration positively moderates the relationship between uncertain dynamic task characteristics with significant dimensions (task impact) along with knowledge sharing purposes (knowledge sharing for exploitation) with task effectiveness.

The standardized $\beta$ coefficient between knowledge sharing for exploitation and task effectiveness was positive and significant $(0.219, p<+)$ when the level of knowledge sharing for exploration was below its median value. However, when the level of knowledge sharing for exploration was equal or above its median value, this relationship was not significant. This result indicates that when the level of knowledge sharing for exploration is less than its median value, the positive impact knowledge sharing for exploitation is greater on task effectiveness as compared to the impact when knowledge sharing for exploration is equal or above its median value. 


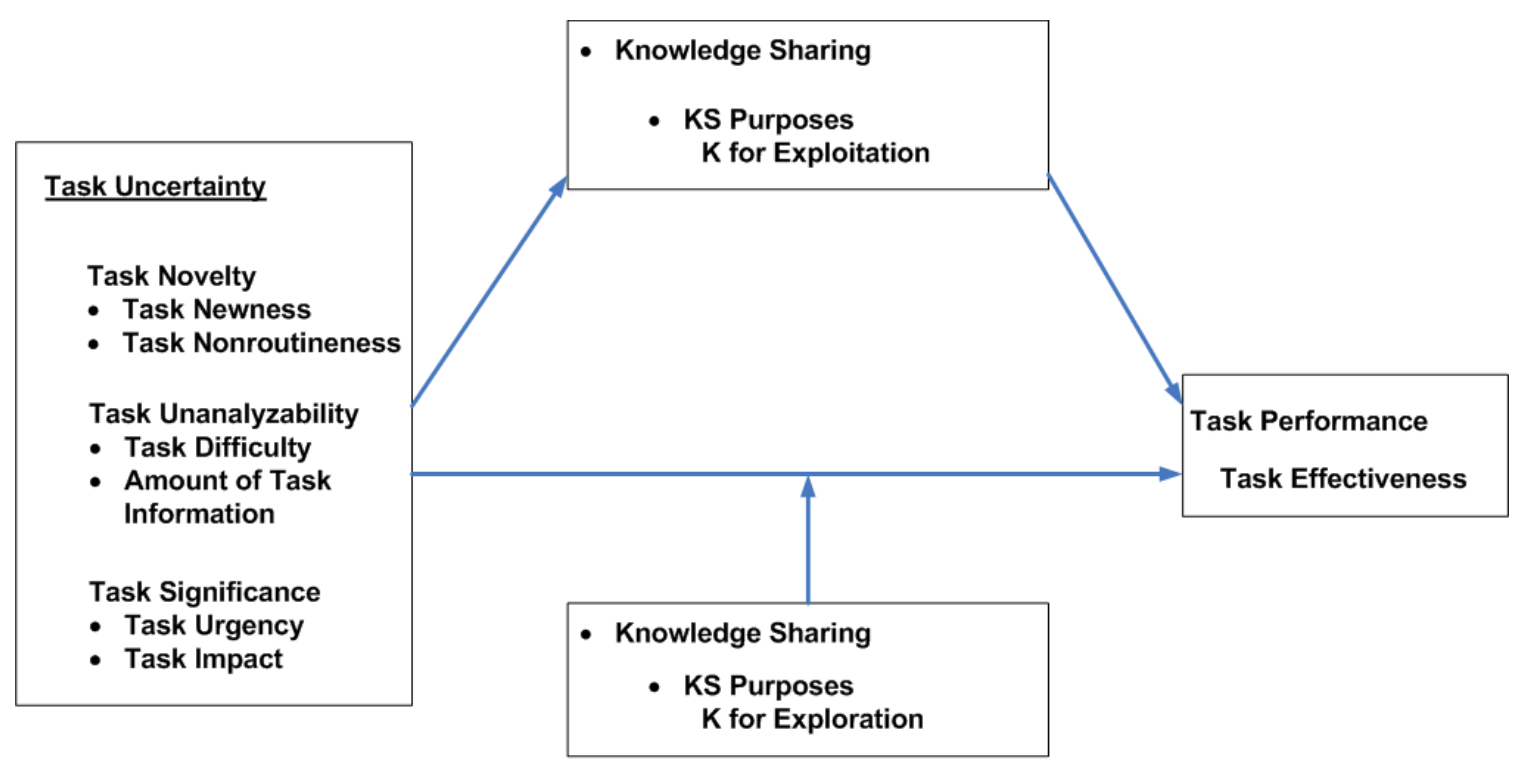

Figure 17. Uncertain dynamic disaster management tasks, knowledge sharing for exploitation and knowledge sharing for exploration moderating effects on task effectiveness

\begin{tabular}{|c|c|c|c|c|}
\hline \multirow{3}{*}{$\begin{array}{c}\text { Independent } \\
\text { Variable } \\
\end{array}$} & \multicolumn{4}{|c|}{ Dependent Variable Task Effectiveness } \\
\hline & \multicolumn{2}{|c|}{ KS Exploration $<4.500$} & \multicolumn{2}{|c|}{ KS Exploration $>=4.500$} \\
\hline & $\begin{array}{l}\text { Standardized } \beta \\
\text { coefficient }\end{array}$ & t-statistic & $\begin{array}{l}\text { Standardized } \beta \\
\text { coefficient }\end{array}$ & t-statistic \\
\hline Task Newness & -0.182 & $\begin{array}{l}-1.677+ \\
\text { H15 }\end{array}$ & 0.178 & 1.421 \\
\hline $\begin{array}{l}\text { Task } \\
\text { Nonroutineness }\end{array}$ & 0.078 & 0.748 & -0.057 & -0.433 \\
\hline Task Difficulty & 0.006 & 0.053 & -0.327 & $\begin{array}{l}-2.583 * \\
\text { H15 }\end{array}$ \\
\hline $\begin{array}{l}\text { Amount of } \\
\text { Task Inf. }\end{array}$ & -0.042 & -0.424 & 0.094 & 0.825 \\
\hline Task Urgency & 0.284 & $\begin{array}{l}2.768 * * \\
\mathrm{H} 16\end{array}$ & 0.194 & $\begin{array}{l}1.673+ \\
\mathrm{H} 16\end{array}$ \\
\hline Task Impact & 0.225 & $\begin{array}{l}1.988+ \\
\mathrm{H} 16\end{array}$ & -0.011 & -0.098 \\
\hline $\begin{array}{l}\text { KS } \\
\text { Exploitation }\end{array}$ & 0.219 & $1.925+$ & -0.163 & -1.440 \\
\hline 1.476 & $\operatorname{Adj} R^{2}=\mathbf{0 . 3 1 0}$ & $F=\mathbf{5 . 8 7 3} * * *$ & $\operatorname{Adj} R^{2}$ & 0.036; $F=$ \\
\hline
\end{tabular}


Note: ${ }^{* * *} p<0.001 ;{ }^{* *} p<0.01 ;{ }^{*} p<0.05 ;{ }^{+} p<0.1$

Effectiveness $=\quad f$ (Newness, Nonroutineness, Difficulty, Amount of Task Inf. , Urgency, Impact, Exploitation)

Table 40. Summary of path analyses, uncertain dynamic disaster management tasks, knowledge sharing for exploitation and knowledge sharing for exploration moderating effects on task effectiveness 
For equation:

Effectiveness $=\quad f$ (Newness, Nonroutineness, Difficulty, Amount of Task Inf. , Urgency, Impact, Personal Contact, Written Documents)

the standardized $\beta$ coefficient between task newness and task effectiveness was negative and significant $(-0.218, p<+)$ when the level of knowledge sharing for exploration was below its median value. However, when the level of knowledge sharing for exploration was equal or above its median value, this relationship was not significant. This result indicates that when the level of knowledge sharing for exploration is less than its median value, the negative impact of task newness is greater on task effectiveness as compared to the impact when knowledge sharing for exploration is equal or above its median value. This result provide support for the hypothesis that knowledge sharing for exploration negatively moderates the relationship between uncertain dynamic task characteristics with novelty dimensions (task newness) along with knowledge sharing mechanisms (knowledge sharing through personal contacts and knowledge sharing through written documents) with task effectiveness.

The standardized $\beta$ coefficient between task difficulty and task effectiveness was negative and significant $(-0.285, p<*)$ when the level of knowledge sharing for exploration was equal or above its median value. However, when the level of knowledge sharing for exploration was below its median value, this relationship was not significant. 
This result indicates that when the level of knowledge sharing for exploration is equal or greater than its median value, the negative impact of task difficulty is greater on task effectiveness as compared to the impact when knowledge sharing for exploration is less than its median value. This result provide support for the hypothesis that knowledge sharing for exploration negatively moderates the relationship between uncertain dynamic task characteristics with and unanalyzability dimension (task difficulty) along with knowledge sharing mechanisms (knowledge sharing through personal contacts and knowledge sharing through written documents) with task effectiveness.

The standardized $\beta$ coefficient between task urgency and task effectiveness was positive and significant $(0.319, p<* *)$ when the level of knowledge sharing for exploration was below its median value. However, when the level of knowledge sharing for exploration was equal or above its median value, this relationship was not significant. This result indicates that when the level of knowledge sharing for exploration is less than its median value, the positive impact of task urgency is greater on task effectiveness as compared to the impact when knowledge sharing for exploration is equal or above its median value. This result provide support for the hypothesis that knowledge sharing for exploration positively moderates the relationship between uncertain dynamic task characteristics with significant dimensions (task urgency) along with knowledge sharing mechanisms (knowledge sharing through personal contacts and knowledge sharing through written documents) with task effectiveness. 
The standardized $\beta$ coefficient between task impact and task effectiveness was positive and significant $(0.307, p<*)$ when the level of knowledge sharing for exploration was below its median value. However, when the level of knowledge sharing for exploration was equal or above its median value, this relationship was not significant. This result indicates that when the level of knowledge sharing for exploration is less than its median value, the positive impact of task impact is greater on task effectiveness as compared to the impact when knowledge sharing for exploration is equal or above its median value. This result provide support for the hypothesis that knowledge sharing for exploration positively moderates the relationship between uncertain dynamic task characteristics with significant dimensions (task impact) along with knowledge sharing mechanisms (knowledge sharing through personal contacts and knowledge sharing through written documents) with task effectiveness.

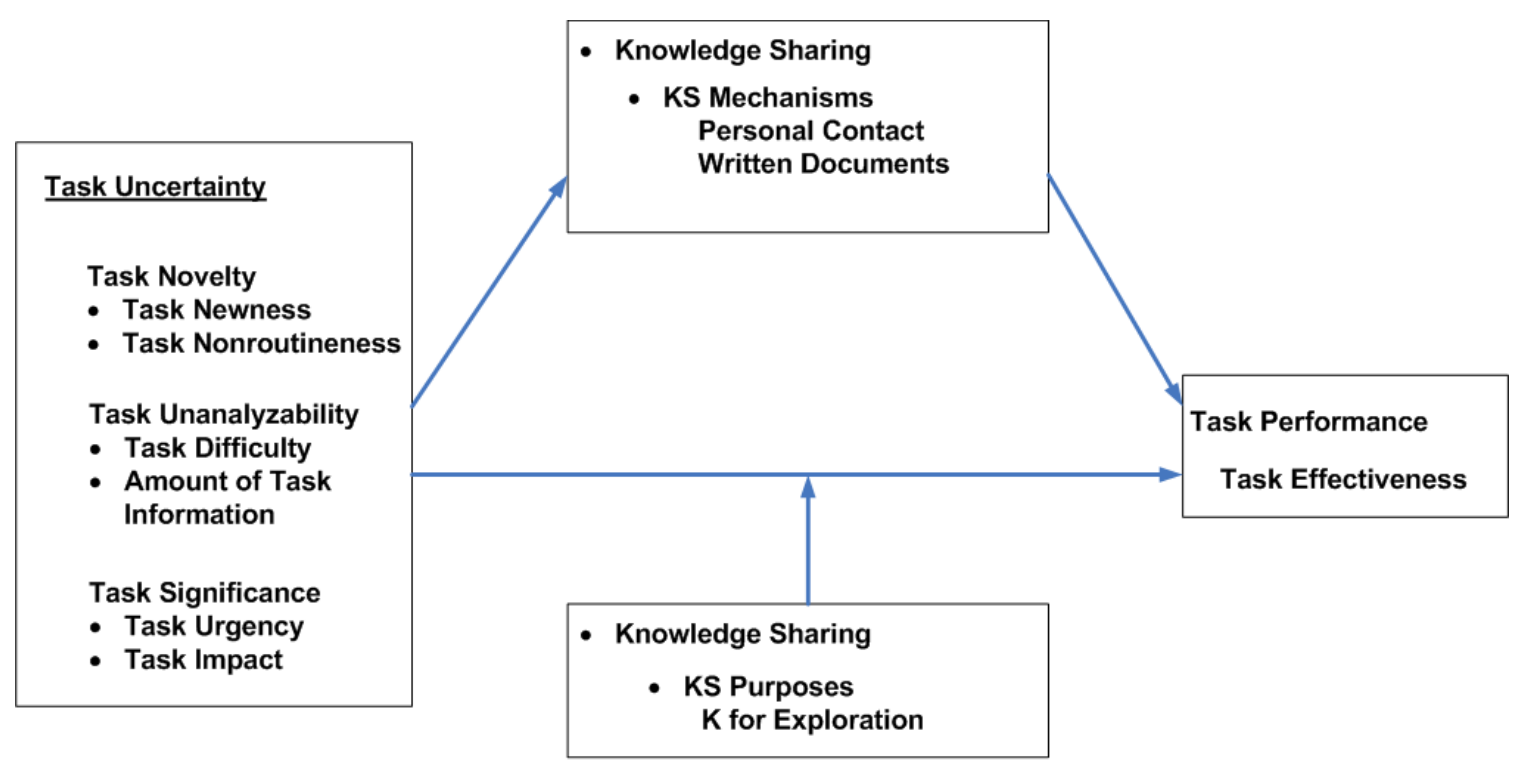

Figure 18. Uncertain dynamic disaster management tasks, knowledge sharing through personal contacts and knowledge sharing through written documents and knowledge sharing for exploration moderating effects on task effectiveness 


\begin{tabular}{|c|c|c|c|c|}
\hline \multirow{3}{*}{$\begin{array}{c}\text { Independent } \\
\text { Variable } \\
\end{array}$} & \multicolumn{4}{|c|}{ Dependent Variable Task Effectiveness } \\
\hline & \multicolumn{2}{|c|}{ KS Exploration $<4.500$} & \multicolumn{2}{|c|}{ KS Exploration $>=4.500$} \\
\hline & \begin{tabular}{|l|}
$\begin{array}{l}\text { Standardized } \beta \\
\text { coefficient }\end{array}$ \\
\end{tabular} & t-statistic & \begin{tabular}{|l|}
$\begin{array}{l}\text { Standardized } \beta \\
\text { coefficient }\end{array}$ \\
\end{tabular} & t-statistic \\
\hline Task Newness & -0.218 & $-1.920+\mathrm{H} 17$ & 0.156 & 1.222 \\
\hline $\begin{array}{l}\text { Task } \\
\text { Nonroutineness }\end{array}$ & 0.060 & 0.550 & -0.075 & -0.561 \\
\hline Task Difficulty & -0.030 & -0.261 & -0.285 & $-2.215^{*} \mathrm{H} 17$ \\
\hline $\begin{array}{l}\text { Amount of } \\
\text { Task Inf. }\end{array}$ & 0.001 & 0.011 & 0.083 & 0.699 \\
\hline Task Urgency & 0.319 & $3.008^{* *} \quad \mathrm{H} 18$ & 0.183 & 1.569 \\
\hline Task Impact & 0.307 & $2.569^{*}$ & -0.031 & -0.244 \\
\hline $\begin{array}{l}\text { KS Personal } \\
\text { Contact }\end{array}$ & 0.032 & 0.267 & 0.097 & 0.816 \\
\hline $\begin{array}{l}\text { KS Written } \\
\text { Documents }\end{array}$ & -0.061 & -0.498 & -0.127 & -1.014 \\
\hline & $\mathrm{j} R^{2}=\mathbf{0 . 2 6 5}$ & $4.421 * * *$ & $\operatorname{Adj} R^{2}=\mathbf{0 . 0 1 7}$ & $=1.192$ \\
\hline
\end{tabular}

Effectiveness $=\quad f$ (Newness, Nonroutineness, Difficulty, Amount of Task Inf. , Urgency, Impact, Personal Contact, Written Documents)

Table 41. Summary of path analyses, uncertain dynamic disaster management tasks, knowledge sharing through personal contacts and knowledge sharing through written documents and knowledge sharing for exploration moderating effects on task effectiveness

According to the third set of moderating hypothesis where knowledge sharing for exploitation and knowledge sharing through personal contacts moderate the relationship between uncertain dynamic task characteristics and task performance

For this group of data, two sets of multiple regression analysis were performed according to the following equations: 
1. Knowledge sharing for exploitation less than its median value Efficiency $=\quad f$ (Newness, Nonroutineness, Difficulty, Amount of Task Inf., Urgency, Impact)

2. Knowledge sharing for exploitation equal or greater than its median value Efficiency $=\quad f$ (Newness, Nonroutineness, Difficulty, Amount of Task Inf., Urgency, Impact)

3. Knowledge sharing through personal contacts less than its median value Efficiency $=\quad f$ (Newness, Nonroutineness, Difficulty, Amount of Task Inf., Urgency, Impact)

4. Knowledge sharing through personal contacts equal or greater than its median value Efficiency $=\quad f$ (Newness, Nonroutineness, Difficulty, Amount of Task Inf., Urgency, Impact)

The significant results are depicted in Figure 19 and Table 42.

For equation:

Efficiency $=\quad f$ (Newness, Nonroutineness, Difficulty, Amount of Task Inf. , Urgency, Impact)

the standardized $\beta$ coefficient between task newness and task efficiency was negative and significant $(-0.297, p<*)$ when the level of knowledge sharing through personal contacts was equal or above its median value. However, when the level of knowledge sharing through personal contacts was below its median value, this relationship was not significant. This result indicates that when the level of knowledge sharing through personal contacts is equal or greater than its median value, the negative impact of task newness is greater on task efficiency as compared to the impact when knowledge sharing through personal contacts is below its median value. 
This result provides support but in the opposite direction for the hypothesis that knowledge sharing through personal contacts negatively moderates the relationship between uncertain dynamic task characteristics with novelty dimensions (task newness) with task efficiency.

The standardized $\beta$ coefficient between amount of task information and task efficiency was positive and significant $(0.242, p<+)$ when the level of knowledge sharing through personal contacts below its median value. Also, when the level of knowledge sharing through personal contacts was equal or above its median value, this relationship was positive and significant $(0.229, p<*)$.

This result indicates that when the level of knowledge sharing through personal contacts is below than its median value, the positive impact of the amount of task information is greater on task efficiency as compared to the impact when knowledge sharing through personal contacts is equal or above its median value. This result provides support for the hypothesis that knowledge sharing through personal contacts positively moderates the relationship between uncertain dynamic task characteristics with unanalyzability dimensions (amount of task information) with task efficiency. 


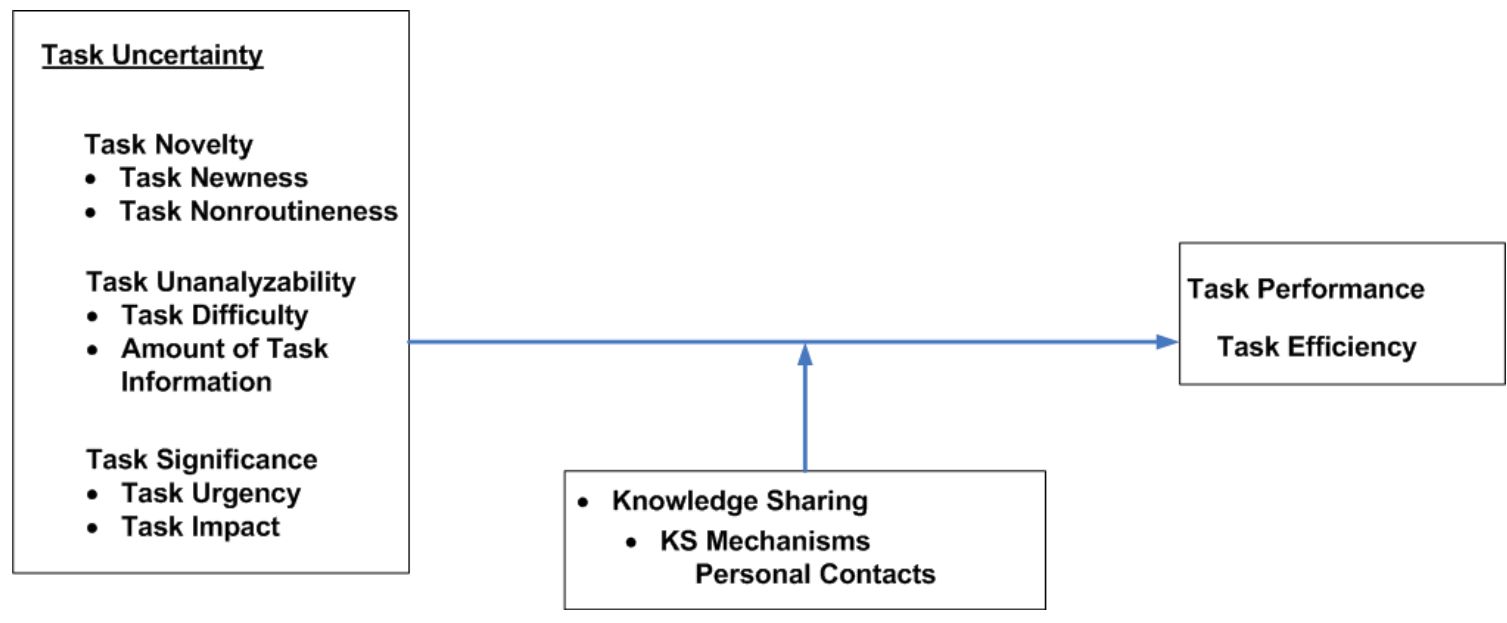

Figure 19. Uncertain dynamic disaster management tasks knowledge sharing through personal contacts moderating direct effects on task efficiency

\begin{tabular}{|c|c|c|c|c|}
\hline \multirow{3}{*}{$\begin{array}{c}\text { Independent } \\
\text { Variable }\end{array}$} & \multicolumn{4}{|c|}{ Dependent Variable Task Efficiency } \\
\hline & \multicolumn{2}{|c|}{ KS Personal Contact $<6.000$} & \multicolumn{2}{|c|}{ KS Personal Contact $>=6.000$} \\
\hline & \begin{tabular}{|l|}
$\begin{array}{l}\text { Standardized } \beta \\
\text { coefficient }\end{array}$ \\
\end{tabular} & t-statistic & $\begin{array}{l}\text { Standardized } \beta \\
\text { coefficient }\end{array}$ & t-statistic \\
\hline Task Newness & 0.152 & 1.105 & -0.297 & $-2.553 * \mathrm{H} 20$ \\
\hline $\begin{array}{l}\text { Task } \\
\text { Nonroutineness }\end{array}$ & -0.087 & -0.674 & 0.134 & 1.255 \\
\hline Task Difficulty & -0.138 & -0.991 & -0.112 & -0.974 \\
\hline $\begin{array}{l}\text { Amount of } \\
\text { Task Inf. }\end{array}$ & 0.242 & $1.954+$ & 0.229 & $2.306^{*} \quad \mathrm{H} 20$ \\
\hline Task Urgency & -0.011 & -0.091 & 0.037 & 0.353 \\
\hline Task Impact & -0.151 & -1.221 & 0.126 & 1.208 \\
\hline \multicolumn{3}{|c|}{$\operatorname{Adj} R^{2}=\mathbf{0 . 0 2 1} ; F=\mathbf{1 . 2 5 1}$} & \multicolumn{2}{|c|}{ Adj $R^{2}=\mathbf{0 . 1 1 3} ; F=\mathbf{3 . 0 0 7 * *}$} \\
\hline
\end{tabular}

Efficiency $=\quad f$ (Newness, Nonroutineness, Difficulty, Amount of Task Inf. , Urgency, Impact)

Table 42. Summary of path analyses, uncertain dynamic disaster management tasks and knowledge sharing through personal contacts moderating direct effects on task efficiency 
For equation:

Efficiency $=f$ (Newness, Nonroutineness, Difficulty, Amount of Task Inf. , Urgency, Impact, Exploitation, Personal Contact, Written Documents)

the significant results are depicted in Figure 20 and Table 43. The standardized $\beta$ coefficient between amount of task information and task efficiency was positive and significant $(0.247, p<*)$ when the level of knowledge sharing for exploration was below its median value. However, when the level of knowledge sharing for exploration was equal or greater its median value, this relationship was not significant. This result indicates that when the level of knowledge sharing for exploration is less than its median value, the positive impact of task amount of task information is greater on task efficiency as compared to the impact when knowledge sharing for exploration is equal or greater than its median value. This result provides support for the hypothesis that knowledge sharing for exploration positively moderates the relationship between uncertain dynamic task characteristics along with knowledge sharing purposes (knowledge for exploitation) and knowledge sharing mechanisms (knowledge sharing through personal contacts and knowledge sharing through written documents) with task efficiency.

The standardized $\beta$ coefficient between knowledge sharing for exploitation and task efficiency was positive and significant $(0.347, p<*)$ when the level of knowledge sharing for exploration was below its median value. However, when the level of knowledge sharing for exploration was equal or greater its median value, this relationship was not significant. 
This result indicates that when the level of knowledge sharing for exploration is less than its median value, the positive impact of knowledge sharing for exploitation is greater on task efficiency as compared to the impact when knowledge sharing for exploration is equal or greater than its median value.

The standardized $\beta$ coefficient between knowledge sharing through written documents and task efficiency was positive and significant $(0.323, p<*)$ when the level of knowledge sharing for exploration was equal or above its median value. However, when the level of knowledge sharing for exploration was below its median value, this relationship was not significant. This result indicates that when the level of knowledge sharing for exploration is equal or greater than its median value, the positive impact of knowledge sharing through written documents is greater on task efficiency as compared to the impact when knowledge sharing for exploration is less than its median value.

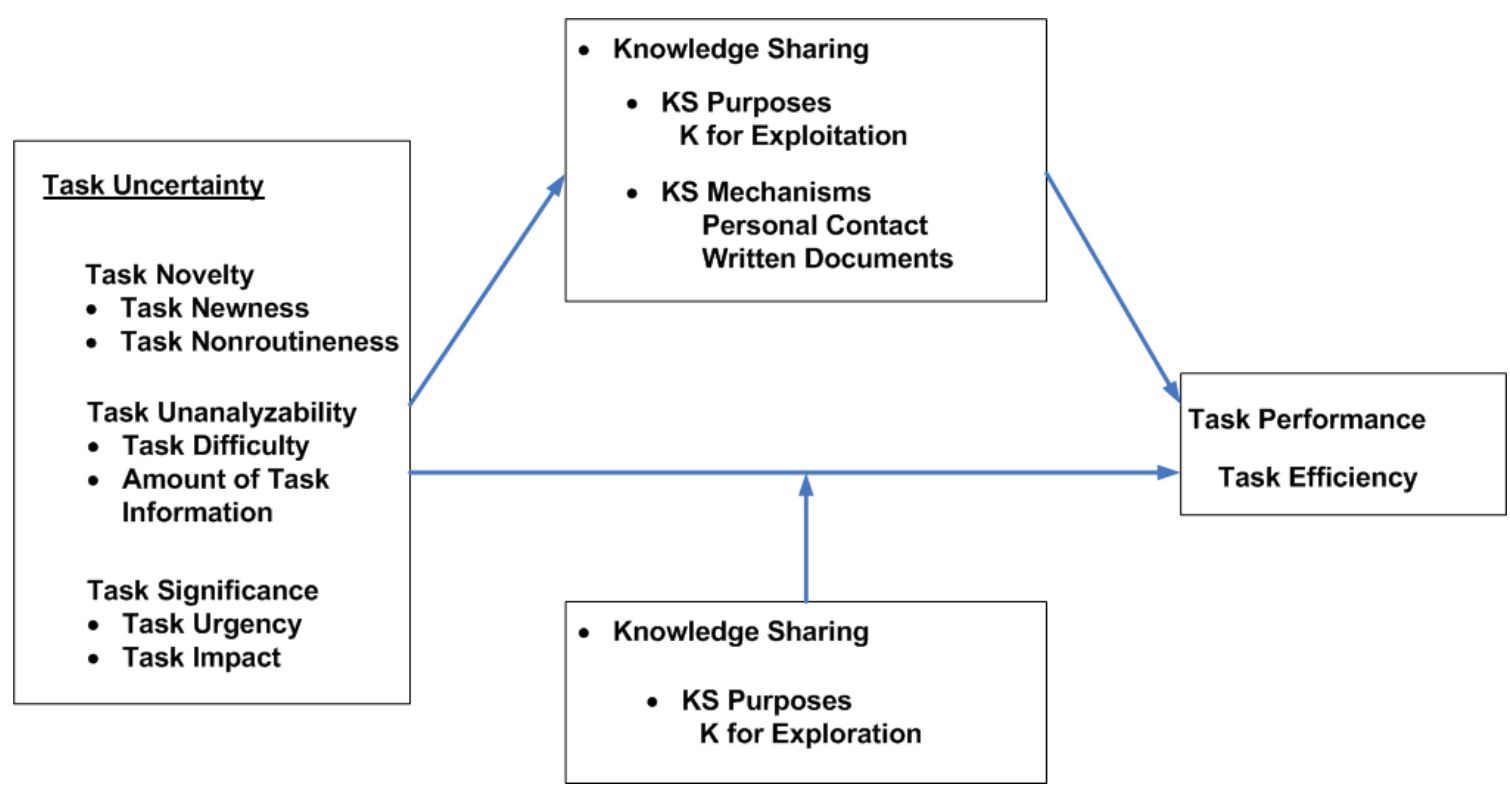

Figure 20. Uncertain dynamic disaster management tasks, knowledge sharing for exploitation, knowledge sharing through personal contacts, knowledge sharing through written documents, and knowledge sharing for exploitation moderating effects on task efficiency 


\begin{tabular}{|c|c|c|c|c|}
\hline \multirow{3}{*}{$\begin{array}{c}\text { Independent } \\
\text { Variable } \\
\end{array}$} & \multicolumn{4}{|c|}{ Dependent Variable Task Efficiency } \\
\hline & \multicolumn{2}{|c|}{ KS Exploration $<4.500$} & \multicolumn{2}{|c|}{ KS Exploration $>=4.500$} \\
\hline & $\begin{array}{l}\text { Standardized } \beta \\
\text { coefficient }\end{array}$ & t-statistic & $\begin{array}{l}\text { Standardized } \beta \\
\text { coefficient }\end{array}$ & t-statistic \\
\hline Task Newness & -0.183 & -1.451 & 0.065 & 0.556 \\
\hline $\begin{array}{l}\text { Task } \\
\text { Nonroutineness }\end{array}$ & -0.036 & -0.304 & 0.075 & 0.603 \\
\hline Task Difficulty & -0.056 & -0.442 & -0.061 & -0.510 \\
\hline $\begin{array}{l}\text { Amount of } \\
\text { Task Inf. }\end{array}$ & 0.247 & $2.162 *$ & 0.077 & 0.704 \\
\hline Task Urgency & 0.028 & 0.231 & -0.131 & -1.212 \\
\hline Task Impact & -0.031 & -0.235 & -0.045 & -0.386 \\
\hline $\begin{array}{l}\text { KS } \\
\text { Exploitation }\end{array}$ & 0.347 & $2.232 *$ & 0.155 & 1.257 \\
\hline $\begin{array}{l}\text { KS Personal } \\
\text { Contact }\end{array}$ & -0.054 & -0.372 & 0.060 & 0.528 \\
\hline $\begin{array}{l}\text { KS Written } \\
\text { Documents }\end{array}$ & -0.160 & -1.126 & 0.323 & $2.513^{*}$ \\
\hline \multicolumn{3}{|c|}{$\operatorname{Adj} R^{2}=\mathbf{0 . 1 1 6} ; F=\mathbf{2 . 1 0 6 *}$} & \multicolumn{2}{|c|}{$\operatorname{Adj} R^{2}=\mathbf{0 . 1 7 1} ; F=\mathbf{3 . 0 5 6}^{* *}$} \\
\hline
\end{tabular}

Efficiency $=f$ (Newness, Nonroutineness, Difficulty, Amount of Task Inf., Urgency, Impact, Exploitation, Personal Contact, Written Documents)

Table 43. Summary of path analyses, uncertain dynamic disaster management tasks, knowledge sharing for exploitation, knowledge sharing through personal contacts, knowledge sharing through written documents, and knowledge sharing for exploitation moderating effects on task efficiency

The table below summarizes the hypothesis and the finding of this study through low - high moderating effects. 


\begin{tabular}{|c|c|c|}
\hline H13 & $\begin{array}{l}\text { Knowledge sharing through written documents negatively } \\
\text { moderates the relationship between uncertain dynamic task } \\
\text { characteristics with unananazability dimension (task } \\
\text { difficulty) with task effectiveness }\end{array}$ & $\begin{array}{l}\text { Marginally } \\
\text { Supported: } \\
*_{p}<0.05\end{array}$ \\
\hline H14 & $\begin{array}{l}\text { Knowledge sharing through written documents positively } \\
\text { moderates the relationship between uncertain dynamic task } \\
\text { characteristics with significance dimensions (task urgency: } \\
\text { Strongly Supported } * * * p<0.001 \text {, and task impact: Marginally } \\
\text { Supported } * p<0.05 \text { ) and task effectiveness }\end{array}$ & Supported \\
\hline H15 & $\begin{array}{l}\text { Knowledge sharing for exploration negatively moderates the } \\
\text { relationship between uncertain dynamic task characteristics } \\
\text { with novelty dimensions (task newness: Marginally Not } \\
\text { Supported }{ }^{+} p<0.1 \text { ) and unanalyzability dimension (task } \\
\text { difficulty: Marginally Supported } * p<0.05 \text { ) along with } \\
\text { knowledge sharing purposes (knowledge sharing for } \\
\text { exploitation) with task effectiveness }\end{array}$ & Supported \\
\hline H16 & 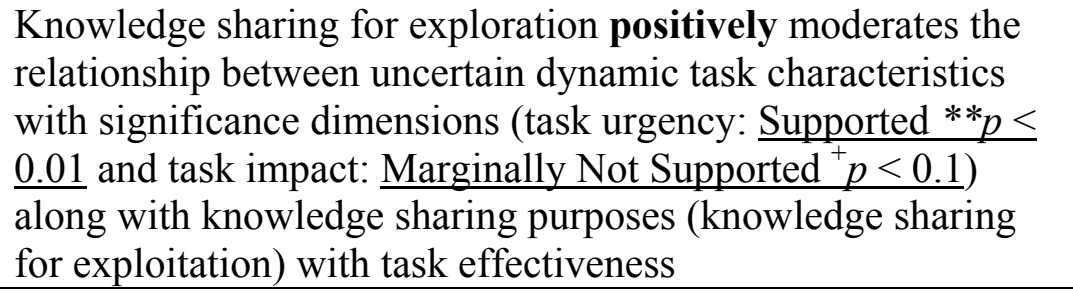 & Supported \\
\hline H17 & $\begin{array}{l}\text { Knowledge sharing for exploration negatively moderates the } \\
\text { relationship between uncertain dynamic task characteristics } \\
\text { with novelty dimensions (task newness: Marginally Not } \\
\text { Supported }{ }^{+} p<0.1 \text { ) and unanalyzability dimension (task } \\
\text { difficulty: Marginally Supported } * p<0.05 \text { ) along with } \\
\text { knowledge sharing mechanisms (knowledge sharing through } \\
\text { personal contacts and knowledge sharing through written } \\
\text { documents) with task effectiveness }\end{array}$ & Supported \\
\hline H18 & $\begin{array}{l}\text { Knowledge sharing for exploration positively moderates the } \\
\text { relationship between uncertain dynamic task characteristics } \\
\text { with significance dimensions (task urgency: Supported } * * p< \\
0.01 \text { and task impact: Marginally Supported } * p<0.05 \text { ) along } \\
\text { with knowledge sharing mechanisms (knowledge sharing } \\
\text { through personal contacts and knowledge sharing through } \\
\text { written documents) with task effectiveness }\end{array}$ & Supported \\
\hline
\end{tabular}

Table 44. Summary of low - high moderating effects and findings 


\begin{tabular}{|l|l|l|}
\hline H20 & $\begin{array}{l}\text { Knowledge sharing through personal contacts positively } \\
\text { moderates the relationship between uncertain dynamic task } \\
\text { characteristics with novelty dimensions (task newness) and } \\
\text { task efficiency }\end{array}$ & $\begin{array}{l}\text { Marginally } \\
\text { Supported: } \\
* p<0.05 \\
\text { but reverse } \\
\text { direction }\end{array}$ \\
\hline $\mathbf{H 2 0}$ & $\begin{array}{l}\text { Knowledge sharing through personal contacts positively } \\
\text { moderates the relationship between uncertain dynamic task } \\
\text { characteristics with unanalyzability dimension (amount of task } \\
\text { information) and task efficiency }\end{array}$ & $\begin{array}{l}\text { Marginally } \\
\text { Supported: } \\
{ }^{*} p<0.05\end{array}$ \\
\hline $\begin{array}{l}\text { Knowledge sharing for exploration positively moderates the } \\
\text { relationship between uncertain dynamic task characteristics } \\
\text { with unanalyzability dimension (amount of task information) } \\
\text { along with knowledge sharing purposes (knowledge sharing } \\
\text { for exploitation) and knowledge sharing mechanisms } \\
\text { (knowledge sharing through written documents) with task } \\
\text { efficiency }\end{array}$ & $\begin{array}{l}\text { Marginally } \\
\text { Supported: } \\
* p<0.05\end{array}$ \\
\hline
\end{tabular}

Table 44. (continued ...)

\subsection{Mediation Analyses}

Sets of multiple regression analyses were conducted to explore the mediated relationships between uncertain dynamic disaster management tasks, knowledge sharing, and task performance. In the first set, the independent variables included the uncertain dynamic disaster management tasks and their respective constructs (task novelty, task unanalyzability, and task significance), and the mediating variables included knowledge sharing with its respective constructs, knowledge-sharing purposes and their dimensions (knowledge sharing for exploration and knowledge sharing for exploitation), and knowledge-sharing mechanisms and their dimensions (knowledge sharing through personal contacts and knowledge sharing through written documents). 
Conversely, the dependent variable included task performance and its respective dimensions (task efficiency and task effectiveness).

In the second set, the independent variables included the uncertain dynamic disaster management tasks and their respective constructs (task novelty, task unanalyzability, and task significance), and the mediating variable included knowledgesharing purposes and their dimensions (knowledge sharing for exploration and knowledge sharing for exploitation. Conversely, the dependent variable was task performance and its respective dimensions (task efficiency and task effectiveness).

In the third set, the independent variables included the uncertain dynamic disaster management tasks and their respective constructs (task novelty, task unanalyzability, and task significance), and the mediating variable included knowledgesharing mechanisms and their dimensions (knowledge sharing through personal contacts and knowledge sharing through written documents). The dependent variable included task performance and its respective dimensions (task efficiency and task effectiveness).

These three sets are represented by the following equations:

Set 1. Uncertain dynamic disaster management tasks and task performance

$$
\begin{array}{ll}
\text { Effectiveness = } & \begin{array}{l}
f \text { (Newness, Nonroutineness, Difficulty, Amount of Task } \\
\text { Inf., Urgency, Impact, Exploration, Exploitation, PC, }
\end{array} \\
& \underline{\text { WD })} \\
\text { Efficiency }= & \begin{array}{l}
\text { (Newness, Nonroutineness, Difficulty, Amount of Task } \\
\text { Inf., Urgency, Impact, Exploration, Exploitation, PC, } \\
\text { WD) }
\end{array}
\end{array}
$$


Set 2. Uncertain dynamic disaster management tasks and task performance

$$
\begin{array}{cc}
\text { Effectiveness }= & f \begin{array}{c}
\text { (Newness, Nonroutineness, Difficulty, Amount of Task } \\
\text { Inf. , Urgency, Impact, Exploration, Exploitation })
\end{array} \\
\text { Efficiency }= & f \begin{array}{c}
\text { (Newness, Nonroutineness, Difficulty, Amount of Task } \\
\text { Inf., Urgency, Impact, Exploration, Exploitation })
\end{array}
\end{array}
$$

Set 3. Uncertain dynamic disaster management tasks and task performance

$$
\begin{aligned}
& \text { Effectiveness }=\quad f \text { (Newness, Nonroutineness, Difficulty, Amount of Task } \\
& \text { Inf. , Urgency, Impact, PC, WD) } \\
& \text { Efficiency }=\quad f \text { (Newness, Nonroutineness, Difficulty, Amount of Task } \\
& \text { Inf. , Urgency, Impact, PC, WD) }
\end{aligned}
$$

Mediation analysis assesses whether a set of interrelated variables has a meditational structure. "A meditational structure posits a particular conceptualization of the mechanism through which an independent variable might affect a dependent variable - not directly, but rather through an intervening process, captured by the mediator variable" [Iacobucci, 2008, p. 1].

The mediating analysis is depicted in Figure 21, wherein X is the model's independent variable, $\mathrm{M}$ is the mediating variable, and $\mathrm{Y}$ is the dependent variable.

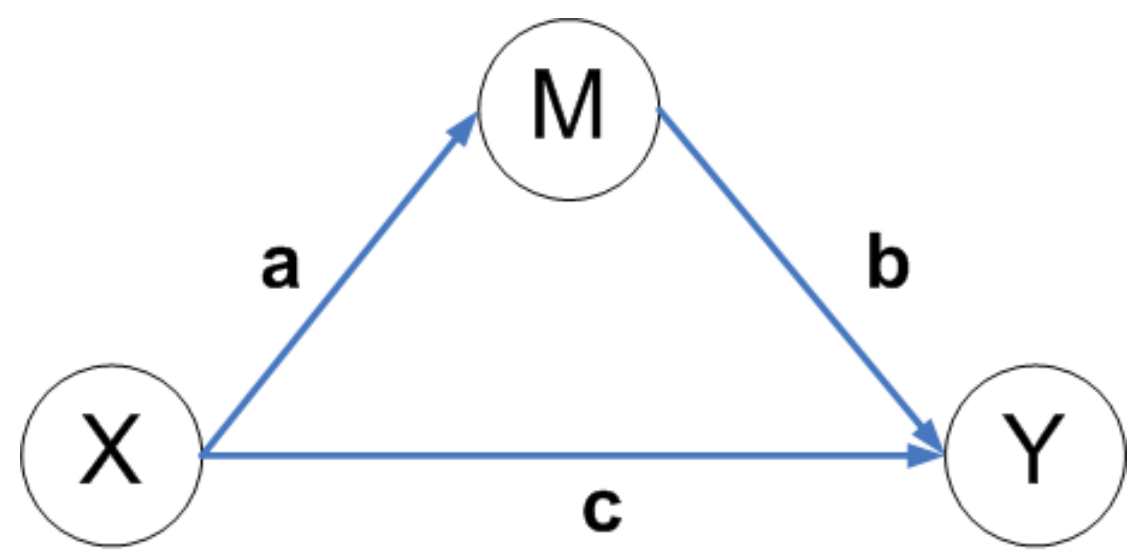

Figure 21. Simple standard trivariate mediation 
These relationships are tested according to the following regression analysis equations:

1. $M=\beta_{1}+\mathbf{a X}+\varepsilon_{1}$

2. $Y=\beta_{2}+\mathbf{c X}+\varepsilon_{2} ;$ and

3. $\mathrm{Y}=\beta_{3}+\boldsymbol{c}^{\prime} \mathrm{X}+\mathbf{b M}+\varepsilon_{3}$,

where $\mathrm{a}, \mathrm{b}, \mathrm{c}$, and $\mathrm{c}^{\prime}$ are the regression coefficients between these variables.

The criterion to assess whether there is sufficient evidence of mediation is said to be likely if the following variables are met:

- The a coefficient is significant because there is a relationship between the independent variable $\mathrm{X}$ and mediator variable $\mathrm{M}$.

- The c coefficient is significant because there is a direct effect relationship between the independent variable $\mathrm{X}$ and dependent variable $\mathrm{Y}$.

- The $\mathbf{b}$ coefficient is significant because the mediator variable helps to predict the dependent variable $\mathrm{Y}$ and the $\mathbf{c}^{\prime}$ coefficient becomes less significant relative to the direct effect coefficient $\mathbf{c}$. 
The relative size comparison between $\mathbf{c}$ and $\mathbf{c}^{\prime}$ is tested by the $\mathrm{z}$ test [Sobel, 1982] through the following equation:

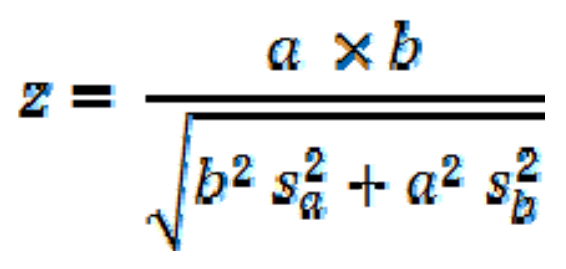

where $\mathbf{a}$ and $\mathbf{b}$ are the regression coefficients mentioned above, and $s_{a}$ and $s_{b}$ are their corresponding standard errors. In addition, it is important to consider that testing this equation is equivalent to assessing the strength of the mediated path $(a \times b)$ that exceeds zero [Iacobucci, 2008]. The significance of the relative size comparison between $\mathbf{c}$ and $\mathbf{c}^{\prime}$, as well as the mediating effect therein, is determined at the following $p$ levels: ${ }^{* *} p<$ $0.001, * * p<0.01,{ }^{*} p<0.05$, and ${ }^{+} p<0.1$.

To test the significance of the relative size comparison between $\mathbf{c}$ and $\mathbf{c}^{\prime}$, as well as the mediating effect therein, this research study used the Goodman sample estimate test equation, as follows:

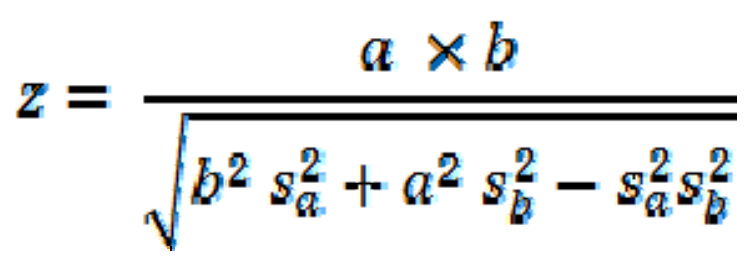

which is a less conservative and more powerful test in comparison to the middling Sobel test [Iacobucci, 2008]. 
If the $\mathbf{a}, \mathbf{b}$, and $\mathbf{c}$ coefficients are significant, it can be determined that there is at least sufficient evidence to assess partial mediation. Additionally, if, in addition to the a, b, and c coefficients being significant, $\boldsymbol{c}^{\prime \prime}$ "is not significantly different from zero" [Iacobucci, 2008, p. 12], then there is sufficient evidence to assess a complete mediation.

Tables 45, 46, 47, and 48 summarize the mediation assessments and results of this study. 


\begin{tabular}{|c|c|c|c|c|c|c|c|c|c|c|}
\hline & \multirow{2}{*}{\multicolumn{2}{|c|}{$\begin{array}{l}\text { a } \\
\text { KS for Exploitation }\end{array}$}} & \multirow{2}{*}{\multicolumn{2}{|c|}{$\begin{array}{l}\text { b } \\
\text { Effectiveness }\end{array}$}} & \multirow{2}{*}{\multicolumn{2}{|c|}{\begin{tabular}{l|} 
c \\
Effectiveness
\end{tabular}}} & \multirow{2}{*}{\multicolumn{2}{|c|}{\begin{tabular}{l|} 
'' \\
Effectiveness
\end{tabular}}} & \multirow{2}{*}{\multicolumn{2}{|c|}{$\begin{array}{l}\mathrm{Z} \\
\text { Sobel }\end{array}$}} \\
\hline & & & & & & & & & & \\
\hline & $\begin{array}{l}\text { Standardize } \\
\mathrm{d} \beta \\
\text { coefficient }\end{array}$ & $\begin{array}{l}\mathrm{t}- \\
\text { statistic }\end{array}$ & $\begin{array}{l}\text { Standardize } \\
\mathrm{d} \beta \\
\text { coefficient }\end{array}$ & $\begin{array}{l}\mathrm{t}- \\
\text { statistic }\end{array}$ & $\begin{array}{l}\text { Standardize } \\
\mathrm{d} \beta \\
\text { coefficient }\end{array}$ & $\begin{array}{l}\text { t- } \\
\text { statistic }\end{array}$ & $\begin{array}{l}\text { Standardize } \\
\mathrm{d} \beta \\
\text { coefficient }\end{array}$ & $\begin{array}{l}\mathrm{t}- \\
\text { statistic }\end{array}$ & $\begin{array}{l}\text { Test } \\
\text { Statist } \\
\text { ic }\end{array}$ & $\begin{array}{l}p- \\
\text { value }\end{array}$ \\
\hline $\begin{array}{l}\text { Task } \\
\text { Newness }\end{array}$ & 0.073 & -0.875 & & & -0.087 & -1.015 & -0.059 & -0.580 & & \\
\hline $\begin{array}{l}\text { Task } \\
\text { Nonroutinene } \\
\text { ss }\end{array}$ & 0.043 & 0.556 & & & 0.087 & 1.110 & 0.072 & 0.917 & & \\
\hline $\begin{array}{l}\text { Task } \\
\text { Difficulty }\end{array}$ & -0.244 & $\begin{array}{l}- \\
2.952 * \\
*\end{array}$ & & & -0.177 & $2.084 *$ & -0.184 & - $2.048 *$ & 1.646 & $\begin{array}{l}\begin{array}{l}0.099 \\
+\quad \\
\mathrm{H} 23\end{array} \\
\end{array}$ \\
\hline $\begin{array}{l}\text { Amount of } \\
\text { Task } \\
\text { Information }\end{array}$ & 0.203 & $\begin{array}{l}2.851 * \\
*\end{array}$ & & & 0.065 & 0.884 & 0.067 & 0.890 & & \\
\hline Task Urgency & 0.196 & $\begin{array}{l}2.668^{*} \\
*\end{array}$ & & & 0.285 & $\begin{array}{l}3.777 * \\
* *\end{array}$ & 0.238 & $\begin{array}{l}3.066^{*} \\
*\end{array}$ & 1.607 & $\begin{array}{l}0.107 \\
+\quad \begin{array}{l}\text { H23 } \\
\text { H }\end{array}\end{array}$ \\
\hline Task Impact & 0.241 & $\begin{array}{l}3.228 * \\
*\end{array}$ & & & 0.178 & $2.331 *$ & 0.195 & $2.304 *$ & 1.677 & \begin{tabular}{|l}
$\begin{array}{l}0.093 \\
+\quad \\
\mathrm{H} 23 \\
\end{array}$ \\
\end{tabular} \\
\hline $\begin{array}{l}\text { KS } \\
\text { Exploration }\end{array}$ & & & -0.018 & -0.174 & & & & & & \\
\hline $\begin{array}{l}\text { KS } \\
\text { Exploitation }\end{array}$ & & & 0.177 & $1.867+$ & & & & & & \\
\hline $\begin{array}{l}\text { KS Personal } \\
\text { Contact }\end{array}$ & & & 0.021 & 0.242 & & & & & & \\
\hline
\end{tabular}




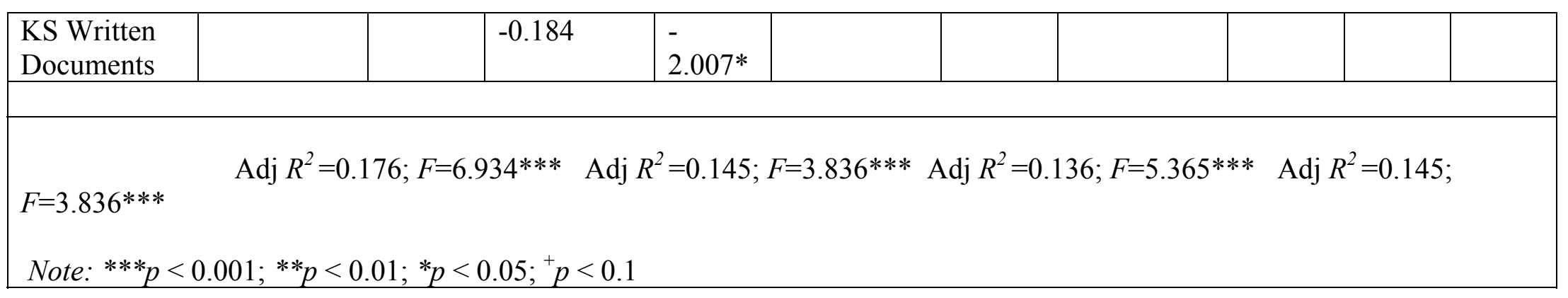

Table 45. Summary of mediation analyses, uncertain dynamic disaster management tasks, knowledge sharing for exploitation, and task effectiveness 
According to Table 45, the Sobel test statistic for task difficulty is significant $(1.646, p=0.099+)$ which indicates that the association between task difficulty and task effectiveness is reduced significantly by the inclusion of knowledge sharing for exploitation as a mediator variable. As a result, there is enough evidence to conclude that knowledge sharing for exploitation completely mediates the task difficulty and task effectiveness relationship. Further, the Sobel test statistic for amount of task information is significant $(1.607, p=0.107+)$ which indicates that the association between amount of task information and task effectiveness is reduced significantly by the inclusion of knowledge sharing for exploitation as a mediator variable. As a result, there is enough evidence to conclude that knowledge sharing for exploitation completely mediates the amount of task information and task effectiveness relationship. Finally, the Sobel test statistic for task impact is significant $(1.677, p=$ 0.093+) which indicates that the association between task impact and task effectiveness is reduced significantly by the inclusion of knowledge sharing for exploitation as a mediator variable. As a result, there is enough evidence to conclude that knowledge sharing for exploitation completely mediates the task impact and task effectiveness relationship. 


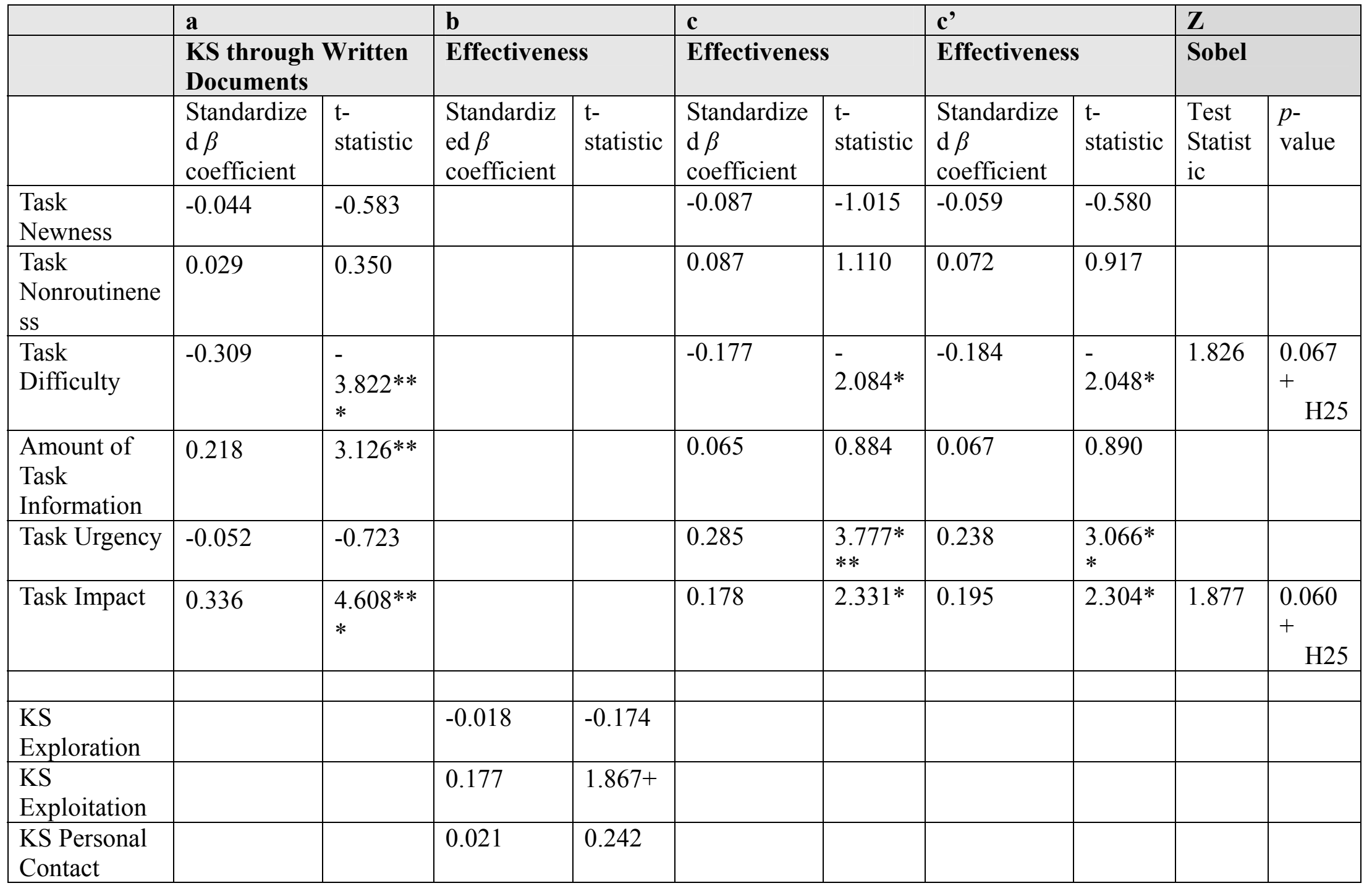




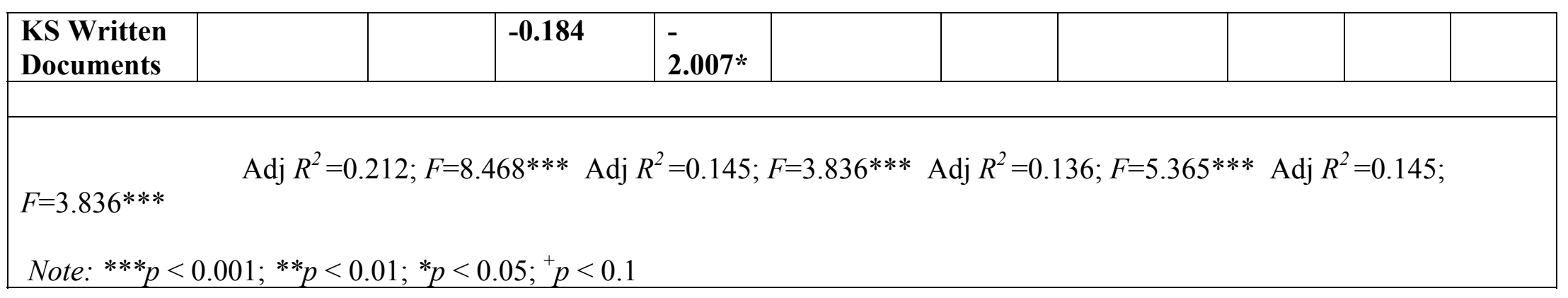

Table 46. Summary of mediation analyses, uncertain dynamic disaster management tasks, knowledge sharing through written documents, and task effectiveness 
According to Table 46, the Sobel test statistic for task difficulty is significant $(1.826, p=0.067+)$ which indicates that the association between task difficulty and task effectiveness is reduced significantly by the inclusion of knowledge sharing through written documents as a mediator variable. As a result, there is enough evidence to conclude that knowledge sharing through written documents completely mediates the task difficulty and task effectiveness relationship. Finally, the Sobel test statistic for task impact is significant $(1.877, p=0.060+)$ which indicates that the association between task impact and task effectiveness is reduced significantly by the inclusion of knowledge sharing through written documents as a mediator variable. As a result, there is enough evidence to conclude that knowledge sharing through written documents completely mediates the task impact and task effectiveness relationship. 


\begin{tabular}{|c|c|c|c|c|c|c|c|c|c|c|}
\hline & \multirow{2}{*}{\multicolumn{2}{|c|}{$\begin{array}{l}\text { a } \\
\text { KS for Exploitation }\end{array}$}} & \multirow{2}{*}{\multicolumn{2}{|c|}{\begin{tabular}{|l|} 
b \\
Efficiency
\end{tabular}}} & \multirow{2}{*}{\multicolumn{2}{|c|}{$\begin{array}{l}\text { c } \\
\text { Efficiency }\end{array}$}} & \multirow{2}{*}{\multicolumn{2}{|c|}{$\begin{array}{l}\text { c' } \\
\text { Efficiency }\end{array}$}} & \multirow{2}{*}{\multicolumn{2}{|c|}{$\begin{array}{l}\mathrm{Z} \\
\text { Sobel }\end{array}$}} \\
\hline & & & & & & & & & & \\
\hline & $\begin{array}{l}\text { Standardize } \\
\mathrm{d} \beta \\
\text { coefficient }\end{array}$ & $\begin{array}{l}\text { t- } \\
\text { statisti } \\
\mathrm{c}\end{array}$ & $\begin{array}{l}\text { Standardize } \\
\mathrm{d} \beta \\
\text { coefficient }\end{array}$ & $\begin{array}{l}\mathrm{t}- \\
\text { statisti } \\
\mathrm{c}\end{array}$ & $\begin{array}{l}\text { Standardize } \\
\mathrm{d} \beta \\
\text { coefficient }\end{array}$ & $\begin{array}{l}\text { t- } \\
\text { statisti } \\
\mathrm{c}\end{array}$ & $\begin{array}{l}\text { Standardize } \\
\mathrm{d} \beta \\
\text { coefficient }\end{array}$ & $\begin{array}{l}\text { t- } \\
\text { statisti } \\
\mathrm{c}\end{array}$ & $\begin{array}{l}\text { Test } \\
\text { Statist } \\
\text { ic }\end{array}$ & $p$-value \\
\hline $\begin{array}{l}\text { Task } \\
\text { Newness }\end{array}$ & 0.073 & -0.875 & & & -0.117 & -1.310 & -0.073 & -0.708 & & \\
\hline $\begin{array}{l}\text { Task } \\
\text { Nonroutinene } \\
\text { ss }\end{array}$ & 0.043 & 0.556 & & & 0.049 & 0.597 & 0.040 & 0.500 & & \\
\hline $\begin{array}{l}\text { Task } \\
\text { Difficulty }\end{array}$ & -0.244 & $\begin{array}{l}- \\
2.952 * \\
*\end{array}$ & & & -0.146 & $-\overline{1.659+}$ & -0.054 & -0.596 & 2.093 & $\begin{array}{r}0.036^{*} \\
\mathrm{H} 27\end{array}$ \\
\hline $\begin{array}{l}\text { Amount of } \\
\text { Task } \\
\text { Information }\end{array}$ & 0.203 & $\begin{array}{l}2.851 * \\
*\end{array}$ & & & 0.226 & $\begin{array}{l}2.973 * \\
*\end{array}$ & 0.161 & $2.093 *$ & 2.061 & $\begin{array}{r}0.039 * \\
\text { H27 }\end{array}$ \\
\hline $\begin{array}{l}\text { Task } \\
\text { Urgency }\end{array}$ & 0.196 & $\begin{array}{l}2.668^{*} \\
*\end{array}$ & & & 0.049 & 0.627 & -0.006 & -0.070 & & \\
\hline Task Impact & 0.241 & $\begin{array}{l}3.228 * \\
*\end{array}$ & & & 0.044 & 0.554 & -0.035 & -0.407 & & \\
\hline $\begin{array}{l}\text { KS } \\
\text { Exploration }\end{array}$ & & & -0.046 & -0.447 & & & & & & \\
\hline $\begin{array}{l}\text { KS } \\
\text { Exploitation }\end{array}$ & & & 0.269 & $\begin{array}{l}\text { 2.794* } \\
*\end{array}$ & & & & & & \\
\hline $\begin{array}{l}\text { KS Personal } \\
\text { Contact }\end{array}$ & & & 0.038 & 0.439 & & & & & & \\
\hline $\begin{array}{l}\text { KS Written } \\
\text { Documents }\end{array}$ & & & 0.041 & 0.442 & & & & & & \\
\hline
\end{tabular}




\begin{tabular}{l}
\hline Adj $R^{2}=0.176 ; F=6.934 * * *$ Adj $R^{2}=0.119 ; F=3.247 * * *$ Adj $R^{2}=0.063 ; F=2.872 * \quad$ Adj $R^{2}=0.119 ;$ \\
Note: $* * * p<0.001 ; * * p<0.01 ; * p<0.05 ;{ }^{+} p<0.1$
\end{tabular}

Table 47. Summary of mediation analyses, uncertain dynamic disaster management tasks, knowledge sharing for exploitation, and task efficiency 
According to Table 47, the Sobel test statistic for task difficulty is significant $\left(2.093, p=0.036^{*}\right)$ which indicates that the association between task difficulty and task efficiency is reduced significantly by the inclusion of knowledge sharing for exploitation as a mediator variable. As a result, there is enough evidence to conclude that knowledge sharing for exploitation completely mediates the task difficulty and task efficiency relationship. Finally, the Sobel test statistic for amount of task information is significant $\left(2.061, p=0.039^{*}\right)$ which indicates that the association between amount of task information and task efficiency is reduced significantly by the inclusion of knowledge sharing for exploitation as a mediator variable. As a result, there is enough evidence to conclude that knowledge sharing for exploitation completely mediates the amount of task information and task efficiency relationship. 


\begin{tabular}{|c|c|c|c|c|c|c|c|c|c|c|}
\hline & \multirow{2}{*}{\multicolumn{2}{|c|}{$\begin{array}{l}\text { a } \\
\text { KS for Exploitation }\end{array}$}} & \multirow{2}{*}{\multicolumn{2}{|c|}{ Efficiency }} & \multicolumn{2}{|c|}{$\mathrm{Nem} \cdot$} & \multicolumn{2}{|l|}{ c' } & \multicolumn{2}{|l|}{$\mathbf{Z}$} \\
\hline & & & & & Efficic & ncy & Efficie & ncy & & bel \\
\hline & $\begin{array}{l}\text { Standardize } \\
\mathrm{d} \beta \\
\text { coefficient }\end{array}$ & $\begin{array}{l}\mathrm{t}- \\
\text { statistic }\end{array}$ & $\begin{array}{l}\text { Standardize } \\
\mathrm{d} \beta \\
\text { coefficient }\end{array}$ & $\begin{array}{l}\mathrm{t}- \\
\text { statistic }\end{array}$ & $\begin{array}{l}\text { Standardize } \\
\mathrm{d} \beta \\
\text { coefficient }\end{array}$ & $\begin{array}{l}\text { t- } \\
\text { statistic }\end{array}$ & $\begin{array}{l}\text { Standardize } \\
\mathrm{d} \beta \\
\text { coefficient }\end{array}$ & $\begin{array}{l}\mathrm{t}- \\
\text { statistic }\end{array}$ & $\begin{array}{l}\text { Test } \\
\text { Statist } \\
\text { ic }\end{array}$ & $\begin{array}{l}p- \\
\text { value }\end{array}$ \\
\hline $\begin{array}{l}\text { Task } \\
\text { Newness }\end{array}$ & 0.073 & -0.875 & & & -0.117 & -1.310 & -0.071 & -0.692 & & \\
\hline $\begin{array}{l}\text { Task } \\
\text { Nonroutinene } \\
\text { ss }\end{array}$ & 0.043 & 0.556 & & & 0.049 & 0.597 & 0.035 & 0.449 & & \\
\hline $\begin{array}{l}\text { Task } \\
\text { Difficulty }\end{array}$ & -0.244 & $\begin{array}{l}- \\
2.952 * \\
*\end{array}$ & & & -0.146 & - & -0.067 & -0.751 & 2.365 & $\begin{array}{l}0.018 \\
*\end{array}$ \\
\hline $\begin{array}{l}\text { Amount of } \\
\text { Task } \\
\text { Information }\end{array}$ & 0.203 & $\begin{array}{l}2.851^{*} \\
*\end{array}$ & & & 0.226 & $\begin{array}{l}2.973 * \\
*\end{array}$ & 0.168 & $2.225^{*}$ & 2.316 & $\begin{array}{l}0.020 \\
*\end{array}$ \\
\hline Task Urgency & 0.196 & $\begin{array}{l}2.668^{*} \\
*\end{array}$ & & & 0.049 & 0.627 & -0.011 & -0.139 & & \\
\hline Task Impact & 0.241 & $\begin{array}{l}3.228^{*} \\
*\end{array}$ & & & 0.044 & 0.554 & -0.019 & -0.232 & & \\
\hline $\begin{array}{l}\text { KS } \\
\text { Exploration }\end{array}$ & & & -0.044 & -0.434 & & & & & & \\
\hline $\begin{array}{l}\text { KS } \\
\text { Exploitation }\end{array}$ & & & 0.303 & $\begin{array}{l}3.720 * \\
* *\end{array}$ & & & & & & \\
\hline$F=4.043^{* * *}$ & $\operatorname{Adj} R^{2}=0$ & $76 ; F=6$ & $34 * * * \mathrm{Ad}$ & $=0.127$ & $=4.043 * * *$ & lj $R^{2}=0$. & $3 ; F=2.872 *$ & Adj & $=0.127$; & \\
\hline
\end{tabular}


Note: $* * * p<0.001 ; * * p<0.01 ;{ }^{*} p<0.05 ;{ }^{+} p<0.1$

Table 48. Summary of mediation analyses, uncertain dynamic disaster management tasks, knowledge sharing for exploitation, and task efficiency 


\begin{tabular}{|l|l|l|l|l|}
\hline & \multicolumn{2}{|c|}{ Effectiveness } & \multicolumn{2}{c|}{ Efficiency } \\
\hline & $\begin{array}{l}\text { Standardized } \\
\beta \text { coefficient }\end{array}$ & t-statistic & $\begin{array}{l}\text { Standardized } \\
\beta \text { coefficient }\end{array}$ & t-statistic \\
\hline Task Newness & -0.117 & -1.310 & -0.071 & -0.692 \\
\hline $\begin{array}{l}\text { Task } \\
\text { Nonroutineness }\end{array}$ & 0.049 & 0.597 & 0.035 & 0.449 \\
\hline Task Difficulty & -0.146 & $-1.659+$ & -0.067 & -0.751 \\
\hline $\begin{array}{l}\text { Amount of } \\
\text { Task } \\
\text { Information }\end{array}$ & 0.226 & $2.973^{* *}$ & 0.168 & $2.225^{*}$ \\
\hline Task Urgency & 0.049 & 0.627 & -0.011 & -0.139 \\
\hline Task Impact & 0.044 & 0.554 & -0.019 & -0.232 \\
\hline KS Exploration & \multicolumn{5}{|l}{-0.044} & -0.434 \\
\hline $\begin{array}{l}\text { KS } \\
\text { Exploitation }\end{array}$ & Adj $R^{2}=\mathbf{0 . 0 6 3} ; F=\mathbf{2 . 8 7 2 *}$ & Adj $R^{2}=0.127 ; F=4.043^{* * *}$ \\
\hline \multicolumn{5}{|l}{} \\
\hline
\end{tabular}

Table 49. Summary of path analyses, uncertain dynamic disaster management tasks, knowledge sharing for exploration, knowledge sharing for exploitation, and task performance 
According to Table 48, the Sobel test statistic for task difficulty is significant $\left(2.365, p=0.018^{*}\right)$ which indicates that the association between task difficulty and task efficiency is reduced significantly by the inclusion of knowledge sharing for exploitation as a mediator variable. As a result, there is enough evidence to conclude that knowledge sharing for exploitation completely mediates the task difficulty and task efficiency relationship. Finally, the Sobel test statistic for amount of task information is significant $\left(2.316, p=0.020^{*}\right)$ which indicates that the association between amount of task information and task efficiency is reduced significantly by the inclusion of knowledge sharing for exploitation as a mediator variable. As a result, there is enough evidence to conclude that knowledge sharing for exploitation completely mediates the amount of task information and task efficiency relationship.

The table below summarizes the hypothesis and the finding of this study through mediation effects.

\begin{tabular}{|l|l|l|}
\hline H23 & $\begin{array}{l}\text { Knowledge sharing purposes and its dimension of } \\
\text { knowledge sharing for exploitation mediates the } \\
\text { relationship between uncertain dynamic disaster } \\
\text { management tasks (task difficulty, task urgency, and task } \\
\text { impact) and task effectiveness }\end{array}$ & $\begin{array}{l}\text { Marginally Not } \\
\text { Supported: } \\
+ \\
p\end{array}<0.1$ \\
\hline $\mathbf{H 2 5}$ & $\begin{array}{l}\text { Knowledge sharing mechanisms and its dimension of } \\
\text { knowledge sharing through written documents mediates } \\
\text { the relationship between uncertain dynamic disaster } \\
\text { management tasks (task difficulty and task impact) and } \\
\text { task effectiveness }\end{array}$ & $\begin{array}{l}\text { Marginally Not } \\
\text { Supported: } \\
+p<0.1\end{array}$ \\
\hline $\mathbf{H 2 7}$ & $\begin{array}{l}\text { Knowledge sharing purposes and its dimension of } \\
\text { knowledge sharing for exploitation mediates the } \\
\text { relationship between uncertain dynamic disaster } \\
\text { management tasks (task difficulty and amount of task } \\
\text { information) and task efficiency }\end{array}$ & $\begin{array}{l}\text { Marginally } \\
\text { Supported: } \\
{ }^{*} p<0.05\end{array}$ \\
\hline
\end{tabular}

Table 50. Summary of mediation effects and findings 


\title{
5.11 Interaction Effects
}

To assess the relationships and interaction effects between uncertain dynamic tasks and their novelty dimensions (task newness and task nonroutineness), unanalyzability dimensions (task difficulty and amount of task information), significance dimensions (task urgency and task impact), and task performance (task effectiveness and task performance) moderated by knowledge-sharing purposes (exploration and exploitation) and mechanisms (personal contacts and written documents), two sets of multiple regression analyses were performed according to the following equations:

\author{
Effectiveness $=\quad f$ (Newness, Nonroutineness, Difficulty, Amount of Task Inf., \\ Urgency, Impact, KS for Exploration, KS for Exploitation, KS \\ through PC, \\ KS through WD, KS for Exploration $x$ Newness, KS for \\ Exploration x Nonroutineness, KS for Exploration x Difficulty, \\ KS for Exploration $\mathrm{x}$ Amount of Task Inf., KS for Exploration \\ $\mathrm{x}$ Urgency, KS for Exploration x Impact, \\ KS for Exploitation $\mathrm{x}$ Newness, KS for Exploitation $\mathrm{x}$ \\ Nonroutineness, KS for Exploitation $x$ Difficulty, KS for \\ Exploitation x Amount of Task Inf., KS for Exploitation $\mathrm{x}$ \\ Urgency, KS for Exploitation x Impact, \\ KS through PC $x$ Newness, KS through PC x Nonroutineness, \\ KS through PC x Difficulty, KS through PC x Amount of Task \\ Inf., KS through PC x Urgency, KS through PC x Impact, \\ KS through WD x Newness, KS through WD $\mathrm{x}$ \\ Nonroutineness, KS through WD x Difficulty, KS through WD \\ x Amount of Task Inf., KS through WD x Urgency, KS \\ through WD x Impact)
}




\begin{tabular}{|c|c|}
\hline \multirow[t]{5}{*}{ Efficiency $=$} & $\begin{array}{l}f \text { (Newness, Nonroutineness, Difficulty, Amount of Task Inf., } \\
\text { Urgency, Impact, KS for Exploration, KS for Exploitation, KS } \\
\text { through PC, }\end{array}$ \\
\hline & $\begin{array}{l}\text { KS through WD, KS for Exploration x Newness, KS for } \\
\text { Exploration x Nonroutineness, KS for Exploration x Difficulty, } \\
\text { KS for Exploration x Amount of Task Inf., KS for Exploration } \\
\text { x Urgency, KS for Exploration x Impact, }\end{array}$ \\
\hline & $\begin{array}{l}\text { KS for Exploitation x Newness, KS for Exploitation x } \\
\text { Nonroutineness, KS for Exploitation x Difficulty, KS for } \\
\text { Exploitation x Amount of Task Inf., KS for Exploitation x } \\
\text { Urgency, KS for Exploitation x Impact, }\end{array}$ \\
\hline & $\begin{array}{l}\text { KS through PC x Newness, KS through PC x Nonroutineness, } \\
\text { KS through PC x Difficulty, KS through PC x Amount of Task } \\
\text { Inf., KS through PC x Urgency, KS through PC x Impact, }\end{array}$ \\
\hline & $\begin{array}{l}\text { KS through WD x Newness, KS through WD x } \\
\text { Nonroutineness, KS through WD x Difficulty, KS through WD } \\
\text { x Amount of Task Inf., KS through WD x Urgency, KS } \\
\text { through WD x Impact) }\end{array}$ \\
\hline
\end{tabular}

The significant results are depicted in Figure 22 and Table 51. 


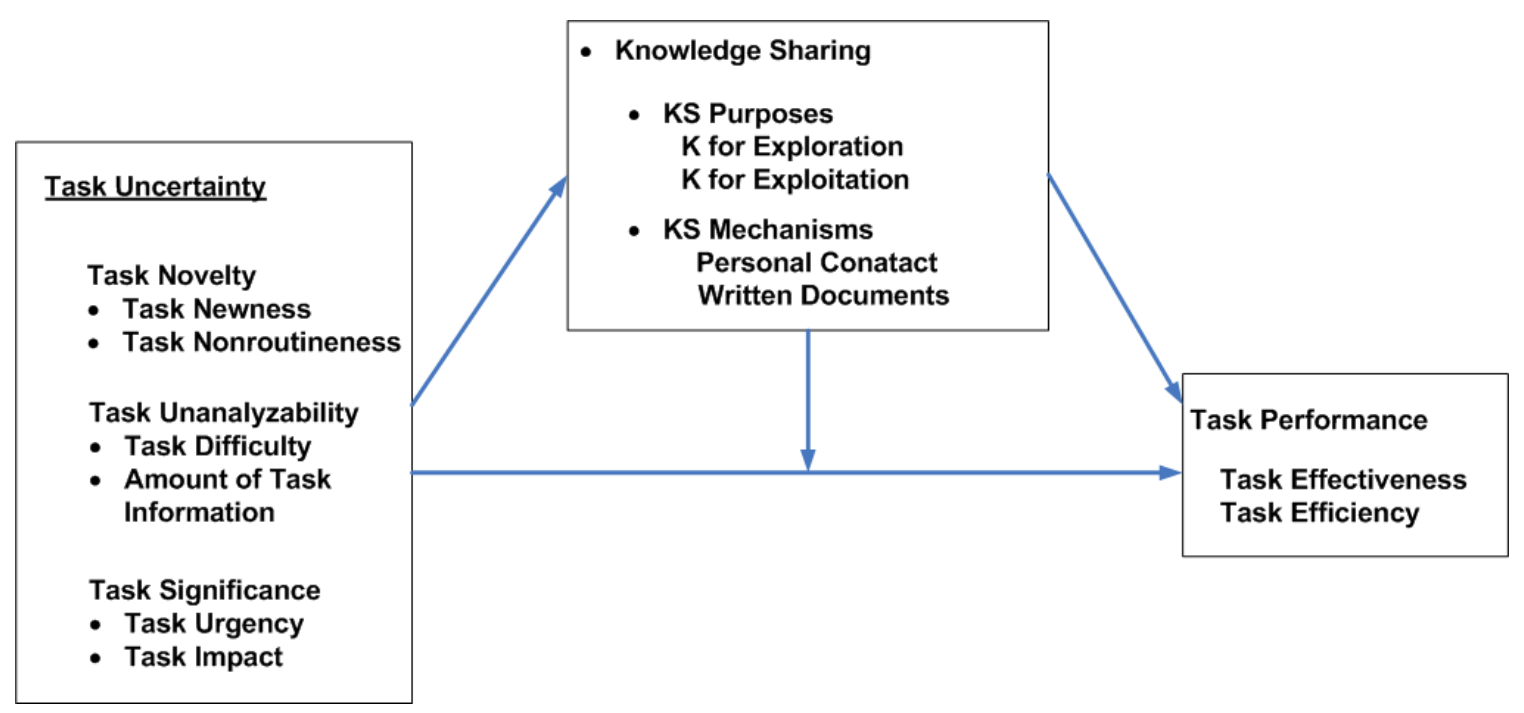

Figure 22. Uncertain dynamic disaster management tasks, knowledge sharing, and task performance interaction effects

\begin{tabular}{|l|r|l|r|r|}
\hline & \multicolumn{2}{|c|}{ Effectiveness } & \multicolumn{2}{c|}{ Efficiency } \\
\hline & $\begin{array}{l}\text { Standardized } \beta \\
\text { coefficient }\end{array}$ & t-statistic & $\begin{array}{l}\text { Standardized } \beta \\
\text { coefficient }\end{array}$ & $\begin{array}{l}\text { t- } \\
\text { statistic }\end{array}$ \\
\hline & 0.007 & 0.009 & 0.045 & 0.052 \\
\hline Task Newness & 0.448 & 0.554 & -0.625 & -0.747 \\
\hline $\begin{array}{l}\text { Task } \\
\text { Nonroutineness }\end{array}$ & 0.160 & 0.220 & 0.301 & 0.400 \\
\hline Task Difficulty & -0.432 & -0.743 & 0.136 & 0.227 \\
\hline $\begin{array}{l}\text { Amount of Task } \\
\text { Information }\end{array}$ & 0.197 & 0.294 & -0.396 & -0.571 \\
\hline Task Urgency & 0.135 & 0.196 & -0.959 & -1.342 \\
\hline Task Impact & 0.439 & 0.983 & -0.205 & -0.445 \\
\hline KS Exploration & 2.438 & $3.765^{* * *}$ & 1.660 & $2.481^{*}$ \\
\hline KS Exploitation & -2.123 & $-2.943^{* *}$ & -1.539 & $-2.066^{*}$ \\
\hline $\begin{array}{l}\text { KS Personal } \\
\text { Contact }\end{array}$ & 0.163 & 0.259 & -0.766 & -1.181 \\
\hline $\begin{array}{l}\text { KS Written } \\
\text { Documents }\end{array}$ & & & & \\
\hline
\end{tabular}

Table 51. Results interaction effects, uncertain dynamic disaster management tasks, knowledge sharing, and task performance 


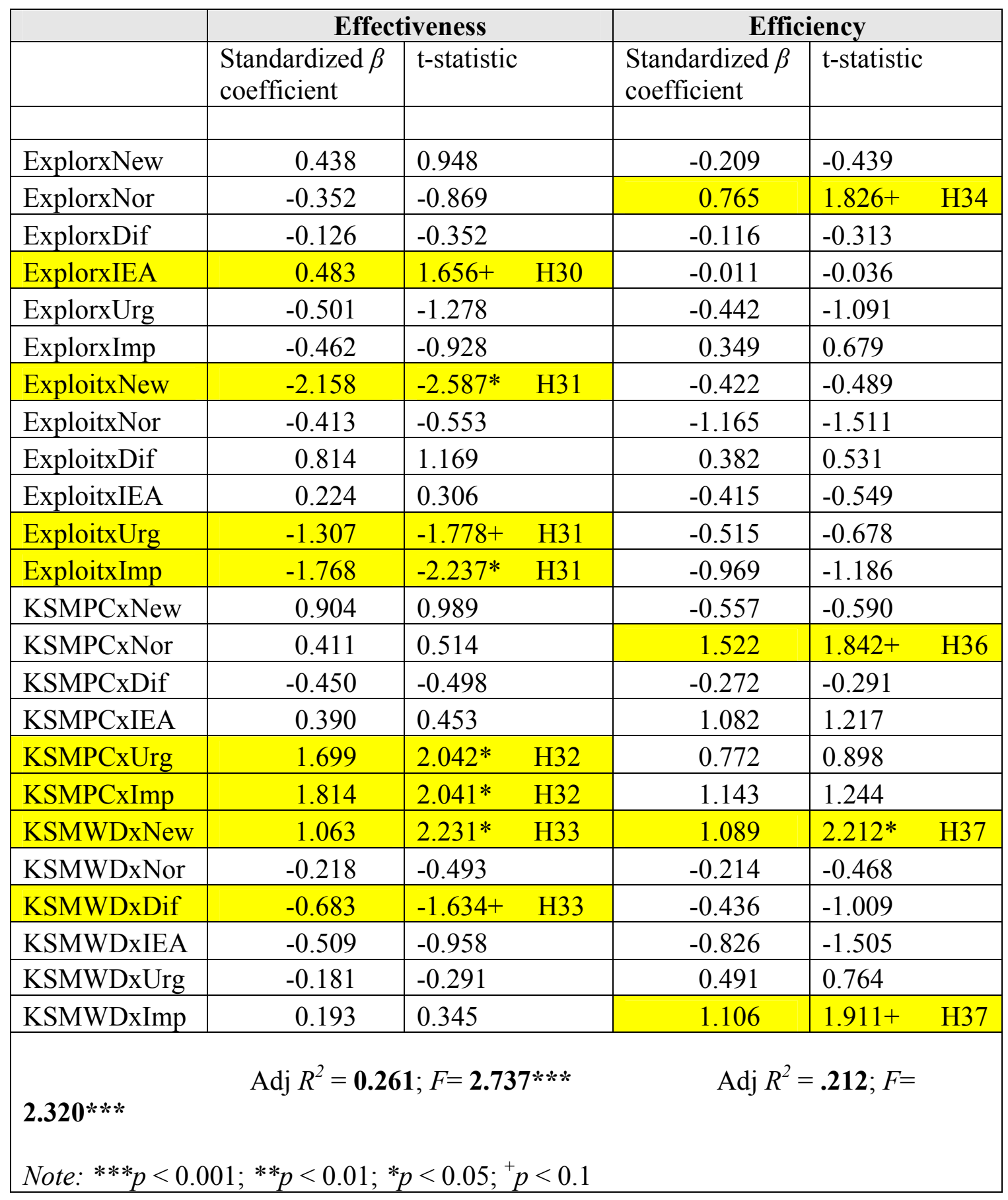

Table 51. (continued ...) 


\subsubsection{Interaction-Moderating Effects}

Figures $23 \mathrm{a}$ and $\mathrm{b}$, the moderating effects of knowledge sharing for exploration on amount of task information and task effectiveness

Figure 23 a

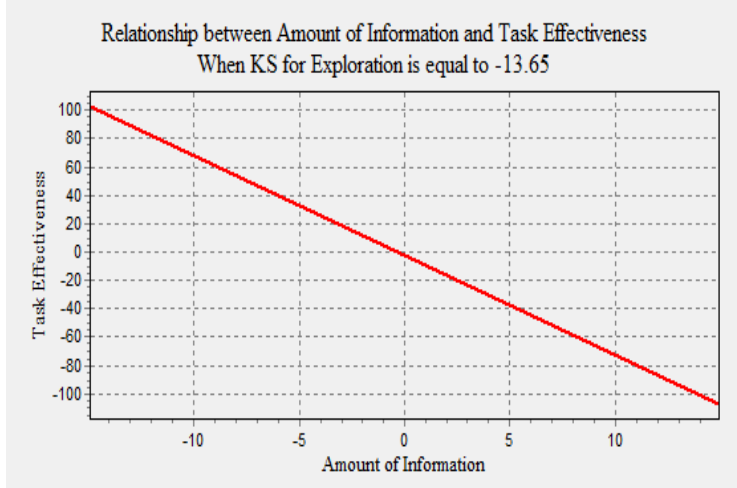

Figure $23 \mathrm{~b}$

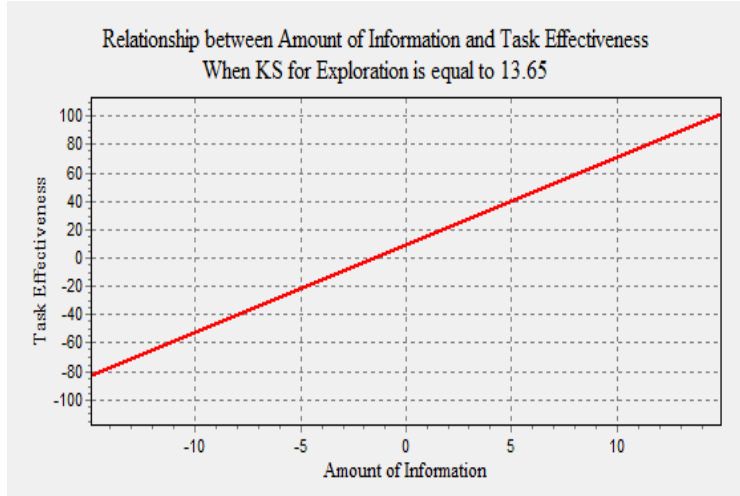

Figures $24 \mathrm{a}$ and $\mathrm{b}$, the moderating effects of amount of task information on knowledge sharing for exploration and task effectiveness

Figure 24 a

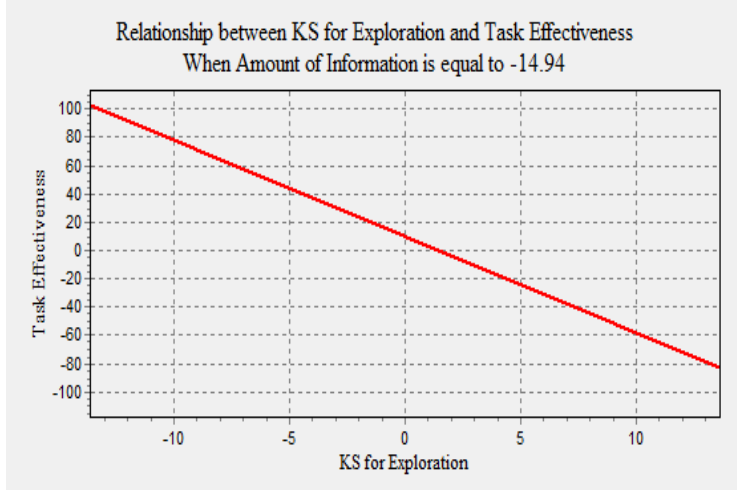

Figure $24 \mathrm{~b}$

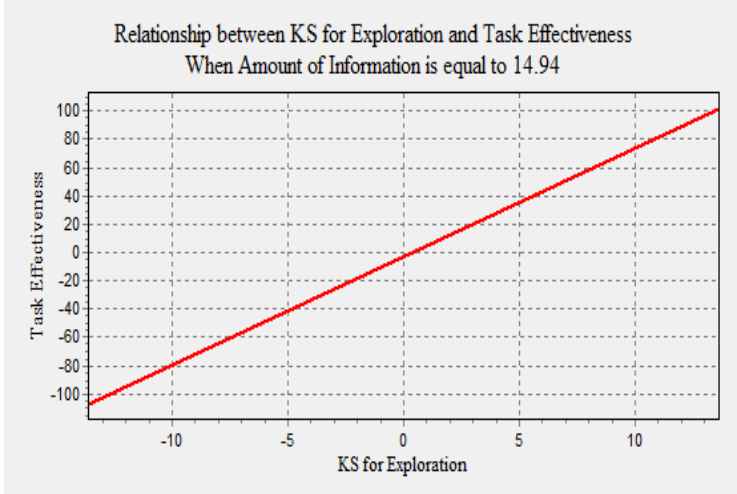


As shown in Table 51, the standardized $\beta$ coefficient for the interaction between knowledge sharing for exploration and amount of task information is positive and significant $(0.483, \mathrm{p}<+)$. Consistently, the plot of this interaction in Figure $23 \mathrm{~b}$ shows a positive relationship between amount of task information and task effectiveness when knowledge sharing for exploration is high. Similarly, Figure $24 \mathrm{~b}$ shows a positive relationship when amount of task information moderates the relationship between knowledge sharing for exploration and task effectiveness when the levels of this moderating variable of amount of task information are high.

As shown in Table 51, the standardized $\beta$ coefficient for the interaction between knowledge sharing for exploitation and task newness is negative and significant $(-2.158$, $\mathrm{p}<*)$. Consistently, the plot of this interaction in Figure $25 \mathrm{~b}$ shows a negative relationship between task newness and task effectiveness when knowledge sharing for exploitation is high. Similarly, Figure $26 \mathrm{~b}$ shows a negative relationship when task newness moderates the relationship between knowledge sharing for exploitation and task effectiveness when the levels of this moderating variable of task newness are high.

As shown in Table 51, the standardized $\beta$ coefficient for the interaction between knowledge sharing for exploitation and task urgency is negative and significant (-1.307, p $<+$ ). Consistently, the plot of this interaction in Figure $27 \mathrm{~b}$ shows a negative relationship between task urgency and task effectiveness when knowledge sharing for exploitation is high. Similarly, Figure $28 \mathrm{~b}$ shows a negative relationship when task urgency moderates the relationship between knowledge sharing for exploitation and task effectiveness when the levels of this moderating variable of task urgency are high. 
Figures $25 \mathrm{a}$ and $\mathrm{b}$, the moderating effects of knowledge sharing for exploitation on task newness and task effectiveness

Figure 25 a

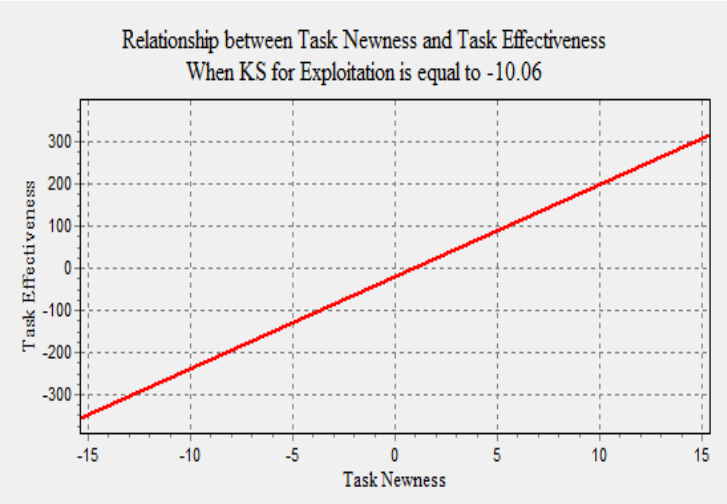

Figure $25 \mathrm{~b}$

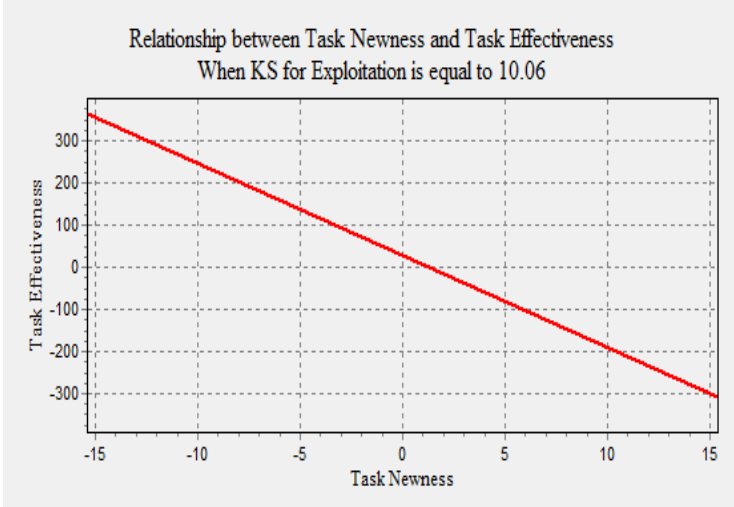

Figures $26 \mathrm{a}$ and $\mathrm{b}$, the moderating effects of task newness on knowledge sharing for exploitation and task effectiveness

Figure 26 a

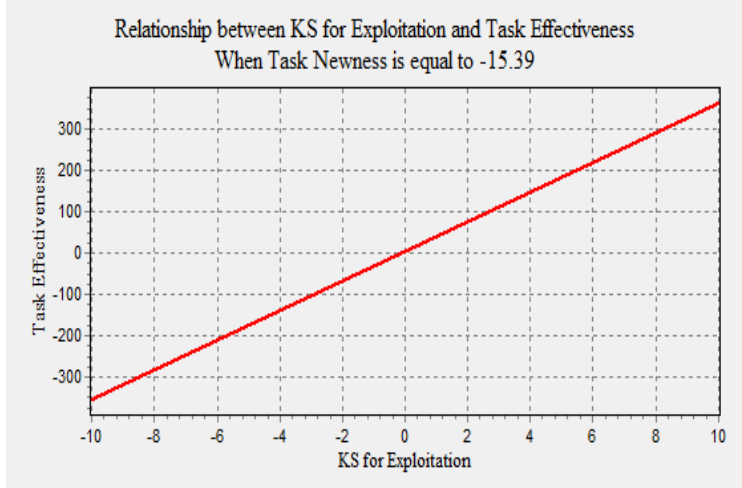

Figure $26 \mathrm{~b}$

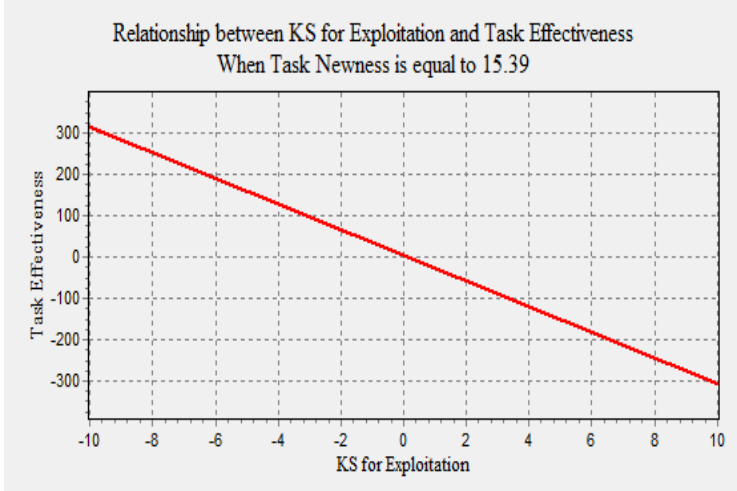


Figures $27 \mathrm{a}$ and $\mathrm{b}$, the moderating effects of knowledge sharing for exploitation on task urgency and task effectiveness

Figure 27 a

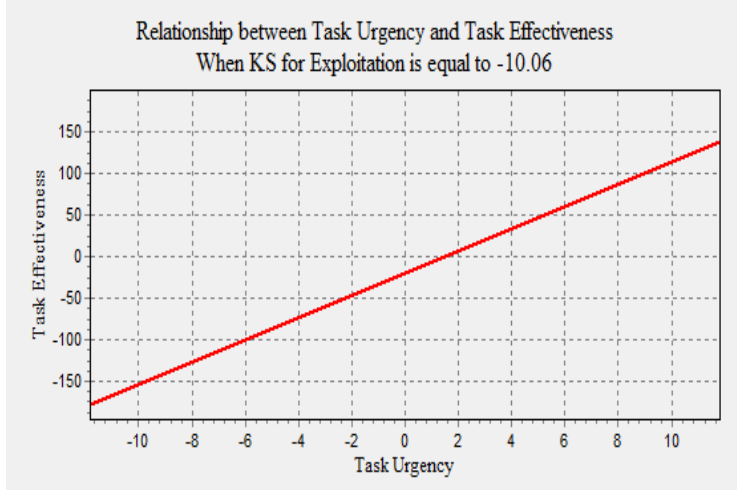

Figure 27 b

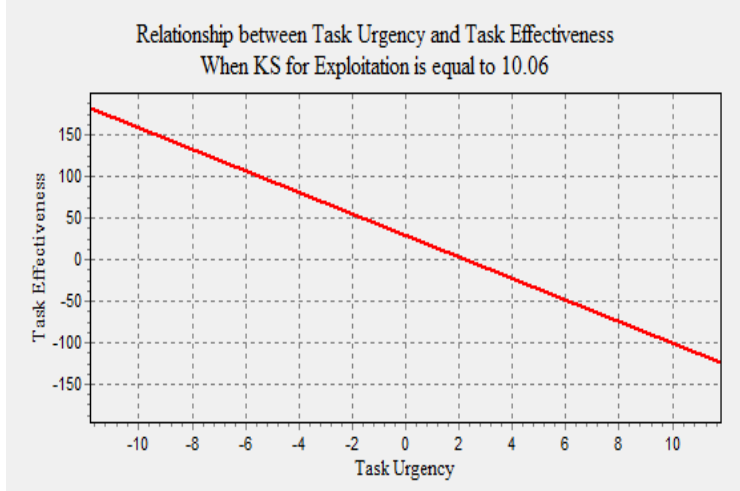

Figures $28 \mathrm{a}$ and $\mathrm{b}$, the moderating effects of task urgency on knowledge sharing for exploitation and task effectiveness

Figure 28 a

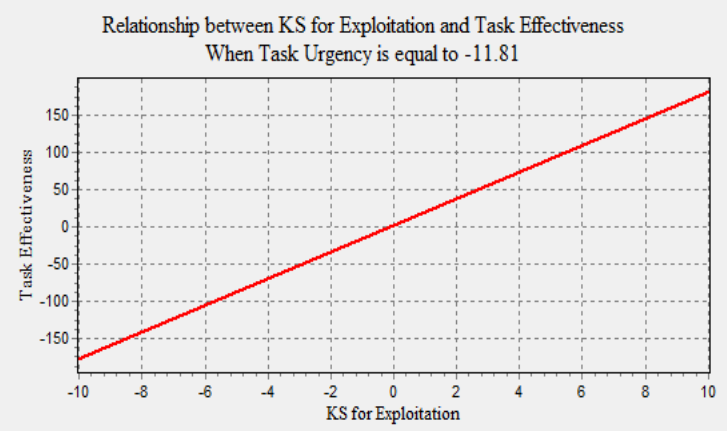

Figure $28 \mathrm{~b}$

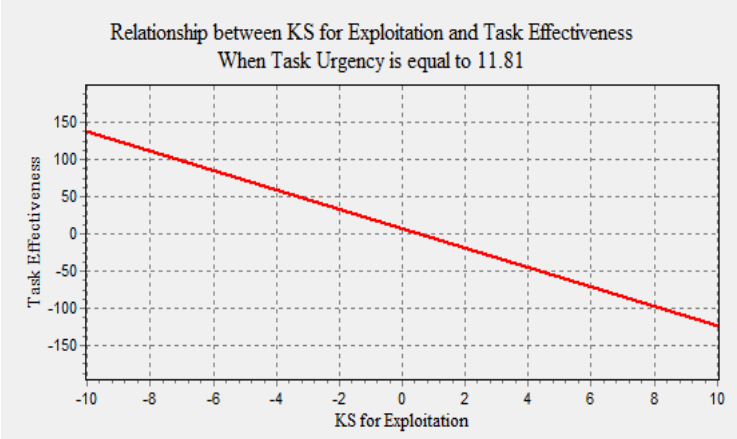


Figures $29 \mathrm{a}$ and $\mathrm{b}$, the moderating effects of knowledge sharing for exploitation on task impact and task effectiveness

Figure 29 a

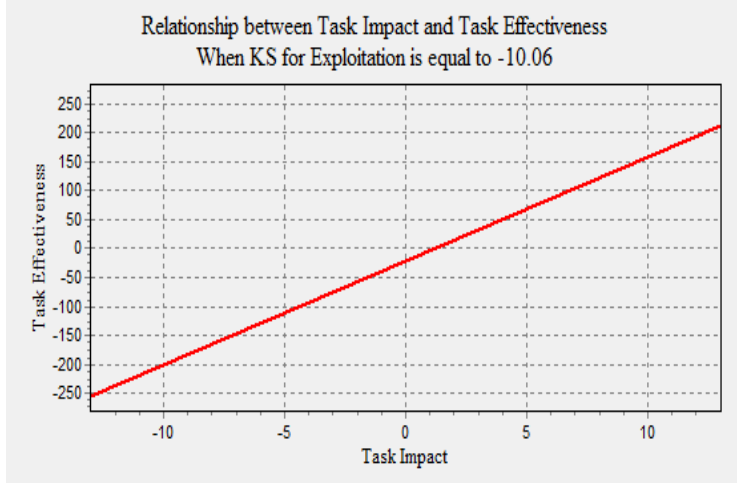

Figure 29 b

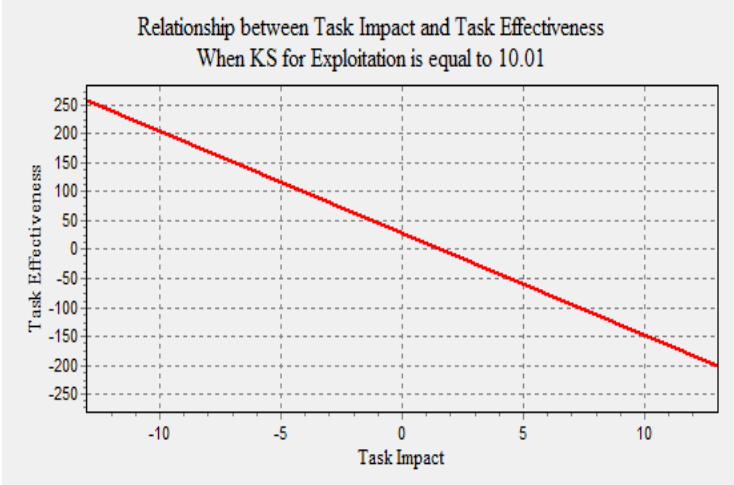

Figures $30 \mathrm{a}$ and $\mathrm{b}$, the moderating effects of task impact on knowledge sharing for exploitation and task effectiveness

Figure $30 \mathrm{a}$

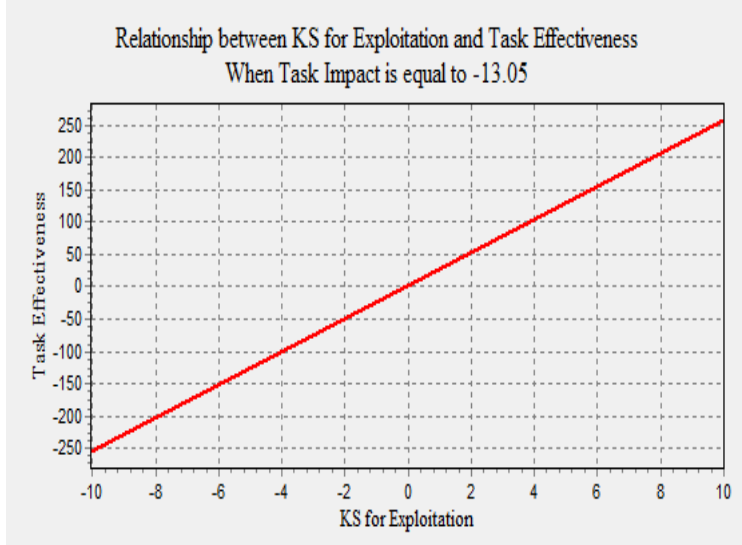

Figure $30 \mathrm{~b}$

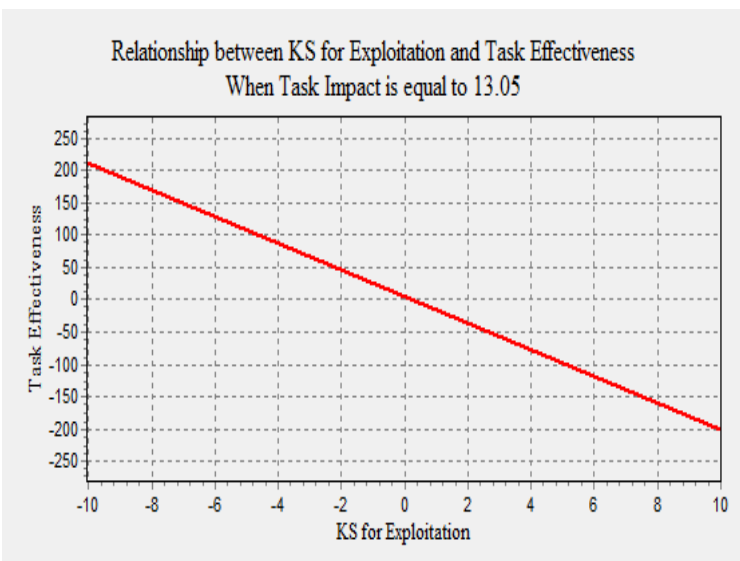


As shown in Table 51, the standardized $\beta$ coefficient for the interaction between knowledge sharing for exploitation and task impact is negative and significant $(-1.768, \mathrm{p}$ $\left.<^{*}\right)$. Consistently, the plot of this interaction in Figure $29 \mathrm{~b}$ shows a negative relationship between task impact and task effectiveness when knowledge sharing for exploitation is high. Similarly, Figure $30 \mathrm{~b}$ shows a negative relationship when task impact moderates the relationship between knowledge sharing for exploitation and task effectiveness when the levels of this moderating variable of task impact are high.

As shown in Table 51, the standardized $\beta$ coefficient for the interaction between knowledge sharing through personal contacts and task urgency is positive and significant $(1.699, \mathrm{p}<*)$. Consistently, the plot of this interaction in Figure $31 \mathrm{~b}$ shows a positive relationship between task urgency and task effectiveness when knowledge sharing through personal contacts is high. Similarly, Figure $31 \mathrm{~b}$ shows a positive relationship when task urgency moderates the relationship between knowledge sharing through personal contacts and task effectiveness when the levels of this moderating variable of task urgency are high.

As shown in Table 51, the standardized $\beta$ coefficient for the interaction between knowledge sharing through personal contacts and task impact is positive and significant $(1.814, \mathrm{p}<*)$. Consistently, the plot of this interaction in Figure $35 \mathrm{~b}$ shows a positive relationship between task impact and task effectiveness when knowledge sharing through personal contacts is high. Similarly, Figure $36 \mathrm{~b}$ shows a positive relationship when task impact moderates the relationship between knowledge sharing through personal contacts and task effectiveness when the levels of this moderating variable of task impact are high. 
Figures $31 \mathrm{a}$ and $\mathrm{b}$, the moderating effects of knowledge sharing through personal contacts on task urgency and task effectiveness

Figure 31 a

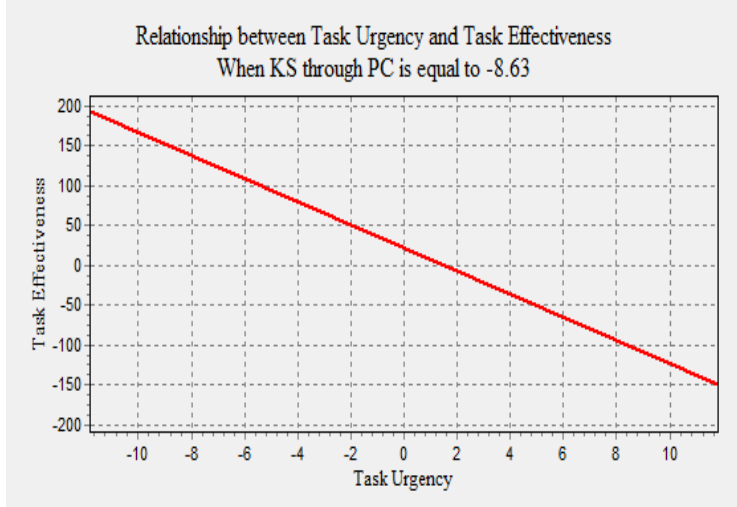

Figure $31 \mathrm{~b}$

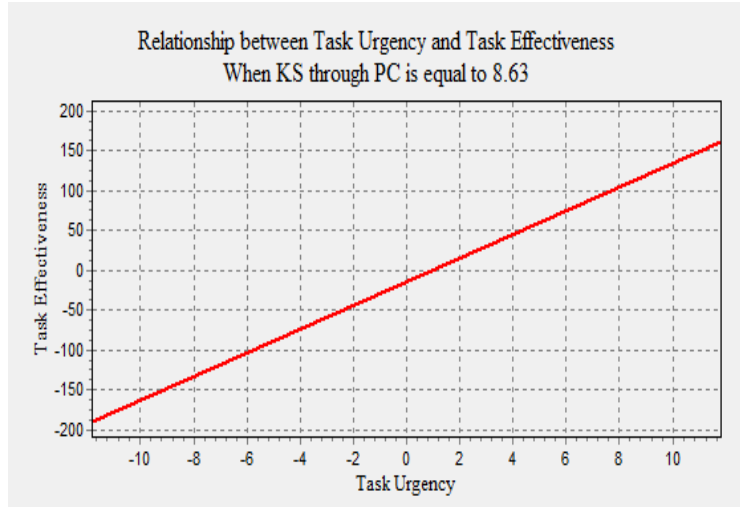

Figures $32 \mathrm{a}$ and $\mathrm{b}$, the moderating effects of task urgency on knowledge sharing through personal contacts and task effectiveness

Figure 32 a

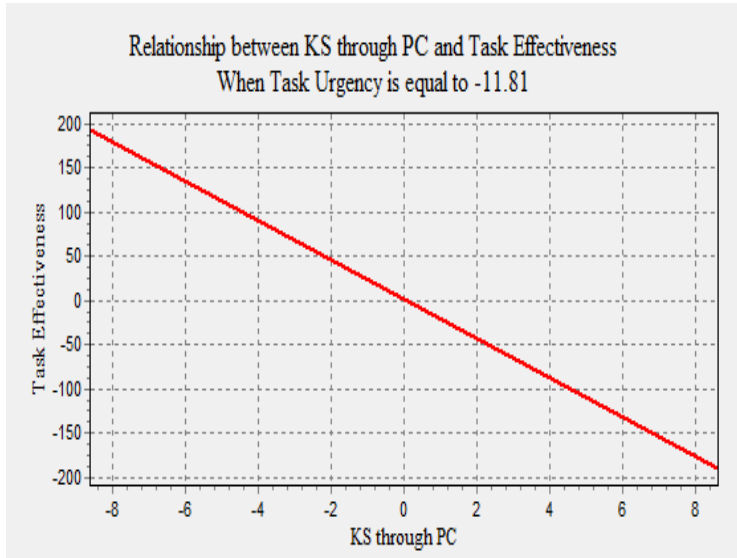

Figure $32 \mathrm{~b}$

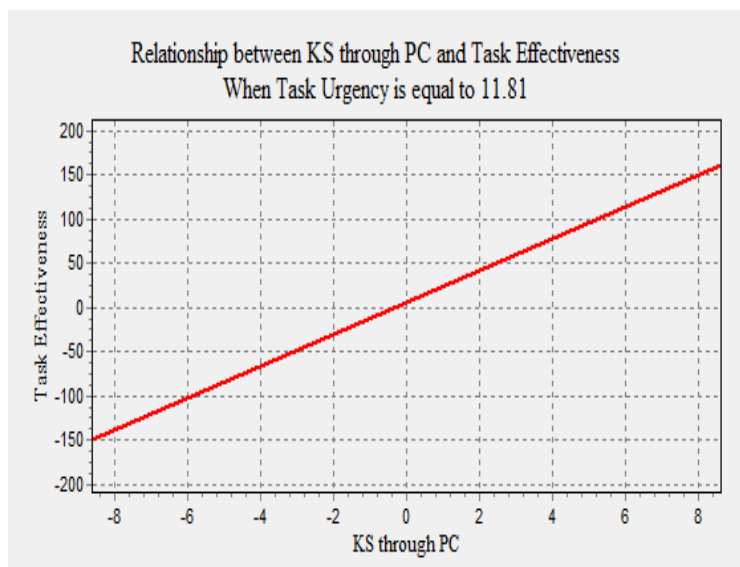


Figures $35 \mathrm{a}$ and $\mathrm{b}$, the moderating effects of knowledge sharing through personal contacts on task impact and task effectiveness

Figure 35 a

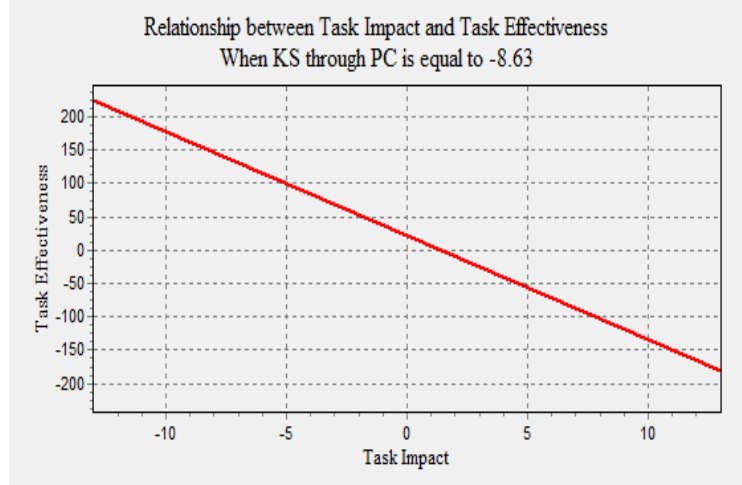

Figure $35 \mathrm{~b}$

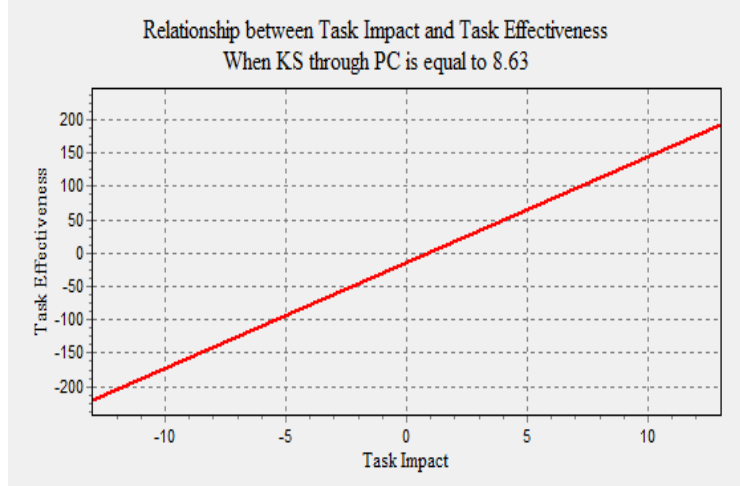

Figures $36 \mathrm{a}$ and $\mathrm{b}$, the moderating effects of task impact on knowledge sharing through personal contacts and task effectiveness

Figure 36 a

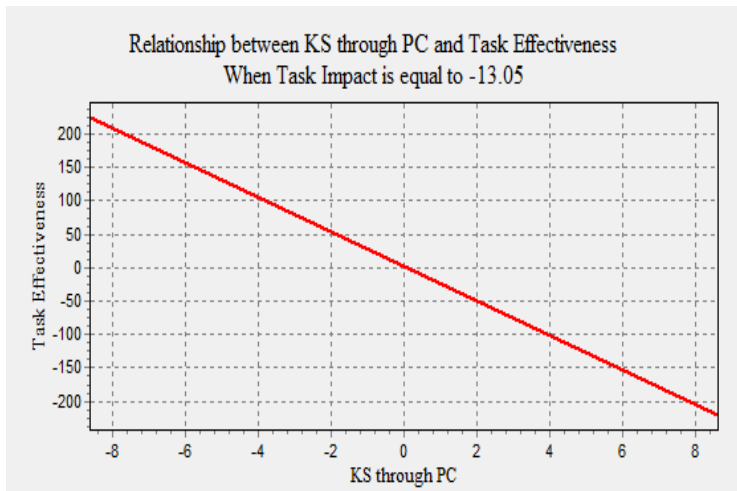

Figure $36 \mathrm{~b}$

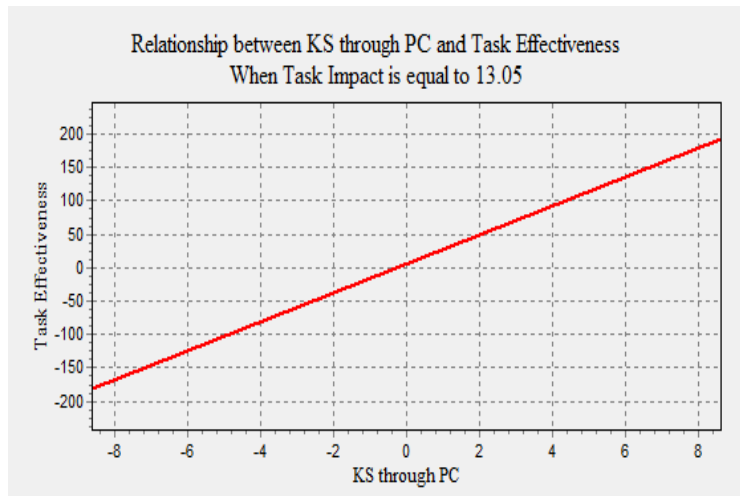


Figures $37 \mathrm{a}$ and $\mathrm{b}$, the moderating effects of knowledge sharing trough written documents on task newness and task effectiveness

Figure 37 a

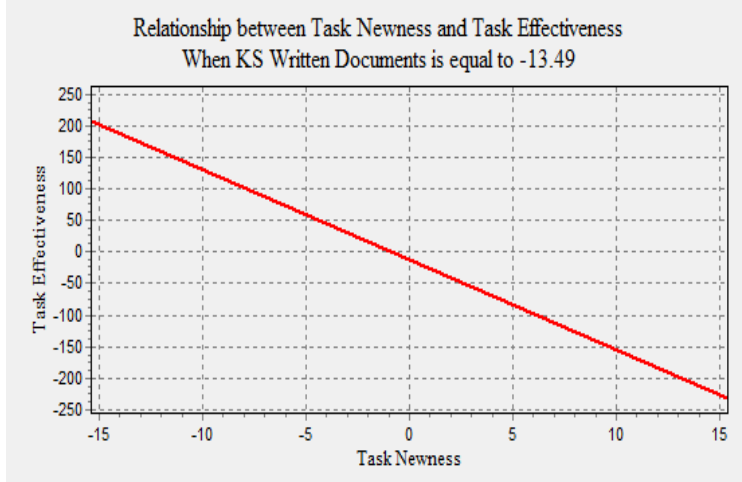

Figure 37 b

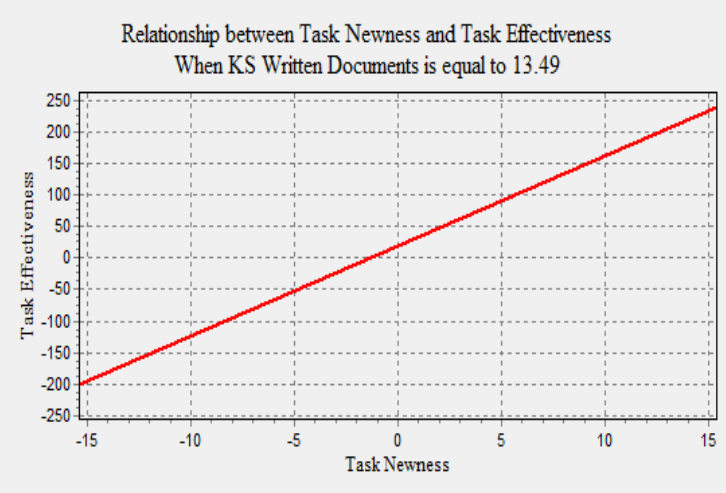

Figures $38 \mathrm{a}$ and $\mathrm{b}$, the moderating effects of task newness on knowledge sharing trough written documents and task effectiveness

Figure 38 a

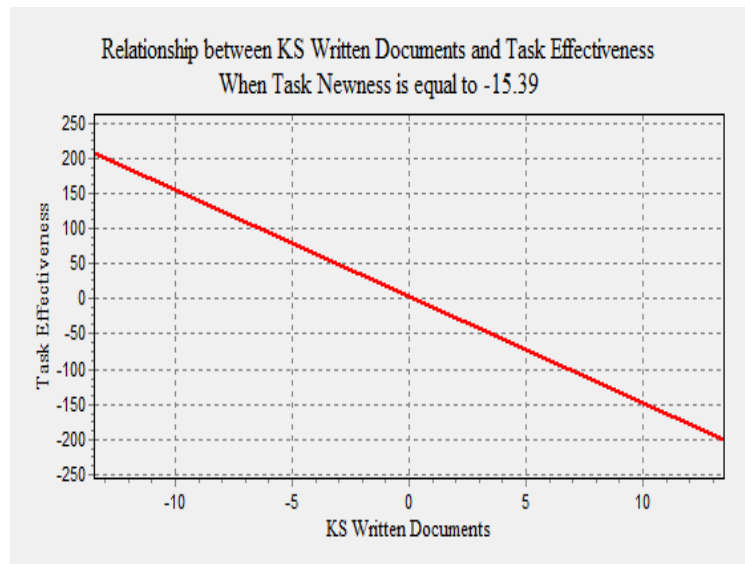

Figure $38 \mathrm{~b}$

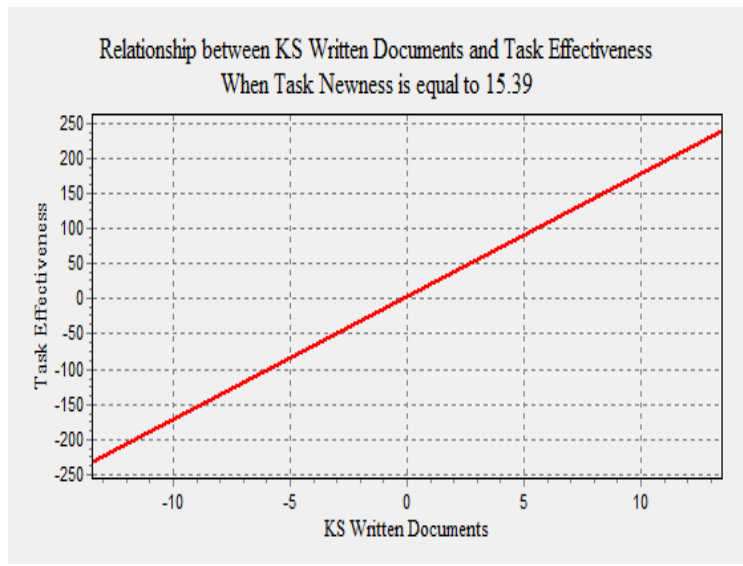


As shown in Table 51, the standardized $\beta$ coefficient for the interaction between knowledge sharing trough written documents and task newness is positive and significant $(1.063, \mathrm{p}<*)$. Consistently, the plot of this interaction in Figure $37 \mathrm{~b}$ shows a positive relationship between task newness and task effectiveness when knowledge sharing trough written documents is high. Similarly, Figure $38 \mathrm{~b}$ shows a positive relationship when task newness moderates the relationship between knowledge sharing trough written documents and task effectiveness when the levels of this moderating variable of task newness are high.

As shown in Table 51, the standardized $\beta$ coefficient for the interaction between knowledge sharing trough written documents and task difficulty is negative and significant $(-0.683, \mathrm{p}<+)$. Consistently, the plot of this interaction in Figure $39 \mathrm{~b}$ shows a negative relationship between task difficulty and task effectiveness when knowledge sharing trough written documents is high. Similarly, Figure $40 \mathrm{~b}$ shows a negative relationship when task difficulty moderates the relationship between knowledge sharing trough written documents and task effectiveness when the levels of this moderating variable of task difficulty are high.

As shown in Table 51, the standardized $\beta$ coefficient for the interaction between knowledge sharing for exploration and task non-routineness is positive and significant $(0.765, \mathrm{p}<+)$. Consistently, the plot of this interaction in Figure $41 \mathrm{~b}$ shows a positive relationship between task non-routineness and task efficiency when knowledge sharing for exploration is high. 
Similarly, Figure $42 \mathrm{~b}$ shows a positive relationship when task non-routineness moderates the relationship between knowledge sharing for exploration and task efficiency when the levels of this moderating variable of task non-routineness are high.

Figures $39 \mathrm{a}$ and $\mathrm{b}$, the moderating effects of knowledge sharing trough written documents on task difficulty and task effectiveness

Figure 39 a

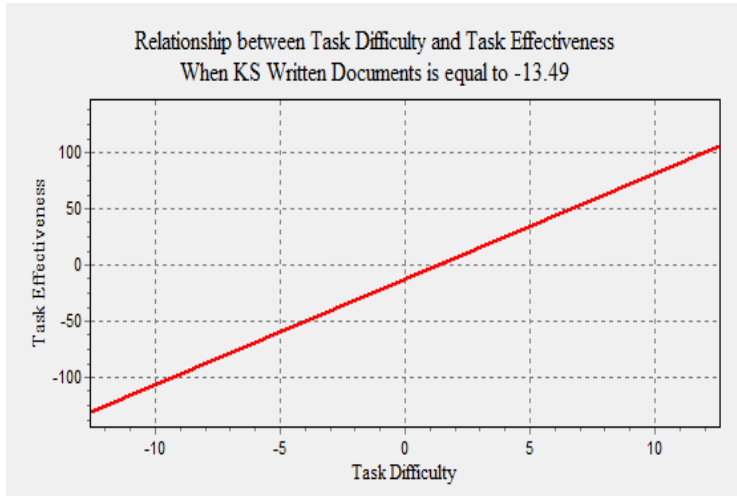

Figure $39 \mathrm{~b}$

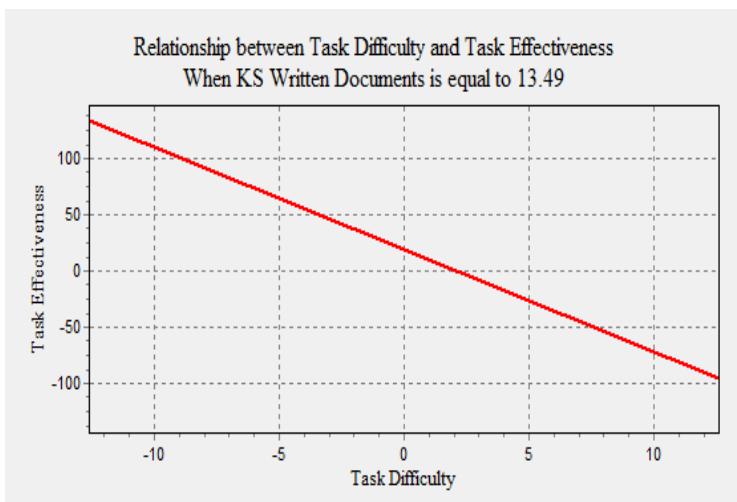

Figures $40 \mathrm{a}$ and $\mathrm{b}$, the moderating effects of task difficulty on knowledge sharing trough written documents and task effectiveness

Figure 40 a

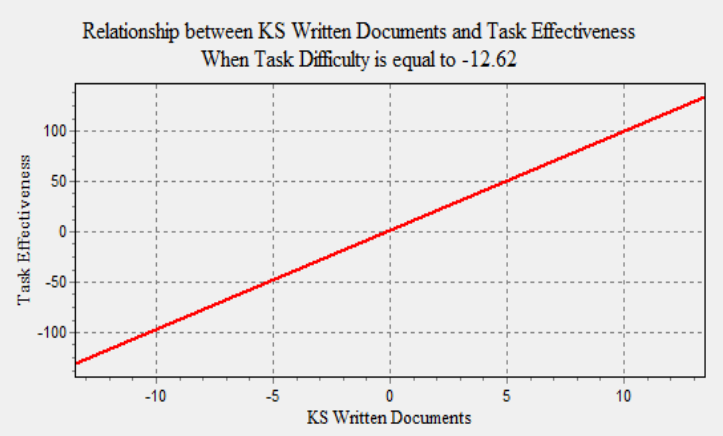

Figure $40 \mathrm{~b}$

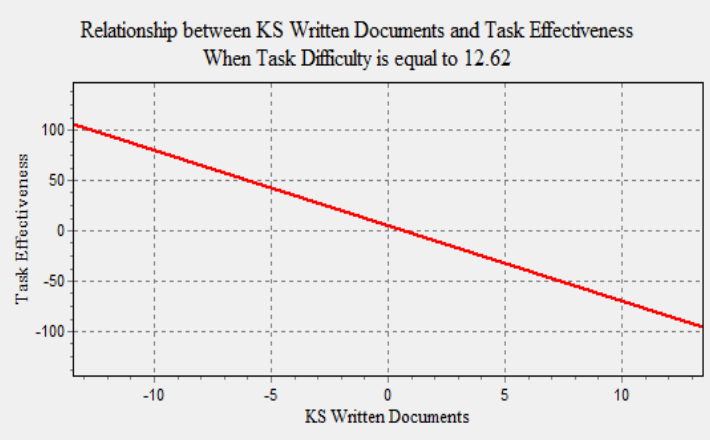


Figures $41 \mathrm{a}$ and $\mathrm{b}$, the moderating effects of knowledge sharing for exploration on task non-routineness and task efficiency

Figure 41 a

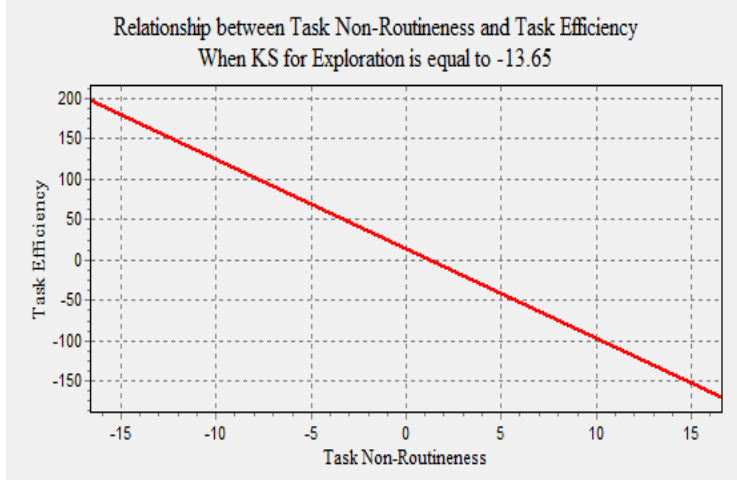

Figure $41 \mathrm{~b}$

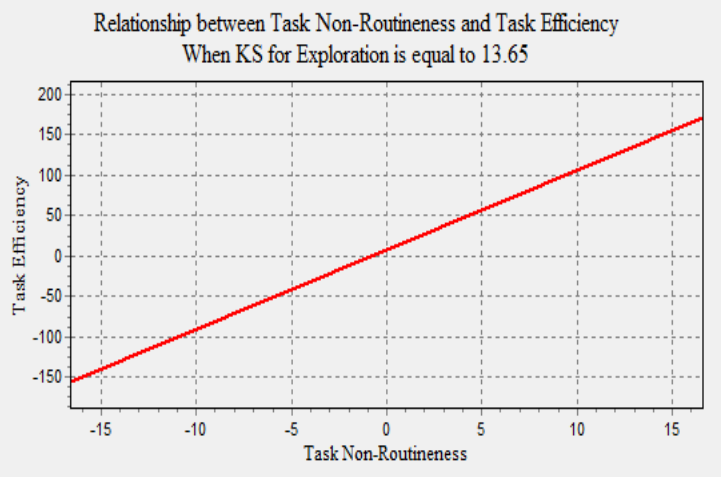

Figures $42 \mathrm{a}$ and $\mathrm{b}$, the moderating effects of task non-routineness on knowledge sharing for exploration and task efficiency

Figure $42 \mathrm{a}$

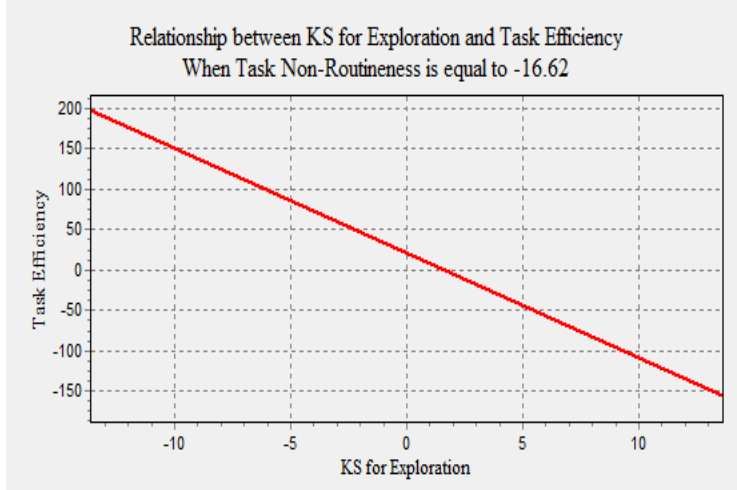

Figure $42 \mathrm{~b}$

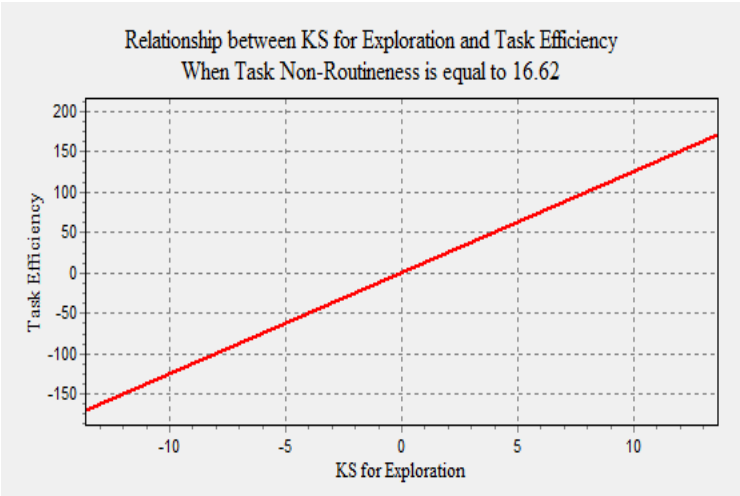


Figures $43 \mathrm{a}$ and $\mathrm{b}$, the moderating effects of knowledge sharing through personal contacts on task non-routineness and task efficiency

Figure 43 a

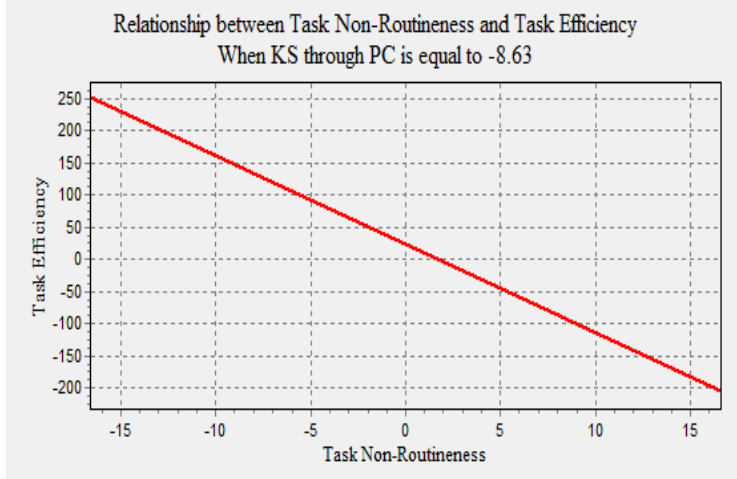

Figure 43 b

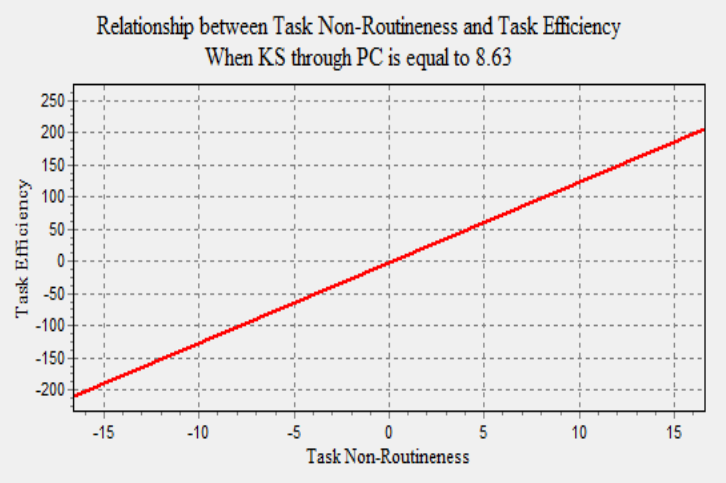

Figures $44 \mathrm{a}$ and $\mathrm{b}$, the moderating effects of task non-routineness on knowledge sharing through personal contacts and task efficiency

Figure 44 a

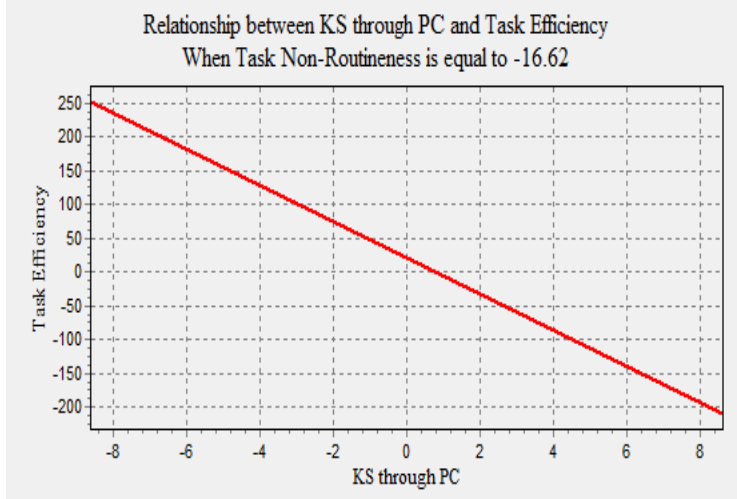

Figure $44 \mathrm{~b}$

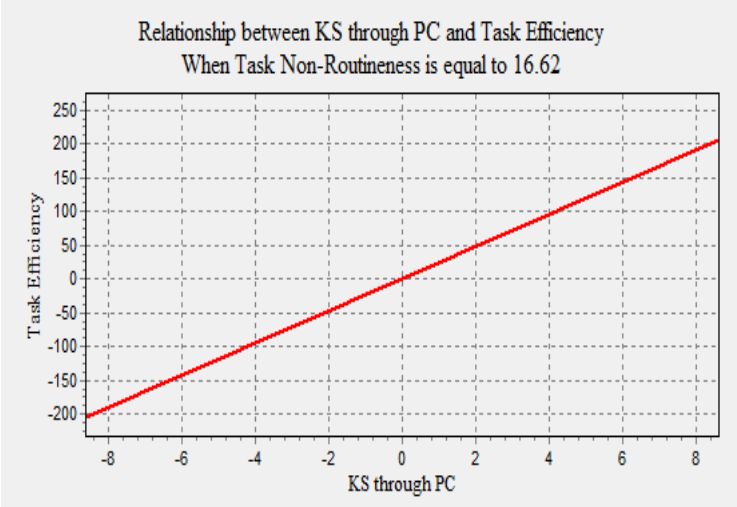


As shown in Table 51, the standardized $\beta$ coefficient for the interaction between knowledge sharing through personal contacts and task non-routineness is positive and significant $(1.522, \mathrm{p}<+)$. Consistently, the plot of this interaction in Figure $43 \mathrm{~b}$ shows a positive relationship between task non-routineness and task efficiency when knowledge sharing through personal contacts is high. Similarly, Figure $44 \mathrm{~b}$ shows a positive relationship when task non-routineness moderates the relationship between knowledge sharing through personal contacts and task efficiency when the levels of this moderating variable of task non-routineness are high.

As shown in Table 51, the standardized $\beta$ coefficient for the interaction between knowledge sharing trough written documents and task newness is positive and significant $(1.089, \mathrm{p}<*)$. Consistently, the plot of this interaction in Figure $45 \mathrm{~b}$ shows a positive relationship between task newness and task efficiency when knowledge sharing trough written documents is high. Similarly, Figure $46 \mathrm{~b}$ shows a positive relationship when task newness moderates the relationship between knowledge sharing trough written documents and task efficiency when the levels of this moderating variable of task newness are high.

As shown in Table 51, the standardized $\beta$ coefficient for the interaction between knowledge sharing trough written documents and task impact is positive and significant $(1.106, \mathrm{p}<+)$. Consistently, the plot of this interaction in Figure $47 \mathrm{~b}$ shows a positive relationship between task impact and task efficiency when knowledge sharing trough written documents is high. Similarly, Figure $48 \mathrm{~b}$ shows a positive relationship when task impact moderates the relationship between knowledge sharing trough written 
documents and task efficiency when the levels of this moderating variable of task impact are high.

Figures $45 \mathrm{a}$ and $\mathrm{b}$, the moderating effects of knowledge sharing trough written documents on task newness and task efficiency

Figure 45 a

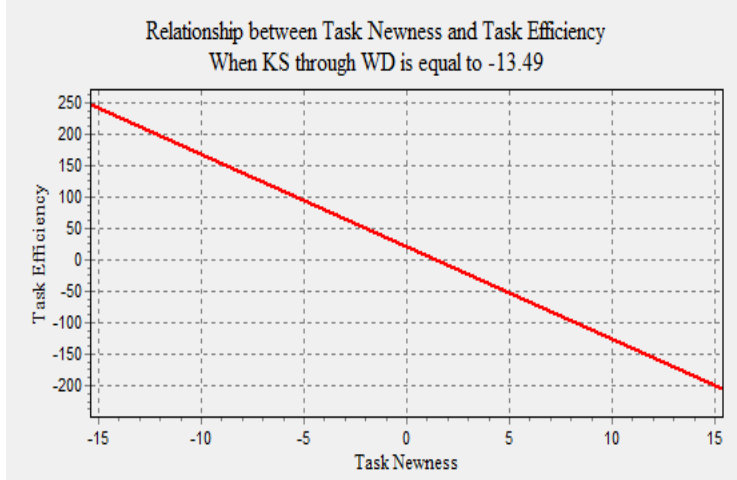

Figure $45 \mathrm{~b}$

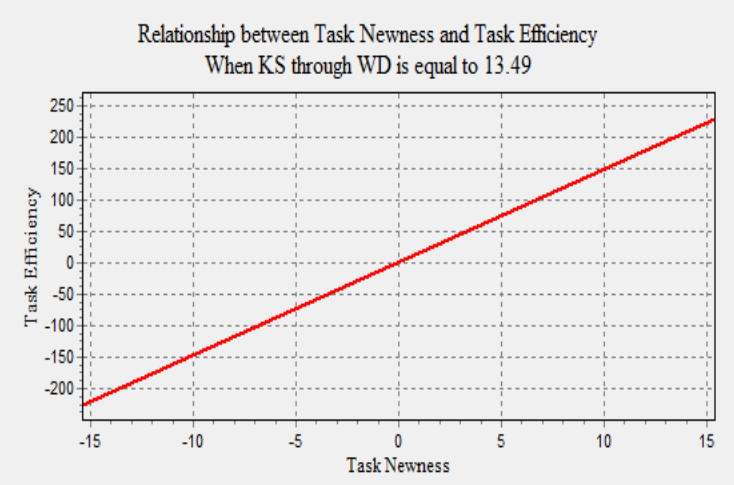

Figures $46 \mathrm{a}$ and $\mathrm{b}$, the moderating effects of task newness on knowledge sharing trough written documents and task efficiency

Figure 46 a

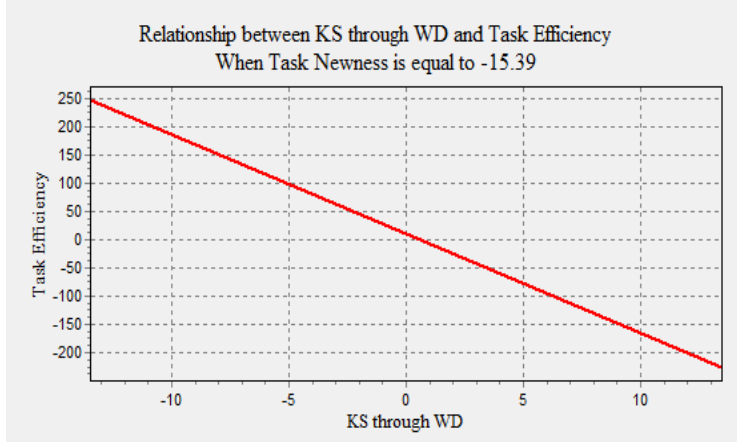

Figure $46 \mathrm{~b}$

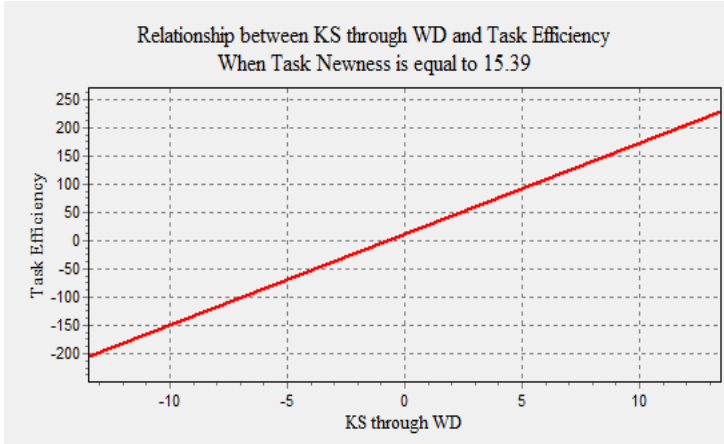


Figures $47 \mathrm{a}$ and $\mathrm{b}$, the moderating effects of knowledge sharing trough written documents on task impact and task efficiency

Figure 47 a

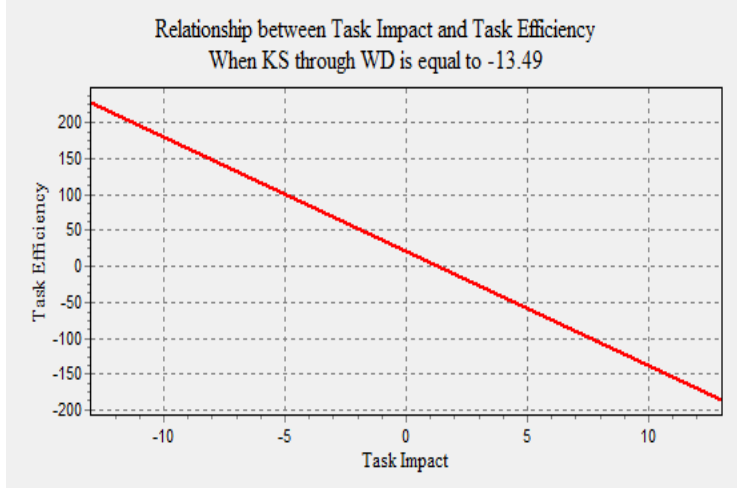

Figure $47 \mathrm{~b}$

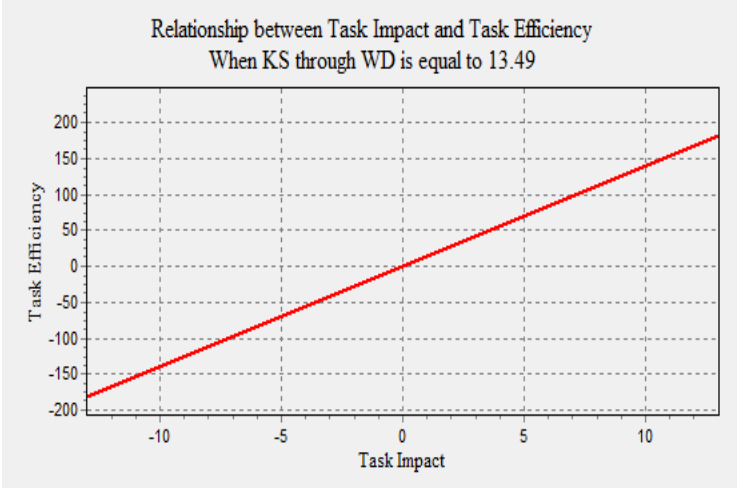

Figures $48 \mathrm{a}$ and $\mathrm{b}$, the moderating effects of task impact on knowledge sharing trough written documents and task efficiency

Figure 48 a

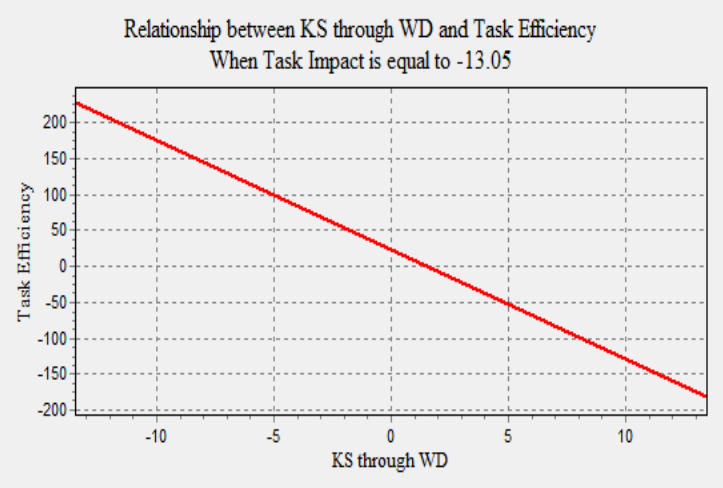

Figure $48 \mathrm{~b}$

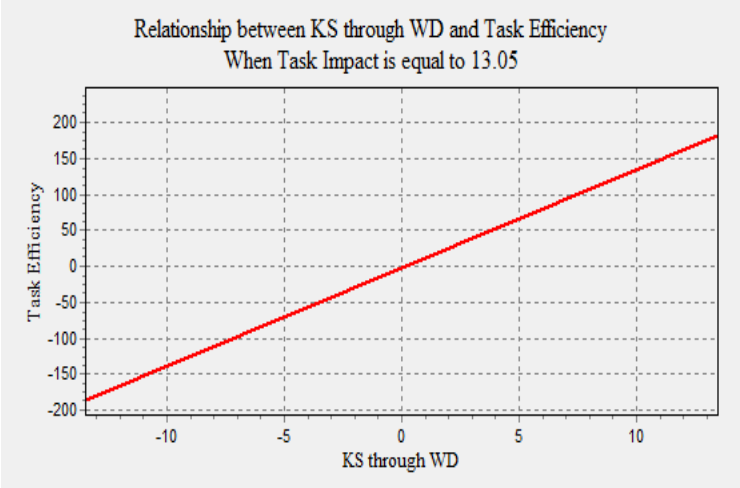


The table below summarizes the hypothesis and the finding of this study through interaction-moderating effects.

\begin{tabular}{|c|c|c|}
\hline H30 & $\begin{array}{l}\text { Knowledge sharing for exploration positively moderates } \\
\text { the relationship between uncertain dynamic task } \\
\text { characteristics with unanalyzability dimension (amount } \\
\text { of task information) with task effectiveness }\end{array}$ & $\begin{array}{l}\text { Marginally Not } \\
\text { Supported: } \\
{ }^{+} p<0.1\end{array}$ \\
\hline H31 & $\begin{array}{l}\text { Knowledge sharing for exploitation negatively } \\
\text { moderates the relationship between uncertain dynamic } \\
\text { task characteristics with novelty dimensions (task } \\
\text { newness: Marginally Supported } * p<0.05 \text { ) and } \\
\text { significance dimensions (task urgency: Marginally Not } \\
\text { Supported }{ }^{+} p<0.1 \text { and task impact: Marginally } \\
\text { Supported }{ }^{*} p<0.05 \text { ) with task effectiveness }\end{array}$ & Supported \\
\hline H32 & $\begin{array}{l}\text { Knowledge sharing through personal contacts positively } \\
\text { moderates the relationship between uncertain dynamic } \\
\text { task characteristics with significance dimensions (task } \\
\text { urgency and task impact) with task effectiveness }\end{array}$ & $\begin{array}{l}\text { Marginally } \\
\text { Supported: } \\
*_{p}<0.05\end{array}$ \\
\hline H33 & $\begin{array}{l}\text { Knowledge sharing through written documents } \\
\text { negatively moderates the relationship between uncertain } \\
\text { dynamic task characteristics with novelty dimensions } \\
\text { (task newness) with task effectiveness }\end{array}$ & $\begin{array}{l}\text { Marginally } \\
\text { Supported: } \\
*_{p}<0.05 \\
\text { but in opposite } \\
\text { direction }\end{array}$ \\
\hline H33 & $\begin{array}{l}\text { Knowledge sharing through written documents } \\
\text { negatively moderates the relationship between uncertain } \\
\text { dynamic task characteristics with unanalyzability } \\
\text { dimension (task difficulty) with task effectiveness }\end{array}$ & $\begin{array}{l}\text { Marginally Not } \\
\text { Supported: } \\
{ }^{+} p<0.1\end{array}$ \\
\hline H34 & $\begin{array}{l}\text { Knowledge sharing for exploration positively moderates } \\
\text { the relationship between uncertain dynamic task } \\
\text { characteristics with novelty dimensions (task } \\
\text { nonroutineness) with task efficiency }\end{array}$ & $\begin{array}{l}\text { Marginally Not } \\
\text { Supported: } \\
{ }^{+} p<0.1\end{array}$ \\
\hline H36 & $\begin{array}{l}\text { Knowledge sharing through personal contacts positively } \\
\text { moderates the relationship between uncertain dynamic } \\
\text { task characteristics with novelty dimensions (task } \\
\text { nonroutineness) with task efficiency }\end{array}$ & $\begin{array}{l}\text { Marginally Not } \\
\text { Supported: } \\
{ }^{+} p<0.1\end{array}$ \\
\hline H37 & $\begin{array}{l}\text { Knowledge sharing through written documents } \\
\text { positively moderates the relationship between uncertain } \\
\text { dynamic task characteristics with novelty dimensions } \\
\text { (task newness), and significance dimensions (task } \\
\text { impact) with task efficiency }\end{array}$ & $\begin{array}{l}\text { Marginally } \\
\text { Supported: } \\
*_{p}<0.05\end{array}$ \\
\hline
\end{tabular}

Table 52. Summary of interaction-moderating effects and findings 


\subsubsection{Interaction-Mediating Effects}

To assess the mediation effects of this section, this research study used the same interaction effects results of the previous section. Similarly, the same mediation assessment procedures that were used in previous sections were followed. Tables 53, 54, 55, and 56 summarize the mediation assessments and results of this section. 


\begin{tabular}{|c|c|c|c|c|c|c|c|c|c|c|}
\hline & \multirow{2}{*}{\multicolumn{2}{|c|}{$\begin{array}{l}\text { a } \\
\text { KS for Exploitation }\end{array}$}} & \multirow{2}{*}{\multicolumn{2}{|c|}{\begin{tabular}{|l|} 
b \\
Effectiveness \\
\end{tabular}}} & \multirow{2}{*}{\multicolumn{2}{|c|}{$\begin{array}{l}\text { c } \\
\text { Effectivenes } \\
\end{array}$}} & \multirow{2}{*}{\multicolumn{2}{|c|}{$\begin{array}{l}c^{\prime} \\
\text { Effectivenes } \\
\end{array}$}} & \multirow{2}{*}{\multicolumn{2}{|c|}{\begin{tabular}{|l|}
$\mathrm{Z}$ \\
Sobel \\
\end{tabular}}} \\
\hline & & & & & & & & & & \\
\hline & $\begin{array}{l}\text { Standardize } \\
\mathrm{d} \beta \\
\text { coefficient }\end{array}$ & $\begin{array}{l}\text { t- } \\
\text { statisti } \\
\mathrm{c}\end{array}$ & $\begin{array}{l}\text { Standardize } \\
\mathrm{d} \beta \\
\text { coefficient }\end{array}$ & $\begin{array}{l}\mathrm{t}- \\
\text { statistic }\end{array}$ & $\begin{array}{l}\text { Standardiz } \\
\text { ed } \beta \\
\text { coefficient }\end{array}$ & $\begin{array}{l}\text { t- } \\
\text { statisti } \\
\mathrm{c}\end{array}$ & $\begin{array}{l}\text { Standardize } \\
\mathrm{d} \beta \\
\text { coefficient }\end{array}$ & $\begin{array}{l}\text { t- } \\
\text { statisti } \\
\mathrm{c}\end{array}$ & $\begin{array}{l}\text { Test } \\
\text { Statist } \\
\text { ic }\end{array}$ & $p$-value \\
\hline $\begin{array}{l}\text { Task } \\
\text { Newness }\end{array}$ & & & & & & & & & & \\
\hline $\begin{array}{l}\text { Task } \\
\text { Nonroutinen } \\
\text { ess }\end{array}$ & & & & & & & & & & \\
\hline $\begin{array}{l}\text { Task } \\
\text { Difficulty }\end{array}$ & -0.244 & $\begin{array}{l}- \\
2.952 * \\
*\end{array}$ & & & -0.177 & - $2.084 *$ & & & 2.375 & $\begin{array}{r}0.017 * \\
\text { H39 }\end{array}$ \\
\hline $\begin{array}{l}\text { Amount of } \\
\text { Task } \\
\text { Information }\end{array}$ & 0.203 & $\begin{array}{l}2.851 * \\
*\end{array}$ & & & & & & & & \\
\hline $\begin{array}{l}\text { Task } \\
\text { Urgency }\end{array}$ & 0.196 & $\begin{array}{l}2.668 * \\
*\end{array}$ & & & 0.285 & $\begin{array}{l}3.777 * \\
* * \\
\end{array}$ & & & 2.229 & $\begin{array}{r}0.025^{*} \\
\text { H39 }\end{array}$ \\
\hline Task Impact & 0.241 & $\begin{array}{l}3.228^{*} \\
*\end{array}$ & & & 0.178 & $2.331 *$ & & & 2.501 & $\begin{array}{r}0.012 * \\
\text { H39 } \\
\end{array}$ \\
\hline $\begin{array}{l}\mathrm{KS} \\
\text { Exploration }\end{array}$ & & & & & & & & & & \\
\hline $\begin{array}{l}\mathrm{KS} \\
\text { Exploitation }\end{array}$ & & & 2.438 & $\begin{array}{l}3.765 * \\
* *\end{array}$ & & & & & & \\
\hline $\begin{array}{l}\text { KS Personal } \\
\text { Contact }\end{array}$ & & & -2.123 & $\begin{array}{l}- \\
2.943 * \\
*\end{array}$ & & & & & & \\
\hline KS Written & & & & & & & & & & \\
\hline
\end{tabular}




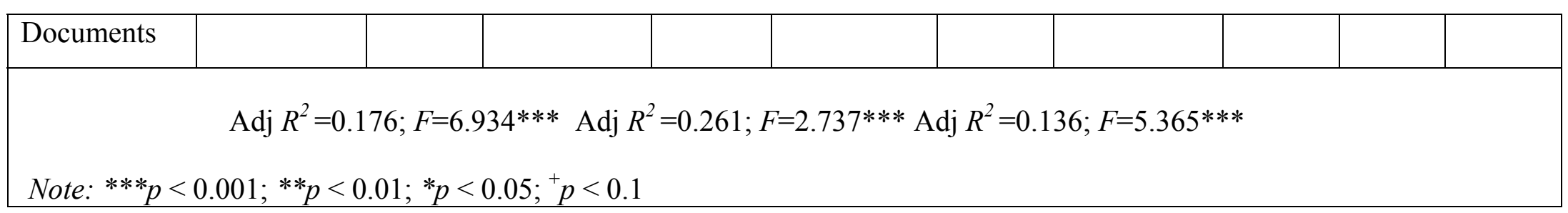

Table 53. Summary of interaction-mediation affects analyses, uncertain dynamic disaster management tasks, knowledge sharing for exploitation, and task effectiveness 


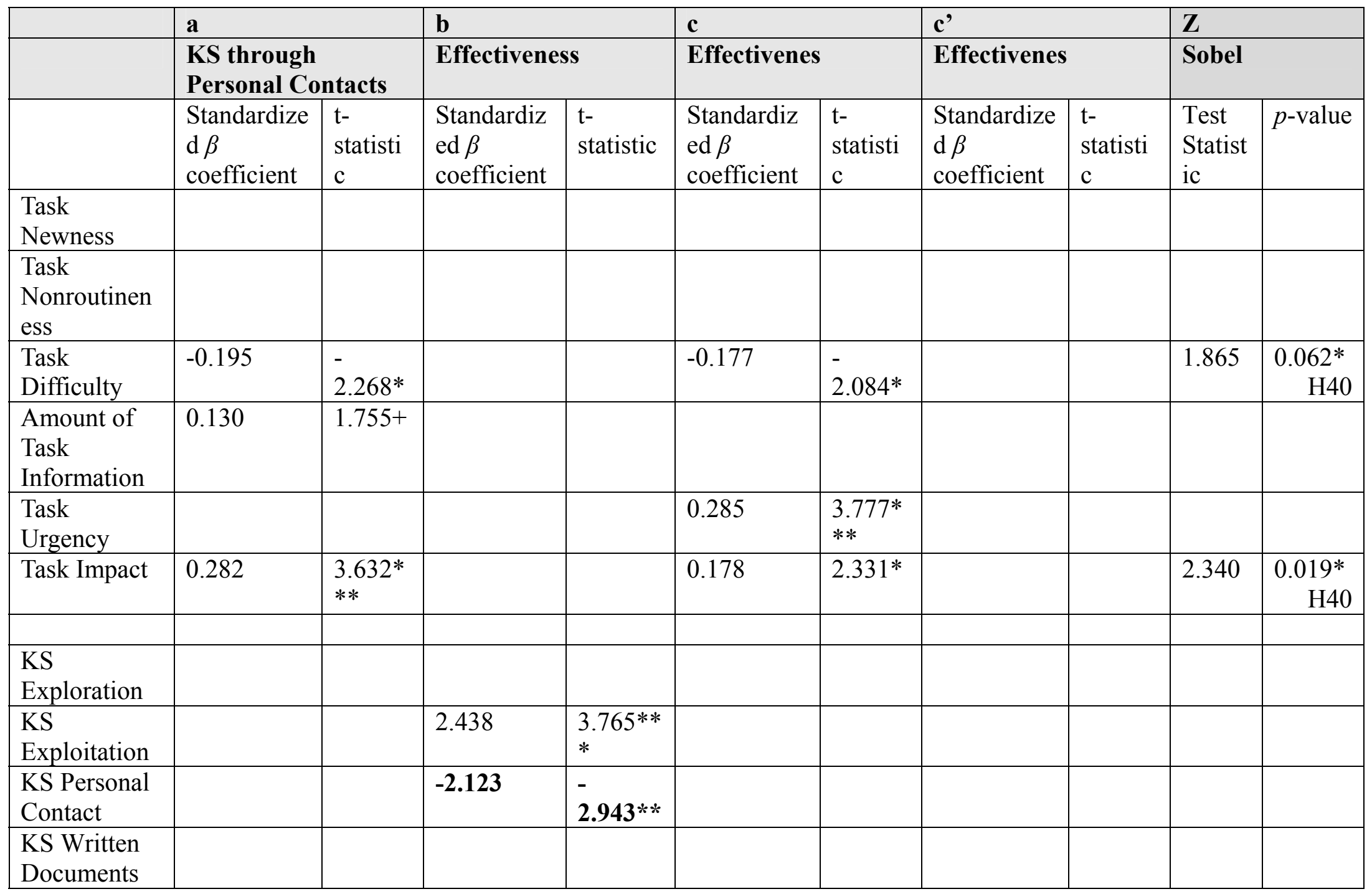


$\operatorname{Adj} R^{2}=0.109 ; F=4.408 * * * \operatorname{Adj} R^{2}=0.261 ; F=2.737 * * * \operatorname{Adj} R^{2}=0.136 ; F=5.365 * * *$

Note: ${ }^{* * *} p<0.001 ;{ }^{* *} p<0.01 ;{ }^{*} p<0.05 ;{ }^{+} p<0.1$

Table 54. Summary of interaction-mediation affects analyses, uncertain dynamic disaster management tasks, knowledge sharing through personal contacts, and task effectiveness 


\begin{tabular}{|c|c|c|c|c|c|c|c|c|c|c|}
\hline & \multirow{2}{*}{\multicolumn{2}{|c|}{$\begin{array}{l}\text { a } \\
\text { KS for Exploitation }\end{array}$}} & \multirow{2}{*}{\multicolumn{2}{|c|}{$\begin{array}{l}\text { b } \\
\text { Efficiency }\end{array}$}} & \multirow{2}{*}{\multicolumn{2}{|c|}{$\begin{array}{l}\text { c } \\
\text { Efficiency }\end{array}$}} & \multirow{2}{*}{\multicolumn{2}{|c|}{$\begin{array}{l}\text { c' } \\
\text { Efficiency }\end{array}$}} & \multirow{2}{*}{\multicolumn{2}{|c|}{$\begin{array}{l}\text { Z } \\
\text { Sobel }\end{array}$}} \\
\hline & & & & & & & & & & \\
\hline & $\begin{array}{l}\text { Standardize } \\
\mathrm{d} \beta \\
\text { coefficient }\end{array}$ & $\begin{array}{l}\text { t- } \\
\text { statisti } \\
c\end{array}$ & $\begin{array}{l}\text { Standardize } \\
\mathrm{d} \beta \\
\text { coefficient }\end{array}$ & $\begin{array}{l}\text { t- } \\
\text { statisti } \\
c\end{array}$ & $\begin{array}{l}\text { Standardize } \\
\mathrm{d} \beta \\
\text { coefficient }\end{array}$ & $\begin{array}{l}\text { t- } \\
\text { statisti } \\
\mathrm{c}\end{array}$ & $\begin{array}{l}\text { Standardize } \\
\mathrm{d} \beta \\
\text { coefficient }\end{array}$ & $\begin{array}{l}\text { t- } \\
\text { statisti } \\
c\end{array}$ & $\begin{array}{l}\text { Test } \\
\text { Statist } \\
\text { ic } \\
\end{array}$ & $p$-value \\
\hline $\begin{array}{l}\text { Task } \\
\text { Newness }\end{array}$ & & & & & & & & & & \\
\hline $\begin{array}{l}\text { Task } \\
\text { Nonroutinen } \\
\text { ess }\end{array}$ & & & & & & & & & & \\
\hline $\begin{array}{l}\text { Task } \\
\text { Difficulty }\end{array}$ & -0.244 & $\begin{array}{l}- \\
2.952 * \\
*\end{array}$ & & & -0.146 & $-\overline{1.659+}$ & & & 1.966 & $\begin{array}{r}0.049 * \\
\text { H43 }\end{array}$ \\
\hline $\begin{array}{l}\text { Amount of } \\
\text { Task } \\
\text { Information }\end{array}$ & 0.203 & $\begin{array}{l}2.851^{*} \\
*\end{array}$ & & & 0.226 & $\begin{array}{l}2.973 * \\
*\end{array}$ & & & 1.940 & $\begin{array}{r}0.052^{*} \\
\mathrm{H} 43\end{array}$ \\
\hline $\begin{array}{l}\text { Task } \\
\text { Urgency }\end{array}$ & 0.196 & $\begin{array}{l}2.668 * \\
*\end{array}$ & & & & & & & & \\
\hline Task Impact & 0.241 & $\begin{array}{l}3.228^{*} \\
*\end{array}$ & & & & & & & & \\
\hline $\begin{array}{l}\text { KS } \\
\text { Exploration }\end{array}$ & & & & & & & & & & \\
\hline $\begin{array}{l}\text { KS } \\
\text { Exploitation }\end{array}$ & & & 1.660 & $2.481 *$ & & & & & & \\
\hline $\begin{array}{l}\text { KS Personal } \\
\text { Contact }\end{array}$ & & & -1.539 & - $2.066^{*}$ & & & & & & \\
\hline $\begin{array}{l}\text { KS Written } \\
\text { Documents }\end{array}$ & & & & & & & & & & \\
\hline
\end{tabular}




Adj $R^{2}=0.176 ; F=6.934 * * * \operatorname{Adj} R^{2}=0.212 ; F=2.320 * * * \operatorname{Adj} R^{2}=0.063 ; F=2.872 *$
Note: ${ }^{* * *} p<0.001 ; * * p<0.01 ;{ }^{*} p<0.05 ;{ }^{+} p<0.1$

Table 55. Summary of interaction-mediation affects analyses, uncertain dynamic disaster management tasks, knowledge sharing for exploitation, and task efficiency 


\begin{tabular}{|c|c|c|c|c|c|c|c|c|c|c|}
\hline & \multirow{2}{*}{\multicolumn{2}{|c|}{$\begin{array}{l}\text { a } \\
\text { KS through Personal } \\
\text { Contacts } \\
\end{array}$}} & \multirow{2}{*}{\multicolumn{2}{|c|}{$\begin{array}{l}\text { b } \\
\text { Efficiency }\end{array}$}} & \multirow{2}{*}{\multicolumn{2}{|c|}{$\begin{array}{l}\text { c } \\
\text { Efficiency }\end{array}$}} & \multirow{2}{*}{\multicolumn{2}{|c|}{$\begin{array}{l}\text { c' } \\
\text { Efficiency }\end{array}$}} & \multirow{2}{*}{\multicolumn{2}{|c|}{\begin{tabular}{|l|}
$\mathrm{Z}$ \\
Sobel
\end{tabular}}} \\
\hline & & & & & & & & & & \\
\hline & $\begin{array}{l}\text { Standardize } \\
\mathrm{d} \beta \\
\text { coefficient }\end{array}$ & $\begin{array}{l}\text { t- } \\
\text { statistic }\end{array}$ & $\begin{array}{l}\text { Standardiz } \\
\text { ed } \beta \\
\text { coefficient }\end{array}$ & $\begin{array}{l}\mathrm{t}- \\
\text { statisti } \\
\mathrm{c}\end{array}$ & $\begin{array}{l}\text { Standardize } \\
\mathrm{d} \beta \\
\text { coefficient }\end{array}$ & $\begin{array}{l}\mathrm{t}- \\
\text { statisti } \\
\mathrm{c}\end{array}$ & $\begin{array}{l}\text { Standardize } \\
\mathrm{d} \beta \\
\text { coefficient }\end{array}$ & $\begin{array}{l}\text { t- } \\
\text { statisti } \\
\mathrm{c}\end{array}$ & $\begin{array}{l}\text { Test } \\
\text { Statist } \\
\text { ic } \\
\end{array}$ & $p$-value \\
\hline $\begin{array}{l}\text { Task } \\
\text { Newness }\end{array}$ & & & & & & & & & & \\
\hline $\begin{array}{l}\text { Task } \\
\text { Nonroutinen } \\
\text { ess } \\
\end{array}$ & & & & & & & & & & \\
\hline $\begin{array}{l}\text { Task } \\
\text { Difficulty }\end{array}$ & -0.195 & $-2.268^{*}$ & & & -0.146 & $\begin{array}{l}- \\
1.659+\end{array}$ & & & 1.615 & $\begin{array}{r}0.106+ \\
\mathrm{H} 44\end{array}$ \\
\hline $\begin{array}{l}\text { Amount of } \\
\text { Task } \\
\text { Information }\end{array}$ & 0.130 & $1.755+$ & & & 0.226 & $\begin{array}{l}2.973^{*} \\
*\end{array}$ & & & & \\
\hline $\begin{array}{l}\text { Task } \\
\text { Urgency }\end{array}$ & & & & & & & & & & \\
\hline Task Impact & 0.282 & $\begin{array}{l}3.632 * * \\
*\end{array}$ & & & & & & & & \\
\hline & & & & & & & & & & \\
\hline $\begin{array}{l}\mathrm{KS} \\
\text { Exploration }\end{array}$ & & & & & & & & & & \\
\hline $\begin{array}{l}\mathrm{KS} \\
\text { Exploitation }\end{array}$ & & & 1.660 & $2.481^{*}$ & & & & & & \\
\hline $\begin{array}{l}\text { KS Personal } \\
\text { Contact }\end{array}$ & & & -1.539 & $2.066 *$ & & & & & & \\
\hline $\begin{array}{l}\text { KS Written } \\
\text { Documents }\end{array}$ & & & & & & & & & & \\
\hline
\end{tabular}




Adj $R^{2}=0.109 ; F=4.408 * * * \operatorname{Adj} R^{2}=0.212 ; F=2.320 * * * \operatorname{Adj} R^{2}=0.063 ; F=2.872 * * *$
Note: $* * * p<0.001 ; * * p<0.01 ; * p<0.05 ;{ }^{*} p<0.1$

Table 56. Summary of interaction-mediation affects analyses, uncertain dynamic disaster management tasks, knowledge sharing through personal contacts, and task efficiency 
According to Table 53, the Sobel test statistic for task difficulty is significant $(2.375, p=0.017 *)$ which indicates that the association between task difficulty and task effectiveness is reduced significantly by the inclusion of knowledge sharing for exploitation as a mediator variable. As a result, there is enough evidence to conclude that knowledge sharing for exploitation completely mediates the task difficulty and task effectiveness relationship. Further, the Sobel test statistic for task urgency is significant $\left(2.229, p=0.025^{*}\right)$ which indicates that the association between task urgency and task effectiveness is reduced significantly by the inclusion of knowledge sharing for exploitation as a mediator variable. As a result, there is enough evidence to conclude that knowledge sharing for exploitation completely mediates the task urgency and task effectiveness relationship. Finally, the Sobel test statistic for task impact is significant $(2.501, p=0.012 *)$ which indicates that the association between task impact and task effectiveness is reduced significantly by the inclusion of knowledge sharing for exploitation as a mediator variable. As a result, there is enough evidence to conclude that knowledge sharing for exploitation completely mediates the task impact and task effectiveness relationship.

According to Table 54, the Sobel test statistic for task difficulty is significant $(1.865, p=0.062 *)$ which indicates that the association between task difficulty and task effectiveness is reduced significantly by the inclusion of knowledge sharing through personal contacts as a mediator variable. As a result, there is enough evidence to conclude that knowledge sharing through personal contacts completely mediates the task difficulty and task effectiveness relationship. 
Finally, the Sobel test statistic for task impact is significant $\left(2.340, p=0.019^{*}\right)$ which indicates that the association between task impact and task effectiveness is reduced significantly by the inclusion of knowledge sharing through personal contacts as a mediator variable. As a result, there is enough evidence to conclude that knowledge sharing through personal contacts completely mediates the task impact and task effectiveness relationship.

According to Table 55, the Sobel test statistic for task difficulty is significant $(1.966, p=0.049 *)$ which indicates that the association between task difficulty and task efficiency is reduced significantly by the inclusion of knowledge sharing for exploitation as a mediator variable. As a result, there is enough evidence to conclude that knowledge sharing for exploitation completely mediates the task difficulty and task efficiency relationship. Finally, the Sobel test statistic for amount of task information is significant $\left(1.940, p=0.052^{*}\right)$ which indicates that the association between amount of task information and task efficiency is reduced significantly by the inclusion of knowledge sharing for exploitation as a mediator variable. As a result, there is enough evidence to conclude that knowledge sharing for exploitation completely mediates the amount of task information and task efficiency relationship.

According to Table 56, the Sobel test statistic for task difficulty is significant $(1.615, p=0.106+)$ which indicates that the association between task difficulty and task efficiency is reduced significantly by the inclusion of knowledge sharing through personal contacts as a mediator variable. As a result, there is enough evidence to conclude that knowledge sharing through personal contacts completely mediates the task difficulty and task efficiency relationship. 
The table below summarizes the hypothesis and the finding of this study through interaction-mediation effects.

\begin{tabular}{|c|c|c|}
\hline H39 & $\begin{array}{l}\text { Knowledge sharing purposes and its dimension of } \\
\text { knowledge sharing for exploitation mediates the } \\
\text { relationship between uncertain dynamic disaster } \\
\text { management tasks (task difficulty) and task } \\
\text { effectiveness }\end{array}$ & $\begin{array}{l}\text { Marginally } \\
\text { Supported: } \\
*_{p}<0.05\end{array}$ \\
\hline H39 & $\begin{array}{l}\text { Knowledge sharing purposes and its dimension of } \\
\text { knowledge sharing for exploitation mediates the } \\
\text { relationship between uncertain dynamic disaster } \\
\text { management tasks (task urgency) and task } \\
\text { effectiveness }\end{array}$ & $\begin{array}{l}\text { Marginally } \\
\text { Supported: } \\
*_{p}<0.05\end{array}$ \\
\hline H39 & $\begin{array}{l}\text { Knowledge sharing purposes and its dimension of } \\
\text { knowledge sharing for exploitation mediates the } \\
\text { relationship between uncertain dynamic disaster } \\
\text { management tasks (task impact) and task effectiveness }\end{array}$ & $\begin{array}{l}\text { Marginally } \\
\text { Supported: } \\
*_{p}<0.05\end{array}$ \\
\hline H40 & $\begin{array}{l}\text { Knowledge sharing mechanisms and its dimension of } \\
\text { knowledge sharing through personal contacts mediates } \\
\text { the relationship between uncertain dynamic disaster } \\
\text { management tasks (task difficulty) and task } \\
\text { effectiveness }\end{array}$ & $\begin{array}{l}\text { Marginally } \\
\text { Supported: } \\
*_{p}<0.05\end{array}$ \\
\hline H40 & $\begin{array}{l}\text { Knowledge sharing mechanisms and its dimension } \\
\text { knowledge sharing through personal contacts mediates } \\
\text { the relationship between uncertain dynamic disaster } \\
\text { management tasks (task impact) and task effectiveness }\end{array}$ & $\begin{array}{l}\text { Marginally } \\
\text { Supported: } \\
*_{p}<0.05\end{array}$ \\
\hline $\mathbf{H 4 3}$ & $\begin{array}{l}\text { Knowledge sharing purposes and its dimension of } \\
\text { knowledge sharing for exploitation mediates the } \\
\text { relationship between uncertain dynamic disaster } \\
\text { management tasks (task difficulty) and task efficiency }\end{array}$ & $\begin{array}{l}\text { Marginally } \\
\text { Supported: } \\
*_{p}<0.05\end{array}$ \\
\hline H43 & $\begin{array}{l}\text { Knowledge sharing purposes and its dimension of } \\
\text { knowledge sharing for exploitation mediates the } \\
\text { relationship between uncertain dynamic disaster } \\
\text { management tasks (amount of task information) and } \\
\text { task efficiency }\end{array}$ & $\begin{array}{l}\text { Marginally } \\
\text { Supported: } \\
*_{p}<0.05\end{array}$ \\
\hline H44 & $\begin{array}{l}\text { Knowledge sharing mechanisms and its dimension of } \\
\text { knowledge sharing through personal contacts mediates } \\
\text { the relationship between uncertain dynamic disaster } \\
\text { management tasks (task difficulty) and task efficiency }\end{array}$ & $\begin{array}{l}\text { Marginally Not } \\
\text { Supported: } \\
{ }_{p}^{+}<0.1\end{array}$ \\
\hline
\end{tabular}

Table 57. Summary of interaction-mediation effects and findings 


\begin{tabular}{|c|c|c|c|c|c|c|c|c|c|c|c|c|c|c|c|c|c|c|c|c|}
\hline & \multicolumn{20}{|c|}{ Correlations } \\
\hline & & Mean & $\begin{array}{r}\text { Std. } \\
\text { Deviation }\end{array}$ & 1 & 2 & 3 & 4 & 5 & 6 & 7 & 8 & 9 & 10 & 11 & 12 & 13 & 14 & 15 & 16 & 17 \\
\hline 1 & TNvNewMean & 4.079 & 1.539 & 1 & & & & & & & & & & & & & & & & \\
\hline 2 & TNvNoRMean & 4.573 & 1.662 & $0.321^{* *}$ & 1 & & & & & & & & & & & & & & & \\
\hline 3 & TUnDifMean & 3.338 & 1.262 & $0.502^{* *}$ & $0.291^{* *}$ & 1 & & & & & & & & & & & & & & \\
\hline 4 & TUnIEAMean & 4.177 & 1.494 & -0.020 & -0.123 & -0.010 & 1 & & & & & & & & & & & & & \\
\hline 5 & TSgUrgMean & 5.514 & 1.181 & 0.105 & 0.143 & $0.154^{*}$ & -0.062 & 1 & & & & & & & & & & & & \\
\hline 6 & TSgImpMean & 5.081 & 1.305 & $0.185^{*}$ & $0.179^{*}$ & 0.144 & 0.073 & $0.258^{* *}$ & 1 & & & & & & & & & & & \\
\hline 7 & KSPExorMean & 4.354 & 1.365 & $0.642^{* *}$ & $0.231^{* *}$ & $0.429^{* *}$ & 0.086 & 0.117 & $0.346^{* *}$ & 1 & & & & & & & & & & \\
\hline 8 & KSPExitMean & 5.646 & 1.006 & -0.121 & -0.006 & $-0.206^{* *}$ & $0.207^{* *}$ & $0.207^{* *}$ & $0.265^{* *}$ & 0.041 & 1 & & & & & & & & & \\
\hline 9 & KSMPCMean & 5.876 & 0.863 & -0.056 & -0.041 & $-0.154^{*}$ & 0.151 & 0.121 & $0.280^{* *}$ & 0.116 & $0.505^{* *}$ & 1 & & & & & & & & \\
\hline 10 & KSMWDMean & 4.745 & 1.349 & -0.088 & -0.099 & $-0.269^{* *}$ & $0.254^{* *}$ & -0.030 & $0.291^{* *}$ & -0.008 & $0.519^{* *}$ & $0.391^{* *}$ & 1 & & & & & & & \\
\hline 11 & TEfcyMean & 5.194 & 1.235 & $-0.166^{*}$ & -0.044 & $-0.179^{*}$ & $0.224^{* *}$ & 0.019 & 0.039 & -0.091 & $0.351^{* *}$ & $0.210^{* *}$ & $0.244^{* *}$ & 1 & & & & & & \\
\hline 12 & TEfss Mean & 6.010 & 0.910 & -0.086 & 0.072 & -0.126 & 0.053 & $0.303^{* *}$ & $0.230^{* *}$ & -0.005 & $0.251^{* *}$ & $0.159^{*}$ & 0.030 & $0.366^{* *}$ & 1 & & & & & \\
\hline 13 & Experience & 9.416 & 8.080 & -0.003 & 0.052 & 0.103 & -0.036 & -0.002 & 0.094 & -0.061 & 0.074 & 0.054 & 0.026 & -0.016 & -0.127 & 1 & & & & \\
\hline 14 & Expertise & 4.881 & 1.585 & -0.100 & 0.092 & -0.064 & 0.006 & -0.073 & 0.041 & -0.022 & $0.249^{* *}$ & 0.136 & $0.186^{*}$ & 0.056 & -0.048 & $0.537^{* *}$ & 1 & & & \\
\hline 15 & WorkedYs & 13.497 & 9.087 & -0.126 & -0.041 & \begin{tabular}{l|l}
0.088 \\
\end{tabular} & -0.031 & 0.083 & 0.078 & -0.048 & \begin{tabular}{l|l|}
0.099 \\
\end{tabular} & 0.000 & -0.142 & 0.075 & 0.065 & $0.274^{* *}$ & 0.132 & 1 & & \\
\hline 16 & WorkEOCY & 5.738 & 5.306 & 0.094 & $0.191^{*}$ & 0.020 & -0.092 & 0.090 & 0.036 & -0.015 & 0.123 & 0.004 & -0.017 & -0.005 & 0.076 & $0.184^{*}$ & $0.249^{* * *}$ & $0.275^{* * *}$ & 1 & \\
\hline 17 & WorkEMYs & 10.090 & 8.774 & 0.108 & $0.187^{*}$ & \begin{tabular}{|l|l|}
$0.185^{*}$ \\
\end{tabular} & $-0.161^{*}$ & 0.010 & $0.201^{* *}$ & 0.099 & \begin{tabular}{|l|l|}
-0.038 \\
\end{tabular} & -0.028 & $-0.176^{*}$ & \begin{tabular}{|l|}
-0.088 \\
\end{tabular} & 0.065 & $0.251^{* *}$ & $0.195^{*}$ & $0.188^{*}$ & $0.396^{* *}$ & 1 \\
\hline \multicolumn{21}{|c|}{ **. Correlation is significant at the 0.01 level (2-tailed). } \\
\hline & *. Correlation i & icant & he 0.05 & evel (2- & ed). & & & & & & & & & & & & & & & \\
\hline
\end{tabular}

Table 58. Means, standard deviations, and correlations 


\section{Conclusions}

\subsection{Research Implications}

This study aimed to understand the characteristics of the task involved in disaster management response and their effect on task performance. This study also investigated the moderating and mediating roles of knowledge sharing, including purposes and mechanisms, to improve decision-making and task performance. The following discussions are based on field observations, at the Miami-Dade Office of Emergency Management and Emergency Operation Center (OEM-EOC), interviews and discussions with emergency personnel over a multi-year period, and empirical results from a questionnaire survey conducted during September and October of 2008. Field observations were conducted at the Miami-Dade OEM-EOC during Tropical Storm Ernesto in August 2006 and training simulations in annual meetings every May since 2007. Furthermore, this study also incorporated insights from a series of disaster management simulations and practice drills that provided useful points for analysis and discussion with EOC personnel. In addition, the discussion in the following sections is based on the EOC archives of Standard Operations Procedures, Local Response Protocols, Situation Reports, Incident Action Plans Reports, ICT Collaborative Software Systems, and e-mail Logs from Hurricanes Katrina, Rita, and Wilma. 


\subsubsection{Relationships between Task Characteristics, Knowledge Sharing And Task Performance, and the Implications of the Moderating and Mediating Effects of Knowledge Sharing}

The results described in Chapter 5 provide useful insights about the relationships between disaster management task characteristics, knowledge sharing, and task performance specifically how knowledge sharing plays a significant role in mediating and/or moderating previous relationships. As described in the previous sections, this research conceptualized task characteristics associated with the decision maker in contrast with those intrinsic to the task. Furthermore, this research categorized uncertain and dynamic disaster management tasks into three constructs and their respective dimensions: task novelty (task newness and task nonroutineness), task unanalyzability (task difficulty and amount of task information), and task significance (task urgency and impact). Knowledge sharing was categorized according to purpose (knowledge sharing for exploration and for exploitation) and mechanisms (knowledge sharing through personal contacts and through written documents).

Finally, task performance was defined in terms of task effectiveness and task efficiency. The relationships between uncertain dynamic disaster management tasks and task performance were tested through direct effects and the moderating and mediating effects of knowledge sharing. Overall, the results, which are discussed below, supported the main conceptualizations and hypotheses proposed in this study. 
According to the results presented in Chapter 5, the relationships between the characteristics of uncertain dynamic disaster management tasks and the dimensions of task performance were significant, and were moderated and mediated by knowledge sharing purposes and mechanisms. The following paragraphs discuss the most significant outcomes for each dimension of uncertain dynamic disaster management tasks; their direct effects on task performance and effectiveness; and the moderating and mediating effects of knowledge sharing.

\subsubsection{Task Newness}

Considering the characteristics of task newness, some of the most significant and interesting findings are as follows:

1. The use of knowledge sharing for exploration activities alone in performing a new task had a negative impact on task effectiveness. However, when EOC participants (EOC personnel, infrastructure groups, and related organizations) used personal contacts and written documents to support knowledge sharing for exploration activities to discover new knowledge and alternatives, the negative impact of new tasks on task effectiveness was reduced. These results confirmed that the use of knowledge sharing for exploration activities reduced the negative impact of new tasks on task effectiveness. 
Indeed, knowledge sharing for exploration activities such as search, variation, and discovery are key to be leveraged through personal interactions at the EOC and written documents (EOC's archives of Standard Operations Procedures, Local Response Protocols, Situation Reports, Incident Action Plans Reports, ICT Collaborative Software Systems, and e-mail logs). In terms of managerial implications, these findings suggest for EOC participants that higher task effectiveness performance can be achieved by implementing knowledge sharing for exploration strategies that seamlessly integrate knowledge sharing through both personal contacts and written documents activities when facing new tasks.

2. The use of knowledge sharing for exploration activities coupled with knowledge sharing for exploitation activities strengthened positively the task effectiveness outcomes when facing new tasks. This result suggest that EOC participants could achieve higher levels of task effectiveness when facing new tasks if knowledge sharing for exploitation strategies are implemented to direct search and immediately utilize the search, variation, and discovery of new knowledge and alternatives when facing new tasks.

A practical example of new tasks can be found in Table 59 which describes the Situation Report No. 3 during the EOC activation for Hurricane Katrina. 


\section{Situation Report No. 3.}

1. Incident Name: Hurricane Katrina 2.. Date Prepared: $\underline{8 / 26 / 05}$

3. Time Prepared: 1300

4. Operational Period: \#3 0700 thru 1900 8/26/05

\section{Current N/A}

\section{Current Situation}

7. Bridge collapse at 97 Ave overpass of SR836. SR836 is closed from 87 Ave to 107 Ave until 2100

\section{Critical Issues}

2. $12^{\text {th }}$ Avenue Bridge and Flagler Street bridge have sustained damage that may delay their ability to open to marine traffic

Resource Requests N/A

Planned Activities N/A

Table 59. Hurricane Katrina: Situation Report No. 3

Hurricane Katrina: Situation Report No. 3 illustrates the unexpected and exceptional circumstances of a new tasks never faced before by the EOC participants: "Bridge collapse at 97 Ave overpass of SR836" and the " $12^{\text {th }}$ Avenue Bridge and Flagler Street bridge have sustained damage that may delay their ability to open to marine traffic". The results previously discussed suggest that the EOC participants could use a mix of different knowledge sharing strategies (knowledge sharing for exploration combined with knowledge sharing mechanisms) to address these new tasks. 
On one hand, EOC participants could engage in knowledge sharing for exploration activities to discover solutions to new problems through personal contacts (experience and expertise) and written documents (EOC's archives of Standard Operations Procedures, Local Response Protocols, Situation Reports, Incident Action Plans Reports, ICT Collaborative Software Systems, and e-mail logs). On the other hand, a combination of searching for prior solutions to similar problems (knowledge sharing for exploitation) in addition to new ideas about how to solve the problems at hand (knowledge sharing for exploration) for new tasks could have an even greater positive impact on task effectiveness. As a result of the implementation of this mix of knowledge sharing strategies and activities, EOC participants can minimize the repercussions of these new tasks and can improve task performance.

\subsubsection{Task Difficulty}

Considering the characteristics of task difficulty, some of the most significant and interesting findings are as follows:

1. When EOC participants face difficult tasks represented by unstructured, equivocal, and conflicting interpretation characteristics, using knowledge sharing through written documents, such as EOC's archives of Standard Operations Procedures, Local Response Protocols, Situation Reports, Incident Action Plans Reports, ICT Collaborative Software Systems, and e-mail logs, had a negative impact on task effectiveness. 
This finding suggests that when EOC participants face difficult tasks using knowledge sharing through written documents becomes a distraction because EOC participants face challenging conditions while trying to find a solution for the task at hand. As a result, EOC participants are not quite sure what to look for or how to approach the knowledge sharing mechanisms (personal contacts and written documents) activities to define the difficult task and therefore decide the appropriate course of action.

2. However, similar to task newness the combination of knowledge sharing for exploration strategies carried out via knowledge sharing through both personal contacts and written documents further reduced the negative impact of task difficulty on task effectiveness. These findings suggest that EOC participants must keep insisting in using knowledge sharing for exploration activities (search, variation, and discovery) to define and see new ways to approach and resolve the difficult task at hand in order to determine the most appropriate way to perform successfully the difficult task.

A practical example of difficult tasks is found in Table 60 which describes the Incident Action Plan No. 2 during the EOC activation for Hurricane Wilma. 


\section{Incident Action Plan No. 2.}

1. Incident Name: $\underline{\text { Hurricane Wilma }}$ 2.. Date Prepared: $\underline{10 / 22 / 05}$

3. Time Prepared: $\underline{1100}$

4. Section/Functional Group/Agency Completing Report: Miami-Dade EOC Planning Section

5. Operational Period: \#2 1100 10/22/05 thru 0700 10/23/05

\section{Summary of Current Situation, Operations, and Objectives}

4. Four hundred twenty five (429) People with Special Needs (PSN) have requested evacuation: 300 Medical Management Facility (MMF) patients and 129 PSN.

\section{Problems Encountered or Potential Obstacles}

1. Large volume of last minute requests for evacuation assistance may pose evacuation resource shortage.

\section{Assistance Required}

1. None

\section{Projected Incident Objectives}

3. Movement of two hundred ninety six (296) Medical Management Facilities patients will begin today.

4. Continue calldown of people with special needs.

5. Begin movement of non-ventilator MMF today.

6. Continue preparing for movement of ventilator MMF on Sunday.

Table 60. Hurricane Wilma: Incident Action Plan No. 2 
Hurricane Wilma: Incident Action Plan No. 2 illustrates the difficulty of task when several disaster management tasks happen at the same time where it is hard for EOC participants to see into the tasks at hand to prioritize and assign resources because all these tasks have high priorities. Furthermore, when this kind of difficult tasks aggregate with limited timeframes to be performed, EOC participants must act quickly to understand the tasks at hand in order to efficiently execute them.

In this example, EOC participants had to convene in order to discuss (knowledge sharing for exploitation) what resources were available and work together to prioritize the steps (knowledge sharing for exploration) required to solve the difficult task at hand.

\subsubsection{Information Required to Perform the Task at Hand}

Considering the information required to perform the task at hand, the most significant finding was that knowledge sharing for exploration positively enhances the impact of information required to perform the task at hand on task effectiveness. This means that EOC participants have to gather as much data, information, and knowledge as possible through knowledge sharing for exploration strategies (search, variation, and discovery) to make a better sound decision about the task at hand.

An appropriate practical example which illustrates the amount of task information needed to perform the task at hand is portrayed in Table 61 which describes the Incident Action Plan No. 3 during the EOC activation for Hurricane Katrina. 


\section{Incident Action Plan No. 3.}

1. Incident Name: Hurricane Katrina 2.. Date Prepared: $\underline{8 / 26 / 05}$

3. Time Prepared: $\underline{0600}$

4. Section/Functional Group/Agency Completing Report: Miami-Dade EOC Planning Section

5. Operational Period: \#3 0700 8/26/05 thru 1900 8/26/05

\section{Summary of Current Situation, Operations, and Objectives}

4. Widespread power outages, debris, and flooding exist throughout the county.

\section{Problems Encountered or Potential Obstacles}

1. Anticipated hazards include: flooded roads; downed live power lines; debris throughways; sharp or jagged objects; missing or damaged traffic signal devices; venomous or dangerous animals.

2. Increase demand for shelters.

3. Power outages at critical facilities (hospitals, public safety facilities, etc.).

4. Increase demand for already stressed services.

5. County telephone infrastructure may not be able to keep up with demand.

\section{Assistance Required}

\section{$\mathrm{N} / \mathrm{A}$}

\section{Projected Incident Objectives}

1. Identify immediate life safety issues in the general community and electrically dependent residents.

2. Implement snapshot assessment and conduct damage and needs assessments.

3. Initiate coordinated debris clearance plan.

5. Provide public information about safety precautions and return of government services.

6. Assess need for additional shelters or other human services.

Table 61. Hurricane Katrina: Incident Action Plan No. 3 
According to the incident action plan mentioned above, there are many pieces of data and information that need to be put together before deciding a course of action. It is evident that knowledge sharing for exploration activities plays a critical role for EOC personnel, infrastructure groups and related organizations to make sound decisions on tasks that need to be accomplished in the immediate short term. Furthermore, knowledge sharing for exploration activities are the trigger point to disaster management response tasks and subsequently disaster management recovery tasks.

\subsubsection{Task Significance: Task Urgency}

From the results of our data analysis, the impact of urgent tasks is as follows:

1. The use of knowledge sharing for exploration activities in performing an urgent task had a negative impact on task effectiveness. This means when EOC participants face urgent tasks, spending time exploring for potential solutions is not the best option to readily perform the task at hand.

2. Similarly to new and difficult tasks, for urgent tasks it was observed that the combination of knowledge sharing for exploration strategies (finding new knowledge through search, experimentation, and discovery) and knowledge sharing for exploitation activities (refinement, selection, and implementation) had a much less negative impact on task effectiveness when urgent tasks were performed. 
3. Both knowledge sharing mechanisms (knowledge sharing through personal contacts and through written documents) and knowledge sharing purposes (knowledge sharing for exploration and for exploitation) in performing urgent tasks were important in reducing the negative impact of urgent tasks on task effectiveness.

4. The use of knowledge sharing mechanisms through personal contacts had the most positive and significant impact on task effectiveness when urgent tasks were performed. These results suggest that when EOC participants face urgent tasks their focus must be on directly addressing the urgent tasks at hand using primarily knowledge sharing through personal contacts in addition to knowledge sharing through written documents.

An appropriate practical example of urgent tasks can be found in Table 62 which describes the Situation Report No. 2 during the EOC activation for Hurricane Katrina. 


\section{Situation Report No. 2.}

1. Incident Name: Hurricane Storm Katrina 2.. Date Prepared: $\underline{8 / 26 / 05}$

3. Time Prepared: $0 \underline{130}$

4. Operational Period: \#2 1800 thru 0100 8/26/05

\section{Current}

1. Weather forecast: eye wall passed over Miami-Dade from northeast to southwest. Winds at eyewall were near $80 \mathrm{mph}$. Tropical storm force winds expected to continue until late morning (9-11 am).

\section{Current Situation}

3. Power out to 525,137 in Miami-Dade

4. HEC 200 people, MMF 47

5. Homestead hospital and police department on generator power. Homestead hospital without city water supply.

6. Doctors and Westchester hospitals on generator power.

7. Doctors hospital reports 1 st floor flooding.

8. Jackson South hospital without power.

9. West Gables Health Center out of power.

10. Calls from non-registered MMF to 911 are up to 140.

11. MDFR responded to multi unit fire but only 1 unit affected. No injuries.

12. Bridge collapse: SR836 closed from 87 Ave to 107 Ave.

13. Total calls to Answer Center 10,351. This hour: power lines (108), trees blocking roads (78), flooding (12).

14. MDFR has begun snapshot assessment.

\section{Critical Issues}

1. High anticipated demand for Advance Life Support (ALS) expected to lead to stressed system.

2. EOC support systems having trouble: power, AC.

\section{Resource Requests}

1. Request for one (1) Advance Life Support (ALS) Rescue Strike Team will be placed in Tracker

Planned Activities N/A

Table 62. Hurricane Storm Katrina: Situation Report No. 2 
Hurricane Storm Katrina, Situation Report No. 2 illustrates the urgency of tasks being faced by EOC participants such as:

- Hospitals with no power

- Anticipated demand for Advance Life Support (ALS)

- Request for one (1) Advance Life Support (ALS) Rescue Strike Team will be placed in Tracker.

Most of these urgent tasks involve human lives so EOC participants must act

immediately with no time to spare. As showing by previous, the knowledge sharing mechanisms strategies and activities primarily through personal contacts in addition to written documents enable EOC participants to efficiently perform the urgent tasks at hand on the spot and with no distractions.

\subsubsection{Task Significance: Task Impact}

The effects of tasks with a large potential impact on task effectiveness were similar to the ones described for urgent tasks.

1. The use of knowledge sharing for exploration activities in performing tasks with a large potential impact had a negative effect on task effectiveness. 
2. Similar to urgent tasks, for tasks with a large potential impact, it was observed that the combination of knowledge sharing for exploration strategies (finding new knowledge through search, experimentation, and discovery) and knowledge sharing for exploitation activities (refinement, selection, and implementation) had a much less negative impact on task effectiveness when tasks with a large potential impact were performed.

3. Both knowledge sharing mechanisms (knowledge sharing through personal contacts and through written documents) and knowledge sharing purposes (knowledge sharing for exploration and for exploitation) were important in reducing the negative impact of tasks with a large potential impact on task effectiveness.

4. The use of knowledge sharing mechanisms through personal contacts had the most positive and significant impact on task effectiveness when tasks with a large potential impact were performed. These results suggest that when EOC participants face tasks with a large potential impact their focus must be on directly addressing the task at hand using primarily knowledge sharing through personal contacts in addition to knowledge sharing through written documents. 
In fact, given the involvement of potential economic loses and infrastructure repercussions, EOC participants must act right on the spot using knowledge sharing through personal contacts or knowledge sharing through written documents strategies and activities to minimize the potential risks associated with this kind of tasks. These results suggest that EOC participants could improve the effectiveness of tasks with a large potential impact by promoting knowledge sharing for exploitation and knowledge sharing through personal contacts strategies and activities.

An appropriate practical example of tasks with potential impact can be found in Table 63 which describes the Incident Action Plan 2 during the EOC activation for Hurricane Katrina. 


\section{Incident Action Plan No. 2.}

1. Incident Name: Hurricane Katrina 2.. Date Prepared: $\underline{8 / 25 / 05}$

3. Time Prepared: $\underline{1700}$

4. Section/Functional Group/Agency Completing Report: Miami-Dade EOC Planning Section

5. Operational Period: \#2 1700 8/25/05 thru 0700 8/26/05

\section{Summary of Current Situation, Operations, and Objectives}

3. Tropical Storm Force Winds are currently affecting Miami-Dade County and are expected to do so until 1700 hours Saturday evening. Additionally, there is a storm surge potential of 2-4', with the high tide occurring between 0100-0200 this evening.

6. Seaport remains closed to marine and shipping operations.

7. All drawbridges remain locked down.

\section{Problems Encountered or Potential Obstacles N/A}

\section{Assistance Required N/A}

\section{Projected Incident Objectives}

2. Continue to monitor storm, collect and analyze data and disseminate as appropriate

4. Maintain situation and resource status information.

Table 63. Hurricane Katrina: Incident Action Plan No. 2

Hurricane Katrina, Incident Action Plan No. 2 illustrates the magnitude of the disaster event in terms of force winds, storm surge potential in addition to the high tide occurring in the middle of the event. As showing by the previous results, the knowledge sharing mechanisms strategies and activities primarily through personal contacts in addition to written documents enable EOC participants to better perform the tasks with potential impact on the spot and with no distractions. 


\subsection{Research Significance and Contributions}

Research on the intersection of knowledge management and disaster management is scarce. This study proposes a theoretical framework at the intersection of these domains, which is a new field of research. Furthermore, this study expands prior research by examining the knowledge sharing purposes and mechanisms that are associated with disaster management.

This study contributes to the fields of disaster and knowledge management in two additional ways. First, this research responds to the critical issues and gaps mentioned in the first chapter of this research work. Second, the empirical analysis and methodology used in this research will shed light on the role of knowledge sharing purposes and mechanisms in disaster management response tasks. This study also provides recommendations to disaster management agencies around the world on the development of a knowledge sharing environment that will enable them to better respond to disaster events.

This study's findings have significant implications for future research. Although it has been widely recognized that disaster management tasks are difficult to perform because these tasks are inherently uncertain, no prior research has examined the dimensions that characterize the uncertain and dynamic aspects of disaster management tasks. 
Most of the previous research has conceptualized dynamic task uncertainty as a single construct, whereas this study defined it as a multi-dimension construct. Six dimensions, task newness, task nonroutineness, task difficulty, amount of task information, task urgency, and task impact, and their corresponding measures, were developed and empirically validated to provide a solid ground for theory development and testing.

The results of testing the complex relationships between the six dimensions of task uncertainty, four dimensions of knowledge sharing, and two dimensions of task performance suggest that a rich set of theories can be developed to explain the conditions under which knowledge sharing mechanisms (exploration and exploitation) are required and those under which knowledge sharing purposes (personal contacts and written documents) are best utilized to improve task performance.

Finally, this study addressed the knowledge gaps in the research on disaster and knowledge management by providing a model that focuses on uncertain and dynamic disaster management tasks, knowledge sharing, and task performance. This study's theoretical concepts provide new insights into the critical issues of task performance in disaster management response activities.

\subsection{Practical Implications}

This study has significant implications for practice. EOC personnel and disaster management teams usually cannot precisely identify the dimensions of uncertain dynamic disaster management tasks during a disaster event or threat. 
This study provides an initial framework for conceptualizing uncertain dynamic disaster management tasks and for understanding knowledge sharing approaches to improve task performance. In addition, EOC personnel and disaster management managers and planners can better understand the novelty, unanalyzability, and significance of uncertain dynamic disaster management tasks to improve their disaster management operating procedures during the planning stages. Similarly, these disaster management tasks, knowledge sharing, and task performance constructs and dimensions can be used as parts of a reference framework after a disaster event or threat, when response teams review post-mortem reports and lessons learned.

Additionally, EOC personal and disaster management managers may approach the relationships between uncertain dynamic disaster management tasks, knowledge sharing, and task performance dimensions as guidelines to better perform the tasks at hand. Thus, they can determine whether they should prioritize knowledge sharing purposes and/or knowledge sharing mechanisms in uncertain dynamic disaster management tasks to efficiently and effectively accomplish the performance of these tasks.

Furthermore, the findings of this research work will help disaster management agencies and personnel to improve their performance during a disaster management response event or threat and, ultimately, to save lives and minimize economic repercussions. Appendix B includes the executive report presented at the EOC Directors, Managers, and Functional Groups Coordinators. 


\subsection{Research Limitations and Future Research}

As previously mentioned, this study explored disaster response tasks as the unit of analysis in order to research how to improve decision-making during a disaster event. This research focused on disaster management activities during the initial response to a disaster event; it also investigated how knowledge sharing moderated and mediated the uncertain and dynamic characteristics of a task in order to identify how disaster response teams might accomplish their task objectives more effectively. Thus, this study aimed to understand dynamic disaster management response activities and knowledge sharing practices related to the efficient performance of tasks characterized by uncertainty.

Some limitations of this research are related to the task characteristics it addressed. The existing literature has identified other task characteristics, such as intrinsic complexity, variety, and interdependence [Dean and Snell, 1991]. Thus, this study purposely did not focus on these intrinsic (static) task characteristics. Additionally, the survey respondents in this study were involved in disaster management response activities at the Miami-Dade County Office of Emergency Management. Further studies should therefore conduct research at other offices of emergency management at the city, county, state, and federal government levels. Finally, the uncertain disaster management tasks and knowledge sharing measures studied in this paper were exploratory in nature; as such, further research are needed to validate and improve these measures. 


\section{BIBLIOGRAPHY}

Adler, P. and Seok-Woo Kwon (2002) "Social Capital: Prospects for a new concept", Academy of Management Review, (27)1, pp. 17-40.

Alavi, M. and D. E. Leidner (2001). "Review: Knowledge management and knowledge management systems: Conceptual foundations and research issues." Mis Quarterly 25(1): 107-136.

Alavi, M. and D.E. Leinder (2001) "Knowledge Management and Knowledge Management Systems: Conceptual Foundations and Research Issues", MIS Quarterly (25)1, pp. 107-136.

Andres, H.P. and Zmud, R.W. "A Contingency Approach to Software Project Coordination," Journal of Management Information Systems (18:3), Winter 2002, pp. 41-70.

Argote, L. and Paul Ingram (2000) "Knowledge Transfer: A basis for competitive advantage in firms" Organizational Behavior and Human Decision Processes (82)1, pp. 150-169.

Argote, L., Paul Ingram, John M. Levine and Richard L. Moreland (2000) "Knowledge Transfer in Organizations: Learning from the Experience of Others", Organizational Behavior and Human Decision Processes (82)1, pp. 1-8.

Bagozzi, R.P. and L.W. Phillips (1982) "Representing and Testing Organizational Theories: A Holistic Construal", Administrative Science Quarterly, (27), pp. 459-489.

Baron, S, Field J., and Schuller, T (2000) Social Capital - Critical Perspectives, Oxford University Press, Oxford.

Bassett-Jones, N. and Geoffrey C. Lloyd (2005) "Does Herzberg's motivation theory have staying power?", The Journal of Management Development (24)10, pp. 929943.

Becerra-Fernandez, I. and Prietula, M. Project Ensayo: Integrating simulation, training, discovery, and support", Presentation and Proceedings of the North American Association for Computational Social and Organizational Science (NAACSOS 2006), June 22-23 2006, Notre Dame, Indiana.

Becerra-Fernandez, I. and R. Sabherwal (2001). "Organizational knowledge management: A contingency perspective." Journal of Management Information Systems 18(1): 23-55. 
Becerra-Fernandez, I. Prietula, M., Madey, G., Rodriguez, D. (2007), "Project Ensayo: a Virtual Emergency Operations Center for Disaster Management Research, Training, and Discovery." Proceedings of the First International Conference on Global Defense and Business Continuity, San Jose, CA.

Becerra-Fernandez, I. Prietula, M., Madey, G., Rodriguez, D., Valerdi, R., Wright, T. Design and Development of a Virtual Emergency Operations Center for Disaster Management Research, Training, and Discovery. Proceedings of the 41st HICSS, January 2008, Hawaii.

Becerra-Fernandez, I., \& Prietula, M. (2006). Project Ensayo: Integrating simulation, training, discovery, and support. Paper presented at the Proceedings of the North American Association for Computational Social and Organizational Science (NAACSOS 2006), Notre Dame, Indiana.

Becerra-Fernandez, I., Avelino González, and Rajiv Sabherwal (2004) Knowledge Management, $1^{\text {st }}$ Edition, Upper Saddle River, New Jersey: Pearson Education, Inc.

Becerra-Fernandez, I. Prietula, M., Madey, G. , Rodriguez, D., Gudi, A., and Rocha, J. Project Ensayo: A Virtual Emergency Operations Center. Research paper published at the Conference Proceedings of the IAMOT 2007-16th International Conference on Management of Technology "Management of Technology for the Service Economy", Miami Beach, Florida, USA, May 13-17, 2007.

Becerra-Fernandez, I., Prietula, M., Madey, G., Rodriguez, D., Valerdi, R., \& Wright, T. (2008). Design and development of a Virtual Emergency Operations Center for disaster management research, training, and discovery. Paper presented at the Presentation and proceedings of 41st Hawaii International Conference on System Science (HICSS 2008), Big Island, Hawaii.

Becerra-Fernandez, I., T. Wang, et al. (2005). "Actor Model and Knowledge Management Systems: Social Interaction as a Framework for Knowledge Integration." Lecture Notes in Computer Science(3782): 19-31.

Becerra-Fernandez, I., Xia, W., Gudi, A., and Rocha, J. (2008), Task Characteristics, Knowledge Sharing and Integration, and Emergency Management Performance: Research Agenda and Challenges. Research paper published at the Conference Proceedings of the 5th International Conference on Information Systems for Crisis Response and Management: Creating Advanced Systems for Inter-organizational Information Sharing and Collaboration, Washington, DC, May 4-7, 2008.

Becerra-Fernandez, Irma and Rajiv Sabherwal (2001) "Organization Knowledge Management: A Contingency Perspective", Journal of Management Information Systems (18)1, pp. 23-55. 
Becerra-Fernandez, Irma and Rajiv Sabherwal (2003) "An Empirical Study of the Effect of Knowledge Management Processes at Individual, Group, and Organizational Levels." Decision Sciences (34)2, pp. 225-260.

Beckman, T.J. "The current state of Knowledge Management” in Liebowitz, J. (ed.) (1999) Knowledge Management, Handbook, $1^{\text {st }}$ Edition, Boca Raton, FL.: CRC Press LLC.

Bennet, David H. "Learning and the Knowledge Worker" in Koenig, Michael E.D. and T. Kanti (ed.) (2004) Knowledge management lessons learned: what works and what doesn't, 1st Edition, Medford, N.J.: American Society for Information Science and Technology by Information Today.

Blili, S., L. Raymond, et al. (1998). "Impact of task uncertainty, end-user involvement, and competence on the success of end-user computing." Information \& Management 33(3): 137-153.

Boh, W.F. (2007) "Mechanisms for sharing knowledge in project-based organizations", Information and Organization, (17)1, pp. 27-58.

Bosua, R. and Scheepers, R. (2007) Towards a model to explain knowledge sharing in complex organizational environments, Knowledge Management Research and Practice, 5(2):93-109.

Brewer, M. B., \& Gardner, W. (1996). Who is this "we"? Levels of collective identity and self representations. Journal of Personality and Social Psychology, 71, 83-93.

Burt, R. S. 1992. Structural holes: The social structure of competition. Cambridge, Mass.:Harvard University Press.

Campbell, D. J. (1988). Task Complexity: A Review and Analysis. Academy of Management. The Academy of Management Review, 13(1), 40.

Chang, R. D., Y. W. Chang, et al. (2003). "The effect of task uncertainty, decentralization and AIS characteristics on the performance of AIS: an empirical case in Taiwan." Information \& Management 40(7): 691-703.

Choi SO, Brower RS. When practice matters more than government plans: a network analysis of local emergency management. Admin Soc 2006;37(6):651-78.

Choo, C.C. (1998) The knowing organization: how organizations use information to construct meaning, create knowledge and make decisions, Oxford University Press, New York.

Clarke, T. (2001) “The Knowledge Economy”, Education \& Training, (43)4/5, pp. 189197. 
Cohen, D. and L. Prusak (2001) "In Good Company: How social capital makes organizations work”, Boston: Harvard Business School Press.

Coleman, J. (1990) Foundations of Social Theory, Belknap Harvard, Cambridge, MA.

Comfort, L. K., Dunn, M., Johnson, D., Skertich, R., \& Zagorecki, A. (2004). Coordination in complex systems: Increasing efficiency in disaster mitigation and response. International Journal of Emergency Management, 2(1-2), 62-80.

Comfort, L. K., Ko, K., \& Zagorecki, A. (2004). Coordination in Rapidly Evolving Disaster Response Systems: The Role of Information. The American Behavioral Scientist, 48(3), 295.

Comfort, Louise K., Mark Dunn, David Johnson, Robert Skertich, and Adam Zagorecki (2004) "Coordination in complex systems: increasing efficiency in disaster mitigation and response", International Journal of Emergency Management, (2)12, pp. $62-80$.

Creswell, J. W. (2003). Research design: Qualitative, quantitative and mixed methods approaches. Thousand Oaks, California: Sage publications, Inc.

Daft, R.L. and Robert H. Lengel (1986) "Organizational Information Requirements, Media Richness and Structural Design”, Management Science, (32)5, pp. 554571.

Daft, R.L., and Macintosh, N.B. (1981). A Tentative Exploration into the Amount and Equivocality of Information Processing in Organizational Work Units, Administrative Science Quarterly, 26, 207-224.

Dean, J. W. and Scott. A. Snell (1991) "Integrated Manufacturing and Job Design: Moderating Effects of Organizational Inertia", Academy of Management Journal, (34)4, pp. 776-804.

Dunegan, K.J.; Duchon, D.; and Uhlbien, M. (1992) "Examining the link between leadermember exchange and subordinate performance - Te role of task analyzability and variety as moderators", Journal of Management, (18)1, pp. 59-76.

Dyer, Jeffrey H. and Kentaro Nobeoka. 2000. "Creating and Managing a HighPerformance Knowledge-Sharing Network: The Toyota Case.” Strategic Management Journal 21: 345-367.

Edmondson, A. C., M. A. Roberto, et al. (2003). "A dynamic model of top management team effectiveness: managing unstructured task streams." Leadership Quarterly 14(3): 297-325. 
Eschenfelder, E., Heckman, R., Sawyer, S., 1998, "The distribution of computing: the knowledge markets of distributed technical support specialists", Information Technology and People, 11, 2, 84-103.

Fields, D.L. (2002), Taking the measure of work : a guide to validated scales for organizational research and diagnosis, Thousand Oaks, Calif.: Sage.

Flynn, F.J. (2005). Identity orientations and forms of social exchange in organizations. Academy of Management Review. 30, 737-750.

Fukuyama, F. (1995) "Social capital and the global economy", Foreign Affairs, 74(5), pp. 89-103.

Gabbay, S.M., Leenders, R.Th.A.J. (Eds.), 2001. Social capital of organizations. In: Bachrach, S.B. (Ed.), Research in the Sociology of Organizations, vol. 18. Elsevier, Oxford.

Galbraith, J. (1973). Designing Complex Organizations. Reading, MA: Addison-Wesley Publishing Co.

GAO, (2006). Hurricane Katrina: GAO's Preliminary Observations Regarding Preparedness, Response, and Recovery.

Gelderman, M. (2002). "Task difficulty, task variability and satisfaction with management support systems." Information \& Management 39(7): 593-604.

Goodhue, D. L. and R. L. Thompson (1995). "Task-Technology Fit and IndividualPerformance." Mis Quarterly 19(2): 213-236.

Goodhue, D.L. (1995) "Understanding user evaluations of information systems", Management Science, 41(12), pp. 1827-1844.

Grant, Robert M. (1996) "Toward a Knowledge-Based Theory of the Firm” Strategic Management Journal, (17) Special Issue, pp. 109-122.

Green, S. B., \& Salkind, N. J. (2005). Using SPSS for Windows and Macintosh: Analyzing and Understanding Data. New Jersey: Pearson Prentice Hall.

Grover, V. and T. H. Davenport (2001). "General perspectives on knowledge management: Fostering a research agenda." Journal of Management Information Systems 18(1): 5-21.

Gudi, A., Irma Becerra-Fernández, and Weidong Xia (2009) "Effective Knowledge Integration in Emergency Response Organizations", Ph.D. Dissertation, Florida International University, College of Business Administration. 
Hackman, J.R. and G.R. Oldham (1974) "The Job Diagnostic Survey: An Instrument for the diagnosis of jobs and the evaluation of job redesign projects", Tech. Rep. 4, New Haven, Ct. Yale University, Department of Administrative Sciences.

Hackman, J.R., and Oldham, G.R. (1980) Work Redesign. Reading, MA: AddisonWesley.

Haerem, T. and D. Rau (2007). "The influence of degree of expertise and objective ask complexity on perceived task complexity and performance." Journal of Applied Psychology 92(5): 1320-1331.

Hair, J. F., Anderson, R. E., Tatham, R. L., \& Black, W. C. Multivariate Data Analysis. Englewood Cliffs, New Jersey: Prentice-Hall, 1998.

Hannemann R.A. (2001) "Introduction to Social Network Methods" http://faculty.ucr.edu/\%7Ehanneman/SOC157/TEXT/TextIndex.html.

Hansen, M. T. and Martine R. Hass (2001) "Different Knowledge, Different Benefits: Toward a Productivity Perspective on Knowledge Sharing in Organizations", Academy of Management Proceedings 2001 MC:C1.

Hansen, M.T., Nitin Nohria, and Thomas Tierney (1999) "What's your strategy for managing knowledge", Harvard Business Review, (77)3, pp. 196-206.

Harris, K. (2003) "Management Update: A Guide to Key Knowledge Management Terms and Concepts", Gartner, 16 July 2003.

Haythornthwaite, C. (1996). Social network analysis: An approach and technique for the study of information exchange. Library and Information Science Research, 18, 323-342.

Hazleton, V. and Kennan, W. (2000) "Social capital: reconceptualizing the bottom line", Corporate Communications, 5(2), pp. 81-86.

Hendriks, P. (1999) "'"Why share knowledge? The influence of ICT on the motivation for knowledge sharing", Knowledge and Process Management, (6)2, pp. 91-100.

Herzberg, F. (1968) “Work and the Nature of Man”, London: Granada Publishing.

Herzberg, F. (1987) “One more time - How do you motivate employees?", Harvard Business Review, (65)5, pp.109-120.

Hoffman, J., Mark L Hoelscher, and Karma Sherif (2005) "Social capital, knowledge management, and sustained superior performance", Journal of Knowledge Management, (9), 3, pp. 93-100. 
Hopp, W. J., S. M. R. Iravani, et al. (2007). "Operations systems with discretionary task completion." Management Science 53(1): 61-77.

Huysman, M. and Volker Wulf (2006) "IT to support knowledge sharing in communities, towards a social capital analysis", Journal of Information Technology, (21), pp. 40-51.

Iacobucci, Dawn (2008), Mediation Analysis, Thousand Oaks, CA: Sage.

Ito, J. K. and R. B. Peterson (1986). "EFFECTS OF TASK-DIFFICULTY AND INTERUNIT INTERDEPENDENCE ON INFORMATION-PROCESSING SYSTEMS." Academy of Management Journal 29(1): 139-149.

Jaccard, J., \& Turrisi, R. (2003). Interaction effects in multiple regression (2nd ed.). Thousand Oaks, CA: Sage.

Jenkins, Jr., William O. (2006) "Emergency Preparedness and Response, Some Issues and Challenges Associated with Major Emergency Incidents" United States Government Accountability Office, February 23, 2006 GAO-06-467T.

Jensen, M. C., \& Meckling, W. H. (1996). Specific and general knowledge, and organizational structure. In P. S. Myers (Ed.), Knowledge management and organizational design (pp. 17-38). Newton, MA: Butterworth-Heinemann.

Kakabadse, N. K., Andrew Kakabadse, Alexander Kouzmin (2003). "Reviewing the knowledge management literature: Towards a taxonomy." Journal of Knowledge Management 7(4): 75-91.

Kane, G. C. and M. Alavi (2007). "Information technology and organizational learning: An investigation of exploration and exploitation processes." Organization Science 18(5): 796-812.

Kapucu, Naim (2006) "Interagency Communication Networks During Emergencies", American Review of Public Administration, (36)2, pp. 207-225.

Karimi, J., Toni M Somers, and Yash P Gupta (2004) "Impact of Environmental Uncertainty and Task Characteristics on User Satisfaction with Data", Information Systems Research, (15)2, pp. 175-193.

Kim, Jeffrey and John King,"Managing knowledge work: specialization and collaboration of engineering problem- solving",Journal of Knowledge Management, Volume: 8. Issue: 2; 2004 ,pp53-63. 
Kim, S. and Dagobert Soergel (2005) " Selecting and Measuring Task Characteristics as Independent Variables", Sparking Synergies: Bringing Research and Practice Together@ASIST '05 (ASIS\&T 2005), Westin Charlotte, Charlotte, North Carolina, October 28 - November 2, 2005.

Kogut, B. and Udo Zander (1992) "Knowledge of the Firm, Combinative Capabilities, and the Replication of Technology", Organizational Science, (3)3, pp. 383-397.

Kull, M. (2005) "Retention: Capturing Critical Knowledge for Workforce Transformation" in The e-gov Institute: Knowledge Management Proceedings (2005).

Kumar, G Stanley Jaya (2000) "Disaster management and social development", The International Journal of Sociology and Social Policy (20)7, pp. 66-81.

Larsen, K.R.T. (2003) "A taxonomy of Antecedents of Information Systems Success: Variable Analysis Studies”, Journal of Management Information Systems, (20)2, pp. 169-246.

Lesser, E.L. (2000). "Knowledge and Social Capital: Foundations and applications", Boston, MA: Butterworth Heinemann.

Liden, R. C., S. J. Wayne, et al. (1997). "Task interdependence as a moderator of the relation between group control and performance." Human Relations 50(2): 169181.

Liebowitz, J. (2005). Conceptualizing and implementing knowledge management. Oxford: Elsevier Butterworth-Heinemann.

Lillrank, P. (2003). "The quality of standard, routine and nonroutine processes." Organization Studies 24(2): 215-233.

Lim, K. H. and I. Benbasat (2000). "The effect of multimedia on perceived equivocality and perceived usefulness of information systems." Mis Quarterly 24(3): 449-471.

Lin, N. (2001), Social Capital, Cambridge University Press, Cambridge, UK.

Lytras, Miltiadis D and Athanasia Pouloudi (2003) "Project management as a knowledge management primer: The learning infrastructure in knowledge-intensive organizations: projects as knowledge transformations and beyond", The Learning Organization, (10)4, pp. 237-250.

Majchrzak, A., Cooper, L. P., \& Neece, O. E. (2004). Knowledge reuse for innovation. Management science, 50(2), 174-188. 
Malhotra, A., \& Majchrzak, A. (2004). Enabling knowledge creation in far-flung teams: Best practices for IT support. Journal of Knowledge Management, 8(4), 75-89.

Malik, K. "Coordination of Technological Knowledge Flows in Firms." Journal of Knowledge Management 8, no. 2(2004) : 64-72.

March, J.G. (1991) "Exploration and Exploitation in Organizational Learning", Organization Science, (2)1, pp. 71-87.

Markus, Hazel Rose and Shinobu Kitayama (1991), "Culture and the Self: Implications for Cognition, Emotion, and Motivation,” Psychological Review, 98 (2), 224-253.

Maslow, A.H. (1954) “Motivation and Personality”, New York: Harper \& Row.

McClelland, D.C. (1971) “Assessing Human Motivation”, Morristown: General Learning Press.

McElroy, M. W. (2000). "Integrating complexity theory, knowledge management and organizational learning." Journal of Knowledge Management 4(3): 195-203.

McElroy, M. W. (2003). The new knowledge management: Complexity, learning, and sustainable innovation. New York: Knowledge management consortium international.

McGrath, R.G. (2001) "Exploratory Learning, Innovative Capacity, and Managerial Oversight", Academy of Management Journal, 44(1), pp. 118-131.

McGregor, D. (1960) “The Human Side of Enterprise”, New York: McGraw-Hill.

Mertler, C.A. and Rachel A Vannatta (2005) "Advanced and Multivariate Statistical Methods", $3^{\text {rd }}$ Edition, Glendale, AZ.: Pyrczak Publishing.

Nahapiet, J., and Ghoshal, S. (1998) "Social Capital, Intellectual Capital, and the Organizational Advantage", Academy of Management Review, (23)2, pp. 242-266.

Nohria, N., and Eccles, R. G. (1992) "Face-to-Face: Making Network Organizations Work," in Networks and Organizations: Structure, Form and Action, N. Nohria and R. G. Eccles (Eds.), Harvard Business School Press, Boston, pp. 288-308.

Nonaka, I, Ryoko Toyama (2003) "The knowledge-creating theory revisited: knowledge creation as a synthesizing process", Knowledge Management Research \& Practice, 1, pp. 2-10. 
Nonaka, I. (1994) "A dynamic theory of organizational knowledge creation", Organization Science, (5)1, pp. 14-37.

Nonaka, Ikujiro (1991) "The Knowledge-Creating Company" Harvard Business Review, (69)6, pp. 96-104.

Nonaka, Ikujiro. (1999) "The Dynamics of Knowledge Creation" in DanHoltshouse, Christopher Meyer, and Rudy Ruggles (ed.) (1999) The Knowledge Advantage: 14 Visionaries Define Marketplace Success in the New Economy, Chico, California: Capstone Publications.

Norris, D., J., Jon Mason, and Paul Lefrere (2003) Transforming e-Knowledge, $1^{\text {st }}$ Edition, Ann Arbor, Michigan: Society for College and University Planning .

O'Dell, C., and Jackson, C. (1998) If Only we Know What we Know: The Transfer of Internal Knowledge and Best Practice, New York, New York: Free Press.

Paton, Douglas and Duncan Jackson (2002) "Developing disaster management capability: An assessment centre approach", Disaster Prevention and Management, (11)2, pp. $115-122$.

Perrow, C. (1984). Normal Accidents: Living with high-risk technologies. Princeton, New Jersey: Princeton University Press.

Perrow, C. (2004). A personal note on Normal Accidents. Organization \& Environment, $17(1), 9,6$.

Perry, Ronald W (2003) "Incident management systems in disaster management" Disaster Prevention and Management, (12)5, pp. 405-412.

Piccolo, Ronald F. and Jason A. Colquitt (2006) "Transformational Leadership and Job Behaviors: The Mediating Role of Core Job Characteristics", Academy of Management Journal, (49)2, pp. 327-340.

Plunkett, P. (2001) Managing knowledge @ work, an overview of knowledge management. Knowledge Management Working Group of the Federal Chief Information Officers Council, U.S General Services Administration, Office of Information Technology, pearl.butler@gsa.gov.

Polanyi, M. (1966) “The Tacit Dimension”, New York, NY: Anchor Day Books.

Putnam, R. (1995) “Tuning in, Tuning Out: The Strange Disappearance of Social Capital in America”, Political Science and Politics, December, pp. 664-683. 
Queensland Disaster Management Planning Guidelines, 2005 for Local Government. Queenslan Government, Department of Emergency Management.

Rice, R. E. (1992). "TASK ANALYZABILITY, USE OF NEW MEDIA, AND EFFECTIVENESS - A MULTISITE EXPLORATION OF MEDIA RICHNESS." Organization Science 3(4): 475-500.

Rocha, J., Irma Becerra-Fernandez, Weidong Xia, and Arvind Gudi, Dealing with Task Uncertainty in Disaster Management: The Role of Knowledge Sharing for Exploration and Exploitation. Research paper published at the Conference Proceedings of the 2009 Americas Conference on Information Systems, San Francisco, California, August 6-9, 2009.

Rowan, B., S. W. Raudenbush, et al. (1993). "TEACHING AS A NONROUTINE TASK - IMPLICATIONS FOR THE MANAGEMENT OF SCHOOLS." Educational Administration Quarterly 29(4): 479-500.

Sabherwal , Rajiv and Irma Becerra-Fernandez (2005) " Integrating Specific Knowledge: Insights From the Kennedy Space Center ", IEEE Transactions On Engineering Management, pp. 301-315.

Sabherwal, R., \& Becerra-Fernandez, I. (2003). An empirical study of the effect of knowledge management processes at individual, group, and organizational levels. Decision sciences, 34(2), 225-261.

Salvendy, Gavriel (2001) Handbook of industrial engineering: technology and operations management, John Wiley \& Sons, Inc.: Canada.

Schildt, H. A., Markku V.J. Maula, and Thomas Keil (2005) "Explorative and Exploitative Learning from External Corporate Ventures”, Entrepreneurship Theory and Practice, July 2005, pp. 493-515.

Schwab, D.P. (1980) "Construct Validity in Organizational Behavior", Research in Organizational Behavior, (2), pp. 2-43.

Sharman, Raj, Jin Ki Kim, H. Raghav Rao, and Shambhu Upadhyaya (2006) "A Delphi Study on Priorities - Lessons Learned from the Gulf Coast", $1^{\text {st }}$ Annual Symposium on Information Assurance: Intrusion, Detection and Prevention, Conference Proceedings June 14-15, 2006, pp. 27-36.

Smith, Wally and John Dowell (2000) "A case study of co-ordinative decision-making in disaster management”, Ergonomics, (43)8, pp. 1153-1166. 
Snell, S. A. and James W. Dean, Jr. (1994) "Strategic compensation for integrated manufacturing: the moderating effects of jobs and organizational inertia", Academy of Management Journal, (37)5, pp.1109-1140.

Sobel, M. E. (Ed.). (1982). Asymptotic confidence intervals for indirect effects in structural equation models. San Francisco: Jossey-Bass.

Tatikonda, M. V. and S. R. Rosenthal (2000). "Technology novelty, project complexity, and product development project execution success: A deeper look at task uncertainty in product innovation." Ieee Transactions on Engineering Management 47(1): 74-87.

Triandis, H. C., Bontempo, R., Villareal, M. J., Asai, M., \& Lucca, N. (1988a). Individualism and collectivism: Cross-cultural perspectives on self-ingroup relationships. Journal of Personality and Social Psychology, 54, 323-338.

Truch, Edward (2004) Knowledge Orientation in Organizations, $1^{\text {st }}$ Edition, Burlington, VT : Ashgate Publishing Company.

Turoff, Murray (2002) "Past and future Emergency Response Information Systems" Communications of the ACM, (45)4, pp. 29-32.

Van de Ven, A.H. and André L. Delbecq (1974) "A task contingent model of work unit structure”, Administrative Science Quarterly, (19)2, pp. 183-197.

Van de Ven, A.H. and D.L. Ferry (1980) "Measuring and Assesing Organizations", Wiley, Inter-Science, New York.

Van der Spek, R., and Spijkervet, A. 1996, Knowledge Management, Dealing Intelligently with Knowledge. Kenniscentrum CIBIT, Utrecht, The Netherlands.

Vroom, V.H. (1964) “Work and Motivation”, New York: Wiley.

Van Wijk, R., Van Den Bosch, F. A. J., \& Volberda, H. W. (2003). Knowledge and Networks. In M. Easterby-Smith \& M. A. Lyles (Eds.), The Blackwell Handbook of Organizational Learning and Knowledge Management (pp. 428-453). Oxford.

Waller, M. J. (1999). "The timing of adaptive group responses to nonroutine events." Academy of Management Journal 42(2): 127-137.

Wasko McLure, M. and Samer Faraj (2005), "Why should I share? Examining social capital and knowledge contribution in electronic networks of practice", MIS Quarterly, 29(1), pp. 35-57. 
Weber, R., Aha, D. W., \& Becerra-Fernandez, I. (2001). Intelligent lessons learned. Expert systems with applications, 17, 17-34.

Wickert A \& Herschel R (2001) Knowledge-management issues for smaller businesses. Journal of Knowledge Management 5(4): 329-337.

Widén-Wulff, Gunilla and Mariam Ginman (2004) "Explaining knowledge sharing in organizations through the dimensions of social capital", Journal of Information Science, 30(5), pp. 448-458.

Wiig, K. (1997) "Knowledge Management: where did t come from and where will it go?" Expert Systems with Applications, (14) Fall.

Wood, R.E. (1986). Task Complexity: Definition of the Construct. Organizational Behavior and Human Decision Processes, 37, 1, 60-82.

Woolcock, Michael, and Deepa Narayan (2000) "Social Capital: Implications for Development Theory, Research, and Policy" World Bank Research Observer 15(2): 225-250.

Xia, W., \& Lee, G. (2005) “Complexity of Information Systems Development Projects: Conceptualization and Measurement Development", Journal of Management Information Systems, 22(1), pp. 45-83.

Xia, Weidong, Becerra-Fernandez, Irma , Gudi, Arvind P. and Rocha, Jose . "Emergency Management Task Complexity and Knowledge Sharing Strategies" Cutter IT Journal, January 2011.

Xia, W., Irma Becerra-Fernandez, Jose Rocha, and Arvind Gudi, Knowledge Management Task Complexity In Emergency Management: An Instrument Development. Research paper published at the Conference Proceedings of the 2010 Americas Conference on Information Systems, Lima, Perú, August 12-15, 2010.

Yang, J.T. (2004). Job-related Knowledge Sharing: comparative case studies, Journal of Knowledge Management, 8(3), 118-126.

Yi, J. (2005) "A measure of knowledge sharing behavior: scale development and validation", Ph.D Thesis. Indiana University, School of Education.

Zander, U. and Bruce Kogut (1995) "Knowledge and the speed of the transfer and imitation of organizational capabilities: An empirical test", Organization Science, (6)1, pp. 76-92. 


\section{APPENDICES}

Appendix A: Research Study Survey Questionnaire 


\title{
A Study on Emergency Task Uncertainty, Knowledge Sharing and Task Performance
}

\author{
Jose Rocha (Contact Person, 305 519-4651, Fax: 305 348-4126, Jose.Rocha@Business.Fiu.Edu) \\ Dr. Irma Becerra-Fernandez, Dr. Weidong Xia, Arvind Gudi \\ RB250, College of Business Administration \\ Florida International University \\ 11200 SW 8th St., Miami, FL 33199
}

Dear :

We are writing to ask you to help us by participating in a survey study related to "Emergency Task Uncertainty, Knowledge Sharing, and Task Performance" during an emergency management response event or threat. In the last few months, we have been working closely with Mr. Frank Reddish and Mr. David Perez at Miami-Dade EOC to design our study and the survey instrument. Both have kindly sponsored and endorsed us to collect the survey data from the EOC personnel (please see enclosed letter), and he suggested that we contact you to get your help. As a part of a larger research program, this study is also a critical element of Jose (Pepe) Rocha's doctoral dissertation. Your participation and kind help will greatly facilitate the timely completion of Pepe's dissertation and the success of our research.

Because of the limited number of people like you, who have the required extensive experience in disaster management, your help is critical to the success of our research.

We assure you that all information you provide will be treated as confidential. We will not reveal the identities of individuals or organizations in any reports, only aggregated results will be analyzed and reported

The survey has four sections: (1) Characteristics of a dynamic disaster management task in which you were recently involved (2) knowledge sharing that was used to accomplish the task; (3) knowledge sharing mechanisms that were used to accomplish the task; and (4) background information that will help us segment and analyze the data. It would take about 20 minutes to complete the questionnaire

Given the importance of this research and in appreciation for your time and effort, upon completion of the entire survey without any missing values, you will be entered into a drawing to win:

One (1) of Five (5) Prizes of:

1. iPhone $8 \mathrm{~GB}$ for the first 30 people who respond to this survey

2. iTouch $8 \mathrm{~GB}$ for the next 30 people who respond to this survey

3. iPod Classic $80 G B$ for the next 30 people who respond to this survey

4. iPod Nano 4GB for the next 30 people who respond to this survey, and

5. iPod Shuffle $2 \mathrm{~GB}$ for the next 30 people who respond to this survey

We would greatly appreciate it, if you could take about 20 minutes to help us by completing the survey right away, the sooner you complete the entire survey the more helpful it is for us and also you increase your chances of getting a better prize. Please respond no later than $\underline{\text { October } 15^{\text {th }}, 2008}$

For your convenience, we also created an online version of the survey at: http://uww.questionpro.com/akira/TakeSurvey?id=1033825

If you have any questions or suggestions concerning this survey, please contact Jose (Pepe) Rocha.

Thanks in advance for your help with this survey and good luck in the drawing !! $\odot$

Page 1 


\section{RULES FOR DRAWING:}

- One (1) respondent will be drawn to receive an iPhone 8GB from the first 30 people who respond to this survey today with a valid PIN number no later than $\underline{\text { October } 15^{\text {th }}, 2008}$.

- One (1) respondent will be drawn to receive an iTouch $8 G B$ from the next 30 people who respond to this survey with a valid PIN number no later than October $15^{\text {th }}, 2008$.

- One (1) respondent will be drawn to receive an iPod Classic 80GB from the next 30 people who respond to this survey with a valid PIN number no later than October $15^{\text {th }}, 2008$.

- One (1) respondent will be drawn to receive an iPod Nano 4GB from the next 30 people who respond to this survey with a valid PIN number no later than October $\mathbf{1 5}$ th, 2008.

- One (1) respondent will be drawn to receive an iPod Shuffle 2GB from the next 30 people who respond to this survey with a valid PIN number no later than October $15^{\text {th }}, 2008$.

A valid respondent must fill in their contact information at the end of the survey. The order in which each survey is received is according to the survey date/time stamp recorded by the survey system website on each survey responded. No substitution is allowed. One winner per survey and one survey per respondent is allowed. Not valid where prohibited by law. Chances of winning depend on the first, second, third, fourth, and fifth group of 30 people responding. Total value of all gifts is $\$ 1,145$.

An endorsement messages from Mr. Frank Reddish, Emergency Management Coordinator, Manager, Recovery \& Mitigation and Mr. David Perez, Government Affairs Coordinator from the Miami-Dade EM \& HS are attached with this survey.

Page 2 


\section{Section 1: Task Characteristics}

1.1 For the purposes of this study, we define a task as a set of activities that were coordinated/performed to accomplish specific emergency management objectives within a given time frame.

Please identify one task that you were recently involved in and were responsible for as a representative of your organization. If you do not do this particular job anymore, please go back in time when you did. The following is a list of typical EOC tasks related to the response and recovery efforts following an incident, such as a hurricane. The list is not meant to be exhaustive -- it only provides some sample tasks. If the task you were recently involved in is on the list, please check it If not, please specify the task (similar in nature to the sample tasks) in the space provided.

We intend to understand these tasks with respect to their variations in the degree of novelty, lack of analyzability, and significance (relatively high to low). All tasks at the EOC are important; however we expect them to vary in degree of nonroutineness, newness, difficulty, conflicting information, urgency, and potential impact

\section{Typical unexpected dynamic EOC tasks:}

$\square$ Search and rescue operations of missing people due to a collapsed building

$\square$ Evacuation of patients from a MMF (Medical Management Facility) without power to other MMF with power due to irreparable electric damages impossible to fix in the short run

$\square$ Bridge collapsed on a main expressway and unknown amount of debris on nearby alternative routes to allow safe circulation of emergency vehicles

$\square$ Hospitals and municipalities running low on diesel fuel for generators and lack of re-supply source

$\square$ Assistance requested in protecting downed power lines to make the transit of emergency vehicles safe

$\square$ Increase in short term shelter demands as buildings are declared unsafe

$\square \quad$ Lost power in critical agencies such as 911 or 311 and backup generators not working as priorities and demands for alternative power sources (generators) increase

$\square$ Other

1.2 Background of the task. Please provide your best approximate estimates. In this section, please skip the question if there is no information available or you don't have the information handy.

1. Which agency was leading this task

2. For this particular task, how many years of experience did you have the last time you coordinated/performed this task?

3. For this particular task, what was your level of expertise the last time you coordinated/performed this task? hours

4. What was the planned time for the task completion (in hours):

5. What was the actual time required for completing the task (in hours):

6. What was the planned budget/cost for the task: $\$$

7. What was the actual budget/cost for the task: $\$$ $\square \quad$ Wide spread life threatening fire reported in a shelter or essential life support facilities, patients and medical staff need to be evacuated

$\square$ Early activation of debris clearance procedures to clear impassable roadways and alternative routes for emergency vehicles due to unexpected increase of emergency situations

$\square$ Search, assignment, and delivery of additional suitable power generators to newly needed emergency care facilities

Drawbridge locked in down position due to vessel collision under Miami River's bridge with huge potential economic impact by the hour

$\square$ Repair air-conditioning units at a full capacity special needs shelter

$\square \quad$ EOC functional groups radio communications towers knocked down

Due to unexpected rush of injured people, additional medical staff needed in medical facilities and shelters

Othe 
8. The task was completed within the planned time schedule

9. The task was completed within the allocated budget

$\begin{array}{llllllll}1 & 2 & 3 & 4 & 5 & 6 & 7\end{array}$

10. The task was completed within the planned number of person-hours

11. The task was completed with efficient use of all available resources

$\begin{array}{lllllll}1 & 2 & 3 & 4 & 5 & 6 & 7\end{array}$

12. Completing the task did not required additional unanticipated resources

$\begin{array}{lllllll}1 & 2 & 3 & 4 & 5 & 6 & 7\end{array}$

13. The task was completed satisfactorily for all participants

14. All incident requirements were met when the task was completed

15. The task was completed successfully without negatively impac

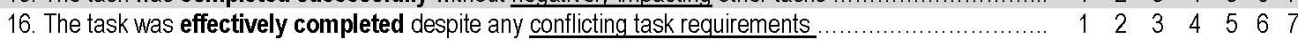

1.3 Please indicate the extent to which you disagree or agree with each of the following statements by CIRCLING the appropriate number from 1 to 7 . If your response is "do not know" or "not applicable", circle 4.

Strongly Strongly

Disagree Neutral Agree

1 Setting the objectives of this new task required answering questions that have not been asked before $\quad \begin{array}{lllllll}1 & 2 & 3 & 4 & 5 & 6 & 7\end{array}$

2 Coordinating/performing the activities of this new task required answering questions that have not been asked before .

$\begin{array}{llllllll}1 & 2 & 3 & 4 & 5 & 6 & 7\end{array}$

Setting the objectives for this new task required adopting new procedures

$\begin{array}{lllllll}1 & 2 & 3 & 4 & 5 & 6 & 7\end{array}$

4 Coordinating/performing the activities of this new task required adopting new ways of doing things ........ $1 \begin{array}{llllllll}2 & 2 & 3 & 4 & 5 & 6 & 7\end{array}$

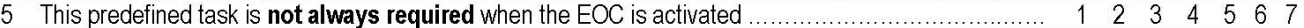

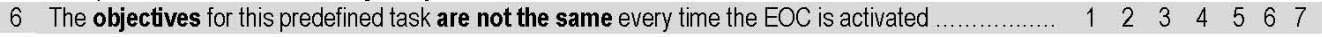

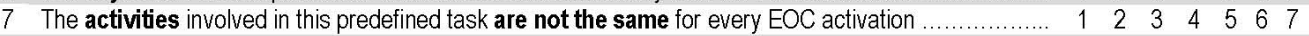

8 This task involves activities that are not previously specified in existing standard operating procedures

9 This predefined task requires changing the required activities

$\begin{array}{lllllll}1 & 2 & 3 & 4 & 5 & 6 & 7\end{array}$

10 It is difficult to see clearly the sequence of steps that can be followed to coordinate/perform the activities of this task

11 You came across specific difficult problems that you were not sure how to solve immediately

12 Coordinating/performing the task required you to spend additional time to think and solve specific problems

$\begin{array}{lllllll}1 & 2 & 3 & 4 & 5 & 6 & 7\end{array}$ $\begin{array}{lllllll}1 & 2 & 3 & 4 & 5 & 6 & 7\end{array}$

13 While coordinating/performing the task, it was difficult to know whether the results of your efforts would be correct

14 The objectives set for this task were not clearly defined according to existing standard operating procedures

Before you started this task, the information used for setting the objectives of this task meant different things to different people

16 During the execution of this task, the information used to accomplish the task objectives meant different things to different people

$\begin{array}{lllllll}1 & 2 & 3 & 4 & 5 & 6 & 7\end{array}$

There were multiple possible ways to interpret how to achieve the objectives of this task

$\begin{array}{llllllll}1 & 2 & 3 & 4 & 5 & 6 & 7\end{array}$

There were multiple ways to interpret the possible outcomes for this task

There were no clear measures to evaluate the task outcomes and performance

$\begin{array}{lllllll}1 & 2 & 3 & 4 & 5 & 6 & 7\end{array}$

This task required your immediate attention

The pressure to complete this task did not allow you time to think

The task did not have built-in slack time which allowed you time to think

The activities of this task must be done as fast as possible

You were primarily focused on achieving the immediate objectives for this task

Failure to complete this task would significantly impact the lives or well-being of people

Failure to complete this task would have significant economic impact

Failure to complete this task would incur significant infrastructure loss during the disaster

$\begin{array}{lllllll}1 & 2 & 3 & 4 & 5 & 6 & 7\end{array}$

$\begin{array}{lllllll}1 & 2 & 3 & 4 & 5 & 6 & 7\end{array}$

$\begin{array}{lllllll}1 & 2 & 3 & 4 & 5 & 6 & 7\end{array}$

$\begin{array}{llllllll}1 & 2 & 3 & 4 & 5 & 6 & 7\end{array}$

$\begin{array}{lllllll}1 & 2 & 3 & 4 & 5 & 6 & 7\end{array}$

$\begin{array}{llllllll}1 & 2 & 3 & 4 & 5 & 6 & 7\end{array}$

$\begin{array}{llllllll}1 & 2 & 3 & 4 & 5 & 6 & 7\end{array}$

$\begin{array}{llllllll}1 & 2 & 3 & 4 & 5 & 6 & 7\end{array}$

$\begin{array}{lllllll}1 & 2 & 3 & 4 & 5 & 6 & 7\end{array}$

$\begin{array}{llllllll}1 & 2 & 3 & 4 & 5 & 6 & 7\end{array}$

$\begin{array}{llllllll}1 & 2 & 3 & 4 & 5 & 6 & 7\end{array}$

$\begin{array}{llllllll}1 & 2 & 3 & 4 & 5 & 6 & 7\end{array}$

28 Failure to complete this task would create a pile-up of activities in your own work

$\begin{array}{lllllll}1 & 2 & 3 & 4 & 5 & 6 & 7\end{array}$ 
29 Failure to complete this task would slow down or create a bottleneck for other people

30 You waited until all relevant information was examined before deciding a course of action to execute the activities for this task

31 You kept gathering data until an excellent solution emerged before deciding a course of action to execute the activities for this task

32 You acquired all possible information before making a final decision to execute the activities for this task

You went over all the available information until an excellent solution appeared before deciding a course of action to execute the activities for this task

\section{Section 2: Evaluation of Knowledge Sharing Purposes}

2.1 Please indicate the extent to which you disagree or agree with each of the following statements by CIRCLING the appropriate number from 1 to 7 . If your response is "do not know" or "not applicable", circle 4.

Strongly Strongly Disagree Neutral Agree

1 You searched for new ways to coordinate/perform the activities of this task

$\begin{array}{llllllll}1 & 2 & 3 & 4 & 5 & 6 & 7\end{array}$ You had to modify existing procedures to coordinate/perform the activities of this task $\quad \begin{array}{llllllll}1 & 2 & 3 & 4 & 5 & 6 & 7\end{array}$ You had to learn new skills or knowledge to coordinate/perform the activities of this task .................... $1 \begin{array}{lllllll}1 & 2 & 3 & 4 & 5 & 6 & 7\end{array}$ You discovered different procedures to coordinate/perform this task ..................................... $1 \begin{array}{lllllll}1 & 2 & 3 & 4 & 5 & 6 & 7\end{array}$ To coordinate/perform this task, you used the experience you gained from coordinating/performing similar tasks in the past To coordinate/perform this task, you used your expertise

7 You applied the needed knowledge you obtained from existing standard operating procedures

\section{Section 3: Evaluation of Knowledge Sharing Mechanisms}

3.1 Please indicate the extent to which you disagree or agree with each of the following statements by CIRCLING the appropriate number from 1 to 7 . If your response is "do not know" or "not applicable", circle 4.

Strongly Strongly Disagree Neutral Agree New personnel can acquire the required knowledge for this task by face-to-face on-the-job training

Personal contact interactions were required to execute the activities for this task You were able to interact with others when coordinating/performing this task

People were available for personal interaction during the execution of this tack

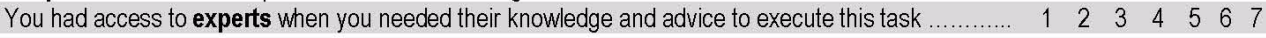

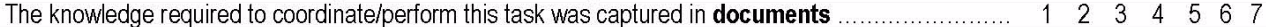

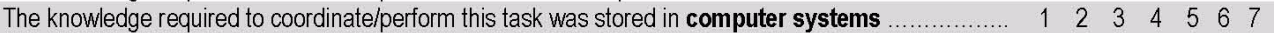

9 An extensive documentation describing critical parts of the knowledge is required to coordinate/perform this task

$\begin{array}{llllllll}1 & 2 & 3 & 4 & 5 & 6 & 7\end{array}$

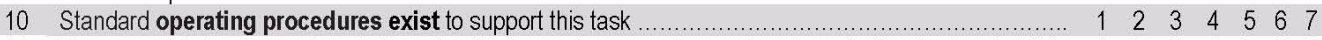

11 You were able to access to existing standard operating procedures when coordinating/performing this $1122 \quad 3 \quad 4 \quad 567$ task ......

12 Standard operating procedures were available to support this task

13 New employees can learn how to coordinate/perform this task by studying existing standard operating procedures 


\section{Section 4: Background Information}

4.1 Please provide the following background information, which will help us segment the sample to understand how the relationship between task uncertainty, knowledge sharing purposes and mechanisms varies according to your experience, expertise, and functional group. Once again we assure you that your input will be treated as confidential and no personal information will be reported.

1. Name of your organization:

2. Your title:

3. How long have you worked at your current organization? Years

4. Did you work in another organization involved in emergency management? Yes No

5. If yes, which organization?

6. How long have you been assigned at the EOC? Years

7. In total, how long have you been working in the emergency management field? Years

8. To which functional group do you belong at the Office of Emergency Management/Emergency Operations Center? _ Infrastructure Group - Other, please describe: _Human Services Group Public Safety Group

9. Your educational degrees and corresponding fields:

Degree:

Degree:

Degree:
Field:

Field:

Field:

For the purpose of communicating the prize drawing results, please provide your name, phone, and e-mail address information. Also, we will email you an Executive Summary of our study.

Name:

Phone:

e-Mail address: 
Appendix B: Disaster Management Task Uncertainty Characteristics:

An Empirical Study of Knowledge Sharing for

Exploration and Exploitation Purposes

Executive Summary 


\title{
Disaster Management Task Uncertainty Characteristics:
}

\section{An Empirical Study of Knowledge Sharing for Exploration and Exploitation Purposes}

\author{
Executive Summary
}

Report to:

\author{
Director \\ Miami-Dade Emergency Management and Homeland \\ Security \\ Emergency Management Coordinator, \\ Manager Recovery and Mitigation
}

Prepared by:

Jose Rocha

Irma Becerra-Fernandez

Weidong Xia, and

Arvind Gudi

College of Business Administration

Florida International University

March 2009

The authors wish to acknowledge the support of (1) the National Science Foundation under grant CNS0452180 and (2) Frank J. Reddish, Miami-Dade Office of Emergency Management Coordinator, Robert Palestrant, Division Chief, Miami Dade Fire Rescue, David Perez, Government Affairs Coordinator, Soheila Ajabshir, GIS Manager / Senior Systems Analyst, Troy Johnson, Emergency Management Coordinator, and Raymond Misomali, Emergency Management Coordinator who selflessly have educated and mentored our research team. 


\section{SUMMARY}

Since November 2007, a team of researchers at the College of Business Administration at Florida International University have undertaken a comprehensive research about emergency management tasks and knowledge management at the Miami Dade Department of Emergency Management and Homeland Security. The study seeks to understand the characteristics of the emergency response tasks at the Emergency Operations Center and how knowledge management can assist in the effective and efficient disposition of those tasks. The first part of this research dealt with task characteristics related to complexity, interdependence and procedure rigidity, and the role that knowledge integration plays in performing those tasks. The second part of this research and the topic of this report, is related to the degree of uncertainty in these tasks as characterized by the novelty, lack of analyzability, and significance of these tasks, and the role that knowledge sharing plays in the successful performance of these tasks.

Analysis of the results of a survey collected from 167 Miami-Dade County emergency managers during the dates of October 2008 - January 2009 suggests that: 
1. Many of the emergency tasks undertaken at the EOC are high in their level of uncertainty. We assessed the uncertainty of a task in terms of three dimensions: novelty (unexpected and novel events that occur in performing a task), unanalyzability (the procedures required to solve a problem are ambiguous), and significance (the task can have a substantial impact on the lives of people and also have economic consequences). The availability of the right personnel with the required expertise as well as accessibility to the right information at critical times is essential for effective knowledge sharing at the OEM-EOC. We observed that in general, OEM-EOC personnel deal with tasks characterized by uncertainty and high degree of non-routineness (variability) every time a disaster event occurs. Furthermore, OEM-EOC personnel are thorough, try to gather as much information as possible, and if required look for new approaches and procedures when they determine that the existing ones are not adequate for the task.

2. Despite the prevalence of a sophisticated technology infrastructure and elaborate mechanisms for knowledge sharing such as communication systems, we found that emergency personnel do not get all the information required to perform the task from existing documents and procedures. Interestingly, the greater the difficulty of the task on hand, the more likely they are to shift to sharing knowledge through personal contact rather than using prescribed mechanisms such as operating procedures and documents. This indicates that when the task is critical, emergency personnel rely heavily on their own experience as well as the expertise of others also involved in the activation procedures. The results may also suggest that for highly uncertain tasks, it may not be possible to plan and outline all the required processes and resources before the disaster event. 
3. When OEM-EOC personnel face emergency tasks with a high degree of uncertainty and novelty, they tend to share knowledge for two purposes. First, they explore new approaches and procedures to resolve the task at hand and in doing so, often times OEM-EOC personnel discover new procedures which are helpful in modifying current standard operating procedures (SOPs), in order to support the necessary assessment and decision-making for the task to be performed. Second, when emergency tasks characterized with high degree of uncertainty and significance (urgency and impact) arise during a disaster event, OEM-EOC personnel rely heavily on knowledge sharing for exploitation, that seek to reuse their experience, expertise, and existing SOPs in order to address the task at hand. 


\section{BACKGROUND}

Researchers at the College of Business Administration at Florida International University, in collaboration with the Miami-Dade Department of Emergency Management and Homeland Security, have undertaken a research to study the uncertainty of emergency management tasks at the Miami-Dade Emergency Operations Center (EOC) and how knowledge sharing can improve task performance. These tasks are novel, unstructured, and often present themselves with conflicting information and interpretation. This study reaches beyond a simplistic assessment of emergency task performance (for example finding answers to "what went wrong?") by trying to understand the inherent nature of EOC tasks which can make them unpredictable and difficult to manage.

Since November 2007, we have been collecting survey data with the help of personnel involved in EOC operations during emergencies. The first survey, completed in November 2007, focused on assessing task characteristics related to interdependencies and procedure, as well as knowledge integration in performing a task. An Executive Summary was sent to the survey participants in March 2008. The second survey which is the focus of this Executive Summary was completed in January 2009, and focuses on assessing task characteristics related to uncertainty and knowledge sharing for explorative (search) and exploitative (reuse) purposes. These questionnaires were carefully developed based on extensive reviews of the literature, field observations, interviews with emergency management personnel, and reviews of EOC procedures and policies.

As a value to the survey participants, we are sending this Executive Summary to each respondent of the second survey. We expect that the study results will help managers and policy-makers better understand the inherent uncertainty aspects of emergency management tasks and the critical role that knowledge sharing can play in improving task performance.

\section{SUMMARY OF FINDINGS}

Most emergency tasks at the EOC are highly uncertain and dynamic, characterized by high levels of novelty, urgency, and impact. Yet, they are in general completed successfully because of the skillful use and sharing of knowledge by the individuals assigned to the tasks. Effective communication and collaboration through information and knowledge sharing are extremely important when performing EOC tasks. The EOC organizational structure, managers, and technological infrastructure provide a favorable and dynamic knowledge sharing environment for the effective and efficient restoration of community continuity. 


\section{SUMMARY OF STUDY}

The survey had four sections: (1) Dynamic characteristics of disaster management task; (2) knowledge sharing purposes that were used to complete the task; (3) knowledge sharing mechanisms that were used to complete the task; and (4) respondent background information that will help us segment and analyze the data. Respondents were asked to identify a specific emergency management task and their agreement/disagreement with a set of statements about the task novelty, lack of analyzability, significance, and knowledge sharing characteristics.

Dynamic task characteristics can be understood and analyzed from three different perspectives:

1. Task Novelty: extent to which different activities of the task are completely new and/or

are not performed on a routine basis

2. Task Unanalyzability: extent to which different activities of the task are difficult to analyze due to conflicting interpretations and/or lack

information

needed to make a decision

3. Task Significance:

extent to which different activities of the task need to be performed

urgently to save lives and minimize economic impact.

Knowledge is shared in emergency management tasks for two purposes:

1. Exploration: search of new alternatives to perform the task

2. Exploitation: reuse of existing knowledge, organized and stored in

information repositories

Two types of knowledge sharing mechanisms are normally utilized in executing emergency management tasks:
1. Personal Contact:
person-to-person communications 
2. Written Documents:

written planning guidelines, standard operating

procedures, best

practices, lessons learned, and after action reports

Table 1 shows some examples of the tasks that survey participants identified, the name of the agency leading the task during the EOC activation, and the reported level of task uncertainty, and relevant knowledge sharing purposes and mechanisms used to perform these tasks. 
Table 1. Sample tasks, EOC Leading Groups, and levels of Uncertainty Task, Knowledge Sharing Purposes and Mechanisms

\begin{tabular}{|c|c|c|c|c|c|}
\hline $\begin{array}{l}\mathbf{N} \\
\mathbf{0}\end{array}$ & Task Description & $\begin{array}{l}\text { EOC Lead } \\
\text { Groups }\end{array}$ & $\begin{array}{l}\text { Uncertainty } \\
\text { Levels }\end{array}$ & $\begin{array}{l}\text { Knowledge } \\
\text { Sharing } \\
\text { Purposes } \\
\end{array}$ & $\begin{array}{l}\text { Knowledge } \\
\text { Sharing } \\
\text { Mechanisms } \\
\end{array}$ \\
\hline 1 & $\begin{array}{l}\text { Early activation of debris } \\
\text { clearance procedures to } \\
\text { clear impassable roadways } \\
\text { and alternative routes for } \\
\text { emergency vehicles due to } \\
\text { unexpected increase of } \\
\text { emergency situations }\end{array}$ & $\begin{array}{l}\text { Infrastructure } \\
\text { Public Safety }\end{array}$ & $\begin{array}{l}\text { Novelty level: } \\
4.6 \text { (Medium) } \\
\text { Uncertainty } \\
\text { level: } 3.5 \\
\text { (Medium) } \\
\text { Significance } \\
\text { level: } 5.7 \text { (Mod. } \\
\text { High) }\end{array}$ & $\begin{array}{l}\text { Exploration } \\
\text { purpose: } 4.2 \\
\text { (Medium) } \\
\text { Exploitation } \\
\text { purpose: } 5.5 \\
\text { (Mod. High) }\end{array}$ & $\begin{array}{l}\text { Personal contact: } \\
\text { High) } 5.7 \text { (Mod. } \\
\text { Written } \\
\text { document: } \\
\quad 4.7 \text { (Mod. } \\
\text { High) }\end{array}$ \\
\hline 2 & $\begin{array}{l}\text { Evacuation of patients from } \\
\text { a MMF (Medical } \\
\text { Management Facility) } \\
\text { without power to other } \\
\text { MMF with power due to } \\
\text { irreparable electric damages } \\
\text { impossible to fix in the } \\
\text { short run }\end{array}$ & $\begin{array}{l}\text { Human } \\
\text { Services } \\
\text { Public Safety }\end{array}$ & $\begin{array}{l}\text { Novelty level: } \\
4.1 \text { (Medium) } \\
\text { Uncertainty } \\
\text { level: } 4.0 \\
\text { (Medium) } \\
\text { Significance } \\
\text { level: } 5.0 \text { (Mod. } \\
\text { High) }\end{array}$ & $\begin{array}{l}\text { Exploration } \\
\text { purpose: } 4.3 \\
\text { (Medium) } \\
\text { Exploitation } \\
\text { purpose: } 5.1 \\
\text { (Mod. High) }\end{array}$ & $\begin{array}{l}\text { Personal contact: } \\
\quad 5.9 \text { (Mod. } \\
\text { High) } \\
\text { Written } \\
\text { document: } \\
\quad 4.2 \\
\text { (Medium) }\end{array}$ \\
\hline 3 & $\begin{array}{l}\text { Assistance requested in } \\
\text { protecting downed power } \\
\text { lines to make the transit of } \\
\text { emergency vehicles safe }\end{array}$ & Public Safety & $\begin{array}{l}\text { Novelty level: } \\
3.2 \\
\text { (Mod. Low) } \\
\text { Uncertainty } \\
\text { level: } 2.4 \text { (Low) }\end{array}$ & $\begin{array}{l}\text { Exploration } \\
\text { purpose: } 2.8 \\
\text { (Mod. Low) } \\
\text { Exploitation } \\
\text { purpose: } 5.9 \\
\end{array}$ & $\begin{array}{l}\text { Personal contact: } \\
\quad 6.0 \\
\text { (High) } \\
\text { Written } \\
\text { document: }\end{array}$ \\
\hline
\end{tabular}




\begin{tabular}{|c|c|c|c|c|c|}
\hline $\begin{array}{l}\mathbf{N} \\
\mathbf{0}\end{array}$ & Task Description & $\begin{array}{l}\text { EOC Lead } \\
\text { Groups }\end{array}$ & $\begin{array}{l}\text { Uncertainty } \\
\text { Levels }\end{array}$ & $\begin{array}{l}\text { Knowledge } \\
\text { Sharing } \\
\text { Purposes } \\
\end{array}$ & $\begin{array}{l}\text { Knowledge } \\
\text { Sharing } \\
\text { Mechanisms } \\
\end{array}$ \\
\hline & & & $\begin{array}{l}\text { Significance } \\
\text { level: } 5.2 \text { (Mod. } \\
\text { High) }\end{array}$ & (Mod. High) & $\begin{array}{r}4.0 \\
\text { (Medium) }\end{array}$ \\
\hline 4 & $\begin{array}{l}\text { Lost power in critical } \\
\text { agencies such as } 911 \text { or } 311 \\
\text { and backup generators not } \\
\text { working as priorities and } \\
\text { demands for alternative } \\
\text { power sources (generators) } \\
\text { increase }\end{array}$ & $\begin{array}{l}\text { Infrastructure } \\
\text { Public Safety }\end{array}$ & $\begin{array}{l}\text { Novelty level: } \\
4.1 \text { (Medium) } \\
\text { Uncertainty } \\
\text { level: } 3.9 \\
\text { (Medium) } \\
\text { Significance } \\
\text { level: } 6.1 \text { (High) }\end{array}$ & $\begin{array}{l}\text { Exploration } \\
\text { purpose: } 4.3 \\
\text { (Medium) } \\
\text { Exploitation } \\
\text { purpose: } 5.6 \\
\text { (Mod. High) }\end{array}$ & $\begin{array}{l}\text { Personal contact: } \\
5.3 \text { (Mod. } \\
\text { High) } \\
\text { Written } \\
\text { document: } \\
3.7 \\
\text { (Medium) }\end{array}$ \\
\hline
\end{tabular}




\begin{tabular}{|c|c|c|c|c|c|}
\hline 5 & $\begin{array}{l}\text { Search and rescue } \\
\text { operations of missing } \\
\text { people due to a collapsed } \\
\text { building }\end{array}$ & Public Safety & $\begin{array}{l}\text { Novelty level: } \\
4.7 \\
\text { (Mod. High) } \\
\text { Uncertainty } \\
\text { level: } 3.8 \\
\text { (Medium) } \\
\text { Significance } \\
\text { level: } 5.5 \text { (Mod. } \\
\text { High) }\end{array}$ & $\begin{array}{l}\text { Exploration } \\
\text { purpose: } 4.0 \\
\text { (Medium) } \\
\text { Exploitation } \\
\text { purpose: } 6.0 \\
\text { (High) }\end{array}$ & $\begin{array}{l}\text { Personal contact: } \\
\quad 5.8 \text { (Mod. } \\
\text { High) } \\
\text { Written } \\
\text { document: } \\
\quad 5.6 \text { (Mod. } \\
\text { High) }\end{array}$ \\
\hline 6 & $\begin{array}{l}\text { Hospitals and } \\
\text { municipalities running low } \\
\text { on diesel fuel for generators } \\
\text { and lack of re-supply } \\
\text { source }\end{array}$ & $\begin{array}{l}\text { Infrastructure } \\
\text { Public Safety }\end{array}$ & $\begin{array}{l}\text { Novelty level: } \\
5.9 \\
\text { (Mod. High) } \\
\text { Uncertainty } \\
\text { level: } 4.5 \\
\text { (Medium) } \\
\text { Significance } \\
\text { level: } 4.8 \text { (Mod. } \\
\text { High) }\end{array}$ & $\begin{array}{l}\text { Exploration } \\
\text { purpose: } 4.5 \\
\text { (Medium) } \\
\text { Exploitation } \\
\text { purpose: } 4.6 \\
\text { (Medium) }\end{array}$ & $\begin{array}{l}\text { Personal contact: } \\
\quad 3.9 \\
\text { (Medium) } \\
\text { Written } \\
\text { document: } \\
\quad 2.6 \text { (Mod. } \\
\text { Low) }\end{array}$ \\
\hline 7 & $\begin{array}{l}\text { Increase in short term } \\
\text { shelter demands as } \\
\text { buildings are declared } \\
\text { unsafe }\end{array}$ & $\begin{array}{l}\text { Infrastructure } \\
\text { Human } \\
\text { Services }\end{array}$ & $\begin{array}{l}\text { Novelty level: } \\
5.3 \\
\text { (Mod. High) } \\
\text { Uncertainty } \\
\text { level: } 2.7 \text { (Mod. } \\
\text { Low) } \\
\text { Significance } \\
\text { level: } 5.9 \text { (Mod. } \\
\text { High) }\end{array}$ & $\begin{array}{l}\text { Exploration } \\
\text { purpose: } 4.7 \\
\text { (Mod. High) } \\
\text { Exploitation } \\
\text { purpose: } 6.0 \\
\text { (High) }\end{array}$ & $\begin{array}{l}\text { Personal contact: } \\
\quad 6.8 \\
\text { (High) } \\
\text { Written } \\
\text { document: } \\
\quad 5.0 \text { (Mod. } \\
\text { High) }\end{array}$ \\
\hline
\end{tabular}


High (6, 7), Moderately High (4.7 - 5.9), Medium (3.4-4.6), Moderately Low (2.1 - 3.3), to Low $(1,2)$. 


\section{Task Novelty}

Figure 1 (boxplot chart) below illustrates average scores and range of responses of the components (new questions, new procedures, and new approaches) of task novelty (7 - very high in novelty, and 1 - very low in novelty).

Figure 1. Task Novelty (average and range of responses).

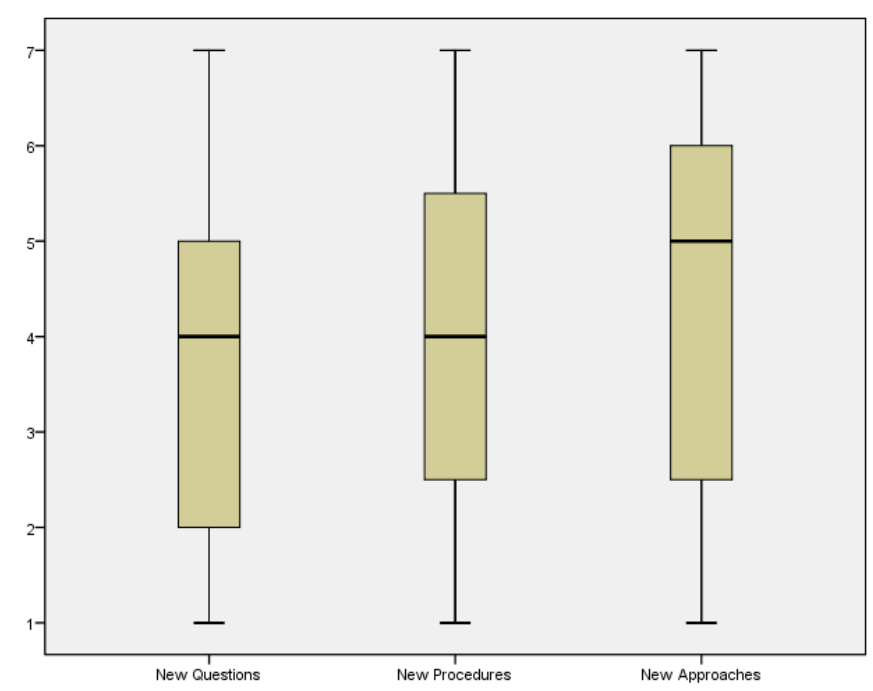

Figure 1 shows that the activities involved in the emergency tasks identified in the survey require new approaches to perform the novel task at hand. Each emergency event presents itself with new tasks that require responses and procedures that are not routinely performed; hence EOC personnel search for and select new approaches and alternatives to necessary to perform these tasks. For example, during hurricane Katrina, a new and unexpected task was the sudden collapse of the SR836 overpass bridge in construction between $87^{\text {th }}$ Ave. and $107^{\text {th }}$ Ave.

Furthermore, the majority of respondents of these three task novelty measures indicated that:

- Coordinating/performing the activities of this new task required answering questions that have not been asked before (40\%).

- Setting the objectives for this new task required adopting new procedures $(43 \%)$, and 
- Coordinating/performing the activities of this new task required adopting new ways of doing things $(51 \%)$

These results suggest that it is necessary for OEM-EOC personnel respond to uncertain tasks through searching for new approaches and procedures.

\section{Task Non-routineness}

Figure 2 (boxplot chart) below illustrates average scores and range of responses of the components of task non-routineness ( 7 - very high in non-routineness, and 1 - very low in non-routineness).

Figure 2. Task Non-Routineness (average and range of responses).

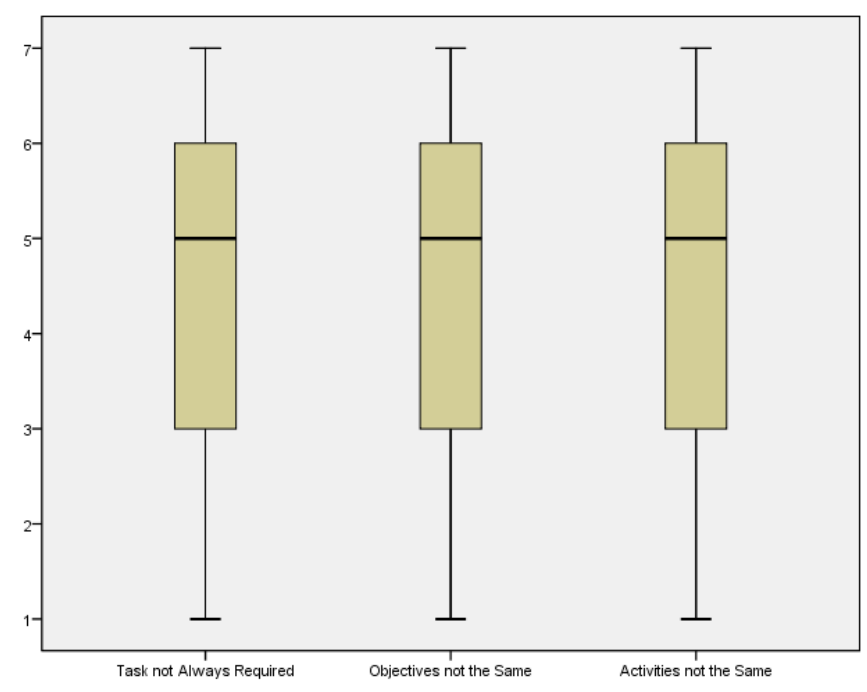

These results indicate that EOC personnel deal with a high degree of nonroutineness and variability in assessing the task at hand as shown in Figure 3 below.

Figure 3. Distribution of responses to the three task Non-Routineness measures. 


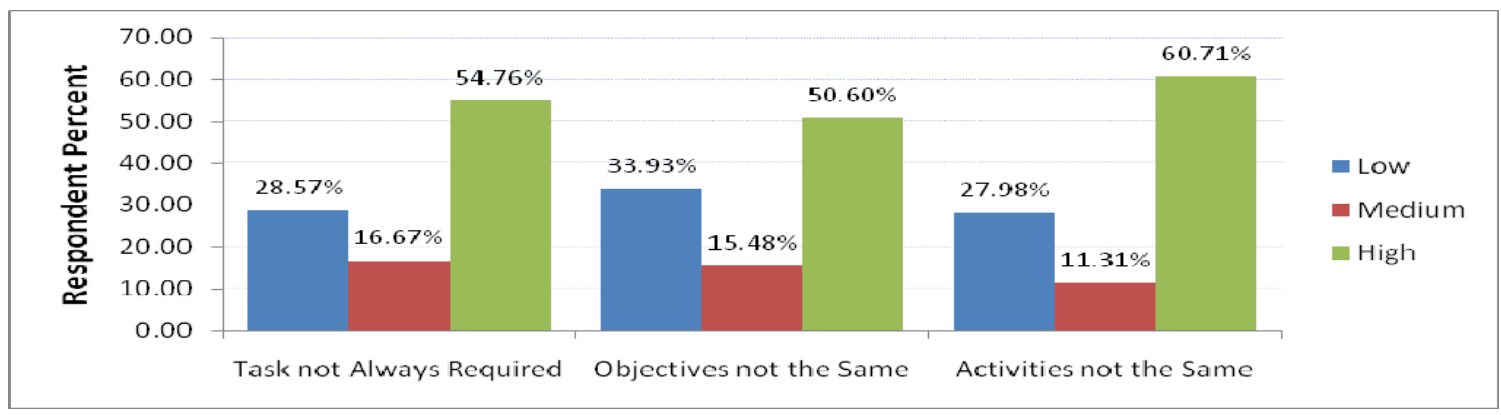

The above results suggest that uncertain disaster management tasks have a high degree of non-routineness characteristics that change from event to event.

\section{Task Difficulty}

Figure 4 (boxplot chart) below illustrates average scores and range of responses of the components of task difficulty ( 7 - very high in difficulty, and 1 - very low in difficulty). These results indicate that when EOC personnel encounter tasks with high degree of difficulty, they require additional time to think and solve the specific challenges and problems inherent of that particular task.

Figure 4. Task Difficulty (average and range of responses).

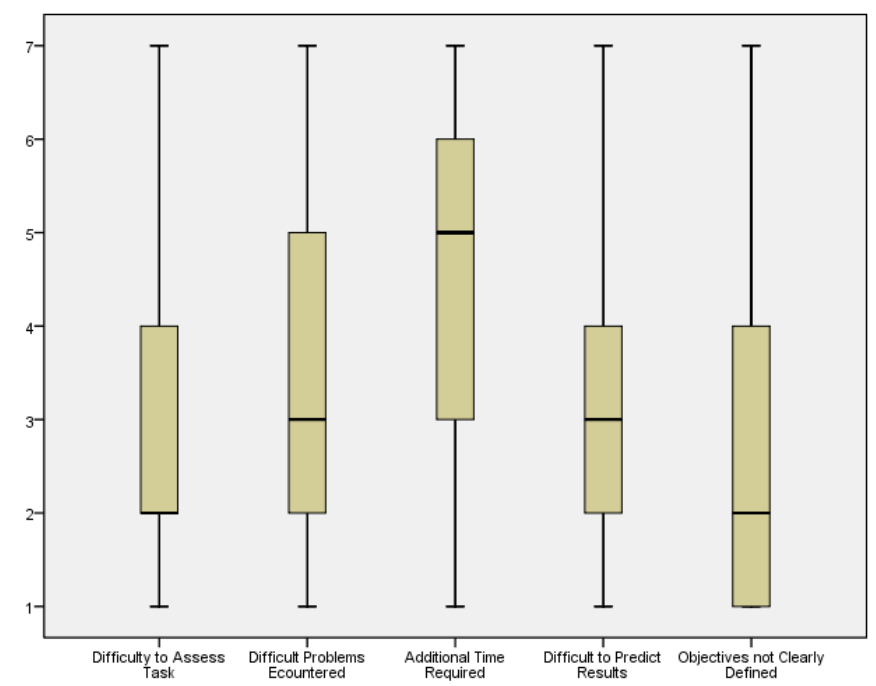

In addition, the majority of respondents pointed out that when facing uncertain tasks with difficult characteristics, they required to spend additional time to think and 
solve specific problems concerning to the task at hand. This indicates that uncertain tasks with difficult characteristics require OEM-EOC personnel to spend additional time to fully assess and understand the task requirements in order to make the most appropriate decisions.

\section{Amount of Task Information}

Figure 5 (boxplot chart) below illustrates average scores and range of responses of the components of Amount of Task Information needed (7 - very high in Amount of Task Information needed, and 1 - very low in Amount of Task Information needed). 
Figure 5. Amount of Task Information needed (average and range of responses).

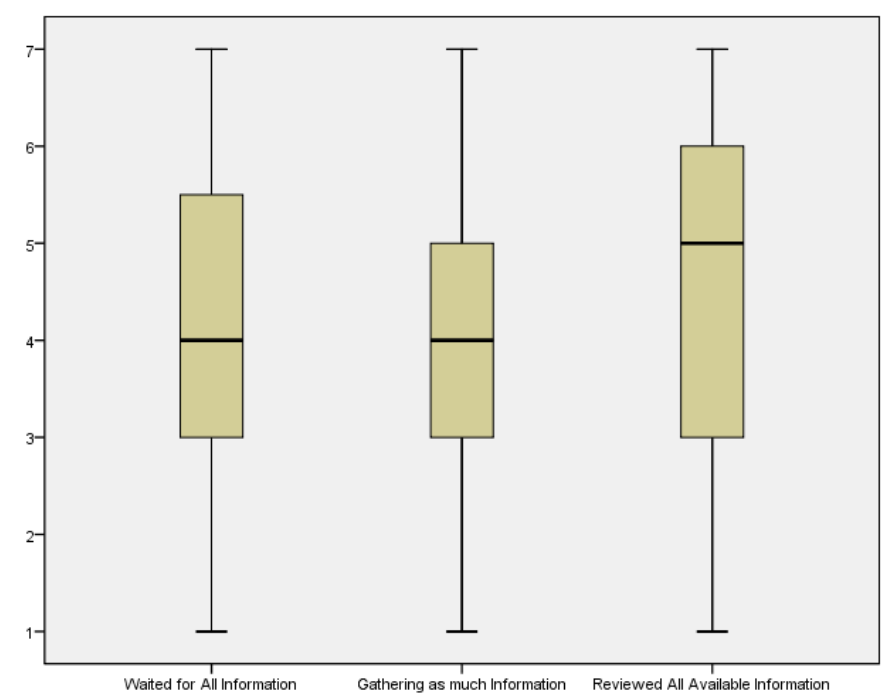

These results indicate that EOC personnel review and wait to have all available information before taking action on the task at hand.

Figure 6 below illustrates the distribution of responses of two measures for Amount of Task Information needed.

Figure 6. Distribution of responses to two Amount of Task Information needed measures.

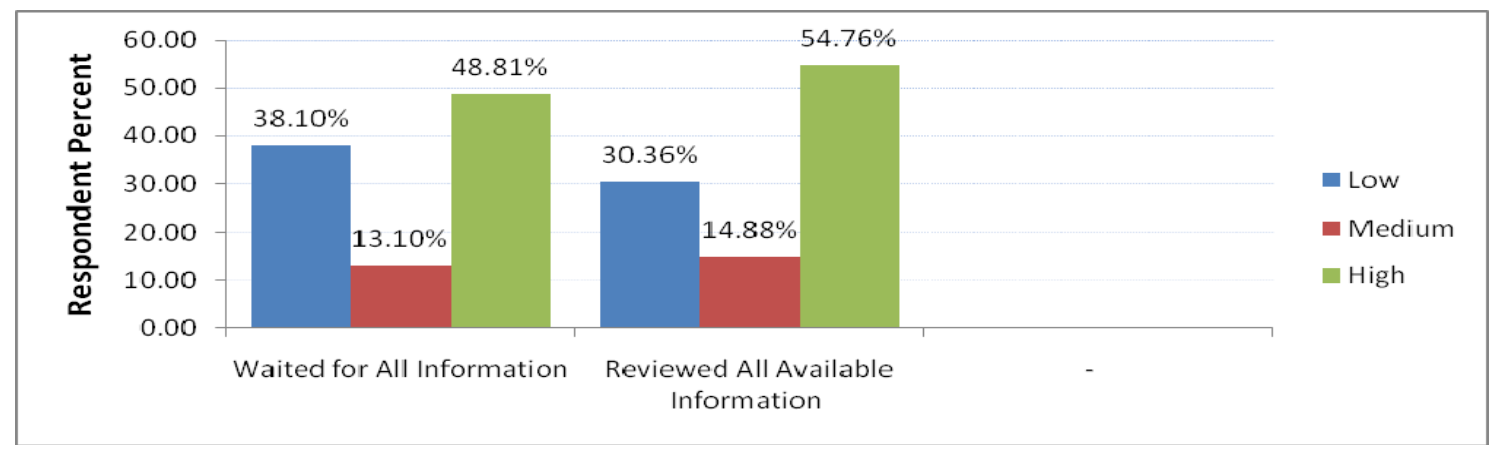

The above results suggest that when facing uncertain tasks, OEM-EOC personnel are very thorough and try to gather as much information and knowledge as possible before performing the tasks. 


\section{Task Urgency}

Figure 7 (boxplot chart) below illustrates average scores and range of responses of the components of Task Urgency ( 7 - very high in Urgency, and 1 - very low in Urgency).

Figure 7. Task Urgency (average and range of responses).

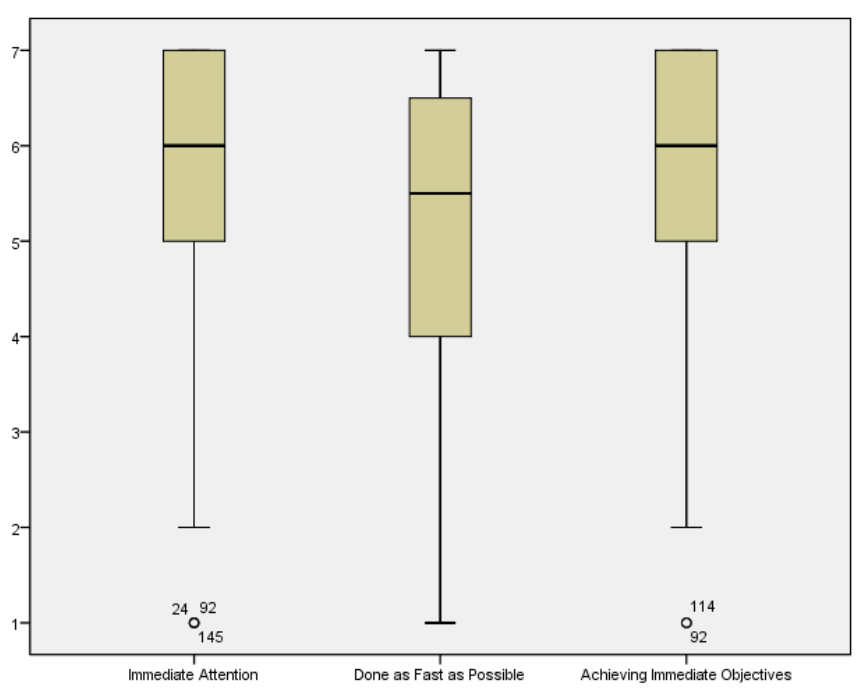

The results shown in Figure 7 indicate that when EOC personnel face a task with high degree of urgency, they turn their immediate attention and focus on the task at hand aiming to perform the task objectives as soon as possible.

For the three task Urgency measures, the majority of respondents indicated that:

- This task required their immediate attention (82\%)

- The activities of this task must be done as fast as possible (71\%)

- They were primarily focused on achieving the immediate objectives for this task $(84 \%)$

These results suggest that when facing urgent tasks, OEM-EOC personnel focus on the highest priority and try to achieve immediate results. This finding presents a very interesting dilemma for emergency managers. We see that EOC personnel are hard pressed to respond to the disaster event as quickly as possible, and equally important they need to take the time to understand the task circumstances as thoroughly as possible before committing to a particular approach or course of action. 


\section{Task Impact}

Figure 8 (boxplot chart) below illustrates average scores and range of responses of the components of Task Impact ( 7 - very high in Impact, and 1 - very low in Impact).

Figure 8. Task Impact (average and range of responses).

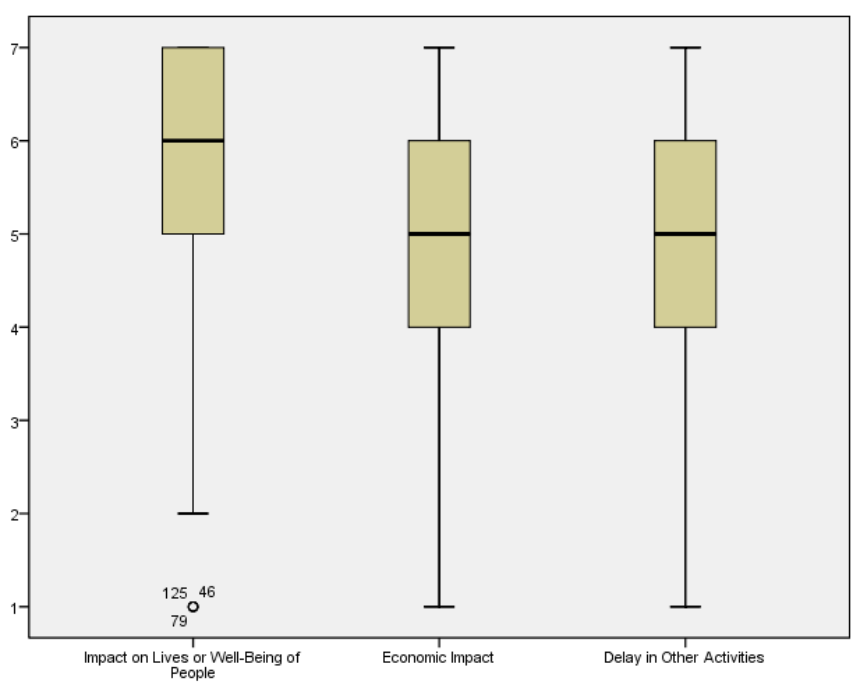

As shown in Figure 8, EOC personnel focus their immediate attention as well on those task that have a high degree of potential impact on lives, well-being of people, and economic repercussions.

Similarly, for the three task Impact measures, the majority of respondents indicated that:

- Failure to complete this task would significantly impact the lives or wellbeing of people $(79 \%)$

- Failure to complete this task would have significant economic impact $(60 \%)$

- Failure to complete this task would create a pile-up of activities in their own work $(54 \%)$

These results show that tasks in the sample have the highest impact on human lives and well-being of people, followed by economic impacts and delays in other activities. 


\section{Knowledge Sharing for Exploration}

Figure 9 (boxplot chart) below illustrates average scores and range of responses for knowledge sharing for exploration. These results indicate that EOC personnel share knowledge for exploration primarily through modifying existing SOPs, and then through searching and discovering new procedures and approaches to perform the task at hand.

Figure 9. Knowledge Sharing for Exploration (average and range of responses).

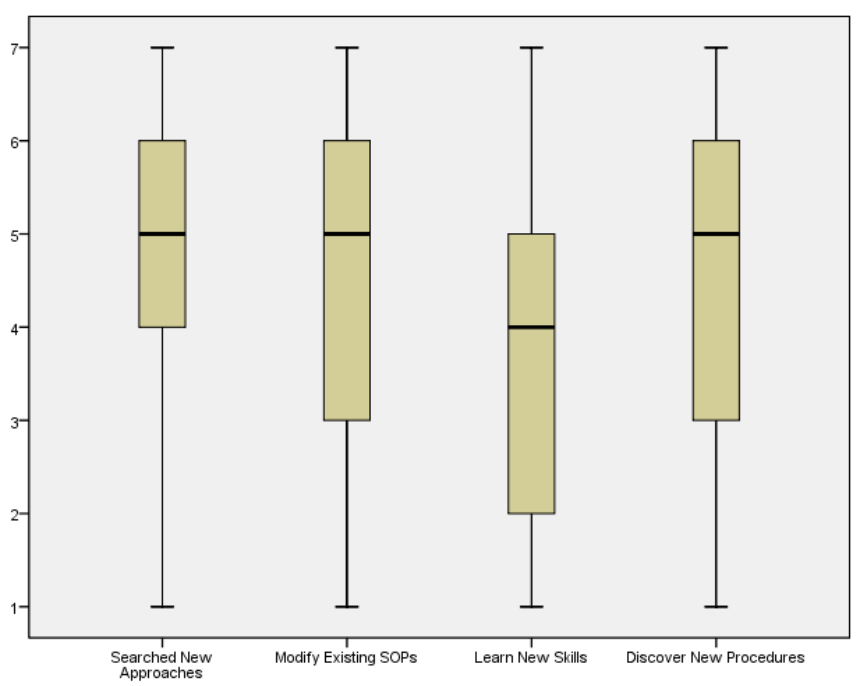

Along these results, for the three knowledge sharing for exploration measures, the majority of respondents indicated that:

- They searched for new ways to coordinate/perform the activities of this task $(57 \%)$

- They had to modify existing procedures to coordinate/perform the activities of this task $(59 \%)$

- They discovered different procedures to coordinate/perform this task (57\%)

These results suggest that when searching for new knowledge to perform tasks, OEM-EOC personnel search about evenly among new approaches, new procedures and modifying existing SOPs. 


\section{Knowledge Sharing for Exploitation}

Figure 10 (boxplot chart) below illustrates average scores and range of responses for Knowledge Sharing for Exploitation.

Figure 10. Knowledge Sharing for Exploitation (average and range of responses).

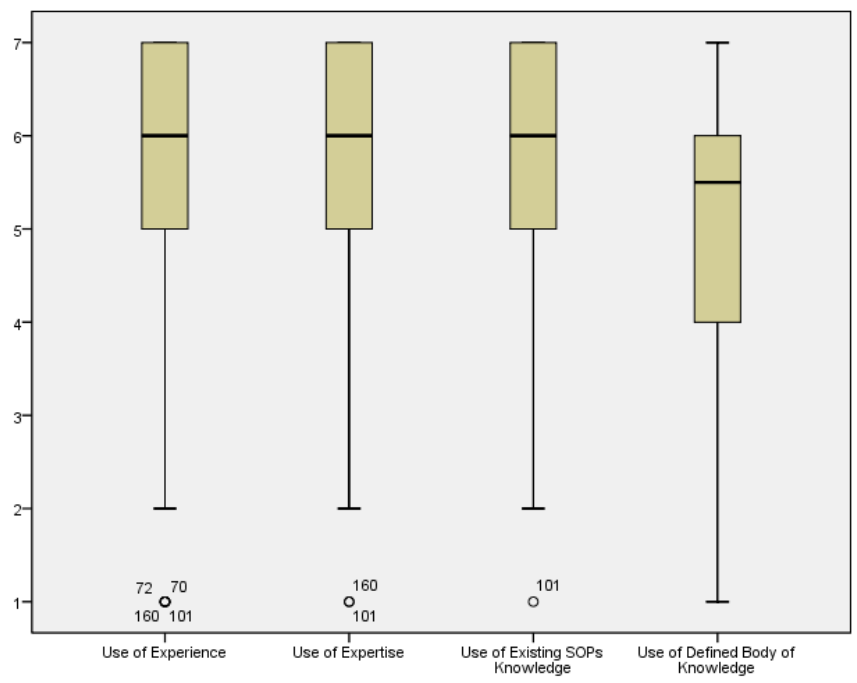

The results shown above indicate that EOC personnel share knowledge through reusing (exploitation) people's experience and expertise and using current SOPs.

Figure 11 below illustrates the distribution of responses of three knowledge sharing for exploitation measures.

Figure 11. Distribution of responses of three Knowledge Sharing for Exploitation measures.

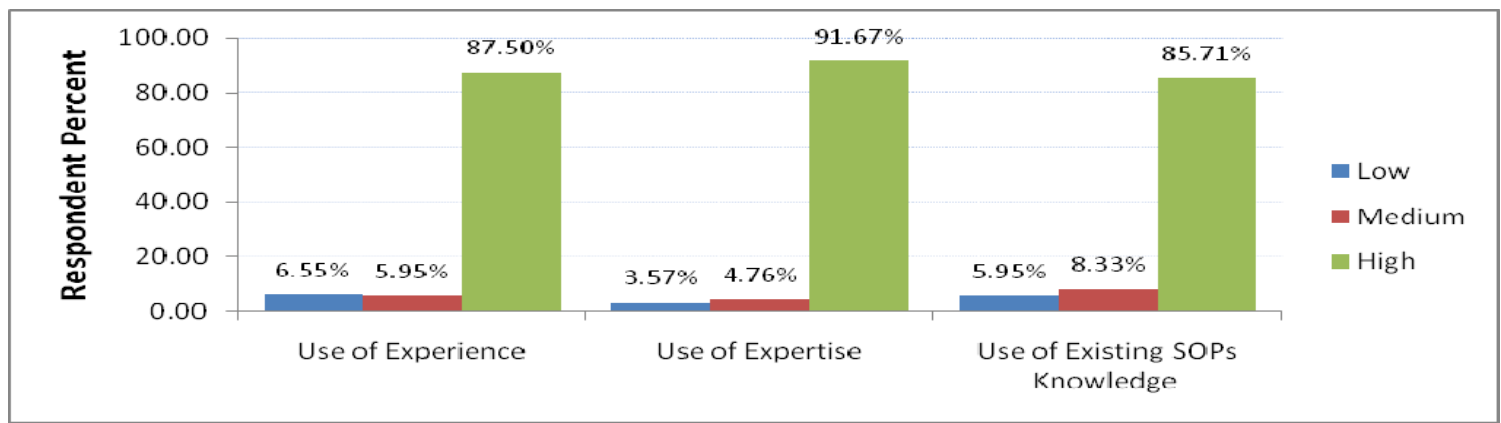


The above results suggest that OEM-EOC personnel rely heavily on their experience, expertise, and current knowledge found in existing standard operating procedures to perform and accomplish the task at hand. 


\section{Knowledge Sharing through Personal Contact}

Figure 12 (boxplot chart) below illustrates average scores and range of responses for knowledge sharing through personal contact. This indicates that given the proximity of people at the EOC, knowledge sharing through personal contact plays a significant role in the interaction of EOC personnel to solve the task at hand.

Figure 12. Knowledge Sharing through Personal Contact (average and range of responses).

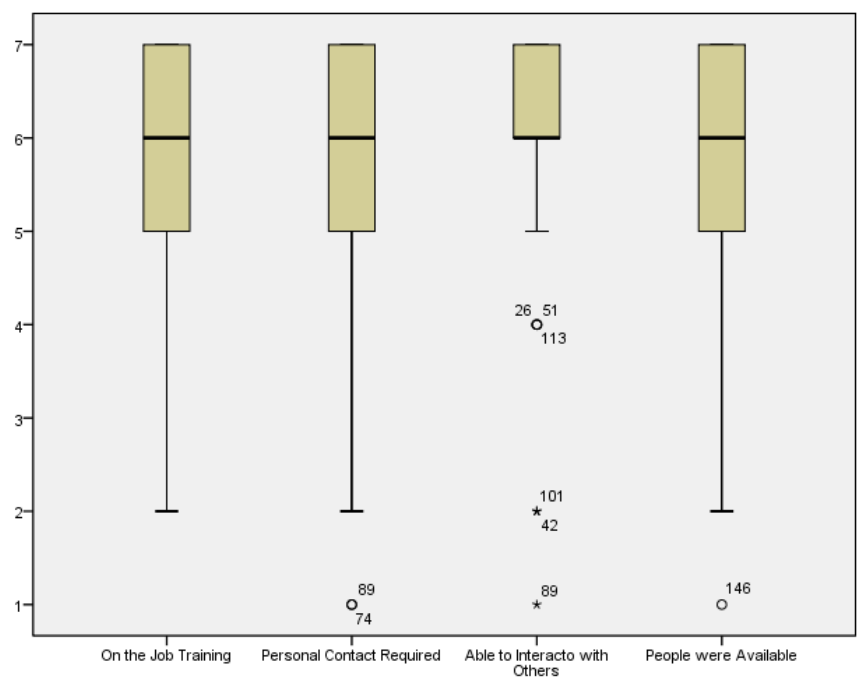

Figure 13 below illustrates the distribution of responses of three Knowledge Sharing through Personal Contact measures.

Figure 13. Distribution of responses to three Knowledge Sharing through Personal Contact measures.

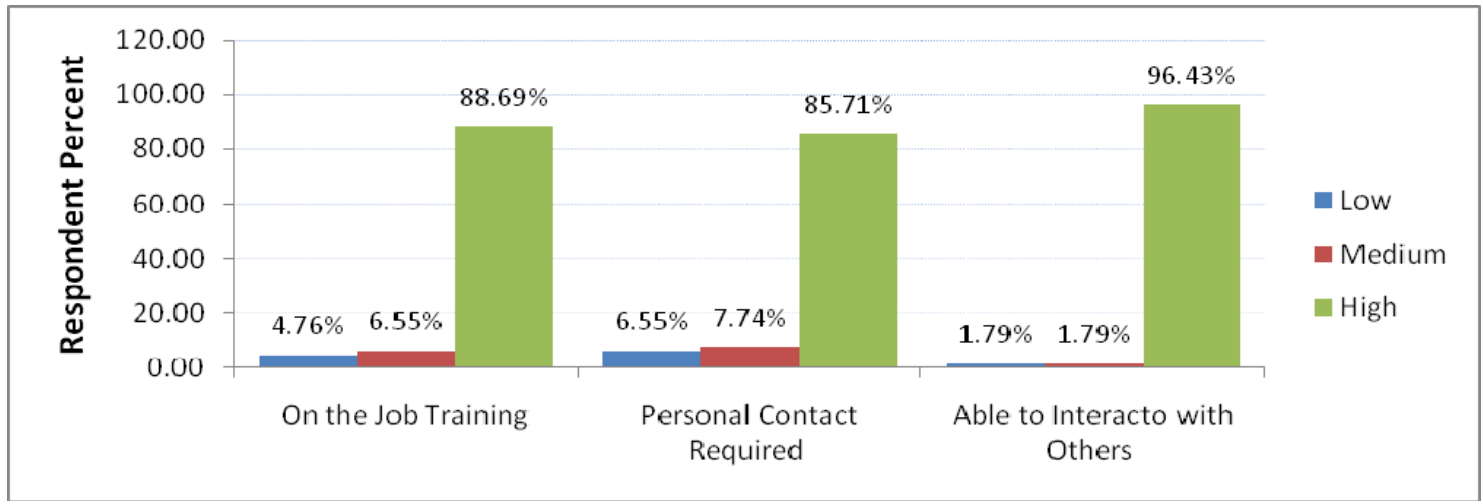


Given the proximity of people at the EOC during a disaster management activation, the results described above confirm the relevance of knowledge sharing through personal contact.

\section{Knowledge Sharing through Written Documents}

Figure 14 (boxplot chart) below illustrates average scores and range of responses for knowledge sharing through written documents. These results indicate that SOPs play a relevant role in sharing knowledge through written documents.

Figure 14. Knowledge Sharing through Written Documents (average and range of responses).

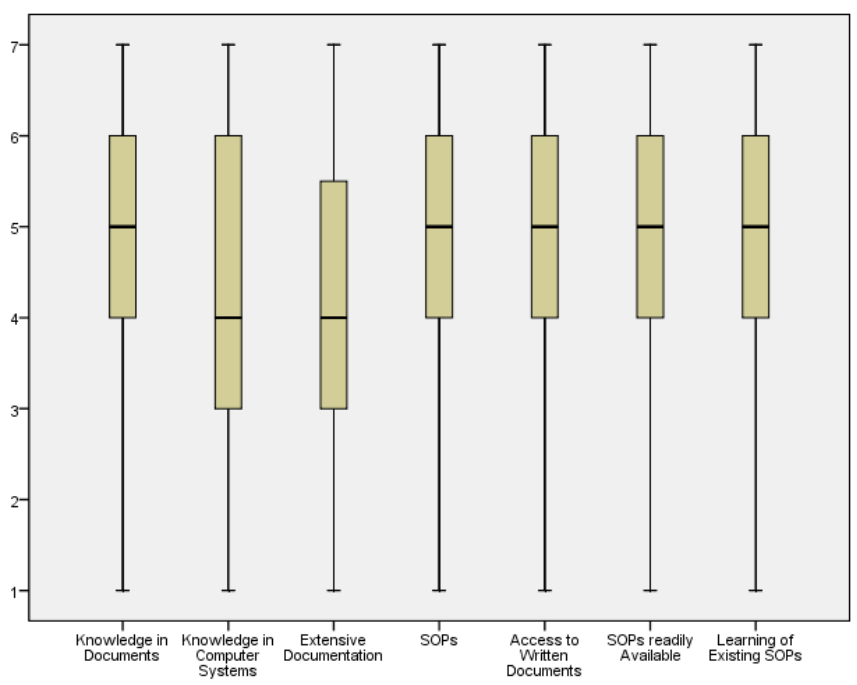

For the three Knowledge Sharing through Written Documents measures, the majority of respondents indicated that:

- Standard operating procedures exist to support this task (70\%)

- They were able to access to existing standard operating procedures when coordinating/performing this task (67\%)

- Standard operating procedures were available to support this task (68\%)

These results suggest written documents are readily available, accessible, and used by OEM-EOC personnel to support their decisions. 


\section{Task Performance (Efficiency)}

Figure 15 (boxplot chart) below illustrates average scores and range of responses for task performance (efficiency). This indicates that despite the high levels of task uncertainty, overall the EOC has been able to efficiently perform emergency management tasks. Tasks are generally well-planned and executed by responsible personnel who are mindful about time constraints and the efficient use of resources.

Figure 15. Task Performance, Efficiency, (average and range of responses).

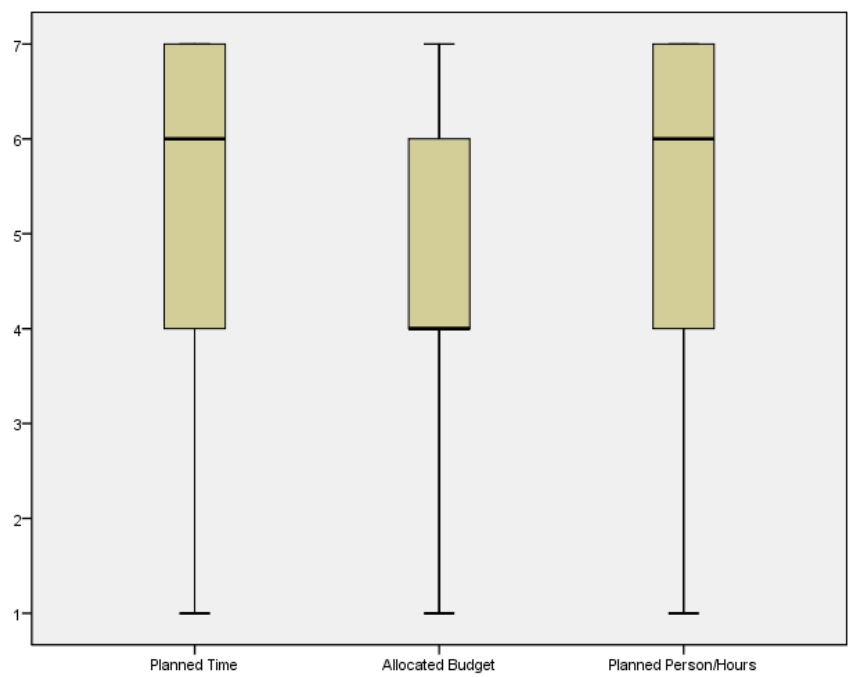

\section{Task Performance (Effectiveness)}

Figure 16 (boxplot chart) below illustrates average scores and range of responses for Task Performance (Effectiveness).

Figure 16. Task Performance, Effectiveness, (average and range of responses). 


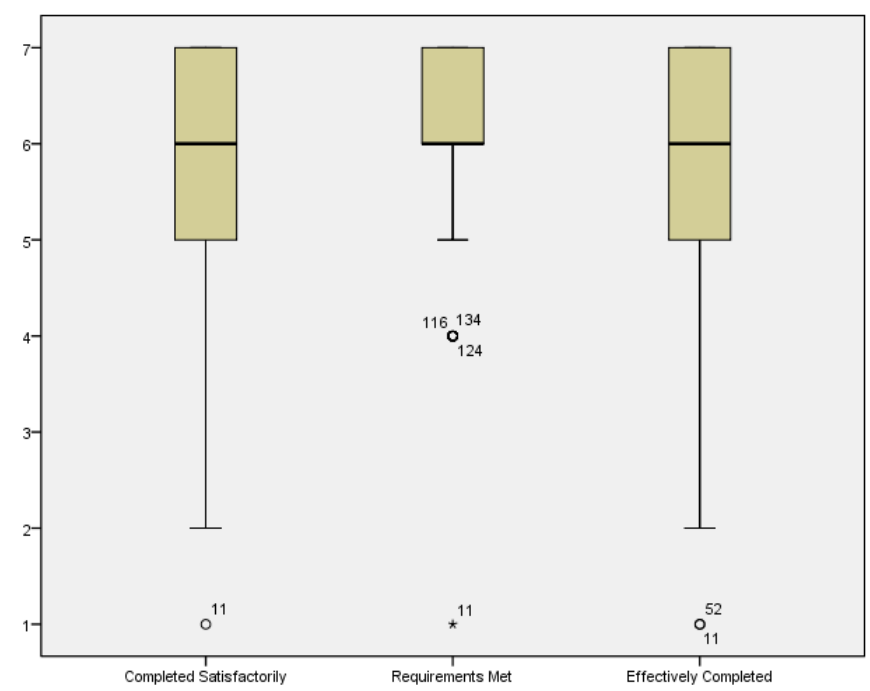

These results indicate that despite the high level of task uncertainty, personnel and organizations involved in EOC emergency tasks have been able to meet the incident requirements, satisfy all participants, avoid negatively impacting other tasks, and are quick in resolving any task conflicts.

\section{DEMOGRAPHICS OF SURVEY PARTICIPANTS}

Table 2 illustrates the relevant sampling characteristics of the respondents of our survey instrument.

Table 2. Relevant Sampling Characteristics of the Respondents of our Survey Instrument.

\begin{tabular}{|ll|}
\hline $\begin{array}{l}\text { Level of expertise had to coordinated and/or performed this } \\
\text { task }\end{array}$ & 4.88 \\
\hline From a scale of 1 to 7 (1 Novice, 7 Expert) & \\
\hline $\begin{array}{l}\text { Years of experience had to coordinated and/or performed this } \\
\text { task } \\
\text { Years worked in the emergency management field }\end{array}$ & $\begin{array}{l}10.41 \text { Years } \\
\text { Years worked at current organization } \\
\text { Years worked at the Emergency Operations Center }\end{array}$ \\
\hline $\begin{array}{l}\text { People who have worked before in another organization } \\
\text { involved in emergency management }\end{array}$ & \begin{tabular}{l}
13.50 Years \\
\hline
\end{tabular} \\
\hline
\end{tabular}




\begin{tabular}{|c|c|c|}
\hline \multicolumn{3}{|c|}{ Organizational Level } \\
\hline \multicolumn{2}{|c|}{ Senior Management } & $41.70 \%$ \\
\hline \multicolumn{2}{|c|}{ Middle Management } & $30.40 \%$ \\
\hline \multicolumn{2}{|c|}{ Operations Management } & $28.00 \%$ \\
\hline \multicolumn{3}{|c|}{$\begin{array}{l}\text { People belonging to the following Office of Emergency } \\
\text { Management and/or Emergency Operations Center functional } \\
\text { groups: }\end{array}$} \\
\hline \multicolumn{2}{|c|}{ Infrastructure Group } & $23.80 \%$ \\
\hline \multicolumn{2}{|c|}{ Human Services Group } & $14.30 \%$ \\
\hline \multicolumn{2}{|c|}{ Public Safety Group } & $35.70 \%$ \\
\hline \multicolumn{3}{|l|}{ Other: } \\
\hline · & Hospitals/Health Care & $3.57 \%$ \\
\hline . & Planning and Logistics & $3.57 \%$ \\
\hline - & Staff and Support Organizations & $2.97 \%$ \\
\hline . & Operations & $2.38 \%$ \\
\hline & City/Municipal & $1.78 \%$ \\
\hline . & Other & $11.90 \%$ \\
\hline
\end{tabular}




\section{Conclusion and Practical Insights}

The tasks undertaken at the EOC inherently have a high degree of uncertainty which depends on the nature of the disaster event and the possible range of responses and recovery approaches. We assessed the uncertainty of emergency tasks along three dimensions: novelty, unanalyzability, and significance. Table 3 summarizes the average of reported levels of task uncertainty and task novelty, unanalyzability, and significance dimensions.

Table 3. Summary, degree of uncertainty of EOC tasks.

\begin{tabular}{|c|c|c|c|}
\hline & Mean & Maximum Score & Interpretation \\
\hline Overall Task Uncertainty: & 4.34 & 6.15 & Medium \\
\hline Task Novelty & 4.32 & 7.00 & Medium \\
\hline Task Unanalyzability & 3.65 & 6.00 & Medium \\
\hline Task Significance & 5.29 & 7.00 & Moderately High \\
\hline \multicolumn{4}{|c|}{$\begin{array}{l}\text { Degree levels are coded by: } \\
\text { High }(6,7), \text { Moderately High }(4.7-5.9) \text {, Medium }(3.4-4.6) \text {, Moderately } \\
\text { Low }(2.1-3.3) \text {, to } \\
\text { Low }(1,2) .\end{array}$} \\
\hline
\end{tabular}

According to the results represented in Table 3, the highest degree of task uncertainty is characterized by task significance through the extent to which different activities of the task need to be performed urgently to save lives and minimize economic impact. The degree of task uncertainty defined by task novelty is relevant for OEM-EOC personnel to assess the extent to which different activities of the task are completely new and hence cannot be performed using routine procedures. Similarly, the degree of task uncertainty portrayed by task unanalyzability is useful for emergency managers when the different activities required by the task are difficult to analyze due to conflicting interpretations and lack of information needed to make critical decisions.

In general, our results suggest that EOC personnel share their knowledge for two purposes: one, for exploring (searching) new approaches; and two, for exploiting or reusing existing procedures. This indicates that the successful execution of the tasks requires knowledge sharing for discovering new procedures (exploration) as well as the proper understanding and reuse of existing procedures (exploitation).

Also, OEM-EOC personnel share their knowledge through two important knowledge sharing mechanisms: personal contacts and written documents. The high degree of knowledge sharing through personal contact reported by many respondents 
underscores the extent to which emergency personnel depend on their own expertise as well as the experience of others in order to respond to a particularly uncertain and difficult task.

Finally, despite the high levels of uncertainty, EOC tasks are mostly completed successfully (effectively and efficiently) because those involved in the disposition of the tasks share their knowledge. The EOC organizational structure, technological infrastructure, and coordinators provide a fertile environment that enables effective knowledge sharing across the personnel and organizations who are assigned to the EOC during the response and recovery efforts in a disaster situation. 
VITA

\section{JOSE ROCHA}

$1987 \quad$ Bachelor of Science Tec de Monterrey (ITESM)

Major: International Business and Management IT Systems

Querétaro, Qro., México

2003 Master of Business Administration

State University of New York at Buffalo

Major: International Business and Management IT Systems

Buffalo, NY, USA

2007 Master of Science, Management of Technology

Concentration: Innovation, Ergonomics, and Human Factors

University of Miami

Miami, FL, USA

2011 Doctoral Candidate, Business Administration

Concentration: Knowledge Management

Florida International University

August 2011

Miami, FL, USA

\section{PUBLICATIONS}

Xia, Weidong, Becerra-Fernandez, Irma , Gudi, Arvind P. and Rocha, Jose . "Emergency Management Task Complexity and Knowledge Sharing Strategies" Cutter IT Journal, January 2011.

Xia, W., Irma Becerra-Fernandez, Jose Rocha, and Arvind Gudi, Knowledge Management Task Complexity In Emergency Management: An Instrument Development. Research paper published at the Conference Proceedings of the 2010 Americas Conference on Information Systems, Lima, Perú, August 12-15, 2010.

Rocha, J., Irma Becerra-Fernandez, Weidong Xia, and Arvind Gudi, Dealing with Task Uncertainty in Disaster Management: The Role of Knowledge Sharing for Exploration and Exploitation. Research paper published at the Conference Proceedings of the 2009 Americas Conference on Information Systems, San Francisco, California, August 6-9, 2009.

Becerra-Fernandez, I., Xia, W., Gudi, A., and Rocha, J. (2008), Task Characteristics, 
Knowledge Sharing and Integration, and Emergency Management Performance: Research Agenda and Challenges. Research paper published at the Conference Proceedings of the 5th International Conference on Information Systems for Crisis Response and Management: Creating Advanced Systems for Inter-organizational Information Sharing and Collaboration, Washington, DC, May 4-7, 2008.

Rocha, J. and Irma Becerra-Fernandez, Effective Inter-organizational Knowledge Sharing in Public Disaster Management Response. Research paper published at the Conference Proceedings of the IAMOT 2007-16th International Conference on Management of Technology "Management of Technology for the Service Economy", Miami Beach, Florida, USA, May 13-17, 2007.

Rocha, J. and Irma Becerra-Fernandez, Communities Of Practice, Leading The Way In Knowledge Sharing Processes In High-Tech Organizations. Research paper published at the Conference Proceedings of the IAMOT 2007-16th International Conference on Management of Technology "Management of Technology for the Service Economy", Miami Beach, Florida, USA, May 13-17, 2007.

Becerra-Fernandez, I. Prietula, M., Madey, G. , Rodriguez, D., Gudi, A., and Rocha, J. Project Ensayo: A Virtual Emergency Operations Center. Research paper published at the Conference Proceedings of the IAMOT 2007-16th International Conference on Management of Technology "Management of Technology for the Service Economy", Miami Beach, Florida, USA, May 13-17, 2007.

\section{CONFERENCES AND PRESENTATIONS}

Rocha, J. Session Chair of the "Commercial Networks" panel. Organizational Communication and Information Systems Division at the 2010 Academy of Management Annual Meeting, Montreal, Canada, August 6-10, 2010.

Rocha, J. Session Chair of the "Knowledge and Interorganizational Partnership Performance" panel. Organizational Communication and Information Systems Division at the 2009 Academy of Management Annual Meeting, Chicago, Illinois, August 7-11, 2009.

Rocha, J. and Irma Becerra-Fernandez, Effective Inter-organizational Knowledge Sharing in Public Disaster Management Response. Research work presented at the Organizational Communication and Information Systems Doctoral Consortium funded by the National Science Foundation at the 2007 Academy of Management Annual Meeting, Philadelphia, Pennsylvania, August 3-4, 2007. 